Joint U.S./Russian Study on the

Development of a Decommissioning

Strategy Plan for RBMK-1000 Unit \#1

at the Leningrad Nuclear Power Plant:

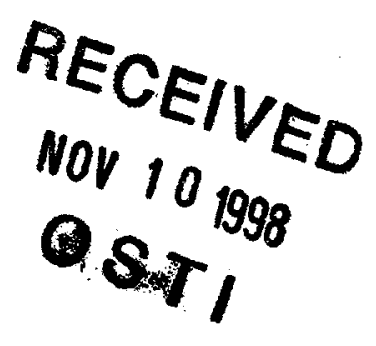
Appendixes

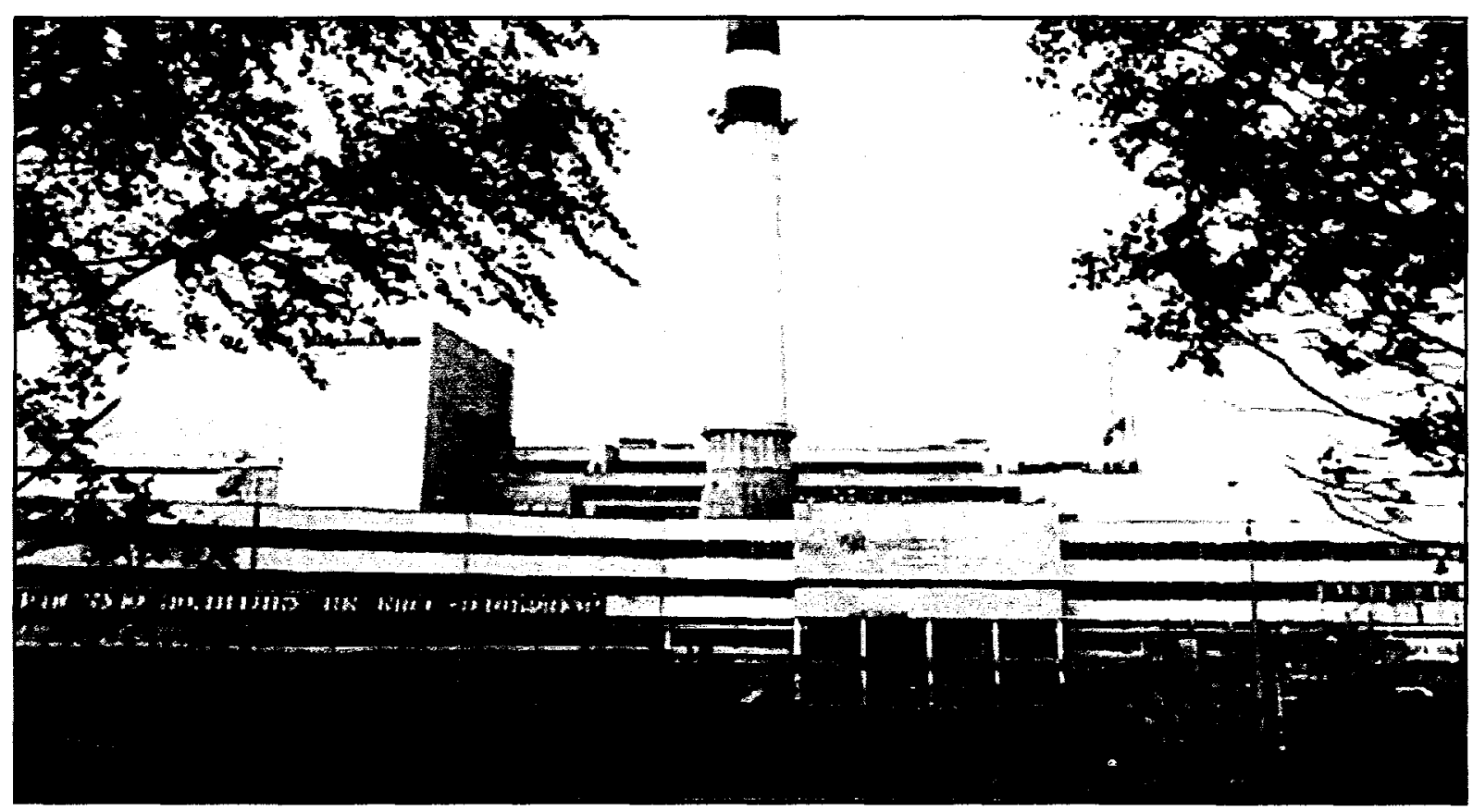

September 1998

Prepared by

Joint U.S./Russian Study Team

Pacific Northwest National Laboratory

Brookhaven National Laboratory

RRC Kurchatov Institute

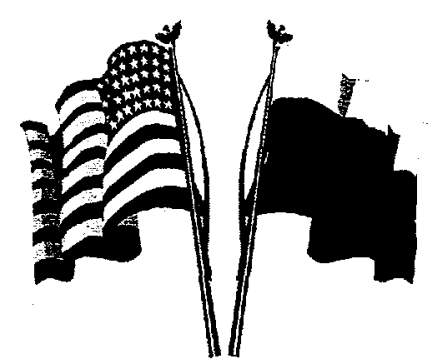

for the

United States Department of Energy and the

Russian Federation Ministry of Atomic Energy 


\section{DISCLAIMER}

This report was prepared as an account of work sponsored by an agency of the United States Government. Neither the United States Government nor any agency thereof, nor any of their employees, make any warranty, express or implied, or assumes any legal liability or responsibility for the accuracy, completeness, or usefulness of any information, apparatus, product, or process disclosed, or represents that its use would not infringe privately owned rights. Reference herein to any specific commercial product, process, or service by trade name, trademark, manufacturer, or otherwise does not necessarily constitute or imply its endorsement, recommendation, or favoring by the United States Government or any agency thereof. The views and opinions of authors expressed herein do not necessarily state or reflect those of the United States Government or any agency thereof. 


\section{DISCLAIMER}

Portions of this document may be illegible in electronic image products. Images are produced from the best available original document. 
Hoint U.S.Russian Study on the Development of A ofommissioning Strategy Plan for RBMK-1000) Nuclearigoner Plapt

\section{Appendixis}

September 1998
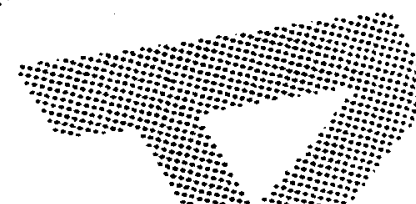

Prepared for

The U.S. Department of Energy

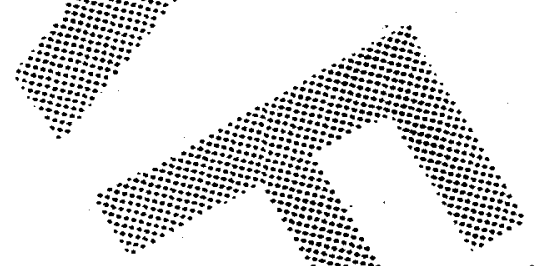

under Contract DE-AC06-76RLO 1830

Pacific Northwest National Laboratory

Richland, Washington 99352 


\title{
Participating Organizations
}

\author{
United States \\ United States Department of Energy (DOE) \\ Pacific Northwest National Laboratory (PNNL) \\ Brookhaven National Laboratory (BNL)
}

Russian Federation

Ministry of Atomic Energy (Minatom)

Leningrad Nuclear Power Plant (LNPP)

Russian Research Center Kurchatov Institute (RRC KI)

GosAtomNadzor (GAN)

All Russian Design and Research Institute of Power Technology (VNIPIET)

Research and Development Institute of Power Engineering (NIKIET)

Moscow Research and Design Institute of Installation Technology (NIKIMT)

Volgodonsk branch of All Russian Research Institute of Nuclear Power Engineering

(Volgodonsk branch of VNIIAM)

Institute of AtomEnergoProekt (AEP)

All Russian Research Institute for Nuclear Power Plant Operation (VNIIAES)

Science Technical Center of Nuclear and Radiation Safety (STC of NRS) 


\section{Study Leaders}

United States Project Manager

Task Manager

Russian Federation Leader

Russian Federation Deputy Leader

Russian Federation Deputy Leader

Russian Federation Project Manager

Russian Federation Project Manager
Ms. S.M.K. Garrett

Pacific Northwest National Laboratory

Mr. R.F. Lavelle

Brookhaven National Laboratory

Dr. N.E. Kukharkin

Russian Research Center "Kurchatov Institute"

Dr. Yu.V. Garusov

Leningrad Nuclear Power Plant

Dr. Yu.F. Chernilin

Russian Research Center "Kurchatov Institute"

Dr. B.K. Bylkin

Russian Research Center "Kurchatov Institute"

Dr. Yu.A. Zverkov

Russian Research Center "Kurchatov Institute" 


\section{Participants - United States}

M.G. Cowgill (Brookhaven National Laboratory, BNL, New York)

G.R. Eidam (Bechtel Hanford Inc., BHI, Richland, WA)

S.M.K. Garrett (Pacific Northwest National Laboratory, PNNL, Richland, WA)

R.F: Lavelle (Brookhaven National Laboratory, BNL, New York)

S.M. Short (Pacific Northwest National Laboratory, PNNL, Richland, WA) 


\section{Participants - Russian Federation}

N.I. Ampelogova (All-Russian Design and Research Institute of Power Technology, VNIPIET, St.-Petersburg)

M.I. Abramov (Research and Development Institute of Power Engineering, NIKIET, Moscow)

A.I. Berela (Volgodonsk Branch of All-Russian Research Institute of Nuclear Power Engineering, VNIIAM, Volgodonsk City)

E.V. Burlakov (Russian Research Center "Kurchatov Institute," RRC KI, Moscow)

B.K. Bylkin (Russian Research Center "Kurchatov Institute," RRC KI, Moscow)

Yu.V. Garusov (Leningrad Nuclear Power Plant, LNPP, Sosnovy Bor City)

G.B. Davydova (Russian Research Center "Kurchatov Institute," RRC KI, Moscow)

Yu.A. Egorov (ATOMENERGOPROYEKT, AEP, Moscow)

N.V. Zhukov (Research and Development Institute of Power Engineering, NIKIET, Moscow)

Yu.A. Zverkov (Russian Research Center "Kurchatov Institute," RRC KI, Moscow)

N.N. Kalyazin (Leningrad Nuclear Power Plant, LNPP, Sosnovy Bor City)

E.P. Kozlov (Leningrad Nuclear Power Plant, LNPP, Sosnovy Bor City)

I.D. Kulikov (All-Russian Design and Research Institute of Power Technology, VNIPIET, St.Petersburg)

N.E. Kukharkin (Russian Research Center "Kurchatov Institute," RRC KI, Moscow)

M.I. Miroshnitchenko (Gosatomnadzor of Russia, RF GAN, Moscow)

D.A. Michailov (Russian Research Center "Kurchatov Institute," RRC KI, Moscow)

A.A. Noskov ( ROSENERGOATOM Concern, REA, Moscow)

M.A. Pavlov (Leningrad Nuclear Power Plant, LNPP, Sosnovy Bor City)

B.A. Paytunin (Research and Design Institute of Installation Technology, NIKIMT, Moscow)

V.G. Romanov (Leningrad Nuclear Power Plant, LNPP, Sosnovy Bor City)

V.N. Ryzhkova (All-Russian Research Institute for NPP Operation, VNIIAES, Moscow)

B.M. Tishkov (Leningrad Nuclear Power Plant, LNPP, Sosnovy Bor City)

V.I. Cheremiskin (Leningrad Nuclear Power Plant, LNPP, Sosnovy Bor City)

O.G. Chernikov (Leningrad Nuclear Power Plant, LNPP, Sosnovy Bor City)

V.A. Shaposhnikov (Leningrad Nuclear Power Plant, LNPP, Sosnovy Bor City)

V.Ya. Shpitser (Volgodonsk Branch of All-Russian Research Institute of Nuclear Power Engineering, VNIIAM, Volgodonsk City)

T.D Shepetina (Russian Research Center "Kurchatov Institute", RRC KI, Moscow)

A.A. Etingen (Volgodonsk Branch of All-Russian Research Institute of Nuclear Power Engineering, VNIIAM, Volgodonsk City) 
Joint U.S./Russian Study on the Development of a Decommissioning Strategy Plan for RBMK-1000 Unit \#1 at the Leningrad Nuclear Power Plant

Appendix A

A Summary of the Shutdown and

Decommissioning Experience for Nuclear

Power Plants in the United States and the

Russian Federation

September 1998

Prepared for

The U.S. Department of Energy

under Contract DE-AC06-76RLO 1830

Pacific Northwest National Laboratory

Richland, Washington 99352 


\section{Table of Contents}

Abbreviations and Definitions of Terms .............................................................. xi

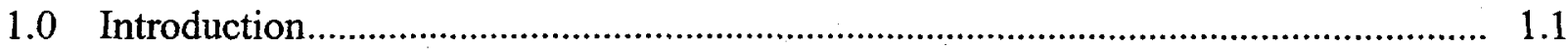

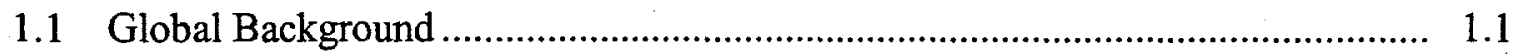

1.2 Decommissioning Stages ......................................................................... 1.1

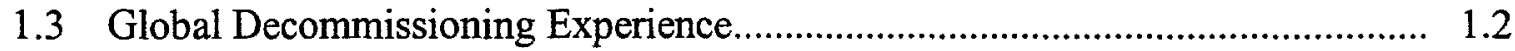

1.4 Decommissioning Costs and Finance ........................................................ 1.3

1.5 International Cooperation ...................................................................... 1.3

1.6 Russian Experience Overview ............................................................. 1.4

2.0 Russian Decommissioning Experience .......................................................... 2.1

2.1 Introduction.................................................................................... 2.1

2.2 Uranium Graphite Plutonium Production Reactors in Russia ......................... 2.3

2.2.1 Construction and Operation ........................................................... 2.3

2.2.2 Design Features.......................................................................... 2.4

2.2.3 Organization and Planning of Reactor Upgrades................................ 2.9

2.2.4 The Development of Technologies and Specialized Equipment for Reactor Upgrades ........................................................................ 2.10

2.2.5 Experience in the Upgrading of Single-Pass Uranium-Graphite Plutonium-Production Reactors ....................................................... 2.13

2.2.6 Upgrading of the Multi-Pass Plutonium-Production Reactors ................ 2.24

2.2.7 Cost of Upgrades and Repairs......................................................... 2.31

2.2.8 Conclusions Based on Repairs and Upgrades.................................... 2.31

2.2.9 Decommissioning Conceptual Approaches ........................................ 2.32

2.2.10 Status of the Decommissioning of Shutdown Reactors ......................... 2.33

2.2.11 Review of the Cutting of Specimens and Samples from Structural Elements of the Shutdown EI-2 Plutonium-Production Reactor ............. 2.34

2.2.12 Relevant Experience with Operational Reactors .............................. 2.36

2.3 RBMK Reactors...................................................................................... 2.41

2.3.1 Repairs and Upgrades .............................................................. 2.41

2.3.2 Radiation Conditions and Radiation Exposure Sustained During Repair Work ....................................................................................... 2.55

2.3.3 Installation of Steam and Gas Dumping Systems............................. 2.57

2.3.4 Features of Dismantling Structural Elements .................................... 2.. 2.59

2.3.5 Organization of Work Approaches for Dismantling During Decommissioning ........................................................................ 2.60

2.4 AMB Units at the Beloyarsk Nuclear Power Plant........................................ 2.63

2.4.1 Design Features.......................................................................... 2.63 


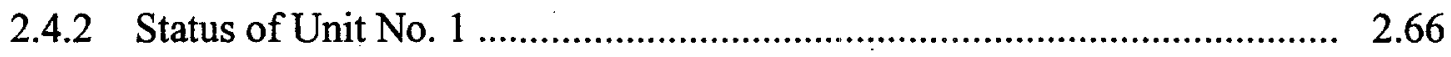

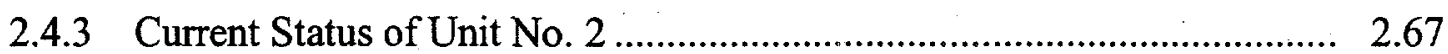

2.4.4 Radiation Characteristics of the First-Phase Units .............................. 2.67

2.4.5 Handling of the Spent Nuclear Fuel of Units No. 1 and 2 ..................... 2.68

2.4.6 Radioactive Wastes Handling Problems Associated with Decommissioning Unit No. 1 and Unit No. 2 .................................... 2.70

2.4.7 Study of the Feasibility and the Development of Technologies for Dismantling Equipment and Structural Elements............................... 2.73

2.4.8 Preparation for Decommissioning ................................................... 2.86

2.5 Development of New Technologies for Dismantling Nuclear Reactors.............. 2.89

2.5.1 Development of Remote-Controlled Systems for Dismantling the Highly Radioactive Structural Elements of Nuclear Reactors..

2.5.2 Development of Techniques for Dismantling the Structural Elements of Nuclear Reactors ...................................................................... 2.98

2.5.3 Technology for Nuclear Reactor Entombment ................................... 2.107

3.0 U.S. Experience With Decommissioning Nuclear Power Reactors ......................... 3.1

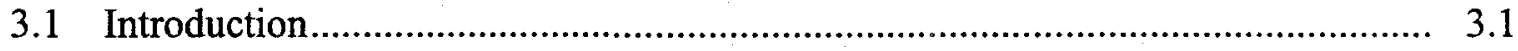

3.2 Regulation of Decommissioning of Nuclear Power Plants.............................. 3.1

3.3 Individual Plant Decommissioning Experience......................................... 3.3

3.3.1 Argonne Experimental Boiling Water Reactor................................... 3.4

3.3.2 Shippingport Atomic Power Station ............................................ 3.4

3.3.3 Dresden Unit 1 ...................................................................... 3.6

3.3.4 Yankee Rowe ............................................................................. 3.7

3.3.5 Saxton Nuclear Experimental Reactor ............................................ 3.8

3.3.6 Indian Point Unit 1.................................................................... 3.8

3.3.7 Humboldt Bay Power Plant Unit 3 ................................................ 3.9

3.3.8 Elk River Reactor................................................................. 3.9

3.3.9 Pathfinder Atomic Power Plant ...................................................... 3.10

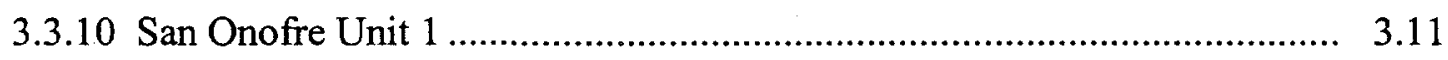

3.3.11 La Crosse .................................................................................... 3.12

3.3.12 Rancho Seco Nuclear Generating Station ........................................ 3.12

3.3.13 Trojan Nuclear Power Plant ..................................................... 3.12

3.3.14 Three Mile Island Unit 2 ............................................................. 3.13

3.3.15 Shoreham Nuclear Power Station ................................................. 3.13

4.0 Conclusions ........................................................................................... 4.1

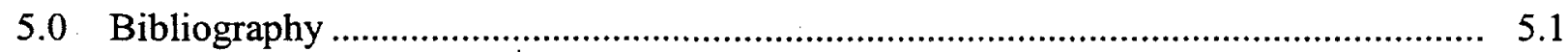

5.1 Related Documents ...................................................................... 5.1

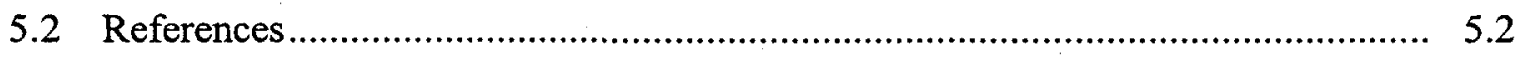




\section{Figures}

Figure 2.1 Diagram of a Single-Pass Plutonium-Production Reactor................................ 2.7

Figure 2.2 Diagram of a Multi-Pass Plutonium-Production Reactor .................................. 2.8

Figure 2.3 Condition of the Bottom Parts of the Technological Channels of the

"A" Reactor.

Figure 2.4 Corrosive Deposits and Damage on the Bottom Parts of the Technological

Channels of the OK-110-3 Plutonium-Production Reactor

Figure 2.5 Corrosion Damage on the Bottom Parts of the Technological Channels

of the OK-110-3 Plutonium-Production Reactor.

Figure 2.6 Corrosive Condition and Deterioration of the Bottom Parts of the

Technological Channels of the OK-110-3 Plutonium-Production Reactor ........

Figure 2.7 Corrosive Condition and Deterioration of the Bottom Parts of the

Technological Channels of the OK-110-3 Plutonium-Production Reactor ....... 2.18

Figure 2.8 The Mounting of Centering Sleeves on the "A" Plutonium-Production

Reactor.

Figure 2.9 Design and Installation of the New Lower Pipe

Figure 2.10 Installing the Zirconium Sleeves in the OK-110-3 Plutonium-

Production Reactor.

Figure 2.11 Tools (Broaches) for the Sizing of the Openings in the Graphite Blocks of a Plutonium-Production Reactor Stack

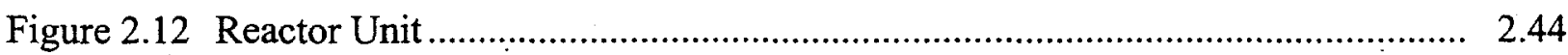

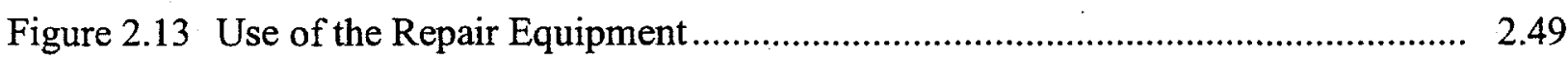

Figure 2.14 Mechanism for Cutting the Upper Tract Retainer ........................................... 2.50

Figure 2.15 Mechanism for Cutting the Miter Weld Connecting the Technological Channel and the Technological Tract

Figure 2.16 Machine for Welding the Edge Joint of a Technological Channel

Figure 2.17 Automatic Machine for Welding the $145 \times 7.5$-millimeter Pipes of the Upper Tract Retainer.

Figure 2.18 Mechanism for Cutting the Return Bend Off a Technological Channel and Cutting Away the Miter Weld.

Figure 2.19 Modernized Emergency Steam and Water Mixture Dumping System of RBMK Unit No. 1 at the Leningrad Nuclear Power Plant

Figure 2.20 2.65

Figure 2.21

Figure 2.22

Figure 2.23 2.79

Figure 2.24

Figure 2.25 2.94

Figure 2.26 


\section{Tables}

Table 2.1 Basic Specification of Russian Plutonium-Production Uranium-Graphite Reactors

Table 2.2 Basic Characteristics of the Uranium-Graphite Plutonium-Production Reactor Repairs and Upgrades in Russia .

Table 2.3 Technical and Economical Indexes for Dismantling Plutonium-Production Reactors Versus Reactor Storage Time

Table 2.4 Classification of Solid Radioactive Wastes...

Table 2.5 Costs of Decommissioning the OK-204, OK-205, and OK-206 PlutoniumProduction Reactors

Table 2.6 Operational Costs for Decommissioning the OK-204, OK-205, and OK206 Plutonium-Production Reactors

Table 2.7 Radiation Conditions in Some Areas of the Beloyarsk Nuclear Power Plant First-Phase Units

Table 2.8 Dynamics of the Intake of Solid Radioactive Wastes at the Storage Facility of the Beloyarsk NPP

Table 3.1 Decommissioning Status of Shutdown Power Reactors 


\section{Acronyms, Abbreviations, and Definition of Terms}

\section{Acronyms and Abbreviations}

AMB AMB-100 or AMB-200 graphite-water pressure tube reactor similar to the RBMK1000 reactor

BV cooling pond

DECON The equipment, structures, and portions of the facility and site containing radioactive contaminants are removed or decontaminated to a level that permits the property to be released for unrestricted use shortly after cessation of operations.

ENTOMB Radioactive contaminants are encased in a structurally long-lived material such as concrete, after which the entombed structure is appropriately maintained and continued surveillance is carried out until the radioactivity decays to a level permitting unrestricted release of the property.

IAEA International Atomic Energy Agency

KhZhO liquid radioactive waste storage facility

KhTO solid radioactive waste storage facility

NEA Nuclear Energy Agency

NPP nuclear power plant

OECD Organization of Economic Cooperation and Development

RBMK RBMK-1000 graphite-uranium pressure tube-type reactor

SAFSTOR The nuclear facility is placed and maintained in a condition that allows it to be safely stored and subsequently decontaminated (deferred decontamination) to levels that permit release for unrestricted use. SAFSTOR usually involves three phases: Custodial (layup), Passive, and Hardened. SAFSTOR alone is not an acceptable decommissioning mode; it must be followed by decontamination to unrestricted use.

Shadr ball-type butterfly flowmeter

TK technological channel

VVER VVER-213, VVER-320, VVER-338, VVER-365, VVER-440, or VVER-1000 reactor, pressure vessel-type reactors

\section{Definition of Terms}

Batching manifold - a section of special piping that has feeds for the individual feeding of cooling water to a technological channel.

Bin - a funnel-shaped metal structure that serves as a receiving vessel for the uranium and other fuel slugs discharged from a plutonium-production reactor, as well as for the managed transfer of these fuel slugs. 
Bottom load-bearing structure - lower bearing metalwork that serves as a support for the graphite stack, consisting of 2 tube sheets into which pipes are welded and an inter-pipe space that is filled with a special protective mixture.

Cassette - mechanisms for the reloading uranium or other fuel slugs into the technological channels of a plutonium-production reactor.

Catch - an attachment (a tool) for the proper orientation of various pieces of equipment, or the subassemblies thereof, during their installation on a mounting seat.

Centering device - a device that ensures the coaxiality and the clearance needed during the assembly of pipes for welding.

Cruciform support - load-bearing metalwork located under the reactor and over the receiving bin, which serves to support the discharging mechanisms (for plutonium-production reactors), or the reactor support structure, made in the shape of a "cross," which supports the load of the reactor (for reactors of the RBMK type).

Curtain-type biological shielding - biological shielding in the form of suspended movable plates, that covers the aperture in the lower section of a plutonium-production reactor.

Drain manifold - a section of special piping that has drains for the individual draining of cooling water from a technological channel.

Feed manifold - a piping section that has stub pipes welded thereto with a specific spacing, which serves for the delivery of cooling water to the batching manifolds.

Flowmeter housing - a vertical pipe with a flowmeter orifice and a choke, which ensures the delivery of cooling water from a batching manifold to each technological channel and the regulation of the water flow rate.

Housing - L-shaped plate metalwork that hermetically seals the volume of the graphite stack in the lower section thereof (for a plutonium-production reactor) or that hermetically seals the cylindrical reactor vessel to compensator assembly (for reactors of the RBMK type).

Impulse line - a piping section (generally with a small diameter of 8 to 12 millimeters) that ensures the delivery of a working medium to different instruments.

Instrument bench - a device for the accommodation and arrangement of instrumentation, service lines, and cables.

Main biological shield tank - an annular tank (reservoir) for the side radiation shielding that is divided into 16 hermetically sealed bays that are filled with water, the circulation and cooling of which is accomplished by means of a pump-equipped heat exchanger.

Nut driver - an automatic device for unscrewing the threaded plugs in one of the structural elements of the discharging mechanisms of a plutonium-production reactor.

Overhead position - a definition of the attitude associated with the performance of various technological operations or tasks (for example, lower position, vertical position, and overhead position).

Penetration assembly - a guide (casing) pipe.

Puller - a mechanism or tool for separating equipment subassemblies or parts from a location where they have become "stuck" over the course of long-term operation. 
Reactor cell - one of the technological tracts in a reactor that has its own numeric number.

Reactor plateau - an upper work area for the installation of technological channels within the proposed design dimensions of a reactor.

Return bend - a U-shaped piping expansion piece for the lower water pipelines.

Technological channel - a special finned tube that has a ball valve in its upper section through which uranium and other slugs are loaded, and through which cooling water is delivered (for plutonium-production reactors), or a pipe that is designed to accommodate fuel assemblies and create a coolant flow (for RBMK reactors).

Technological tract - a set of structural parts extending along the entire height of a reactor, which form a coaxial tract for the installation of the technological channels.

Temperature channel - a channel in which a temperature-measuring sensor is installed.

Tilter - a device for turning (tilting) various pieces of equipment to a different attitude.

Top load-bearing structure - a protective structure of a reactor that is installed above the graphite stack, consisting of 2 tube sheets into which pipes are welded and an inter-pipe space that is filled with a special protective mixture. 


\subsection{Introduction}

\subsection{Global Background}

As of mid-1998, some 80 commercial power reactors, over 250 research reactors and a number of fuel-cycle facilities, have been retired from operation worldwide. While some of these have been fully dismantled, most parts of a nuclear power plant do not become radioactive or are contaminated at very low levels. Proven techniques and equipment are available to dismantle nuclear facilities safely. As experience is gained, decommissioning costs for nuclear power plants, including disposal of associated wastes, are coming down and now amount to less than $5 \%$ of the total cost of electricity generation.

All power plants, whether coal-, oil- or gas-fired, or nuclear, have a finite life beyond which it is not economically feasible to operate them. Generally speaking, nuclear plants were designed for a life of about 30 years, though some have proved capable of continuing well beyond this. Newer plants are designed for a 40- to 60-year operating life. At the end of its life, a power plant needs to be decommissioned and demolished so that the site can be made available for other uses.

\subsection{Decommissioning Stages}

The International Atomic Energy Agency (IAEA) has defined three stages of decommissioning that have been internationally adopted on a general basis:

Stage 1 Storage with surveillance. This begins at shutdown. The spent fuel (and thus $99 \%$ of the radioactivity) is removed from the reactor, the liquid systems are drained, the operating systems are disconnected, and the mechanical openings are securely sealed. The facility is kept under surveillance and inspection to ensure that it remains in a safe condition. Stage 1 takes about five years.

Stage 2 Restricted site release. All equipment and buildings outside the reactor core and its biological shielding are dismantled. With the reactor sealed and monitored ("safe storage"), the rest of the site can be released for reuse.

Stage 3 Unrestricted site use. The reactor is completely dismantled and, unless the site, buildings, or equipment are to be reused for nuclear purposes, all materials still containing significant levels of radioactivity are removed and the site released for unrestricted use. No further inspection or monitoring is required, in effect, returning the area to "green field" status.

The time taken between Stages 1 and 3 varies considerably among countries and projects. Some utilities have chosen to move immediately to Stage 3 decommissioning (an option called prompt dismantling or "DECON" in the United States), while others have chosen a lengthy period of storage (the U.S. "SAFSTOR" option). This period of storage also varies considerably. Because of this, total decommissioning times vary-from five to ten years maximum in Japan, where land is at a premium and long-term storage not practical, to a planned 135 years for some reactors in the United Kingdom (U.K.). In the United States, current regulations allow a period of 60 years for full decommissioning to Stage 3.

About $99 \%$ of the radioactivity from nuclear reactors is associated with the fuel, which is removed in Stage 1. The remaining radioactivity comes from "activation products" formed 
mainly in steel components that have been exposed to neutron irradiation for extended periods. These include such radioactive isotopes as ${ }^{60} \mathrm{Co},{ }^{55} \mathrm{Fe},{ }^{63} \mathrm{Ni}$ and ${ }^{14} \mathrm{C}$. The first two have relatively short half-lives and decay to extremely low levels of radioactivity within 50 years after reactor shutdown. This has implications for reduced worker exposures if dismantling can be delayed by employing the SAFSTOR option.

\subsection{Global Decommissioning Experience}

Over the past 35 years, considerable experience has been gained in decommissioning various types of nuclear facilities. To date, some 80 commercial power reactors, as well as over 250 research reactors and a number of fuel-cycle facilities have been retired from operation.

To decommission its retired gas-cooled reactors at the Chinon, Bugey, and St. Laurent nuclear power stations, Électricité de France has chosen partial dismantling to Stage 2 and has postponed Stage 3 dismantling for 50 years. Although complete dismantling was technically possible, the utility preferred to delay this activity because storage for 50 years will result in a significant reduction in residual radioactivity, thus reducing the radiation hazard during the eventual dismantling. Improved mechanical techniques are also expected to be available by that time, enabling a further reduction in hazards and costs. In the interim, the costs of monitoring and surveillance are expected to be minimal because other reactors will continue to operate at those sites.

The French are building a recycling plant at Marcoule for steel from dismantled nuclear facilities. This metal will contain some activation products, but it can be recycled for use at other nuclear plants.

Decommissioning has begun on the two 138-MWe Magnox reactors at the Berkeley Nuclear Power Station in the U.K. These were closed for economic reasons in 1989, after 27 years of operation. Defueling was completed in March 1992. The plant will now be left for 30 years, after which a containment structure will be built around the residual buildings for a further storage period of 100 years.

Germany, on the other hand, has chosen direct dismantling over safe enclosure for the closed Greifswald nuclear power station in the former East Germany, where five reactors had been operating. Similarly, the site of the $100 \mathrm{MWe}$ Niederaichbach nuclear power plant in Bavaria was declared fit for unrestricted agricultural use in mid-1995. Following removal of all nuclear systems, the radiation shield, and some activated materials, the remainder of the plant was below accepted limits for radioactivity and the state government approved final demolition and clearance of the site.

Experience in the United States has varied. The Rancho Seco facility, an 883-MWe PWR, was closed in 1989 and will be in SAFSTOR until 2008, when funds will be available for dismantling. However, immediate dismantling was the option chosen for the Fort St. Vrain plant, a 330 MWe high-temperature gas-cooled reactor that was also closed in 1989. This took place on a fixed-price contract for $\$ 195 \mathrm{M}$ and cost less than $1 \phi / \mathrm{kWh}$ despite a short operating life. The project has proceeded on schedule to clear the site and relinquish its license early in 1997-the first large U.S. power reactor to achieve this.

At multi-unit nuclear power stations, the choice has been to place the first shutdown unit into storage until the others conclude their operating lives, after which all can be decommissioned in sequence. This will optimize the use of staff and the specialized equipment required for cutting 
and remote operations and achieve cost benefits. Thus SAFSTOR is being used for San Onofre Unit 1, which closed in 1992, until Units 2 and 3 are ready to be decommissioned in 2013. Similarly, after 14 years of comprehensive cleanup activities, including removing fuel and debris and the large quantities of water generated by the March 1979 accident, Three Mile Island Unit 2 was placed in Post-Defueling Monitored Storage (SAFSTOR) in 1993. It will be maintained until the operating license of Unit 1 expires in 2014 so that the two units can be decommissioned together.

The demonstrated experience of completed decommissioning to date has principally involved prototype and smaller power reactors because it is only in recent years that larger commercial power reactors have been closing. A major U.S. DECON project in this area was the 72-MWe Shippingport reactor, which operated commercially from 1957 to 1982 . It was used to demonstrate the safe and cost-effective dismantling of a commercial-scale nuclear power plant (NPP) and the early release of the site. Defueling was completed in two years, and five years later the site was released for use with no restrictions. Because of its small size, the pressure vessel was removed and disposed of intact. For larger units, such components will need to be sectioned.

Many nuclear submarines have been decommissioned over the last decade. In the United States, after defueling, the reactor compartments are cut out of the vessels and transported to the Hanford Site in southeastern Washington, where they are buried as low-level waste.

\subsection{Decommissioning Costs and Finance}

The total cost of decommissioning depends on the sequence and timing of the various stages of the program. Deferment of a stage tends to reduce its cost due to decreasing radioactivity, but this may be offset by increased storage and surveillance costs.

Even allowing for uncertainties in cost estimates and applicable discount rates, decommissioning contributes less than $5 \%$ of total electricity generation costs. For instance, in 1994 Scottish Nuclear made a record profit from operating two nuclear power stations (which supply half of Scotland's electricity) while decommissioning a third. Decommissioning cost was $0.07 \mathrm{P} / \mathrm{kWh}$, or $3.2 \%$ of the total generating cost of $2.2 \mathrm{P} / \mathrm{kWh}$.

Financing methods vary from country to country. Among the most common are

- Prepayment, where money is deposited in a separate account to cover decommissioning costs even before the plant begins operation. This may be done in a number of ways, but the funds cannot be withdrawn other than for decommissioning purposes.

- External sinking fund (Nuclear Power Levy): This is built up over the years from a percentage of the electricity rates charged to consumers. Proceeds are placed in a trust fund outside the utility's control. This is the main system in the United States, where sufficient funds are set aside during the reactor's operating lifetime to cover the cost of decommissioning.

- Surety fund, letter of credit, or insurance purchased by the utility to guarantee that decommissioning costs will be covered even if the utility defaults.

\subsection{International Cooperation}

The IAEA, the Nuclear Energy Agency (NEA) of the Organization of Economic Cooperation and Development (OECD), and the Commission of European Communities are among a number of organizations through which experience and knowledge about decommissioning is shared among technical communities in various countries. 
In 1985, the OECD/NEA launched the International Cooperative Program for the Exchange of Scientific and Technical Information Concerning Nuclear Installation Decommissioning Projects. This international collaboration, covering 15 reactors and six fuel-cycle facilities, has produced a great deal of technical and financial information. The important areas in which experience is being gained and shared are the assessment of the radioactive inventories, decontamination methods, cutting techniques, remote operation, radioactive waste management and health and safety. The aims are to minimize the radiological hazards to workers and to optimize the dismantling sequence and timing to reduce the total decommissioning cost.

Fuller treatment of decommissioning in the United States may be found in Section 3.0.

\subsection{Russian Experience Overview}

No nuclear power reactor unit has been decommissioned in Russia because none of the nuclear power reactor units have reached their end of service life. However, Russia has had a great deal of experience in repairing and upgrading nuclear power reactor units, and much of the experience is directly applicable to decommissioning RBMK nuclear reactors. Also, two water graphite units, similar to RBMK units, were permanently shut down at Beloyarsk NPP in 1981 and 1989. Although the two units are required to meet normal operating conditions and only servicing work has been allowed because the spent fuel has yet to be removed, much of the decommissioning preparatory work being done will be directly applicable to RBMKs.

Russia has amassed a great deal of experience in the repairs and dismantling associated with upgrading of plutonium-production and uranium-graphite reactors, including the repair and reconditioning of graphite stacks. Leningrad NPP Unit 1 is an example of a reactor that has been upgraded. The work at Leningrad NPP Unit 1 included wide-scale replacement of the technological channels, installation of an emergency steam dumping system, the mounting of check valve joints on the batch distribution manifolds, and a number of other operations. The Leningrad NPP Unit 1 experience will relate to the dismantling of structural elements of RBMK reactors during decommissioning.

Russia has also developed several technologies for use in upgrading their nuclear reactors that will be applicable to decommissioning. Several cutting techniques and remote-controlled systems have been designed that can be used for dismantling during decommissioning.

Section 2.0 provides the details of Russia's experiences that relate to NPP unit decommissioning. 


\subsection{Russian Decommissioning Experience}

\subsection{Introduction}

The Program for the Development of the Nuclear Industry that existed in the former Soviet Union developed, constructed, and operated a large number of nuclear reactors of different types: power reactors (for supplying heat and electric power), plutonium-production reactors (for defense needs), and research reactors, as well as transportation-related and marine nuclear facilities. A fairly large percentage of these nuclear reactors have been shut down, and several studies are being performed on problems associated with their decommissioning.

A large number of the nuclear reactors on naval vessels, more than $80 \%$ of the research reactors, and 9 of the 12 plutonium-production reactors are presently shut down. In addition, the NPP units placed into operation during the 1960s and early 1970s are approaching the end of their design operating lives.

Between 1981 and the present, the two tank-type units of the Novovoronezh NPP with VVER-210 and VVER-365 reactors were permanently shut down, as were the two first-phase units of the Beloyarsk NPP with water-graphite channel-type reactors, AMB-100 and AMB-200, which are similar to RBMK-1000 reactors. By the year 2006, 10 nuclear power plant units will have completed their design operating lifetimes, with several more units reaching the end of their design service lives by the year 2020. Altogether, the problems associated with decommissioning 24 Russian NPP units, with a total electrical output of $12,565 \mathrm{MW}$, must be resolved by this time. Units to be shut down include the RBMK-100 units at the Kursk, Leningrad, and Smolensk NPPs, as well as the Bilibino NPP units with water-graphite EGP-6 reactors.

According to the definition contained in the regulatory documents of Russia, the decommissioning of a nuclear power plant unit consists of the process implemented after the removal of the nuclear fuel. Fuel removal precludes the use of a unit as a power source and ensures the safety of personnel, the populace, and the environment. In the strict sense of the definition for decommissioning, the Russian NPP operating organizations (there are two organizations that are independent operatorsthe Leningrad NPP, with four RBMK-1000 units, and the Rosenergoatom that manages the Balakovo, Beloyarsk, Bilibino, Kalinin, Kola, Kursk, Novovoronezh, and Smolensk NPPs) are not ready to perform either full decommissioning or the processing, transportation, and burial of the large amounts of radioactive wastes associated with decommissioning.

Due to the foregoing, decisions have recently been made in Russia concerning the long-term storage of shutdown nuclear reactors, but no dismantling is being performed. Certain types of work associated with preparing and decommissioning NPP units is being performed after the appropriate permit has been received, in accordance with Russian regulations.

A complete set of regulations on decommissioning of NPP reactors and units does not exist in Russia. Until the regulations regarding decommissioning are completed, all proposed engineering solutions must be substantiated and used by the operating organizations only as agreed upon by state safety regulation agencies.

In line with the foregoing, it is imperative that design, engineering, and organizational solutions be developed to ensure the decommissioning of nuclear power facilities after the design service lives have expired. The solutions should consider existing domestic and foreign practical experience in the performance of similar work. 
There are no uranium-graphite channel-type units similar to domestic RBMK reactors in operation in the nuclear power industries of foreign countries, with the exception of the units constructed within the former Soviet Union at the Chernobyl NPP (in the Ukraine) and the Ignalina NPP (in Lithuania). Therefore, the extent to which foreign experience can be tapped when planning for decommissioning work for RBMK units may be quite limited, and the solutions to the many diverse decommissioning problems for RBMK units must be based primarily on domestic experience. In particular, experience in upgrading and modernizing domestic uranium-graphite nuclear reactors of different types can be taken into account.

As previously noted, two water-graphite first-phase units, similar to RBMK units, were permanently shut down at Russia's Beloyarsk NPP in 1981 and 1989. Based on the results of verification inspections, the Russian State Committee on Nuclear and Radiation Safety (Gosatomnadzor) recently made it mandatory to ensure the maintenance of the requisite normal operating conditions for these shutdown units. Because of this and the fact that the spent nuclear fuel had not yet been removed, only servicing work has been permitted at the two shutdown Beloyarsk units.

However, certain decommissioning preparatory work for the first-phase units of the Beloyarsk NPP is being carried out. This includes both design and technological work: the development of various techniques for dismantling equipment and piping, the study of reactor graphite stacks dismantling alternatives, the search for resolving the problems associated with handling the spent nuclear fuel, and so forth.

Considerable experience has been amassed in Russia in the repairs and dismantling work associated with the upgrading of plutonium-production uranium-graphite reactors, including the repair and reconditioning of graphite stacks. Upgrades to the RBMK reactor at the Leningrad NPP Unit 1 include the development of a procedure for the wide-scale replacement of the technological channels, installation of an emergency steam dumping system, mounting check valve joints on the batching manifolds, and a number of other operations.

The experience acquired from upgrading the plutonium-production uranium-graphite reactors and Leningrad NPP Unit 1 can be used during the decommissioning and dismantling of the structural elements of RBMK nuclear reactors. In addition, research and development has been performed by a number of Russian organizations on engineering equipment, such as remote-controlled systems designed for dismantling and fragmenting radioactive equipment and systems of uranium-graphite nuclear reactors.

Analysis has been started of Russian experience with different types of uranium-graphite reactors relevant to decommissioning of RBMK units during their final phase of the life cycle. Russian experience in repair and dismantling work performed during the upgrading of plutonium-production uranium-graphite reactors is presented in this report. A description is given of the status of the studies to resolve problems associated with decommissioning the reactors. In addition, relevant experience related to the upgrading of RBMK units is described, the decommissioning work performed on the shutdown uranium-graphite first-phase AMB units at the Beloyarsk Nuclear Power Plant is reviewed, and Russian innovations in certain new technologies essential to the performance of the work associated with the dismantling and fragmentation of the radioactive structural elements and equipment of uranium-graphite nuclear reactors are discussed. 


\subsection{Uranium Graphite Plutonium Production Reactors in Russia}

\subsubsection{Construction and Operation}

During 1948-1965, 12 uranium-graphite plutonium-production channel-type nuclear reactors were constructed and placed into operation in the former Soviet Union for producing weapons-grade plutonium and other isotopes. The design of the reactor water-coolant circulation loop in the first six plutonium-production reactors was the single-pass type; i.e., these reactors had an open water cooling circulation loop. The next six plutonium-production reactors were multi-pass reactors that in addition to isotope production, generated thermal energy and electric power by virtue of the closed water cooling circulation loop. The basic specifications of the uranium-graphite reactors constructed in Russia are summarized in Table 2.1.

No design operating lifetime was established for the first plutonium-production reactors constructed in the former Soviet Union. The maintainability of these reactors was characterized by low qualitative and quantitative indexes. Each reactor was a plant consisting of numerous components and parts that were interconnected to form a unified structure. For this reason, the failure of any of the components or parts could lead to the emergency shutdown of the reactor or to the disruption of its safe operation.

The only nuclear reactor subassemblies regularly replaced over the course of the operation of the plutonium-production reactors were

- the technological channels, which had an operating life of 1-2 years

- the graphite inserts mounted in the graphite blocks, which had an operating life of 3-5 years

- the group reloading system (cassettes), that had a long enough operating life to allow for their regular replacement during planned shutdowns.

Table 2.1. Basic Specification of Russian Plutonium-Production Uranium-Graphite Reactors

\begin{tabular}{|l|c|c|c|c|c|}
\hline $\begin{array}{c}\text { Place of } \\
\text { Construction }\end{array}$ & $\begin{array}{c}\text { Reactor } \\
\text { Name }\end{array}$ & $\begin{array}{c}\text { Type of Reactor } \\
\text { Circuit Design }\end{array}$ & $\begin{array}{c}\text { Number of } \\
\text { Channels }\end{array}$ & $\begin{array}{c}\text { Year of } \\
\text { Start }\end{array}$ & $\begin{array}{c}\text { Year of } \\
\text { Shutdown }\end{array}$ \\
\hline Chelyabinsk & "A" & Single Pass & 1200 & 1948 & 1987 \\
\hline Chelyabinsk & OK-110-1 & Single Pass & 2000 & 1949 & 1989 \\
\hline Chelyabinsk & OK-110-2 & Single Pass & 2000 & 1951 & 1990 \\
\hline Chelyabinsk & OK-110-3 & Single Pass & 2000 & 1952 & 1990 \\
\hline Tomsk & I-1 & Single Pass & 2000 & 1955 & 1989 \\
\hline Tomsk & EI-2 & Multi-Pass & 2800 & 1958 & 1990 \\
\hline Tomsk & OK-140 & Multi-Pass & 2800 & 1963 & - \\
\hline Tomsk & OK-204 & Multi-Pass & 2800 & 1963 & - \\
\hline Tomsk & OK-205 & Multi-Pass & 2800 & 1965 & - \\
\hline Krasnoyarsk & OK-120 & Single Pass & 2800 & 1958 & 1992 \\
\hline Krasnoyarsk & OK-135 & Multi-Pass & 2800 & 1962 & 1993 \\
\hline Krasnoyarsk & OK-206 & Multi-Pass & 2800 & 1964 & - \\
\hline
\end{tabular}


The repair or replacement of the remaining subassemblies was not envisioned over the course of the nuclear reactor operating process. During just the first 10 years of operation, a wide range of design and engineering deficiencies appeared that led to the failure of some subassemblies and parts. Safe operation could only proceed following the implementation of major repairs and upgrades. For this reason, all the plutonium-production reactors in Russia underwent major repairs and upgrades between 1963 and 1980, thereby ensuring their safe and accident-free operation for almost the next 40 years.

A summary of the plutonium-production reactors' repairs and upgrades are presented in Table 2.2.

\subsubsection{Design Features}

Russian production reactors are channel-type nuclear reactors with a thermal neutron spectrum, using uranium fuel and a graphite moderator that are arranged in the reactor core in a heterogeneous fashion. Diagrams of the two types of uranium-graphite plutonium-production reactors constructed and operated in Russia are presented in Figures 2.1 and 2.2.

The main design features of Russian multi-pass, uranium-graphite plutonium-production reactors are discussed below as applicable to the OK-204, OK-205, and OK-206 (Table 2.1). The overall construction consists of support metalwork within which the reactor's graphite stack, enclosed in a hermetically sealed metal housing, is situated. The graphite stack is the central component of the reactor. The stack contains up to 4,000 vertical columns that are assembled from graphite blocks with a cross-section of some $200 \times 200 \mathrm{~mm}$, with axial openings of a diameter approximately $70 \mathrm{~mm}$, which form vertical cubicles. The stack is assembled from graphite blocks of different lengths $(200,400,500$, and $600 \mathrm{~mm})$.

The columns of the graphite stack are mounted on the supports of shroud plates that are secured to the upper sheet of the metalwork of the bottom load-bearing structure. Replaceable sets of graphite inserts are set into the cubicles of the graphite stack for bonding of the blocks. In the area of the reflector, the openings in the blocks are filled with graphite rods.

The graphite stack has vertical openings that constitute technological channels (or tracts) that are formed by the connecting parts of the metalwork of the top or bottom load-bearing structure and the graphite stack inserts. The technological tracts consist of a set of structural elements (pipes, sleeves, inserts, and other parts) that are distributed along the height of the reactor and form a coaxial tract for the installation of the technological channels.

The upper protective structure of the reactor (top load-bearing structure) is mounted over a graphite insert. It consists of two tube plates (tube sheets) with the pipes welded into them, the space between which is filled with biological shielding.

The technological channels and the reactor control and protection system actuator channels of the nuclear reactor are installed in the through vertical openings. A total of 2,000 to 3,000 channels are installed in the graphite stack.

Fuel-bearing slugs and inert slugs made from aluminum are loaded into the technological channels. These slugs are discharged into a special bin located under the nuclear reactor, from which they are forwarded by means of a hydraulic conveyer for sorting and temporary holding. A reloading device that seals the lower ends of the technological channels with a gate is installed at the outlet of each cubicle underneath the metalwork of the bottom load-bearing structure. 
Table 2.2. Basic Characteristics of the Uranium-Graphite Plutonium-Production Reactor Repairs and Upgrades in Russia

\begin{tabular}{|c|c|c|}
\hline $\begin{array}{l}\text { Reactor } \\
\text { Name }\end{array}$ & $\begin{array}{l}\text { Year of } \\
\text { Activity }\end{array}$ & Description of Work Performed \\
\hline \multirow[t]{3}{*}{ "A" } & 1963 & $\begin{array}{l}\text { Building up of tubes of upper shield structure of the top load-bearing structure } \\
\text { Strengthening of the top load-bearing structure shield } \\
\text { Upgrading of water shield tanks } \\
\text { Mounting of centering tubes for failed lower pieces of tracts } \\
\text { Upgrading of upper water communication lines and reloading system }\end{array}$ \\
\hline & 1969 & Hermetic sealing of bottom compartments of water shield tanks \\
\hline & 1976 & $\begin{array}{l}\text { Reconstruction of lower pieces of technological tracts } \\
\text { Repair of graphite stack blocks } \\
\text { Review and repair of reactor cells }\end{array}$ \\
\hline \multirow[t]{3}{*}{ OK-110-1 } & 1967 & Hermetic sealing of bottom compartments of water shield tanks \\
\hline & 1972 & $\begin{array}{l}\text { Reconstruction of lower pieces of technological tracts } \\
\text { Design of the channel-by-channel temperature control system } \\
\text { Design of spray system for compartment rows of water shield tanks } \\
\text { Repair of graphite stack blocks. Review and repair reactor cells }\end{array}$ \\
\hline & $1973-75$ & Reconstruction of the coaxiality of upper tract parts \\
\hline \multirow[t]{2}{*}{ OK-110-2 } & 1971 & $\begin{array}{l}\text { Reconstruction of lower pieces of technological tracts } \\
\text { Design of the channel-by-channel temperature control system } \\
\text { Repair of graphite stack blocks } \\
\text { Review and repair reactor cells }\end{array}$ \\
\hline & 1975 & Fixation of the plate planking and reconstruction of the coaxiality of upper tract parts \\
\hline OK-110-3 & $\overline{1971-72}$ & $\begin{array}{l}\text { Reconstruction of lower pieces of technological tracts } \\
\text { Design of the channel-by-channel temperature control system } \\
\text { Repair of graphite stack blocks } \\
\text { Review and repair reactor cells }\end{array}$ \\
\hline \multirow[t]{2}{*}{ I-1 } & 1968 & Hermetic sealing of bottom compartments of water shield tanks \\
\hline & 1976 & $\begin{array}{l}\text { Reconstruction of lower pieces of technological tracts } \\
\text { Design of the channel-by-channel temperature control system } \\
\text { Reconstruction of the coaxiality of upper tract parts in the compensatory region } \\
\text { Modernization of the upper water communication lines } \\
\text { Repair of graphite stack blocks } \\
\text { Review and repair of reactor cells }\end{array}$ \\
\hline \multirow[t]{2}{*}{$\overline{\mathrm{EI}-2}$} & 1968 & $\begin{array}{l}\text { Modernization of the reloading system and of the lower water communication lines } \\
\text { Repair of graphite stack blocks } \\
\text { Review and repair of reactor cells }\end{array}$ \\
\hline & 1975 & $\begin{array}{l}\text { Modernization of upper water communication lines and flowmeter racks } \\
\text { Repair of graphite stack blocks } \\
\text { Review and repair of reactor cells }\end{array}$ \\
\hline \multirow[t]{2}{*}{ OK-140 } & 1968 & Reconstruction of the reactor bottom and modernization of reloading system \\
\hline & 1972 & $\begin{array}{l}\text { Replacement of upper group header racks and impulse lines } \\
\text { Repair of graphite stack blocks } \\
\text { Review and repair of reactor cells }\end{array}$ \\
\hline \multirow[t]{2}{*}{ OK-204 } & 1970 & Replacement of lower group headers and reverse valves \\
\hline & & $\begin{array}{l}\text { Installation of header extensions } \\
\text { Replacement of the attachment hardware of the downloading system } \\
\text { Reconstruction of the CPS system } \\
\text { Reconstruction of the temperature measuring system }\end{array}$ \\
\hline
\end{tabular}


Table 2.2. (contd.)

\begin{tabular}{|c|c|c|}
\hline $\begin{array}{c}\text { Reactor } \\
\text { Name }\end{array}$ & $\begin{array}{l}\text { Year of } \\
\text { Activity }\end{array}$ & Description of Work Performed \\
\hline & 1973 & $\begin{array}{l}\text { Modernization of reloading system, upper water communication lines, and flowmeter } \\
\text { racks } \\
\text { Repair of graphite stack blocks } \\
\text { Review and repair of reactor cells }\end{array}$ \\
\hline OK-205 & 1972 & $\begin{array}{l}\text { Replacement of upper group header racks, impulse lines, and the CPS channels } \\
\text { Repair of graphite stack blocks } \\
\text { Review and repair of reactor cells }\end{array}$ \\
\hline \multirow[t]{2}{*}{ OK-120 } & 1973 & $\begin{array}{l}\text { Elevation and fixing of the plate planking } \\
\text { Reconstruction of the coaxiality of upper technological tract parts } \\
\text { Manufacturing of tubes of the technological channels integrity control system } \\
\text { Installation of the technological channels integrity control system } \\
\text { Repair of group header slide valves, replacement of flowmeter racks } \\
\text { Replacement of group headers } \\
\text { Dismantling and installation of impulse tubes }\end{array}$ \\
\hline & 1974 & $\begin{array}{l}\text { Repair of the upper diaphragm of the cylindrical liner and reconstruction of nitrogen } \\
\text { blow-through system parameters } \\
\text { Repair of graphite stack blocks } \\
\text { Review and repair of reactor cells }\end{array}$ \\
\hline OK-135 & 1973 & $\begin{array}{l}\text { Repair of upper water communication lines } \\
\text { Installation of lower water headers } \\
\text { Coating of the bottom of the bottom load-bearing structure } \\
\text { Replacement of slide valves } \\
\text { Repair of the reloading system } \\
\text { Installation of the temperature measuring system }\end{array}$ \\
\hline OK-206 & 1970 & $\begin{array}{l}\text { Assembly dismantling } \\
\text { Dismantling of the assembly gap shield } \\
\text { Dismantling of the water distribution panels, installation of put segments, and tracks } \\
\text { for nut tighteners } \\
\text { Installation of the blind shield } \\
\text { Replacement of slide valves } \\
\text { Installation of nut tighteners } \\
\text { Hydraulic testing of assemblies in the reactor bottom } \\
\text { Dismantling and installation of the steam exhaust system }\end{array}$ \\
\hline $\begin{array}{l}\text { For all } \\
\text { reactors }\end{array}$ & $\begin{array}{l}\text { since } \\
1971\end{array}$ & $\begin{array}{l}\text { Scientific substantiated system for preventive maintenance of systems, } \\
\text { assemblies, and equipment of plutonium-production reactors is implemented. }\end{array}$ \\
\hline
\end{tabular}

Along the perimeter, the graphite stack is lined with silumin (an aluminum alloy) insets and is bound by straps equipped with spring-loaded thermal expansion compensators. The entire graphite stack, together with its attachment components, is enclosed in a hermetically sealed housing.

The side biological shielding (circular tank) is formed by iron water shield tanks, the concrete walls of the nuclear reactor cavity, and sand fill (between the walls of the cavity and the iron water shield tanks). The overhead floor slab plays the role of an upper biological shielding (top load-bearing structure), through which the technological channels, made from an aluminum alloy, pass and to which they are secured. The lower support structures (bottom load-bearing structure) also serve as a biological shielding.

The cooling of the nuclear reactor is accomplished by means of pressurized water that circulates through the reactor channels. Coolant feed is accomplished from above, while coolant drainage is 
Cooling system

Batching manifolds

Top load-bearing structure

Water shielding tanks

Bottom parts of the technological tracts

Reloading system (cassettes)

Graphite, inserts

Figure 2.1. Diagram of a Single-Pass Plutonium-Production Reactor 
Upper batching manifolds

Top load-bearing structure

Water shielding tanks

Reloading mechanisms

Bottom load-bearing structure

Graphite inserts

Lower batching manifolds

Drain manifolds

Figure 2.2. Diagram of a Multi-Pass Plutonium-Production Reactor 
accomplished from below. Coolant circulation through the primary circuit is accomplished by means of circulation pumps. Once past these pumps, the water enters the reactor channels, where it is heated by the fuel. Once past the reactor, the water is directed to the steam generators, where it imparts heat to the secondary-circuit coolant, then undergoes aftercooling in the end coolers and proceeds to the pump intake.

The extracted reactor heat is used to produce steam for generating electric power and heat. The steam formed in the secondary-circuit steam generators is directed to the turbogenerator, thereby ensuring the generation of electric power. In addition, the secondary-circuit coolant is used to generate the heat that goes toward meeting internal needs, as well as heating the population centers located near production reactor operations areas.

\subsubsection{Organization and Planning of Reactor Upgrades}

In almost all sectors of the former Soviet Union, the organization and planning of various types of repair work was carried out in compliance with an accepted system of planned preventive maintenance. The regulatory requirements of this system defined the repair cycle, the structure of repair cycles, repair time standards, labor efficiency standards for different types of repairs, spare part consumption rates, and consumption rates for basic and auxiliary materials, as well as the complement of requisite engineering and organizational materials.

Owing to its specific features, the preventive maintenance system was not introduced during the early years of the nuclear industry in the former Soviet Union. The scheduled preventive maintenance system was only adopted by the nuclear industry during the early 1970 s, following the accumulation of experience and statistical data obtained during the upgrades and major repairs of nuclear reactors.

During the initial period of operating production reactors, the organization and planning of the repair and reconditioning work was carried out on the basis of the following source data:

- the results of the analysis of data concerning the failures, malfunctions, and other defects detected and entered in the logs by shift operations personnel

- the results of verifications and inspections of the status of the systems; equipment, and subassemblies of reactors performed by special commissions during the scheduled shutdowns

- the data from expert reports on corrosive conditions of equipment, subassemblies, and parts

- entries in repair logs concerning the defects detected and the results of the repair actions

- other operational information.

The source data listed, together with reports from the chief designer and research supervisor of the reactors, constituted the basis upon which the Ministry of the Atomic Industry reached a decision concerning the shutdown of each nuclear reactor for upgrades or major repairs. Such a decision subsequently served as the basis upon which planning, organizational, technical, and engineering preparations were made for future repair and reconditioning for each nuclear reactor.

As a rule, an order for upgrades or major repairs to a plutonium-production reactor was made by the minister of the nuclear industry 1.5-2.5 years prior to shutting down the nuclear reactor for the work. Over the course of this time frame, the following preparations were performed:

- the design and project documentation was prepared 
- the technological process was developed, and drawings of the specialized repair equipment and items of technological equipment were prepared

- the new technological equipment, spare parts, materials, etc., were manufactured

- the repair equipment was fabricated and bench tested, and mockups were test-operated, i.e., brought to a state of readiness for industrial use and placed into serial production

- decisions were made concerning the enlistment of the appropriate specialized organizations for the performance of the work

- the questions surrounding financial support for all the tasks were resolved.

The various construction and installation firms that performed the installation work during the construction of the production reactors in Russia (Table 2.1) were located and functioned at the reactor sites. It was generally these firms that were enlisted to perform the work that fit their respective areas of specialization. Here, the division of work among operations personnel was undertaken in the 1.5-2 years prior to the repairs or upgrades. The division of work was reflected in various documents, including the work performance network schedules. Such an organizational form for the performance of work had its advantages:

- the work was performed by the specialists who had installed this facility and who were naturally familiar with it

- the dose levels were distributed among the hired construction and installation personnel (who generally had the lower radiation doses) and the operations personnel (who generally had the higher dose levels)

- the installation organizations had at their disposal ample resources for enlisting the highly qualified specialists needed to perform the specific dismantling and installation tasks. .

Major repairs and upgrades were performed around the clock according to a rotating schedule. During the performance of work, constant designer supervision was carried out; however, the services of the representatives and specialists of the supplier of the equipment were only enlisted as necessary.

The method described for the organization and performance of work is a framework that was used with minor adjustments during the upgrading of all the production reactors at all three reactor construction and operation sites.

\subsubsection{The Development of Technologies and Specialized Equipment for Reactor Upgrades}

The philosophy and approaches used during the development of the technologies and specialized equipment needed for upgrading production reactors took into account the specific nature of the facilities and the conditions under which the work was to be performed. Work performance methods were selected as a function of the radiation environment and the amount of labor required. Work performance methods can be tentatively classified as remote, semi-remote, and conventional methods:

- Remote methods are used where it is not possible for personnel to be in the immediate area of the specific operation. Remote repair methods were employed when the equivalent dose rate level in the work performance area was 100 milliroentgens per hour or higher.

- Semi-remote methods are used where it is possible for personnel to be in the work area for a limited amount of time. For example, the installation of a piece of equipment might be carried 
out by personnel in the work area, while the servicing of the equipment over the course of the performance of industrial operations (cutting, welding, etc.) would involve the use of a remote control panel located outside the work area. Semi-remote methods were employed when the equivalent dose rate level in the work performance area ranged from 28 to 100 milliroentgens per hour.

- Conventional methods are used where personnel are located directly in the work area throughout the entire operation. In instances when the labor intensity of the work was considerable (1,000 man-hours or more), the total radiation exposure of repair personnel was reduced to a level of 2.8 milliroentgens per hour in various ways (e.g., by decontamination, bringing in additional radiation shielding, etc.).

Of course, in addition to the personnel radiation dose rate and the intensity of the work, other factors also influence the selection of work performance methods such as:

- the physical access to the area

- the effectiveness of the dose rate reduction as a result of decontamination or through the use of radiation shielding

- organizational capabilities and condition for the use of personnel who have already sustained a radiation dose of 3 roentgen-equivalent man during the quarter for the performance of other relatively "clean" work over the remaining calendar year

- the skill level of the personnel required to perform the work.

All the factors listed above were considered during the formulation of the basic engineering and technological solutions. As a rule, several alternatives of the technologies and organization of the work were reviewed and subjected to critical analysis, after which the most optimum work performance methods were identified.

Implementing the approach described is a complex problem. However, successful work performance was largely dependent upon the results obtained from the resolution of this problem. The general rules that guided the developers of the technological processes were as follows:

- design analysis from the standpoint of the possibility of access and the performance of technological operations through the use of simple equipment (both standard and specially developed equipment)

- the analysis of the initial radiation environment and the search for potential means of improving it through the use of decontamination or radiation shielding devices.

Technological operations and preparatory work that ensured access for the work using the simplest possible techniques and equipment were subjected to analysis and criticality analysis, as were total radiation exposure estimates for personnel when using different alternatives to perform the work. Allowance was made for the fact that decontamination might only clean equipment surface contamination, whereas equipment repair most often involved the induced radioactivity of the equipment. Therefore, the performance of decontamination in these instances would not yield the requisite result.

The feasibility of using radiation shielding devices to improve the radiation environment within a work performance area was studied on a case-by-case basis. This is one of the simplest and most practical means of reducing dose rate, one that can be achieved with low skill-level labor and that provides substantial dose reduction during the performance of work requiring high skill levels. The 
shielding devices simplify the work performance techniques, the design of the equipment, and the specialized items of equipment needed.

It was realized that low skill-level personnel are available for the work on any nuclear facility, but there is always a shortage of high skill-level personnel (e.g., operators, fitters, high-discharge welders, etc.). A technological process alternative was selected and approved on the basis of the analysis results, after which the construction of the requisite equipment and specialized items of equipment was begun.

The equipment and specialized equipment can be divided into the following types, depending upon functional purpose:

- equipment for mechanical or thermal cutting (e.g., pipe cutters, bevel cutters, drilling and milling devices, apparatuses for remote and semi-remote plasma and electrocontact cutting)

- special welding equipment (e.g., automatic welding machines for the welding and spotwelding of pipes and other subassemblies)

- hoisting, rigging, and transfer equipment (e.g., clamps, automatic and semiautomatic slings, pullers, tilters, and catches)

- shielding devices and protective transportation containers (e.g., special protective booths, transfer casks, pressure suits, and other local means of protection)

- mechanisms for the disassembly and repair of threaded joints (e.g., special wrenches, nut drivers, stud runners, devices for the extraction of studs, jigs, and apparatuses for the cleaning and reconditioning of threaded joints)

- specialized modular equipment (e.g., manipulators, robots, and special protective booths containing multifunctional equipment)

- monitoring equipment and observation aids (e.g., periscopes, observation television monitors)

- other equipment and items of technological equipment (e.g., flaring tools, special gauging tools, plugs, various cleaning devices, and other auxiliary items of technological equipment).

In the majority of cases, the types of specialized technological equipment were not universal because standard designs were not used for nuclear reactors and their technological equipment.

The entire history of specialized equipment for production reactors in Russia is characterized by individual design solutions for separate subassemblies. Even for reactors of a single type, unique equipment and specialized technological equipment were used for each reactor. Nevertheless, upgrading imposed certain general requirements on the development of equipment and specialized technological equipment:

1. The least equipment contamination and the equipment's ease of decontamination. This requirement was satisfied by means of implementing the following solutions:

- using protective coatings that are easy to decontaminate

- the extensive use of stainless steel or corrosion-resistant materials with clean finished (polished) surfaces, as well as chrome-plated or nickel-plated parts made from carbon steels, in structural elements

- designs that minimize contamination holding areas in the structural elements of equipment (e.g., cracks) 
- the use of polyethylene bellows, casings, and other protective structures for the screw pairs, guides, and other exposed moving parts of equipment

- sealing off reducers, gearboxes, and other similar subassemblies from the possibility of internal contamination.

2. The easy or automatic detachment of damaged parts and subassemblies from a mechanism or a piece of equipment.

3. Employment of massive housings of the bedplate and other subassemblies as radiation shielding for the operator if necessary.

4. The subassemblies that secure and anchor equipment in the operational position must ensure the lowest possible residence time for personnel in a "dirty" work area.

5. Ensuring the removal of equipment from work areas if the equipment fails over the course of the operating process.

6. Using water rather than oil as the working medium in hydraulic drives (with the exception of the equipment needed to repair nuclear reactors with sodium coolant).

7. Using materials and component units that are resistant to radiation.

8. The reliability of equipment regardless of the nature of its use - one-time use or short-term operation.

9. A mandatory check of the serviceability of equipment on mockups and benches that simulate conditions encountered in the work environment.

10. Using equipment delivery packages containing benches and mockups, which is done to recheck the serviceability of the equipment prior to its use in a direct application, as well as for training and instructing operations personnel.

11. Delivering equipment in hermetically sealed crates and containers, to ensure the safety of the equipment during protracted work interruptions and transfer from storage to the work area.

The technical requirements for the requisite equipment were formulated while preparing the request for proposals on the design and following the criticality analysis and selection of an actual technology alternative.

\subsubsection{Experience in the Upgrading of Single-Pass Uranium-Graphite Plutonium- Production Reactors}

The first 10 years' operation of single-pass plutonium-production reactors (Table 2.1) demonstrated that their most inefficient subassemblies were the bottom parts of the technological channels. The structural steels and aluminum alloys under conditions of a hot (up to $70^{\circ} \mathrm{C}$ ) entrained-flow water coolant deteriorated considerably in the subassemblies due to electrochemical corrosion.

Several sensing lines made from austenitic steel (with a diameter of $12 \times 1 \mathrm{~mm}$ ) were ruptured, the channel temperature measurement system failed in part, and lower technological channels deteriorated (Figures 2.3 through 2.7). In addition, the coaxial alignment of the technological channels in the upper portion of the reactor was disturbed as a result of radiation-induced changes and shrinkage of the reactor stack graphite, which caused the technological channels to disengage from the graphite blocks. 
Figure 2.3. Condition of the Bottom Parts of the Technological Channels of the " $A$ " Reactor 
Figure 2.4. Corrosive Deposits and Damage on the Bottom Parts of the Technological Channels of the OK-110-3 Plutonium-Production Reactor 
Figure 2.5. Corrosion Damage on the Bottom Parts of the Technological Channels of the OK-110-3 Plutonium-Production Reactor 


Figure 2.6. Corrosive Condition and Deterioration of the Bottom Parts of the Technological Channels of the OK-110-3 Plutonium-Production Reactor 
Figure 2.7. Corrosive Condition and Deterioration of the Bottom Parts of the Technological Channels of the OK-110-3 Plutonium-Production Reactor 
Therefore, all single-pass reactors underwent upgrades and major repairs between 1963 and 1976, after which they operated successfully until their final shutdown (Table 2.1). The following characterized the upgrades and repairs of single-pass production reactors:

- the brief shutdown times for performing repairs and upgrades

- the lack of holding time for the shutdown reactors to allow a decrease in the dose rate from the natural decay of the short-lived and medium-lived radionuclides

- the lack of domestic practical experience in similar work

- the need for a number of unexpected and unforeseen technologies that were identified during the course of the repairs and upgrades

- other features peculiar to single-pass plutonium-production reactors.

\subsubsection{Upgrade of the "A" Plutonium-Production Reactor}

The causes behind the shutdown of the " $\mathrm{A}$ " production reactor for modernization and major repair in 1963 were corrosion damage to subassemblies, deterioration of equipment, and a wide range of design, engineering, and planning deficiencies that revealed themselves over the 15-year operating period and hindered its normal operation and maintenance.

In order to upgrade and repair the " $\mathrm{A}$ " reactor, it was necessary to dismantle

- all the water cooling systems within the plateau of the nuclear reactor (feed manifolds with a diameter of up to $800 \mathrm{~mm}$ )

- the batching manifolds for the individual feed of the water coolant to the technological channels

- the channel water coolant rate system

- the connecting piping and valves.

Moreover, it was necessary to install a new water cooling system.

Because of the alteration of the batching manifold, it was necessary to lengthen all the pipes of the top load-bearing structure by trimming the ends of the old pipes and welding 400 -mm-long stub pipes onto them. It was necessary to shorten and reconstruct the upper portions of the water tank that protruded $200 \mathrm{~mm}$ above floor level, so that their upper elevation corresponded to the floor elevation of the control room.

It was proposed that the coaxial alignment of the lower tracts, which had been disturbed as a result of corrosion damage to the parts, be restored through the installation of centering sleeves (Figure 2.8).

In order to perform each task listed above, the corresponding project and design documentation was prepared, new equipment and component units were ordered and delivered, a technological process was developed for the performance of the work, and specialized repair equipment and technological equipment were developed and fabricated (some 50 items). The most complicated pieces of equipment needed were the equipment for shortening and beveling the pipes of the top load-bearing structure; the automatic welding machine for the welding of the stub pipes; the special centering device for the assembly of the stub pipes prior to welding, which ensured the coaxial alignment of said pipes after welding; the pulling and rigging devices for the dismantling of the batching manifolds through the use of a traveling crane; and other items of technological equipment. 
Figure 2.8. The Mounting of Centering Sleeves on the "A" Plutonium-Production Reactor 
One of the most complex operations in the technical sense and one with the most unpredictable results proved to be the one involving the pulling of the batching manifolds from their mounting seats on the pipes of the top load-bearing structure. With a manifold weight of less than 1 ton, a force of 500,000 newtons was not sufficient to pull a manifold from its mounting seat. Consequently, several manifolds were cut from their mounting seats by mechanical means, which was not envisioned beforehand.

During the upgrade of the " $A$ " reactor, the remote plasma cutting of pipes with diameters of $160 \mathrm{~mm}$ to several meters was employed for the first time.

The total down time of the " $\mathrm{A}$ " reactor for upgrades and repairs came to approximately three months. In addition to the regular reactor personnel, the services of some 110 specialists from various organizations were enlisted. The specialists performed most of the work, with the exception of mounting the centering sleeves in the bottom parts of the technological tracts. Here, the individual radiation doses for the hired personnel did not exceed 3 roentgen equivalents-man.

\subsubsection{Upgrading of the OK-110 Type Plutonium-Production Reactors}

The operation of the single-pass plutonium-production reactors for 10-15 years led to the deterioration of the bottom parts of the technological channels that were made from aluminum alloys (particularly in the OK-110 reactors, Table 2.1) and to the failure of the temperature measurement system. Because of these failures, the normal operation and servicing of the reactors was hindered to a considerable extent (especially the work associated with the scheduled replacement of the technological channels), which dictated a need for resolving the problems surrounding their upgrades.

The high $\gamma$-radiation rates in the area where the defective subassemblies were approximately 20 100 roentgens per hour and the extremely limited access demanded uncommon solutions to the problem of upgrading the OK-110 type reactors.

The best method for upgrading the OK-110 type reactors was selected on the basis of a set of research and experimental studies. This method consisted of replacing damaged or defective pipes with new pipes that had an altered (modernized) design. In addition to its former functions, the new pipe with the altered design (Figure 2.9) ensured coolant water drainage by virtue of a perforation in its upper section, as well as coolant water temperature measurement through the use of a built-in thermocouple. The newly designed pipe also served as a support for the overhead descending parts by virtue of its increased length.

The parts in the midsection of the nuclear reactor that had defects were reinforced via the installation of zirconium sleeves (Figure 2.10). Here, a zirconium sleeve ensured the coaxial alignment of the damaged portion of a pipe, while a perforation in the sleeve facilitated the free outlet of the nitrogen that was blown through the reactor's graphite stack.

The technological process for upgrading OK-110 type reactors included the following:

- dismantling the cassettes (the reloading devices)

- unscrewing or cutting the nuts securing the lower pipe

- removing the old pipes or the damaged portions thereof

- installing the new pipes

- installing the compensating leads issuing from each pipe's thermocouple in the area of the reactor plateau and the switching panels 
Figure 2.9. Design and Installation of the New Lower Pipe 
Figure 2.10. Installing the Zirconium Sleeves in the $\mathrm{OK}-110-3$ Plutonium-Production Reactor 
- installing the zirconium sleeves

- the anchoring of the zirconium sleeves by flaring them.

The most labor-intensive operation was unscrewing the nuts and removing the pipes. In addition to special wrenches and powerful nut drivers, special equipment also had to be used to destroy the nuts, since some of them would not unscrew.

Two methods were used for dismantling the old pipes: pulling the pipes out from below and knocking the pipes out with rods from above. The second method proved to be more efficient, and the first method was discarded. However, the majority of these pipes were removed following their mechanical destruction. The commercial test introduction of the method selected was undertaken in 1969 for the OK-110-3 reactor (Table 2.1). The test was also done to perfect the technology and check the serviceability of the new components of OK-110 reactors. Based on the results of the commercial test introduction, the technological process and the repair equipment were adjusted, then the method was commercially introduced for all $\mathrm{OK}-110$ reactors.

Between 1970 and 1973, three reactors located at Chelyabinsk were upgraded, while the I-1 reactor located at Tomsk was upgraded in 1976. The shutdown for the upgrades ranged from 2 to 4 months and depended on the condition of the subassemblies being replaced, as well as on the need for work on other reactor equipment.

The technological process called for the use of up to 40 items of specialized equipment and technological equipment. Each item of equipment was used one time and was manufactured separately for each reactor.

During work performance, the personnel work areas were the nuclear reactor control room, which had a $\gamma$-radiation level of some 1-5 microroentgens per second, and the lower compartments of the reactor, where the dose rate varied from 1-100 microroentgens per second. The work involved in the repair and replacement of the upper water pipelines did not present any technical difficulty, since these pipelines were situated in an accessible work area with a mild radiation environment.

The individual doses sustained by personnel during the performance of work associated with the repairs and upgrades of the OK-110 type plutonium-production reactors did not exceed 3 roentgenequivalent man over a three-month period. Here, the total number of personnel taking part in the performance of this work came to approximately 120 persons.

\subsubsection{Upgrading of the Multi-Pass Plutonium-Production Reactors}

Multi-pass production reactors have a closed water cooling loop. The design is considerably different from that of single-pass reactors (Figures 2.1 and 2.2), especially the structural elements in the lower portion of the reactor. In multi-pass reactors, the water cooling loop pipelines (the pipes, the water batching and drain manifolds, and the valves), the individual reloading devices, the steam evacuation system for the packing glands of the reloading devices, the equipment for the autonomous cooling of the reactor protection and control system channels, and other pieces of equipment are located in the lower portion of the reactor. These differences in design from the single-pass reactor design, together with the improved performance parameters of multi-pass reactors (in temperature and pressure), resulted in the shortening of the service life of their structural elements. 
The common causes for upgrades after 5-9 years' operation were:

- corrosive strain cracking of equipment and piping made from austenitic steel without special coatings

- unsuccessful engineering solutions for reloading devices of different designs

- failure of the threaded joints (bolts and studs) securing the reloading devices to the lower bottom load-bearing structure lattice, which composed the lower support and protective structure of the reactor

- other unsuccessful general configuration and design solutions that hindered the maintenance and operation of multi-pass plutonium-production reactors.

The common causes, together with other individual causes for each reactor, are the main reasons the multi-pass reactors underwent upgrades and major repairs during the late 1960s and the early 1970s.

It should be noted that the structural elements in the lower portions of the multi-pass reactors differed from one another; i.e., there were virtually no identical structural elements in these reactors.

\subsubsection{Upgrading the EI-2 Plutonium-Production Reactor}

The EI-2 reactor, the first in a series of multi-pass plutonium-production reactors, was placed into operation in 1958. In 1964, due to the corrosive cracking of the stainless steel pipes (having a diameter of $10 \times 1 \mathrm{~mm}$ ), through which a hydraulic pulse was delivered for reloading the technological channel, the EI-2 reactor was shut down. During shutdown the pipes were replaced with zirconium alloy pipes, and other repair work was done.

In 1968, the El-2 reactor was shut down again for upgrades. The main reasons for this upgrade were:

- the unreliability of the discharge devices (frequent breakdowns)

- the unreliability of the reactor performance parameter monitoring system

- the cracking of a large number of drain pipes (having a diameter of $26 \times 1.5 \mathrm{~mm}$ ) in the lower water pipelines

- the failure of a succession of other reactor circuit piping.

The upgrades included:

1. Dismantling of the equipment and the water pipelines in the lower portion of the reactor:

- water pipelines from pipes with a diameter of $10 \times 1 \mathrm{~mm}$ (an expanse of some $18 \mathrm{~km}$ )

- lower water pipeline pipes with a diameter of $26 \times 1.5 \mathrm{~mm}$ ( 19 tonnes)

- heat insulation $(\sim 17$ tonnes)

- reloading devices ( 200 tonnes)

- biological shielding, the instrument benches, and the primary-circuit piping of the reactor ( 250 tonnes).

2. Reconditioning of threaded joints (the unscrewing or drilling out of any broken studs and the cutting of new threaded joints) on the lower bottom load-bearing structure lattice (a total number of some 450 items). 
3. The installation of the following equipment and water pipelines:

- new reloading devices ( $\sim 50$ tonnes)

- batching manifolds ( -33 tonnes)

- drain manifolds with a diameter of $800 \mathrm{~mm}$ ( 40 tonnes)

- the equipment for the cooling of the reactor protection and control system channels ( $\sim 5$ tonnes)

- the temperature monitoring system

- the slide valves, gates, and other equipment.

Moreover, during the upgrade of the EI-2 reactor, the need arose for repairs to a number of other reactor subassemblies.

A distinctive feature of the upgrading of the EI-2 reactor was the fact that a large amount of dismantling and installation was needed, but the reactor had only been in operation for nine years. The following engineering problems were resolved:

- the technology and equipment for plasma-arc cutting of sintered pipes made from austenitic steel with a diameter of $26 \times 1.5 \mathrm{~mm}$ were developed and implemented

- methods and equipment were developed for the wide-scale repair of threaded joints in an overhead position

- questions surrounding the mechanization of transfer operations in highly crowded work areas with a heavy flow of materials were resolved

- methods were perfected for cutting lined sheet-type structural elements made from austenitic steels, which tightly abutted concrete surfaces on one side

- other technically complex operations.

In addition to operations personnel, who carried out their standard work procedures, the services of about 400 other specialists from construction and installation organizations were enlisted. Some 55 items of repair equipment and specialized technological equipment were used to perform the work. The total duration of the shutdown of the EI-2 reactor for the upgrades was 123 days, as opposed to the 128 days originally projected. The personnel collective radiation dose came to some 1,200 roentgen equivalents-man. Approximately 10 million rubles (at 1968 prices) were spent on the upgrades.

\subsubsection{The Major Repair of the OK-140 Plutonium-Production Reactor}

The major repair of the OK-140 plutonium-production reactor, for which the design of the lower portion is conceptually different from that of the EI-2 reactor, was undertaken in 1968 due to the following principal irregularities:

- the corrosive cracking of the lower batching manifolds of the reactor cooling circuit, which were made from austenitic steel without a protective coating

- the extremely unsatisfactory condition of the reloading mechanism fasteners

- the failure of a portion of the channel temperature monitoring system

- the deterioration of certain reloading mechanism subassemblies. 
According to the plan and the technological process, it was necessary to:

- dismantle all the equipment and systems located in the lower part of the nuclear reactor (250 tonnes)

- recondition the threaded recesses for securing the reloading device in the lower bottom loadbearing structure lattice

- bore out the lower pipes to accommodate the increased diameter of the technological channels

- inspect and recondition the reloading devices, replacing any devices not suitable for repair with new ones

- install new or repaired equipment and systems of the nuclear reactor.

The greatest difficulties encountered came during the reconditioning of the threaded joints. When dismantling the reloading devices, approximately 3,300 bolts were broken, and only 400 of these could be unscrewed. The remaining 2,900 broken bolts had to be drilled out and new threaded openings cut. Special mechanisms were employed for this technically difficult operation, which included the mechanized cutting of threads in the overhead position with thread cutters. Peak productivity during this operation consisted of the reconditioning of some 120 threaded openings per day. Vibrating the bolts before unscrewing them was first employed during the performance of this work. It yielded good results but, unfortunately, was not introduced until the second half of the operation.

The idle time for the major repairs to the OK-140 reactor was 110 days. The personnel collective radiation dose reached approximately 1,700 roentgen equivalents-man because of the high labor intensity for reconditioning the threaded joints on the lower bottom load-bearing structure lattice and for the disassembly, inspection, and repair of the reloading devices. The work involved in the performance of these two operations made a major contribution to the total radiation exposure sustained.

\subsubsection{Upgrading the OK-204 Plutonium-Production Reactor}

Although the OK-204 plutonium-production reactor was developed and constructed at a later date, a number of unsuccessful engineering solutions were employed in the design of the reactor reloading system. In particular, the reactor reloading system design called for using both the individual reloading devices characteristic of multi-pass plutonium-production reactors and the group reloading devices (cassettes) characteristic of the single-pass reactors.

The reactor reloading system, which was quite complex, immediately began to have frequent operational malfunctions. Compounded by a number of other design deficiencies, the reactor reloading system was the principal cause behind the shutdown of the OK-204 reactor for upgrades after just six years of operation.

The upgrades to the OK-204 reactor required similar volumes of dismantling to the EI-2 and the OK-140 reactors. However, the experience acquired on the EI-2 and OK-140 reactors made it possible to avoid the same shortcomings identified during this work.

The preparatory work for the OK-204 upgrade was highly organized and included the following measures: 
- the education and training of personnel for the performance of these highly responsible technological operations

- the preliminary comprehensive decontamination of all equipment and the lower structural elements of the reactor with a new foam decontaminating compound.

The foam decontamination method was used for the first time during the OK-204 upgrade and made it possible to reduce radiation emission rate levels by several factors. Therefore, despite a two- and three-fold increase in the volume and the labor intensity of the work involved the overall personnel collective radiation dose came to a total 700 roentgen equivalents-man compared with 1,300 roentgen equivalents-man for the EI-2 reactor and 1,700 roentgen equivalents-man for the OK-140 reactor.

According to the plan and the technological process developed, the following reactor systems and components were subject to dismantling:

- the cassettes (the group reloading devices)

- the cassette replacement machine

- the curtain-type biological shielding

- the batching manifolds and the connective piping of the water cooling loop

- the individual reloading mechanisms

- the temperature measurement system (the pipes, instrument panels, etc.)

- the subcassette tracks

- the lower support structure for the subcassette tracks (the support structure).

The total weight of the reactor equipment and structural elements dismantled was considerable, coming to approximately 850 tonnes.

After all the dismantling work had been carried out, work was performed in line with upgrades. All the equipment of the new modernized reactor reloading system, the water cooling loop, the instrumentation system, and so forth was installed.

Some 110 items of repair equipment and specialized technological equipment were developed for the OK-204 upgrade. A considerable portion of the developed equipment was designed for rigging and transfer operations (in particular, the special transfer tracks for this work were installed at a total weight of some 28 tonnes).

In addition, the attendant plan called for the old batching manifolds to be used following the application of a metal-polymer coating. However, a portion of these manifolds actually turned out to be unsuitable for reuse due to corrosive cracking of the metal. Therefore, the partial repair of the manifolds or their replacement with newly manufactured manifolds also had to be undertaken, which led to an increase in the length of the scheduled idle period.

The duration of the shutdown of the OK-204 plutonium-production reactor for repairs and upgrades came to 135 days, and the number of personnel enlisted to perform this work was approximately 300 .

\subsubsection{The OK-135, OK-205, and OK-206 Upgrades}

The repairs and upgrades performed on uranium-graphite plutonium-production reactors in Russia are summarized in Table 2.2. The upgrades performed on the OK-135, OK-205, and OK-206 
production reactors are similar to the upgrades performed on the OK-140 and OK-204 production reactors. The repairs and upgrades of the OK-135, OK-205, and OK-206 production reactors were performed at a later date. The experience acquired on the earlier upgrades was fully utilized during the performance of this later work.

The duration of the shutdowns for the OK-135, OK-205, and OK-206 reactor upgrades varied from 90 to 120 days. The total radiation exposure ranged from 600 to 1,000 roentgen equivalents-man. The labor requirements and the volumes of work performed were comparable to the earlier upgrades. Personnel from the construction and installation organizations located on the sites of these reactors were also enlisted for basic dismantling, reconditioning, and installation tasks.

In addition to the previously described work on the lower structural elements of production reactors, the relative significance of which ranged from 7 to $80 \%$ of the total volume of work performed, repairs and replacement of the cooling loop equipment and piping in the upper portions were also performed (Table 2.2). This work presented no technical difficulty, since both the radiation environment and the accessibility of the subassemblies undergoing repair in the upper portions of the reactors were considerably better than the lower portions of reactors.

\subsubsection{Plutonium-Production Reactors Graphite Stack Repairs}

Standard work procedures for graphite stack repairs (the repair of graphite stack cubicles) were carried out by operations personnel on almost all production reactors during the shutdowns for upgrades. This work included the following:

- removal of the complement of graphite inserts from each graphite stack cubicle

- sizing (boring out) of the inner diameters of the graphite blocks over the entire height of a graphite stack using special tools (broaches, see Figure 2.11)

- repair of defective graphite stack cubicles by drilling out the defective sections and filling the cavities with a special polymerizing graphite paste

- installation of a new set of graphite inserts in the graphite stack cubicles

- other requisite work.

The most complicated graphite stack repair work was that associated with the graphite stack on the EI-2 reactor, which was performed in 1982. The complexity of the work was due to various causes. The primary cause was the curvature along the height of the graphite columns (primarily in the peripheral cubicles), which had reached a value of $50-200 \mathrm{~mm}$ by the early 1980 s and which complicated the safe operation of the EI-2 reactor to a considerable extent. The overall idle time of the EI-2 reactor was approximately six months, after which this reactor operated until its final shutdown seven years later. The repair of the EI-2 reactor's graphite stack implemented an entire complement of basic measures that were quite complex in the technical sense:

- straightening out the curvature of the graphite stack through the installation of tensioning gear

- eliminating those graphite block columns that had the greatest curvature by boring (drilling) them out and clearing away the resulting graphite chips

- filling the empty spaces in the graphite stack with a graphite paste

- installing permanent technological channels (tensioners) that prevented further increase in curvature over the course of the operation of the reactor

- other design and engineering solutions. 
Figure 2.11. Tools (Broaches) for the Sizing of the Openings in the Graphite Blocks of a Plutonium-Production Reactor Stack 
As a result of the work performed, it was possible to considerably reduce the curvature of the graphite stack columns, bringing it to a minimum value (roughly some 50 millimeters in the peripheral sections of the graphite stack).

\subsubsection{Cost of Upgrades and Repairs}

Pursuant to the construction rules and regulations of the former Soviet Union, the estimated cost of construction for a given reactor was determined by the design organization, called the "general designer." In this instance, the estimate documentation became an integral part of the design and served as a basis for transacting mutual settlements between the "client" and the contracting firms. This rule did not work with respect to upgrading plutonium-production reactors because the "general designer" either did not take part at all in the development of the technical documentation or only got involved in the small innovations that fell within its competence.

Instead, a procedure was adopted whereby estimates for upgrading production reactors were prepared by the organization that developed the entire technological process; i.e., a set of documents that reflected the volume and organization of the work and procedure. The following documents served as source data for the preparation of estimates:

- the request for proposals of the "client," which contained a list of the impending work

- the design and project documentation for the major repairs and upgrades

- the technological process for the upgrades or repairs.

The estimated cost of the repairs and upgrades of a facility included the following:

- the cost of the work to be performed by the enterprises and organizations enlisted, with the introduction of special coefficients that allowed for increases in the cost of the work under specific conditions

- the cost of manufacturing the repair equipment and technological equipment envisioned for the planned technological process

- the cost of the basic materials, auxiliary materials, and associated equipment and items to be provided by the contracting firm.

Costs for the standard work procedures and routine work to be performed by regular operations personnel were not taken into account in the estimate. Costs for the development of all technical documentation (project documentation, design documentation, technological documentation, and estimate documentation), as well as costs for the acquisition of the new equipment, spare parts, and basic materials procured by the client were taken into account in other documents.

The estimated cost for the major repairs and upgrades of plutonium-production reactors ranged from 3.5 to 15.0 million rubles at the prices of that time. For example, the cost for upgrading the EI-2 reactor came to 10.0 million rubles in 1968, the cost of the major repairs of the OK-140 reactor came to 4.0 million rubles in 1968 , and the cost of upgrading the OK-204 reactor came to 12.5 million rubles in 1970.

\subsubsection{Conclusions Based on Repairs and Upgrades}

Over the course of the major repairs and upgrades of uranium-graphite plutonium-production reactors in Russia, practical experience was acquired in dismantling, installation, and reconditioning tasks for these complex and radiation-hazardous facilities. 
As a result of major repairs and upgrades of the reactors, the following practical problems were resolved:

- the safe and accident-free service life of plutonium-production reactors was extended (to almost 40 years)

- methodical approaches to planning, organization, and performance of reconditioning work were perfected

- a school for developing technological processes, as well as diverse specialized equipment and items of equipment for the performance of similar special work, was created within the nuclear industry

- practical experience was acquired in the area of the organization and performance of similar work with acceptable dose levels for the personnel performing this work

- new methods and technologies were perfected for decontamination, remote cutting, machining, and welding at great depths, and the disassembly and reconditioning of threaded joints under complicated radiation conditions

- development and introduction of a scheduled preventive maintenance system within the nuclear industry.

The experience obtained on production reactors and the engineering solutions and technologies tested and perfected under working conditions have been used with success during repairs and upgrades of nuclear research and power reactors in Russia. In addition, the experience in upgrades and major repairs of production reactors made it possible to improve the maintainability and reliability indexes for newly designed nuclear power engineering facilities.

\subsubsection{Decommissioning Conceptual Approaches}

The first uranium-graphite plutonium-production reactor in Russia was shut down in 1987, and nine of the 12 reactors constructed had been shut down by 1992. Planning, technological, and design work aimed at decommissioning shutdown production reactors was begun during the late 1980 s.

The decommissioning of production reactors is a lengthy process involving the implementationfollowing final reactor shutdown - of engineering and organizational measures aimed at precluding the further use of the reactors for the production of plutonium and power. During decommissioning, physical protection and fissile and radioactive material accountability must be organized. In addition, the safety of personnel, the populace, and the environment must be ensured (both during decommissioning and following its completion, if necessary).

Based on existing world practice in decommissioning uranium-graphite plutonium-production reactors, the three following decommissioning alternatives have been reviewed and analyzed:

SAFESTOR, the reactor's structural elements are not dismantled for a storage period of 50 to 100 years. The nuclear reactor remains in the reactor cavity and is isolated in place by hermetically sealing the appropriate apertures and penetration assemblies. The nuclear reactor's support metalwork is reinforced, and the lower portion of the reactor cavity is filled with concrete.

ENTOMB, the nuclear reactor's structural elements are partially dismantled. The internal cavities of the nuclear reactor are filled with concrete mix, and the reactor's biological shielding and lower support structures are filled with concrete. A special ceiling is installed in the upper portion of the reactor cavity over the reactor. All the appropriate penetration assemblies and apertures are hermetically sealed. 
$D E C O N$, the nuclear reactor, the reactor equipment, and the reactor's structural elements are completely dismantled. The dismantled reactor components, equipment, and structural elements are removed from the reactor operations area and are transported to special storage facilities or burial grounds for solid radioactive wastes.

During the analysis and evaluation of the acceptability of the decommissioning alternatives for the plutonium-production reactors, the following were determining factors:

- the amount of capital expenditures, which were dependent upon the radiation condition of the nuclear reactor's structural elements

- the necessity of using special equipment for dismantling and transporting dismantled components and structural elements, etc.

- the feasibility of the removal and storage of the dismantled equipment and structural elements, with allowance for ensured isolation from the environment.

These factors were evaluated allowing for radioactive decay over time of the structural elements and equipment following reactor shutdown. Based on the results of the analyses, a general concept has been adopted for decommissioning production reactors that consists of the permanent burial of the nuclear reactor in place within the reactor cavity and the creation of a safety barrier that ensures the isolation of the radioactivity accumulated in the plutonium-production reactor's structural elements from the environment for a period of up to 100 years or more. In order to implement the general concept for decommissioning plutonium-production reactors, it is proposed that the following tasks be carried out:

1. Fill the reactor space and the cubicles of the reactor's graphite stack with concrete or bentonite clay.

2. Fill the space between the graphite stack and the reactor core catcher with bentonite clay.

3. Fill the biological shield tanks and the reactor support metalwork areas with concrete.

4. Hermetically seal all existing reactor penetration assemblies, apertures, and piping that open onto the environment.

5. Construct a permanent ceiling over the upper portion of the reactor cavity.

The comparison of certain technical and economic indicators for dismantling plutonium-production reactors after different storage times is presented in Table 2.3.

\subsubsection{Status of the Decommissioning of Shutdown Reactors}

Special technological processes have been developed for decommissioning production reactors. In addition, specialized equipment, tools, and items of technological equipment have been designed (and have already been manufactured in a number of cases). The principal engineering difficulties with respect to these innovations have been getting the fillers into the cavities of the reactor and monitoring the quality of the filling process. Other complex engineering problems include welding the hermetic seals onto the pipe structures and penetration assemblies, and installing the protective ceiling over the reactor cavity.

All of the operations involving the penetration of the reactor space must be carried out with remote methods and equipment. For example, special plasma-arc cutting equipment has been developed and produced for cutting hatches in the ceiling of the plutonium-production reactor's biological shield at a number of elevations ranging in height from 6 to $19 \mathrm{~m}$. Mechanical cutting 
Table 2.3. Technical and Economical Indexes for Dismantling Plutonium-Production Reactors Versus Reactor Storage Time

\begin{tabular}{|l|c|c|c|c|}
\hline \multicolumn{1}{|c|}{ Index } & $\begin{array}{c}\text { Dismantling after } \\
\text { one year of reactor } \\
\text { storage }\end{array}$ & \multicolumn{3}{|c|}{$\begin{array}{c}\text { Dismantling after } \\
\text { reactor storage times } \\
\text { (years) }\end{array}$} \\
\hline & & 10 & 30 & 100 \\
\hline $\begin{array}{l}\text { Dismantling costs, including costs of prepar- } \\
\text { ation and reactor storage (relative values) }\end{array}$ & 1.0 & 1.15 & 1.24 & 1.20 \\
\hline Dismantling time (years) & 6 & 4.5 & 4.5 & 4.5 \\
\hline $\begin{array}{l}\text { Estimation of the personnel collective } \\
\text { equivalent dose (Man*Sv) }\end{array}$ & 13.30 & 7.90 & 4.70 & 4.45 \\
\hline Estimation of the staff needed (people) & 320 & 335 & 365 & 460 \\
\hline
\end{tabular}

using crown-type drills of various diameters has been envisioned for cutting openings in locations where use of plasma-arc cutting is not possible due to dimensional considerations. The mechanical cutting would be carried out using a drilling rig, or if in the overhead position, using a special pneumatic actuator. A plasma-arc cutting device with a small torch has been created for cutting several hundred aluminum technological tracts with a diameter of $66 \times 10 \mathrm{~mm}$ at different elevations.

Analyses are being performed on the composition of the concrete, bentonite, and sand mixtures to be used, technologies for emplacing these mixtures into the reactor cavities, and monitoring the quality of the filling process. Designing the protective ceiling over the reactor is under way, as is developing a technology for installing this ceiling. A series of special automatic welding machines has been created for sealing the technological tracts from above and from below.

The development of the complement of the technological processes, specialized equipment, and mechanisms for the decommissioning of plutonium-production reactors has almost been completed at this time. Shutdown uranium-graphite plutonium-production reactors located near Tomsk are being used as a "proving ground" for testing, checking, and perfecting the proposed technological methods and equipment. The dismantling of "clean" structural elements of the Tomsk reactors has already been completed, and preparations are under way for the proposed decommissioning alternative.

\subsubsection{Review of the Cutting of Specimens and Samples from Structural Elements of the Shutdown EI-2 Plutonium-Production Reactor}

The analysis of the condition of the structural materials from plutonium-production reactors that have been exposed to intense neutron and radioactive irradiation, high temperatures, and humidity for approximately 30 years or longer is of scientific and practical interest to researchers, designers, project engineers, and reactor operations personnel. The results of such analyses are not only essential to the substantiation of the selected decommissioning option for the reactors but may also prove useful in evaluating the serviceability of the materials used in newer reactors.

Cutting and analysis of metal specimens from internal, inaccessible, and hard-to-reach locations in the EI-2 reactor is being performed to substantiate the feasibility of the entombment option (100 to 150 years or more). The analyses of the metal specimens include a full complement of mechanical, metallurgical, radionuclide, and other specimen tests. 
Depending on the location of and radioactivity surrounding the structural element, cutting specimens and samples would be performed either remotely or manually. It was assumed that specimens would be remotely cut from the upper and lower plating of the top load-bearing structure, the top load-bearing structure pipes, and the lower tract parts, as well as from the lower bottom load-bearing structure metalwork. It was assumed that mechanical methods alone would be used for the remote cutting.

It was assumed that manual cutting technologies would be employed in instances of structural accessibility and low radiation levels. It was further assumed that manual methods would be used to cut specimens from the ribs and beams of the upper structural elements of the nuclear reactor, the upper manifolds, the pipes of the ionization chamber blocks, and other components. Thermal cutting was proposed as the method for the manual cutting because the technique can be used on various specimen dimensions, and the machining of the contours of the cut specimens can be performed after the heat-affected layer has been eliminated.

A technological process was developed for the entire complement of operations, together with the requisite mechanisms, items of technological equipment, and tools. The specimens were obtained in November and December of 1993.

The technological process included the following technological operations:

- the remote cutting of four specimens from the upper plate of the upper top load-bearing structure (the thickness of the plate was $36 \mathrm{~mm}$, the structural material used in the plate was carbon steel, and the diameter of the test specimen was $116 \mathrm{~mm}$ )

- the remote cutting of four specimens from the lower plate of the top load-bearing structure (the thickness of the plate was $20 \mathrm{~mm}$, the plate material was carbon steel, the diameter of the test specimen was $100 \mathrm{~mm}$, and the cutting of the specimen was carried out at a depth of $6.9 \mathrm{~m}$ )

- the remote collection of cuttings from predetermined elevations in the upper portions of the technological channels-the top load-bearing structure pipes (the structural material used in these technological tracts was stainless steel)

- the manual cutting of test specimens and samples from a number of the components of the nuclear reactor's upper structural elements.

In order to ensure tool access to the lower plate through the backfill of the top load-bearing structure, a tubular penetration assembly with a diameter of $138 \mathrm{~mm}$ was installed to a positive stop on the lower plate using the vibration technique. The backfill was removed from this penetration assembly with a special screw conveyer. The remote cutting equipment was installed through the tubular penetration assembly. A special drilling machine (drilling rig) was installed on the top of the reactor. Carbide-tipped, crown-type four-tooth cutters were used as the working tools.

The cutting coordinates for the test specimens were determined based on the intensity of the neutron exposure sustained. The design of the cutting mechanism included a special magnetic holder that prevented a cut specimen from being dropped and ensured its extraction.

Eight test specimens were cut (four from the upper plate and four from the lower plate), among which four were extracted from the central portion of the reactor and four from the periphery.

The $\gamma$-radiation rate of the specimens cut from the upper plate reached 40 microroentgens per second, while that of the specimens cut from the lower plate was in excess of 1,600 microroentgens per 
second, which proved to be four times lower than the estimated rate. There was virtually no corrosion on the test specimens.

Special remote controlled equipment was designed and manufactured for cutting specimens at predetermined elevations in the upper portions of the technological channel (the top load-bearing structure tracts). This equipment made it possible to record the elevations at which the specimens and samples were extracted. The samples (stainless steel cuttings with a weight of 5 to 10 grams) were extracted using two slotting tools. The cuttings were collected in a sleeve lowered into the technological tracts beforehand. The operation was performed at four levels of three upper tracts located in the center portion of the reactor, at half the radius, and at its periphery.

Sixteen samples were collected at fixed elevations, for which radionuclide analyses were conducted. It is proposed that similar analyses be performed in the future for samples taken from fixed elevations along the entire height of the technological tracts, which would include different structural materials (stainless steel, aluminum alloys, and graphite).

A cleft with dimensions of $1,500 \times 1,500 \mathrm{~mm}$ and a depth of $2 \mathrm{~m}$, was fashioned along the periphery of the upper plate in the backfill of the top load-bearing structure (a small-fraction iron-ore backfill of $2.5 \mathrm{~m}$ thick and a sand backfill $1.5 \mathrm{~m}$ thick). (The depth was governed by the status of the radiation environment within the structure, which was determined by the induced activity rate from the underlying reactor structural elements, to wit: the graphite stack, the side shielding, and so forth.)

Test specimens, $250 \times 250 \mathrm{~mm}$, were manually cut from the top load-bearing structure support beams, the top load-bearing structure stiffening girder, the cylindrical liner system beam structure, and the upper shielding (circular tank system) beams and plating. A total of 18 test specimens were collected manually.

In 1995, the cutting of metal test specimens from the structural elements of the EI-2 plutoniumproduction reactor was extended. Specimens were taken from the lower structural elements of the reactor by the drill-out technique using crown-type drills. The diameter of the drills (and, consequently, the diameter of the test specimens collected) decreased in proportion to the downward movement of the tool to the elevation of the lower plate of the reactor's lower diaphragm. In addition, cuttings were collected from the aluminum technological tracts located beneath the reactor core in a similar manner using remote techniques.

The program for cutting test specimens and samples from plutonium-production reactors has recently concluded, and the analyses of the metal specimens are coming to a close. The specimens have been treated in hot cells, after which they were subjected to a battery of mechanical, metallurgical, and other tests. The results obtained will be used to substantiate the feasibility of the longterm storage of production reactors.

\subsubsection{Relevant Experience with Operational Reactors}

In the previous sections, the status of decommissioning shutdown production reactors was presented. Three uranium-graphite plutonium-production reactors are still in operation at this time: the OK-206, OK-204, and OK-205 (Table 2.1), which are at the ADE-2, ADE-4, and ADE-5 reactor plants, respectively.

The ADE-2, ADE-4, and ADE-5 reactor plants are multi-pass plants designed to produce special products (plutonium and other radionuclides), and to generate electric power and heat (to meet both commercial and household needs). With the arms reduction treaties and the moratorium on testing 
nuclear weapons, the production of special products must be halted. Therefore, the operating production reactors must be decommissioned.

A complement of decommissioning preparatory work is being carried out for the operational reactors. Technical and economic research is being conducted to substantiate the safety and the cost of decommissioning. The principal results of the preparatory work performed, and the technical and economic research are presented below.

\subsubsection{Status of Operational Reactors}

The condition of the structural elements and technological systems of the OK-206, OK-204, and OK-205 plutonium-production reactors is regularly inspected and analyzed by personnel and by a special commission. Based on the results of the inspections, it can be concluded that the graphite stacks, basic reactor metalwork, reactor protection and control system components, primary circuit piping, process control systems, radiation monitoring systems, emergency cooling systems, thermal power equipment, electric power equipment, nitrogen lines, service water supply systems, drain systems, product acceptance, sorting, and storage systems, process véntilation systems, and gas treatment systems are in good condition and should operate reliably until at least the year 2000 .

The possibility of using these production reactors past the year 2000 , should the need arise, must be determined by a special commission for the extension of operation following an additional inspection.

The activity of equipment, piping, and primary circuit systems is determined by active structural material corrosion products and fuel fission products. The internal surfaces of the primary circuit are contaminated with the following radionuclides: $\mathrm{Co}^{58}, \mathrm{Co}^{60}, \mathrm{Cr}^{51}, \mathrm{Zn}^{65}, \mathrm{Se}^{46}, \mathrm{Mn}^{56}, \mathrm{Zr}^{95}, \mathrm{Nb}^{95}$, $\mathrm{Cs}^{37}$, and $\mathrm{Eu}^{152}$.

An analysis of current levels of ionizing radiation in the vicinity of the main reactor equipment demonstrates that this equipment is available for routine inspection over the course of the operating process should the monitoring of the continuous annual permissible radiation dose for personnel reveal a level of 5 roentgen-equivalent man ( 5 centisieverts).

\subsubsection{The Decommissioning Option for the OK-204 and OK-205 Reactors}

Based on an analysis of the economic situation in Russia, the lack of special equipment needed for dismantling highly radioactive reactor equipment, and the lack of the storage or burial sites for radioactive waste, entombment is being considered as an option for the decommissioning of the OK-204 and OK-205 reactors. Under this option, a reactor is isolated and hermetically sealed in place for a period of 100 years or longer. It is proposed that the machine room equipment and other reactor systems be dismantled when the activity of the equipment and systems has decayed to levels that make it possible to perform dismantling with conventional tools.

The entombment alternative, with deferred dismantling, presupposes a series of steps: preparation for decommissioning, preparation for burial, and storage.

Preparation for decommissioning, the nuclear reactors and its systems are brought to a nuclear-safe status.

In the event that the spent nuclear fuel, and the reactor systems and compartments as a whole, are in a normal (accident-free) condition, or if emergency situations have occurred (e.g., fuel element failure), the reactor is brought up to a nuclear-safe status in compliance with regulations. If a nuclear accident occurs while bringing a reactor up to a nuclear-safe 
status, it is necessary to implement the planned measures formulated by the enterprise that owns the reactor plant. The measures provide instructions for overcoming the aftereffects of such an accident.

During preparation for decommissioning, a reactor is deemed to be in operation until the spent nuclear fuel is removed from the unit, as defined by the requirements of the agencies of the Russian State Committee on Nuclear and Radiation Safety. The reactor is serviced using a specially developed and approved procedure.

After unloading the fuel and draining the primary circuit, a radiation inspection must be made of the plant systems and the reactor. Then a comprehensive engineering and radiation inspection is made of the condition of the reactor components and other systems that must be in operation over the course of the preparatory step (the life support systems). Based on the results of this inspection, a chart of radioactivity distribution by reactor component is prepared, and the presence and quantification of fissile materials is determined. A decision is then made concerning the performance of subsequent work as a function of the total amount of fissile materials present.

The duration of this step is approximately three years, which includes unloading the spent nuclear fuel from the reactor core, holding the fuel in the cooling pond, and shipment of the spent nuclear fuel.

Preparation for burial is divided into several steps: short-term holding of the reactor systems, bringing the reactor into a state of permanent stability, dismantling and handling the reactor equipment and systems, burial ground cleanup, and cleanup of the reactor operations area.

Short-term holding of the reactor systems that have been contaminated by radionuclides is carried out to facilitate the natural decay of radioactivity (primarily that of $\mathrm{Co}^{60}$ ). The holding time can last from 6 to 30 years, depending on the level of the attendant radioactive contamination and the total radiation exposure that would be sustained by personnel taking part in the dismantling work. The dismantling work is performed after the required holding time to reduce the gamma-radiation dose rate associated with the equipment and piping to a value of 1.4 milliroentgens per hour. Technological equipment that has contamination levels of less than 1.4 milliroentgens per hour may be dismantled by personnel without prior holding, provided that regulations are observed.

Bringing the reactor to a state of permanent stability is preparing the reactor and its systems for storage for a period of 100 years or longer, as well as to prevent the escape of radionuclides into the atmosphere, for which three protective barriers are erected around the reactor space. The upper water pipelines, the water pressure headers, and the feed piping are dismantled, the lower water pipelines and manifolds are dismantled, and the top and bottom load-bearing structures stub pipes are hermetically sealed. The first protective barrier is thus created, preventing the escape of radionuclides from the reactor space.

The second protective barrier is created through the use of construction technologies. To this end, the compartments below the reactor compartment and the reactor compartment itself (the "T" system and the support structure) are filled with waterproofing concrete, the bottom load-bearing structure is reinforced, the apertures in the walls of the space between the support structure and the bottom load-bearing structure are filled with waterproofing 
concrete (thereby creating a compartment for monitoring the development of moisture and the condition of the lower reactor metalwork), all the penetration assemblies and apertures in the reactor compartment are filled with concrete, the circular tank system is filled with concrete, the reactor compartment in the control room is overlaid with a reinforced concrete cover that is lined with steel and can withstand the loads created by a falling aircraft, and a compartment is created between this cover and the top load-bearing structure for housing the instruments used to monitor the status of the reactor. The structural elements of the building serve as the third protective barrier.

Dismantling and handling the reactor equipment and systems. The dismantling work is performed sequentially, starting with those items of equipment and system piping that have little or no radioactive contamination (i.e., a dose rate of not more than 1.4 milliroentgens per hour).

It is advisable that dismantling be started after radioactive waste processing plants have been constructed, because the reuse of materials is only possible after their chemical or thermal decontamination. With appropriate redesign, the power plant building's machine room can be used (following the dismantling of the equipment, turbogenerators, condensers, etc.) to house the radioactive waste processing plant equipment. The secondary solid waste is collected and compacted, while the liquid waste is processed into solid waste and containerized for burial or storage.

Items of equipment, system piping, and valves (mainly from the primary circuit) that exhibit contamination with a dose rate of more than 1.4 milliroentgens per hour will be stored to facilitate the natural decay of the radionuclides (primarily $\mathrm{Co}^{60}$ ). Storage time will depend on the amount of time required to reach a dose rate of less than 1.4 milliroentgens per hour in the vicinity of the system (according to estimates, this time frame for the primary circuit is not less than 10 years after the shutdown of the nuclear reactor).

If the construction section of the facility will henceforth not be used, the last operation to be carried out is dismantling the life support systems: the water supply systems, the heating and ventilation systems, the power supply systems, the fire suppression systems, and the lighting systems. The rooms that adjoin the reactor compartment and the control room are preserved for an extended period of time. The remaining rooms can be backfilled with construction wastes or soil.

Burial ground clean up is carried out because near-reactor, class-three radioactive waste burial grounds and trench-type burial grounds containing class-two and class-one radioactive wastes are located within the operations areas of the reactors (Table 2.4). Radioactive waste burial grounds represent a hazard regarding the contamination of the environment in the event of exposure to various potential natural or technological factors. Therefore, the burial grounds must be cleaned up in the preparatory step.

The cleanup of class-three radioactive waste burial grounds will be accomplished with a special system that is still under development. The class-three wastes removed from burial grounds will be containerized and forwarded for burial. The structural elements with contaminated surfaces will be dismantled, containerized, and forwarded for burial. The cleanup of trench-type burial grounds containing class-two and class-one radioactive wastes will be undertaken using the technological equipment being developed. The process for cleanup of 
Table 2.4. Classification of Solid Radioactive Wastes

\begin{tabular}{|c|c|c|c|}
\hline $\begin{array}{c}\text { Solid } \\
\text { Radioactive } \\
\text { Waste Category }\end{array}$ & $\begin{array}{c}\gamma \text { - Radiation dose rate } \\
10 \mathrm{~cm} \text { from waste surface, } \\
\text { (mroentgen } / \mathrm{hr} \text { ) }\end{array}$ & $\begin{array}{c}\text { Specific } \beta \text {-activity, } \\
\text { (Ci/kg) }\end{array}$ & $\begin{array}{c}\text { Specific } \alpha \text {-activity, } \\
\text { (Ci/kg) }\end{array}$ \\
\hline 1 & from 0.03 to 30 & from $2 \times 10^{-6}$ to $1 \times 10^{-4}$ & from $2 \times 10^{-7} \cdot$ to $1 \times 10^{-5}$ \\
\hline 2 & from 30 to 1000 & from $1 \times 10^{-4}$ to $1 \times 10^{-1}$ & from $1 \times 10^{-5}$ to $1 \times 10^{-2}$ \\
\hline 3 & above 1000 & above $1 \times 10^{-1}$ & above $1 \times 10^{-2}$ \\
\hline
\end{tabular}

trench-type burial grounds is in need of updating. The radioactive waste removed is sorted on special units by contamination category and material (steels, nonferrous metals, fuels, soil, etc.), packaged, and forwarded for processing or burial (holding). It is proposed that, after being processed in the radioactive waste processing plants, thermally decontaminated metals be forwarded for reuse, while the secondary radioactive waste be solidified, containerized, and forwarded for burial.

Start of the cleanup of the reactor operations area. The removal of the contaminated soil layer to a depth of 25 to $60 \mathrm{~cm}$ and the backfilling of the cleaned-up areas with "clean" soil has been proposed as the principal means of cleaning up those sections of the area that have been contaminated to different extents by radionuclides. Over the course of this work, the items subject to cleanup are those sections that have a dose rate of more than 30 milliroentgens per hour and roadways that have a dose rate of more than 30 milliroentgens per hour and/or that have irremovable contamination with a level of more than 200 beta-particles per square centimeter per minute.

The work associated with area cleanup must be performed following the removal of radioactive waste from the solid-waste burial grounds. The removed contaminated soil is loaded into containers and forwarded for burial. The trees and shrubs growing in the contaminated area are subject to cleanup, which is accomplished by cutting these items down and burning them in an incinerator constructed in the power plant building. Soil removal will be accomplished with the engineering equipment developed, which will have personnel cabs equipped with biological shielding and life support systems.

Storage. The long-term storage of the reactor lasts for a period of 100 years or longer, depending upon the amount of time required for the natural decay of the attendant radionuclides. Storage begins with the completion of the protective barriers for the reactor.

It is proposed that a system be created for monitoring the status of the reactor and its individual structural elements. The following parameters should be monitored: the temperature of the graphite stack in those areas where fissile materials were found (in the event that accidents have occurred), the radiation dose rate in those locations where fissile materials were found and the decay of activity in the remaining reactor locations, the composition of the gases in the reactor space, the condition of the reactor metalwork (the top load-bearing structure), and the appearance of water in the space below the reactor.

Periodic monitoring would be performed over the entire course of storage. Monitoring of certain parameters might be stopped based on the results of long-term observations. Control samples would be set up to facilitate monitoring changes in the condition of the 
reactor metalwork. It is proposed that nuclear reactor be dismantled after the activity of the reactor components has decayed to levels that make it possible to dismantle it without remote-controlled mechanisms or devices (with the exception of sections of the graphite stack contaminated by fissile materials).

\subsubsection{The OK-206 Reactor Decommissioning Alternative}

One feature of the ADE-2 reactor plant, which houses the OK-206 plutonium-production reactor, is that it is situated within rock. This feature and the extent of the contamination of the reactor's graphite stack by long-lived and highly toxic radionuclides (primarily fission products and actinides) complicates the dismantling of the OK-206 reactor. Therefore, just as for the OK-204 and OK-205 reactors, the entombment alternative with deferred dismantling of reactor systems and equipment is being considered as the main decommissioning option. It is also proposed that the entombment alternative for the OK-206 plutonium-production reactor be performed in three steps: preparation for decommissioning, preparation for entombment, and long-term storage.

The preparation for decommissioning the OK-206 production reactor is similar to that for the OK204 and OK-205 reactors. However, because the OK-206 reactor is situated within a rock mass, the two subsequent steps will have slight differences from the descriptions previously given for the $\mathrm{OK}$ 204 and OK-205 reactors.

First, it is assumed that when bringing the OK-206 reactor into a state of permanent stability, the reactor well will be overlaid with a light metal cover, because the reactor is protected against impact from a falling aircraft by the surrounding rock, which constitutes this reactor's third protective barrier (similar to the structural elements of the buildings for the OK-204 and OK-205 reactors).

Second, it is proposed that the existing burial grounds, which are situated in the same rock mass, not be cleaned up. Only the stabilization of the burial grounds is envisioned.

Third, the area around the reactor plant (the auxiliary service facilities, the transportation tunnels, etc.) is not in need of contamination cleanup, since these facilities do not exert a direct harmful influence on the environment.

\subsubsection{Cost Estimates for Decommissioning the $O K-204, O K-205$, and $O K-206$ Reactors}

Costs have been estimated for the entombment alternative for the OK-204, OK-205, and OK-206 plutonium-production reactors. The following assumption were made:

- capital costs for construction, installation work, and acquisition of equipment were determined at 1991 base prices

- operations and maintenance costs for solid radioactive waste handling and processing, decommissioning, and storage were determined at the prices in effect during the 1st quarter of 1994.

The resulting cost estimates are presented in Table 2.5 and Table 2.6.

\subsection{RBMK Reactors}

\subsubsection{Repairs and Upgrades}

At the nuclear power plants that functioned within the former Soviet Union, 16 RBMK units were operated, 11 of which were located in Russia. The first unit equipped with an RBMK-1000 type reactor (Figure 2.12), which had an electric capacity of 1,000 megawatts, was constructed and placed into operation in 1973 at the Leningrad NPP. 
Table 2.5. Costs of Decommissioning the OK-204, OK-205, and OK-206 PlutoniumProduction Reactors

\begin{tabular}{|c|c|c|c|c|}
\hline \multirow[b]{2}{*}{ Expenditure (1991 prices) } & \multicolumn{2}{|c|}{$\begin{array}{l}\text { OK-204 and OK-205 } \\
\text { (million rubles) }\end{array}$} & \multicolumn{2}{|c|}{$\begin{array}{c}\text { OK-206 } \\
\text { (million rubles) }\end{array}$} \\
\hline & Total & $\begin{array}{c}\text { Equipment } \\
\text { Purchase }\end{array}$ & Total & $\begin{array}{c}\text { Equipment } \\
\text { Purchase }\end{array}$ \\
\hline $\begin{array}{l}\text { I. Nuclear facility } \\
\text { 1. Capital cost of the replacement of limited } \\
\text { resource equipment and systems to be under } \\
\text { operation }\end{array}$ & 0.796 & 0.796 & 0.597 & 0.597 \\
\hline $\begin{array}{l}\text { 2. Removal of class }-3 \text { radioactive wastes } \\
\text { 2.1. Design of special equipment } \\
\text { 2.2. Capital investments }\end{array}$ & $\begin{array}{l}0.52 \\
0.39\end{array}$ & 0.06 & & \\
\hline 3. Reactor entombment capital cost & 1.675 & 0.01 & 0.837 & 0.10 \\
\hline $\begin{array}{l}\text { 4. Capital cost for dismantling } \\
\text { 4.1. Reactor dismantling } \\
\text { 4.2. "Clean" equipment dismantling } \\
\text { 4.3. "Dirty" equipment dismantling after 10- } \\
30 \text { years of storage }\end{array}$ & $\begin{array}{l}11.15 \\
0.23 \\
1.03\end{array}$ & $\begin{array}{l}2.10 \\
0.08\end{array}$ & $\begin{array}{l}5.57 \\
0.14 \\
0.52\end{array}$ & $\begin{array}{l}1.05 \\
0.08\end{array}$ \\
\hline 5. Cost of radioactive waste disposal & 1.75 & 0.18 & 0.875 & 0.09 \\
\hline 6. Other expenditures & 5.50 & & 2.864 & \\
\hline Total for items 1-6 & 23.041 & 3.226 & 11.385 & 1.917 \\
\hline $\begin{array}{l}\text { II. Nuclear power plant } \\
\text { 7. Capital cost for dismantling NPP } \\
\text { 7.1. Dismantling the turbine hall equipment } \\
\text { 7.2. Dismantling the steam generator } \\
\text { equipment after } 30 \text { years of storage }\end{array}$ & $\begin{array}{l}16.0 \\
2.5\end{array}$ & 0.2 & $\begin{array}{l}8.0 \\
1.5\end{array}$ & 0.2 \\
\hline $\begin{array}{l}\text { 8. Capital cost for radioactive waste } \\
\text { reprocessing complex } \\
\text { 8.1. Structures building } \\
\text { 8.2. Equipment and installation }\end{array}$ & $\begin{array}{l}4.3 \\
16.8\end{array}$ & 12.5 & $\begin{array}{l}2.5 \\
8.0\end{array}$ & \\
\hline 9. Radioactive waste disposal cost & 16.0 & 1.6 & 8.0 & \\
\hline 10. Other expenditures & 7.6 & & 4.0 & \\
\hline Total for items $7-10$ & 63.2 & 14.3 & 32.0 & 6.7 \\
\hline $\begin{array}{l}\text { III. Site } \\
\text { 11. Capital cost for site rehabilitation }\end{array}$ & 14.82 & 6.6 & & \\
\hline 12. Capital cost for radioactive waste disposal & 23.36 & 2.3 & & \\
\hline Total for items $11-12$ & 32.18 & 8.9 & & \\
\hline Total for items $1-12$ & 124.421 & 26.426 & 43.385 & 8.617 \\
\hline
\end{tabular}


Table 2.6. Operational Costs for Decommissioning the OK-204, OK-205, and OK-206 Plutonium-Production Reactors

\begin{tabular}{|c|c|c|c|c|}
\hline \multirow[b]{2}{*}{ Expenditure (IQ-1994 prices) } & \multicolumn{2}{|c|}{$\begin{array}{l}\text { OK-204 and OK-205 } \\
\text { (million rubles) }\end{array}$} & \multicolumn{2}{|c|}{$\begin{array}{c}\text { OK-206 } \\
\text { (million rubles) }\end{array}$} \\
\hline & Total & $\begin{array}{c}\text { Staff } \\
\text { Payments }\end{array}$ & Total & $\begin{array}{c}\text { Staff } \\
\text { Payments }\end{array}$ \\
\hline I. Nuclear facility & & & & \\
\hline 1.1. Removal of class-3 radioactive waste & 1525 & 21 & - & - \\
\hline $\begin{array}{l}\text { 1.2. Reprocessing of class- } 1 \text { and class- } 2 \\
\text { radioactive wastes }\end{array}$ & 3500 & 50 & 1750 & 25 \\
\hline 1.3. Nuclear facility storage for 30 years & $250 / y \mathrm{r}$ & $65 / \mathrm{yr}$ & $125 / \mathrm{yr}$ & $32.5 / \mathrm{yr}$ \\
\hline $\begin{array}{l}\text { 1.4. Removal and disposal of casks with } \\
\text { solid radioactive wastes }\end{array}$ & 5000 & - & 1800 & - \\
\hline II. Nuclear power plant & & & & \\
\hline 2.1. Radioactive waste reprocessing & 6100 & 730 & 3200 & 400 \\
\hline $\begin{array}{l}\text { 2.2. Maintenance cost of steam generator } \\
\text { equipment over } 30 \text { years }\end{array}$ & 4528 & 1500 & 2500 & 1000 \\
\hline III. Site & & & & \\
\hline 3.1. Site recultivation activities & 55600 & 4150 & - & - \\
\hline Total & 83753 & 8401 & 13000 & 2400 \\
\hline
\end{tabular}

The design of the RBMK power reactors primarily followed the principles employed in the design of the AMB uranium-graphite power reactor, constructed and operated as the first-phase units, No. 1 and No. 2, of the Beloyarsk NPP.

The design of the RBMK power reactors took into consideration the lessons learned from the operation and upgrades of the uranium-graphite power and plutonium-production reactors in service in the former Soviet Union. For this reason, concurrent with the design of the RBMK, a technology was developed for repair and replacement of the individual subassemblies of the RBMK reactor. This approach had a definite impact and resulted in improved maintainability indices of the individual subassemblies and components of the RBMK-equipped reactor plant. The technology and the equipment used to replace the technological channels and the reactor protection and control system channels were subjected to critical analysis (with allowance for instances of the accident-related failure of these channels), as was the replacement process for the "Shadr" flowmeters, the control valves on the multiple forced-circulation coolant circuit, and a number of other subassemblies and systems.

Following an accident at Unit 1 of the Leningrad NPP in 1975 that resulted in nuclear fuel meltdown in a technological channel, adjustments were made in the approaches used for the remedial maintenance of RBMK reactors. The lower structural elements of Unit 1 became the most contaminated locations because of radioactive deposits in the reactor's lower subassemblies, and especially due to the accident involving fuel meltdown. This necessitated a review of previously accepted engineering solutions for the repair and replacement of subassemblies in RBMK reactors.

Originally, maintenance of the RBMK unit was to include installation and servicing by personnel in the work performance area without the benefit of protective devices. The maintenance plan was revised to make allowance for $\gamma$-radiation fields in the lower structural elements of the reactor. For 
1 - Reactor with protective graphite structure

2 - Lower biological shield

3 - Upper biological shield

4 - Water shield
5 - Main circulation pump

6 - Refueling machine

7 - Drum-type steam separator

Figure 2.12. Reactor unit (sectional view) 
example, a technological process and equipment were developed that made it possible to replace a technological channel from the central area, without personnel having to enter the lower subreactor space.

In the late 1970 s, a repair machine design was developed so that personnel inside a shielded work booth could perform all the cutting and welding operations associated with the lower structural elements of the RBMK. The work includes remote manipulation for installing and removing the cutting and welding equipment. The biological shielding used in the work booth ensured a more than thousand-fold decrease in the $\gamma$-radiation rate. In later designs of RBMK units (i.e., Ignalina and Smolensk Nuclear Power Plants, and the second-phase units of the Kursk and Chornobyl NPPs), the design components needed for deployment and movement of the running gear for the lower structural elements repair machine were envisioned. However, for a number of reasons, the repair machine was never put into practice, even though the fixed components were installed.

The range of reparable RBMK unit subassemblies was expanded based on operational experience. For example, leaks were detected in the steam-water pipelines on Units No. 1 and 2 of the Kursk NPP during the late 1970s and early 1980s, and then similar defects were also detected at other plants (Leningrad, Chornobyl, and Ignalina NPPs). Taking into account the fact that the steamwater pipeline defects were located in different areas and making allowance for the density of the routing of the steam-water pipeline within the nuclear reactor plateau, a universal maintenance process was defined. This process allowed for repair work that ranged from welding defective areas to full replacement of a section of a steam-water pipeline (including the replacement of the standpipe and the modification of the routing of the new pipe). The repair equipment developed contained the full gamut of cutting mechanisms, including devices for the remote cutting of pipes from within, remote-controlled automatic welding machines, ultrasonic inspection devices, and a wide range of other apparatus. Defective sections in the RBMK steam-water pipelines were repaired using this equipment.

In 1986, the ultrasonic inspection was carried out on $100 \%$ of the factory welds on the retainers of all RBMK units. Based on the results of the inspection, a significant portion of the retainers (on the order of several hundred per unit) was replaced. The ultrasonic inspection and replacement of retainers were performed using repair equipment that was produced in individual lots. In addition to the retainer replacement, the wide-scale repair work performed on RBMK units included work in the area of the replacement of the "Shadr" flowmeters, the control valves, and so forth.

Following the Chornobyl accident, a standard list of measures aimed at enhancing the safety of RBMK units was prepared and adopted during 1987-1988. These measures pertained to improving the physical characteristics of the RBMK units, as well as those of the nuclear reactor protection and control systems. The list identified the need for a large amount of repairs and upgrades for RBMK units. The repairs and upgrades included:

- wide-scale replacement of the technological channels

- installation of an emergency steam dumping system

- mounting check valves on the batch-distributing manifolds

- certain other work.

The techniques employed during the performance of the upgrades and repairs, and the principles used to organize the work are similar to the RBMK unit decommissioning work that will be performed. 


\subsubsection{Replacement of the Technological Channels}

Over the course of operation of RBMK units, the shapes of the channel pipes, graphite blocks, and graphite rings were altered as a result of exposure to neutron flux radiation, temperatures, and other factors associated with the effects of creep and an increase in radiation. For technological channel pipes, the graphite block opening diameter decreased and the graphite block height increased. A decrease in the diametrical clearance between the technological channels and the graphite stack ultimately occurred, with an increase in graphite column height.

During the RBMK design process, the nominal diametrical clearance between the technological channels and the graphite stack was set at $3 \mathrm{~mm}$ (or an average value of $2.7 \mathrm{~mm}$ in the tolerance zone). The magnitude of the neutron fluxes encountered during RBMK operations and the variations observed in the pipe material and the graphite proved to be higher than the design values, which resulted in the premature reduction of clearances and the local contact between the technological channels and the graphite stack. This, in turn, led to additional stresses within the graphite blocks, the premature cracking of these blocks, the curvature of the graphite stack, and-as a general consequence - a reduction in the operating life of the nuclear reactor. It is clear that the replacement of technological channels and the boring out of the graphite stack block openings to restore the diametrical clearances between the technological channels and the graphite stack were necessary.

We will examine the principal engineering aspects and features of this work based on the example of the work carried out on Unit 1 of the Leningrad NPP. Unit 1 of the Leningrad NPP was shut down for repair in July 1989. The shutdown was preceded by a two-year study aimed at developing a full complement of repair-related technological processes, the design and manufacture of specialized repair equipment, mechanisms, and technological equipment, and the trial use, adjustment, and refinement of these mechanisms and equipment to bring them up to the required level of technology.

The technology developed envisioned the following basic operations, which were followed in the repair work:

Preparatory Work

- dismantling the plating sections

- unloading the fuel assemblies and placing them into the cooling pond

- removing the "Shadr" flowmeters

- installing plugs in the "Shadr" flowmeters housings

- installing plugs in the steam-water pipelines and temporarily lowering the water level (or in the upper tract during the replacement of the technological channels in the presence of dried drumtype steam separators).

Repair Work

- cutting away and removing the retainers

- discharging water from and then drying the technological channels

- cutting off the technological channel "return bends"

- cutting away the bellows compensator fillet weld and the simultaneously cutting apart the lower sections of the technological channels 
- cutting away the miter (edge) weld between the technological channels and the technological tract

- removing the technological channels and placing them into the machine tools for subsequently cutting off their lower sections

- loading the technological channels into the channel cooling pond

- initial cleaning of the tract groove

- placing the protective plate into the design position

- mounting a plastic bag on the bellows compensator insert for disposing the graphite grit

- inspecting the graphite stack's column, removing graphite chips from the space between the graphite stack's blocks, and placing these blocks into the design positions

- measuring the diameters of the openings in the graphite stack column

- boring out or broaching and measuring the graphite blocks to the repair dimensions

- flaring the lower end of the upper technological tract pipe

- measuring the height of the "miter" (end) of the technological tract and cleaning the cylindrical surface of the upper tract before installing the technological channels

- cutting off the allowances on the lower sections of the new technological channels and machining the edges formed to facilitate welding

- machining the edges of the return bend to facilitate welding and cleaning its inner surface

- installing the new technological channels

- measuring the height of the technological channel "miters" above the tract

- trimming the protruding "miter" edge sections between the technological channels and the technological tract

- removing cuttings from the annual groove of the technological tract

- creating a miter weld at the technological channel-tract juncture

- inspecting the weld created

- dressing the edges of the upper tract to facilitate welding

- adjusting the bellows compensator insert and welding the technological channels

- welding the return bend to the technological channels

- installing the upper tract retainer, welding this retainer into the technological tract, and cleaning the weld created to ensure the performance of ultrasonic flaw detection

- checking the quality of the fillet weld, and the retainer weld seam

- flushing and purging of the technological channels and the steam-water pipelines

- replacing the flow-passage plugs with "Shadr" flowmeters

- removing the dead-end plugs from the stub pipes of the steam-water pipelines and the drumtype steam separator.

Prior to the above work, the following items were installed in the central area of the unit: on the rail track of the main traveling crane, an auxiliary traveling crane with a hoisting capacity of 5 tons; over the nuclear reactor, a gantry crane with a hoisting capacity of 5 tons and metalwork for the suspension of the new technological channels and lengthy tools. Moreover, in the reactor and 
subreactor spaces, special service areas were set up, auxiliary devices and apparatus were installed for the repair work, and receivers were fitted for supplying compressed air to the cutting equipment and mechanisms.

The procedure for replacing the technological channels and boring out the openings in the graphite stack was carried out in cycles, the durations of which were distributed in the following manner:

- the 1 st to 7 th cycles: replacement of 68 to 77 technological channels with a cycle duration of 12 to 24 days

- the 8th to 18 th cycles: replacement of 98 to 105 technological channels with a cycle duration of 13 to 17 days

- the 19th cycle: replacement of 69 technological channels with a cycle duration of 13 days.

At the onset of each successive cycle, 4 to 5 days were spent performing preparatory work.

The dismantled technological channels (a total of 700) were placed into the channel-cooling pond after their lower sections had been cut off. The system for chopping up these technological channels cut the channels into segments with a length of $0.4 \mathrm{~m}$ each. The graphite inserts and rings were removed from the dismantled technological channels within a special container in the channel cooling pond. The segments of the central sections of the technological channels were stored in a burial ground within the operations area of the nuclear power plant, while the upper and lower sections of the technological channels (having a length of $3 \mathrm{~m}$ each) were forwarded for decontamination.

Provisions had been made for replacing the lower bellows compensators at the same time that the technological channels were replaced. However, since the results of an evaluation of the condition of the four dismantled bellows showed that they remained serviceable, the decision was made not to replace the remaining compensators.

More than 300 changes and refinements were introduced into the plan and the technological process for this work. The refinements were dictated by the availability of repair equipment at the Leningrad NPP, the degree of readiness of the equipment, the more accurate definition of the conditions and the use of the equipment, and the experience obtained in the initial replacement cycles. The changes made in the technological process were drawn up in the form of special notices and, in individual cases, in the form of separate engineering solutions, because more than 150 items of cutting and welding equipment, technological repair equipment, and instrumentation were used in replacing the technological channels and boring out the openings in the graphite stack's blocks. Schematic diagrams and characteristics of the basic types of metalworking equipment, welding equipment, and technological equipment used in performance of this work are presented in Figures 2.13 - 2.18.

A great many items of auxiliary special tools and technological equipment were also used. A special device constructed with a pneumatic nut driver as its base and with a pulling force of up to 300 kiloNewtons was used to pull the technological channels. A special clamp with a force of up to 150 kiloNewtons was used to remove the old technological channels and to install and set the new ones. A special clamp was also used during the extraction of the graphite inserts, the adjustment of the bellows compensators, the removal of cuttings from the annular groove of the tract following the cutting away of the miter joint, and during the cutting away of the protruding edges of the channel miters. The boring out of the openings in the graphite blocks was performed with a device equipped with an electric drive having a capacity of $2 \mathrm{~kW}$, a special cutter, and cutting product (graphite grit and dust) section, as well as a technique for standardization of the graphite stack's cubicles by means of their broaching, to which end special broaches and a special weight were employed. 
1. Cutting off and dressing the edges, welding, $x$-raying, and ultrasonic inspection.

2. Cutting away and preparing the tract, trimming the edges, welding, $x$-raying, and helium testing.

3. Removing the technological channels.

4. Flaring and inspection.

5. . Setting.

6. Removing the ring, boring out, and measuring.

7. Placing the graphite blocks into the design positions.

8. Cutting away, tacking, welding, and helium testing.

9. Cutting away and adjusting the inserts, tacking, welding, and helium testing.

10. Cutting off and dressing the edges, welding, and $\mathrm{x}$-raying.

11. Cutting off and dressing the edges of the return bend, removing the metal plating, welding, and $\mathrm{x}$-raying.

12. Trimming the new technological channels and dressing the edges.

Figure 2.13. Use of the Repair Equipment 
Technical Characteristics

Diameter of the item machined, in millimeters

Material composing the item machined

Drive

Capacity, in kilowatts

Operating air pressure in megaPascals, not less than

Air flow rate in cubic meters per minute, not more than

Maximum cutting speed, in meters per minute

Cutting tool feed, in millimeters per revolution

Cutting tools

Dimensions, in millimeters:

- length

- width

- height

Weight in kilograms, not more than

Setting length, in millimeters
08Kh18N10T

pneumatic drive

$0.955 @ 15 \%$

0.5

1.3

$7.2 / 1.5$

0.6

Cutters made from R18 steel

386.5

252

407

$39.5+6$

$234-18$

Figure 2.14. Mechanism for Cutting the Upper Tract Retainer 
Technical Characteristics

Drive

Capacity, in kilowatts

Cutting speed, in meters per minute

Cutting tool

Dimensions, in millimeters

Weight, in kilograms

electric motor

1.1

10.3

cutter

$78.5 \times 32.5 \times 446.5$

$39.5+6$

Figure 2.15. Mechanism for Cutting the Miter Weld Connecting the Technological Channel and the Technological Tract 


\section{Technical Characteristics}

Diameter of the edge joint, in millimeters 121

Maximum welding current, in amperes $\quad 150$

Joint welding speed, in meters per hour 3 - 15

Welding mode

Weight, in kilograms:

- of the welding head

continuous; intermittent

- of the optical sighting device

37

14

Head dimensions, in millimeters

$1,144 \times 131 \times 105$

Figure 2.16. Machine for Welding the Edge Joint of a Technological Channel 
Technical Characteristics

Diameter of the joint welded, in millimeters 145

Pipe wall thickness, in millimeters 7.5

Maximum welding current, in amperes $\quad 250$

Maximum welding speed, in meters per hour 12.5

Maximum filling wire feed rate, meters per hour $\quad 50$

Filling wire diameter, in millimeters

Diameter at the rim seat of the expanding collet, in millimeters

$1.2-1.6$

89

Radius of the rotating parts, in millimeters

Setting length, in millimeters

$122.5+6$

$234-18$

Weight, in kilograms

25

Figure 2.17. Automatic Machine for Welding the $145 \times$ 7.5-Millimeter Pipes of the Upper Tract Retainer 


\section{Technical Characteristics}

Material composing the surfaces machined

Standard 5632-72

Diameter of the surfaces machined in millimeters, not more than

Drive

Face plate rotational speed under load, 1 per second

Automatic feed, millimeters per revolution

Cutting tools

steel, State Standard 19265-73

Dimensions, in millimeters:

- length

- width

- height

Weight, in kilograms:

- with the pneumatic drive

- without the pneumatic drive

Figure 2.18. Mechanism for Cutting the Return Bend Off a Technological Channel and Cutting Away the Miter Weld 
Measuring the resultant diameters of the openings in the blocks was carried out using a special mechanism with an error of $\sim 50$ microns. In addition, the passibility of the openings in the graphite blocks after they had been bored out (broached) was checked using a special gauge, while a visual inspection was performed using television systems. The technique of flaring (separation) the lower end of an upper tract insert was used to avoid the separation of the pipes in the upper tract and the flange assembly, which was possible in the event of graphite block shrinkage. Consequently, the outer diameter of the lower ends of the inserts was increased from 130 to $131-131.8 \mathrm{~mm}$. The quality of the performance of each technological operation was checked with a specially manufactured control apparatus.

The entire replacement of the technological channels of Unit 1 at the Leningrad NPP was performed over the period from July 28, 1989, through July 23, 1990. Because optimal technological processes were used, the duration of repairs was reduced from a planned 341 to 291 days.

150 persons were enlisted to work on Leningrad NPP Unit 1 in five shifts. More than 130 types of repair and technological equipment were used. The average repair time for a single graphite stack cubicle came to approximately 4.1 hours.

The experience acquired on Unit 1 of the Leningrad NPP demonstrated both the practical feasibility of the work and the value of combining such work with other modernizing and upgrading work on power unit equipment and systems.

Replacing the technological channels in Unit 2 of the Leningrad NPP was performed successfully. The technological channels in Unit 1 of the Kursk NPP are being replaced now.

\subsubsection{Radiation Conditions and Radiation Exposure Sustained During Repair Work}

Following the shutdown of an RBMK unit for repair, the radiation in the environment was due primarily to the products of corrosion of the structural elements of the main cooling circuit. For example, dose rate values were on the order of tenths of units and full units of microroentgens per second in the central area of a nuclear reactor, tens and hundreds of microroentgens per second in the main compartments of the multiple forced-circulation cooling circuit, and thousands and tens of thousands of microroentgens per second in certain areas (the subreactor space).

To reduce the radiation, acid decontamination of the multiple forced-circulation cooling circuit was carried out and a special lead shielding was installed on the "return bend." The decontamination procedure was repeated several times over the course of the repair work. In addition, the following were also considered for the improvement of the radiation environment:

- a graphite dust suction system

- removable plasticized rubber coverings for the floors in the central area and the subreactor spaces

- the jacketing of the technological channels removed with plasticized rubber

- a plastic gutter along the transfer route of the removed technological channels

- other measures.

To prevent formation of local areas of intense radiation-induced contamination, provisions were made for the primary coolant circulation pumps in the return bends of the lower water pipelines to be activated during the work in the subreactor spaces. Over the course of the repairs, the $\gamma$-radiation dose rate distribution in the central area of the nuclear reactor was quite stable. The lowest dose rate 
was recorded near the entrance to the central area, while the highest was recorded over the channelcooling pond.

The dose rate values of the repair tools that had remained in the reactor repair areas for a time ranged from 30 to 40 microroentgens per second but reached a level of 2,000 microroentgens per second in certain instances (for example, the graphite dust suction hose). The dose rate in the vicinity of the machine tool for chopping up the technological channels reached 7,000 microroentgens per second.

The $\gamma$-radiation dose rate in the subreactor spaces was caused by radioactive products in the layer of deposits, by local areas of intense radiation-induced contamination in the return bends of the lower water pipelines, and by the radioactive fission products of the fuel compound in the graphite dust that was picked up by the dust collectors. To improve the radiation environment in the subreactor spaces, acid decontamination was performed and a special removable lead shielding was installed. These measures reduced the dose rate as much as 25 times.

A special technological channel-drying regimen was used to eliminate the local areas of intense radiation-induced contamination in the return bends of the lower water pipelines when the coolant circulation was stopped. The water in the technological channels and the connecting lower water pipeline was expelled into a trap by means of compressed air. Consequently, the local areas of intense radiation-induced contamination that had a maximum $\gamma$-radiation dose level of some 4,000 microroentgens per second after purging dropped to 30 microroentgens per second in one day.

It should be noted that radiation-induced contamination occurred during the removal of graphite stack fragments and the extraction of the tools used on work in the graphite stack. For example, contamination came to 1,200 particles per square centimeter per minute for the cutter and 6,000 particles per square centimeter per minute for the cable. During the removal of the graphite rings, the -contamination in the ring removal area came to 7,000 particles per square centimeter per minute for the plasticized rubber and ranged from 4,500 to 7,000 particles per square centimeter per minute for the drip pans.

During the first cycle of repair work, the total radiation exposure for replacing a single channel came to 0.8 roentgen equivalents-man per person. Subsequently, due to the measures described above, the radiation exposure was reduced to 0.45 roentgen equivalents-man per person for this work. During the initial repairs, the bulk of the radiation exposure was due to work performed under the reactor, but later it was due to work performed at the top of the reactor. The most dangerous work, from the standpoint of the radiation exposure, was that performed in the central area of the nuclear reactor during the removal of the technological channels and under the nuclear reactor when cutting the technological channels free from the lower water pipeline return bend.

As a result of the decontamination measures described above, it was possible to achieve a 3- to 4-fold decrease in personnel radiation exposure from that estimated. Ultimately, the personnel radiation exposure for the replacement of a single technological channel came to some 0.48 roentgen equivalents-man (in the presence of an estimated total radiation exposure of 1.6 roentgen equivalents-man).

The nuclide composition and volumetric activity of aerosols were measured, as was the content of the radioactive isotope ${ }^{14} \mathrm{C}$ in the air. The results obtained did not reveal any radionuclide concentrations that exceeded permissible values. 


\subsubsection{Installation of Steam and Gas Dumping Systems}

Based on the standard list aimed at enhancing the reliability and safety of the operation of existing nuclear power plant RBMK units and those under construction, a plan was developed for modernizing the emergency steam and gas dumping system. The original design of the system did not ensure the safety of the nuclear reactor in the event of the simultaneous rupturing of several technological channels. The emergency steam and gas dumping system modernization plan was to install additional piping through a penetration assembly mounted on the bottom plate of the metalwork (Figure 2.19). During mounting, it was necessary to pass the penetration assembly through a backfill in the metalwork with a height of $3,000 \mathrm{~mm}$. Therefore, the modernization plan envisioned cutting openings in the metalwork bottom plate, which is $20 \mathrm{~mm}$ thick. The cutting was accomplished using remote methods. The penetration assembly was inserted into the openings and welded to the bottom plate of the metalwork by means of a strength weld, which was also accomplished using remote methods. Bearing in mind the description given of the operations, as well as the fact that all these operations had to be performed within radiation fields with an exposure rate of some 70 roentgens per hour, performing this work constituted a complex technical task.

The penetration assembly was installed after the nuclear reactor had been shut down and cooled. Special protection measures were developed to protect personnel and equipment from exposure to radiation. Containers needed for packaging and removal of the extracted backfill were prepared, a special ventilation system was installed that ensured a reduction in the gas levels associated with the cutting and welding operations, and all the mechanisms and equipment were readied and tested.

The steam and gas dumping system modernization work itself was performed in the following sequence:

- The sections of the temperature channel situated within the area where the penetration assembly had been installed were dismantled.

- A casing pipe was installed with a jigger, and the backfill was removed through the casing pipe with a screw conveyer.

- The initial cleaning of the upper section of the metalwork bottom plate was done.

- The penetration assembly was installed in the casing pipe and welded to the bottom plate of the metalwork.

- The quality of the weld was checked.

- An opening $570 \mathrm{~mm}$ in diameter was cut in the metalwork bottom plate through the penetration assembly using plasma cutting.

- The installation of a collector was undertaken.

The operations described above were performed at the same time as the wide-scale replacement of the technological channels on the RBMK unit.

The modernization of the emergency steam and gas dumping system of Unit No. 1 at the Leningrad NPP took 30 days. Ten persons took part in this work, and had a total radiation exposure of 40 roentgen equivalents-man. Similar work involving the installation and modernization of emergency steam and gas dumping systems was subsequently performed on Unit No. 2 at the Leningrad NPP and Unit No. 1 at the Kursk Nuclear Power Plant. 
1 - distributing manifold $\emptyset 600$

3 - manifold $\emptyset 400$

5 - collar

7 - penetration assembly

9 - backfill

11 - reactor space
2 - piping $\varnothing 600$

4 - piping $\varnothing 150$

6 - top load-bearing structure top plate

8 - casing pipe

10 - top load-bearing structure bottom plate

12 - flow-passage plug

13 - penetration assembly-bottom plate weld

Figure 2.19. Modernized Emergency Steam-and-Water Mixture Dumping System of RBMK Unit No. 1 at the Leningrad Nuclear Power Plant 


\subsubsection{Features of Dismantling Structural Elements}

The major repair and upgrade experience described above for uranium-graphite plutonium-production reactors and NPP RBMK units gives us an idea of the nature of this work, its performance, the techniques and engineering equipment used, and the results of the work: cost, reactor idle time, labor input, and the total radiation exposure sustained by personnel. The analysis and use of the experience and data obtained make it possible to better select a concept, as well as to evaluate the technical and economic costs of decommissioning NPP RBMK units.

Robotic and remote technologies have not been used to repair and dismantle uranium-graphite plutonium-production reactors and nuclear power plant RBMK units in Russia, with the exception of certain operations using remote-controlled mechanisms. The technologies and equipment used were traditional. However, the technology and equipment selection was made without allowing for the specific features of the work under radiation-hazardous conditions. Instead, the safety of personnel was ensured by means of implementing the following measures:

- the reduction of the dose rate by decontaminating equipment and work areas, together with the extensive use of temporary biological shielding devices to bring the $\gamma$-radiation level in the work performance areas down to not more than 40 microroentgens per second

- the extensive use of temporary local plenum-exhaust ventilation systems

- the systematic and strenuous radiation monitoring of the work areas and personnel

- a shift-by-shift wet cleanup and decontamination of the work areas as necessary

- the organization of a multistage system of radiation protection access points and the use of a wide range of personal protection devices

- engineering and organizational solutions aimed at the performance of the maximum volume of work in "cleaner" areas insofar as possible

- the reduction of the residence time of personnel in "dirty" areas by increasing personnel work time in "clean" areas

- the use of efficient and productive equipment that ensures a minimum residence time of personnel in "dirty" areas

- other partial solutions.

The measures listed above can be fully reviewed and considered over the course of engineeringrelated critical analyses of the dismantling of RBMK-equipped reactor plants in line with their scheduled decommissioning.

What is more, modernization and upgrades were performed, as a rule, without the preliminary holding of the structural elements of the nuclear reactor (i.e., the work was performed under less than favorable conditions. Similar work associated with decommissioning of RBMK-equipped reactor plants can be performed following a protracted storage period (for a period of several decades) the radiation would be lowered as a result of short-lived and medium-lived radionuclide decay.) The radiation conditions under which decommissioning is performed can also be improved through the use of stronger decontamination methods ("rigorous" decontamination) since the end condition of structural materials will not be as important as in the decontamination of servicing operational nuclear reactors. 
However, despite the hundreds of tons of dismantled equipment and structural elements generated by upgrading plants (for example, 850 tons of uranium-graphite reactor equipment and structural elements resulted from the repair of the OK-204 reactor), the volume of waste cannot be compared to that associated with the total dismantling of reactor plants during decommissioning. Estimates are that 10,000 tons of highly active structural elements, equipment, piping, graphite, backfill, and other materials will result from dismantling an RBMK nuclear reactor. It seems obvious that such a volume of work can only be performed with robotic devices.

The analysis of foreign literature demonstrates that a robotic system developed by the Noell firm (Germany) and used to dismantle the nuclear reactor at the Niderraichbach NPP can be regarded as the closest analog to the robotic complex needed to dismantle RBMK reactors. The descriptions of the Noell robot's functional capabilities, its "two-armed" manipulator and hoisting mechanism, and other items of technological equipment lead to a conclusion concerning the feasibility of this system for dismantling RBMK nuclear reactors.

The most complicated and biggest job associated with the dismantling of the structural elements of an RBMK nuclear reactor will be cutting the most active structural elements into fragments and removing them. The most active structural elements include the top load-bearing structure, housing, bottom load-bearing structure, main biological shield tank, upper biological shield tank systems, and the removal of the graphite stack.

The dismantling of the structural elements listed above will have to be performed using a robotic system that is installed and serviced from the central area of the nuclear reactor. A robotic system should also be used to dismantle and remove the reactor's graphite stack, or other simpler and more effective technologies must be found.

\subsubsection{Organization of Work Approaches for Dismantling During Decommissioning}

The time to dismantle an RBMK equipped reactor plant will be determined primarily by the time associated with dismantling the reactor structural elements themselves. Several alternatives may be selected as a function of the requirements imposed by the duration of the dismantling process: short ( 2 to 3 years), medium ( 3 to 5 years), or long (more than 5 years). The selection of a given dismantling alternative will affect, to a considerable extent, both the organization of the work and the method for performing the work. For example, if a short dismantling time ( 2 to 3 years) is chosen, the services of personnel other than the regular personnel must be enlisted, several work areas must be set up to facilitate parallel work (in the central area of the reactor, in the lower reactor structures, in the multiple forced-circulation coolant circuit areas, and so forth), and an additional volume of preparatory work must be performed for organizing and outfitting freight flow transfer routes, facilitating the intermediate storage of radioactive wastes, installing additional radiation protection access points, and the like.

Of course, the definitive complement and range of the subject preparatory work can only be determined on the basis of detailed studies. However, the following work will remain constant regardless of the dismantling alternative adopted:

- unloading and removal of the nuclear fuel

- decontamination of the reactor equipment, piping, and compartments

- installation of temporary local plenum-exhaust ventilation systems

- installation of additional rigging and transfer equipment 
- organization and outfitting of intermediate radioactive waste storage sites

- other work.

Two graphite stack dismantling alternatives should be critically analyzed and evaluated when developing a plan for the dismantling of a reactor:

- removal of the graphite blocks by disintegrating them in place (for example, by boring them out), using suction to draw off the graphite grit, and storing this grit in special vessels and containers (during critical analysis, allowance must be made for the experience acquired relative to similar work on the EI-2 plutonium-production reactor in 1981)

- disassembly of the graphite stack in a block-by-block manner, which can be undertaken following specific operations that ensure acceptable accessibility to the stack.

However, regardless of the dismantling alternative selected for a reactor's graphite stack, the first operation involved in dismantling the reactor must be dismantling the technological channels and the reactor protection and control system component channels, including cutting these channels into fragments, packaging them in containers, and removing and burying them.

The experience obtained from the wide-scale replacement of technological channels during the upgrading of RBMK reactors must be considered when dismantling channels. Cutting the technological channels at the lower elevations can be performed using mechanisms that are operated remotely from "cleaner" locations in the central area of the reactor.

Following the dismantling of the technological channels and the reactor protection and control system component channels, the steam-water pipelines and structural elements situated near the top load-bearing structure (the ventilation ducts, the reactor protection and control system cooling pipes, the steam-water pipeline pipes, and so forth) can be disassembled. This work can be performed remotely from the central area of the reactor using mechanical and heat cutting techniques. Explosive techniques are not excluded in performing this work.

The order of priority of the subsequent operations will be determined by the alternative selected for disassembling the reactor's graphite stack. If the first alternative is chosen, which involves boring out the graphite stack, all the preparatory work must be carried out beforehand (installing suction pumps, service lines, graphite-grit collection subassemblies, etc.). Only after this has been done can the graphite blocks be disintegrated and the fragments removed, which must be accomplished in compliance with the technology developed for this work. After the graphite block has been dismantled, the reactor's other principal subassemblies and structural elements can be disassembled.

Regardless of the alternative selected and implemented for the disassembly of the graphite stack, the disassembly technology for the top load-bearing structure will involve a number of cutting and removal operations that should be performed in two steps. The first step is the disassembly of the top load-bearing structure, including the standpipes (the top load-bearing structure pipes), the upper lattice, and the internal backfill, using remote-controlled mechanisms that are operated from the central area of the reactor. The second step, which includes dismantling the vertical diaphragms and the lower lattice of the top load-bearing structure, must be performed with a remote-controlled system, as must all subsequent work.

Preliminary analyses of similar robotic systems indicate that the makeup of the complement of technological support equipment for such a remote-controlled system must include

- a traveling crane with a hoisting capacity of up to 50 tons 
- a revolving platform that is installed over the nuclear reactor

- a telescopic lifting boom with a hoisting capacity of up to 1 ton

- a freight elevator with a hoisting capacity of 30 tons

- a two-armed master-slave manipulator with identical hoisting capacities of 0.5 tons

- a stereo video system with lighting equipment

- a control system and a control panel for the robotic system.

The technological support equipment listed for the remote-controlled system have been designed for performing all the work associated with the disassembly of the highly active structural elements of a reactor, including the graphite stack's blocks.

If the second alternative is selected, which involves the step-by-step disassembly of the graphite stack's blocks, the design and the complement of the technological support equipment for the remote-controlled system must be adjusted. The main operations to be performed through the use of the remote-controlled system must consist of the following:

- the marking of the cutting boundaries and lines on the subassemblies and parts of the reactor

- the preliminary anchoring of the structural element fragments and the securing of these fragments over the course of the cutting process

- the welding of sling hardware (brackets, eye bolts, studs, etc.) to certain fragments in order to facilitate removal

- the cutting of plate structures and circular parts made from carbon and austenitic steels in different attitudes in the presence of a maximum wall thickness of up to 50 millimeters

- the capture, transfer, and stacking of the fragments being removed, including the blocks of the graphite stack

- the loosening and suction of the backfill materials of the top and bottom load-bearing structures

- the assurance of all transfer operations associated with stack disassembly.

Following the disassembly and dismantling of the top load-bearing structure using a remotecontrolled system, the graphite stack can be disassembled (in accordance with alternative 2) or the cutting and removal of the housing, bottom load-bearing structure, and main biological shield tank system can be begun. When using the second alternative for dismantling the graphite stack, it is advisable that engineering solutions be subjected to analysis and evaluation in layers, from top to bottom, stack block disassembly, block disassembly in vertical columns from the center to the periphery, or other solutions.

One means of reducing the total personnel dose exposure, as well as ensuring dust suppression during metalwork cutting and disassembly of the graphite stack, may be to fill the corre with water within the confines of the main biological shield tank system. During detailed critical analyses of this engineering solution, the total volume of the reactor structures should be divided into several local volumes: the graphite stack within the confines of the interior volume of the housing system, the space between the housing and the main biological shield tank systems, and the interior volumes of the metalwork of the main biological shield tank system. Thereafter, solutions should be analyzed that ensure the on-line and off-line control of filling these areas with water and emptying them during the various steps of the dismantling work. 
Taking the low level of productivity of the remote-controlled system to be used for alternative 2 into account, the technological and organization scheme must envision the cutting and evacuation of large fragments and the subsequent cutting of the fragments for packaging in standard containers, transfer, and burial. The production line for cutting large fragments must be equipped with special mechanisms that ensure the automatic or remote-control of the process as a whole. The production line must have an independent, enclosed, hermetically sealed space that is equipped with filtration and ventilation, as well as with television equipment for monitoring and supervising operations. The subject production line may be situated in the central area or in other areas of the reactor block.

The last operation to be performed in disassembling the structural elements of a reactor must be cutting and removal of the bottom load-bearing structure. The technology for dismantling the bottom load-bearing structure is similar to that involved in disassembling the top load-bearing structure system. However, the removal of the backfill can be down two ways-from above (as is the case with the top load-bearing structure system) or from below (this alternative for backfill removal needs further analysis).

The cutting and removal of the main biological shield tank must be performed after the dismantling of the graphite stack, but before dismantling the bottom load-bearing structure.

\subsection{AMB Units at the Beloyarsk Nuclear Power Plant}

\subsubsection{Design Features}

The first phase of the Beloyarsk NPP includes two units equipped with AMB type uranium-graphite channel-type superheater reactors. Unit No. 1, equipped with an AMB-100 reactor, had an electric capacity of 100 megawatts, and Unit No. 2, equipped with an AMB-200 reactor, had an electric capacity of 200 megawatts. The design of the first phase of the Beloyarsk NPP began in 1957 and construction in 1958. Unit No. 1 was connected to the power system on April 26, 1964, and Unit No. 2 was hooked up on December 31, 1967.

The principal structures of the first-phase reactor units are the main building, the auxiliary building, the demineralizers, the reactor water cleanup filter/demineralizer, the service water supply plant, the gas supply plant, and the electrical engineering facilities.

The main building incorporates the reactor sections of Units No. 1 and 2, the service mezzanine; and the machine section. The reactor sections are made from cast-in-place concrete. The main technological equipment is situated in vaults with sturdy walls made from heavyweight and reinforced concrete. The reactor rooms, which are located over the reactors, contain operations involved in handling the fuel assemblies, where the reactor protection and control system components, etc., are carried out. The structural elements of the machine room and the service mezzanine are made from precast reinforced concrete. The span of the machine room is $39 \mathrm{~m}$, the layout of the turbine units is lateral, and the configuration of the main equipment is modular.

The two units are outfitted with similar reactors, and identical turbines and generator equipment. Unit No. 1 consists of a reactor, a turbogenerator, and a step-up transformer; Unit No. 2 consists of a reactor, two turbogenerators, and two step-up transformers. K-100-99 turbines were standard in heat-and-power engineering during the $1950 \mathrm{~s}$. The parameters of this turbine's steam are $510^{\circ} \mathrm{C}$ and 90 kilograms per square centimeter.

The reactors were based on the design of an experimental reactor of the same type, which went into operation in 1954 at the first NPP in the world in the city of Obninsk. 
Beloyarsk NPP Unit No. 1 was outfitted with a water-graphite reactor (Figure 2.20). The graphite stack had a diameter of $8.8 \mathrm{~m}$ and a height of $9 \mathrm{~m}$, the central section of which housed 1,134 vertical channels. The fuel was installed in 988 of the vertical channels, while the absorption rods of the reactor protection and control system were installed in the remainder.

Some of these technological channels (approximately three-fourths) were evaporation channels, into the inlets of which the cooling water was fed and at the outlets of which a steam-water mixture was formed. The remaining technological channels were steam-superheating channels, which served to superheat the steam to a temperature of approximately $560^{\circ} \mathrm{C}$. The control rod drives were positioned in the area beneath the bottom plate of the reactor (area 8), which made it possible to free up the top of the reactor and facilitate repair and refueling work.

The reactor's graphite stack was enclosed in a steel, hermetically sealed housing, which was filled with nitrogen to avoid the deflagration of the graphite, and the exterior of which was encircled by an annular biological shielding tank. In addition to the graphite reflector and the annular biological shielding tank, which was filled with water, the concrete on the bottom and the sides of the reactor also served as biological shielding, as did the graphite and cast-iron plates on the top of the reactor.

The reactor and its technological channels were equipped with monitoring devices and automation components. The performance of the reactor's technological channels was monitored with particular thoroughness. A technological channel is a welded tubular structure that includes fuel elements, a series of pipes that ensure coolant feed and drainage, graphite inserts, and other structural elements. In evaporative technological channels, the cooling water travels along a central pipe into the lower chamber and from there is distributed along six tubular uptake fuel elements incorporated within the upper chamber. In steam-superheating channels, the steam passes through three down pipes and then rises along three tubular fuel elements.

The steam production configuration of Unit No. 1 was of the two-circuit type, with a closed primary circuit. The water in the first circuit (loop), pressurized by four primary coolant circulation pumps with a productive capacity of 600 tons per hour, was delivered to the evaporative technological channel headers at a temperature of $300^{\circ} \mathrm{C}$ and at a pressure of 155 atmospheres, where it was heated to the saturation temperature $\left(340^{\circ} \mathrm{C}\right)$ and partially evaporated.

The steam-water mixture was subsequently fed into the separator, and the separated steam was then directed to the steam generator evaporators, in which the heat was transferred to the second circuit and the steam was condensed. The water in the second circuit was evaporated by means of the heat from the first circuit. The saturated steam was fed into the steam-superheating channels, where it was superheated to a temperature of $510^{\circ} \mathrm{C}$, then directed to the turbine inlet.

The design of the reactor of Unit No. 2 represented the further refinement of reactors of this type. The reactor had the basic dimensions and the same number of channels as Unit No. 1. However, its capacity had been increased two-fold as the result of a number of modifications. This was achieved by means of equalizing the radial distribution of energy release and increasing the thermal loads and the flow-passage cross-sections of the fuel element pipes. In addition, a single-circuit (loop) configuration was used for Unit No. 2.

In general, the steam production configuration of Unit No. 2 was similar to that of Unit No. 1; it was of the single-circuit type, in which the separated steam proceeded directly from the separator to the steam-superheating channels, where it was superheated and was then fed into the turbine inlet. 
Figure 2.20. 
The transition to a single-circuit configuration simplified the plant, and the cumbersome and complicated steam generators, with their large number of pipes and valves, were eliminated (this configuration was subsequently adopted for use in RBMK units, but without the superheating of the steam). Moreover, the cost of Unit No. 2 was substantially less and its operation was significantly simplified. However, one consequence of this was the imposition of more exacting requirements on water chemistry, which was necessary to ensure the minimal activation of the steam upstream of the turbine and which required a turbine condensate purification system. The operation of both units was controlled from the main control panel.

\subsubsection{Status of Unit No. 1}

Unit No. 1 was permanently shut down on June 18,1981 , due to the unsatisfactory technical condition of the unit, the high cost of repairs, and the presence of major discrepancies in the requirements set forth in safety rules and regulations, as well as the economic inexpediency of bringing this unit up to an acceptable level of safety.

At the time of shutdown, there were 731 fuel assemblies in the nuclear reactor. The nuclear fuel was unloaded from 1981 through January 1987. The spent fuel assemblies were all unloaded. Portions of the plant's metalwork and graphite stack were dismantled to facilitate the unloading of several jammed fuel assemblies (16 items):

- 75 technological channel standpipes were dismantled

- 855 lengths of water and steam lines were dismantled

- 18 hatches were cut in the top plate (these hatches were not sealed)

- 280 graphite and cast-iron blocks were removed from the reactor, with their subsequent disarrayed arrangement.

To ensure reliable nuclear safety conditions at the shutdown reactor, the coordinates of spent fuel element spills were determined and their quality evaluated. The nuclear fuel spills were localized on the basis of the averaged results of neutron and photon sounding: in the graphite stack of Unit No. 1's reactor, an amount of approximately 70 kilograms; and on the bottom plate and in the support sleeves of the stack's graphite columns, an amount of approximately 30 kilograms.

There are presently 30 fully inserted reactor protection and control system working parts in the reactor. The reactor protection and control system's actuators have been de-energized, their electric circuits have been disassembled, and the cooling circuits of the reactor protection and control system have been drained.

The requisite monitoring of the condition of the nuclear reactor is being carried out in compliance with the extant procedure. In particular, power, the power buildup rate, and the temperature of the graphite stack are being monitored.

During the period from 1982 through 1988, heating-engineering machinery, equipment, and piping, the reactor protection and control system's intermediate-circuit equipment, the biological shielding tank, and the reactor bottom plate were all placed into prolonged storage. Compounds of the linasyl type (an inhibitor-impregnated silica gel), a 1\% sodium silicate solution, were used as corrosion retardants and preservatives. Based on observation results, the steady-state corrosion rate falls within the limits of $8 \times 10^{-3}$ to $4 \times 10^{-7}$ grams per square meter per hour. 


\subsubsection{Current Status of Unit No. 2}

Unit No. 2 was permanently shut down on September 26,1989 , due to the unsatisfactory technical condition of the unit as a result of accidents, the large financial outlays and the high dose costs associated with the repairs to the reactor stack, and the presence of major discrepancies in the requirements of safety rules and regulations, as well as to the economic inexpediency of bringing this unit up to an acceptable level of safety.

In 1976, an accident occurred during the operation of Unit No. 2 that had a substantial impact on its operating life and the conditions for decommissioning the reactor. While powering up the unit, scores of fuel assemblies were damaged in the reactor core as the result of a scram. The reasons for this accident were operator error and the faulty coolant flow-rate decrease protection system. The normal triggering of the accident isolation system kept the accident from progressing and prevented the release of activity into the environment.

The accident was classified as a serious one because the ensuing repair work took nine months. The removal of a large number of technological channels from the reactor's graphite stack using unconventional methods resulted in nuclear fuel spills into the graphite stack. Here, small amounts of the nuclear fuel spills found their way into the reactor drains, and portions percolated down to the reactor bottom plate. Also, a large number of damaged technological channels were placed in the reactor cooling pond, causing radioactive contamination of the pond environs.

The fuel assemblies have been almost completely removed from Unit No. 2. Work is ongoing on the neutron and gamma-ray sounding of the graphite stack to more accurately define the content of fuel spills therein. The reactor plant is being monitored pursuant to the instructions for the operation of Unit No. 2 using standard reactor protection and control system equipment.

There are 80 fully inserted reactor protection and control system working parts in the reactor. The reactor protection and control system's actuators have been de-energized and their electric circuits have been disassembled to prevent their removal. The automatic and manual control rod cooling circuit has been filled with noncirculating water, while the emergency protection system rod cooling and circulation system remains in operation.

No work has been performed on placing Unit No. 2's equipment into prolonged storage. Unit No. 2 systems that support the vital activities of the first phase main building (ventilation, heating, radiation monitoring, dosimetry, monitoring the reactor and the spent fuel storage facilities near the reactor, and the active drain systems) are still in operation.

Operations personnel are functioning on the basis of the technological operating procedure, as well as the procedure governing serviceability checks and the operational servicing of systems and equipment essential to safety. The work is being performed pursuant to regulations.

\subsubsection{Radiation Characteristics of the First-Phase Units}

The radiation environment in the first-phase unit areas of the Beloyarsk NPP is largely determined by the contamination of the inner surfaces of the coolant circulation equipment activated by corrosion products and the contamination of the gas circuits and drain systems of the reactor, also activated by fuel fission products.

The total activity distributed within the equipment of Unit No. 1 (with the exception of the fuel cooling pond) is estimated as $6.5 \times 10^{5}$ curies, including

- the activity of the reactor metalwork $-5.8 \times 10^{5}$ curies 
- the activity of the technological equipment $-1.2 \times 10^{4}$ curies

- the activity of the graphite stack $-6 \times 10^{4}$ curies

- the activity of the structural elements $-1.2 \times 10^{2}$ curies.

It has been estimated that the total activity of Unit No. 2's equipment accordingly comes to $1.6 \mathrm{x}$ $10^{6}$ curies.

Radiation conditions in the spent fuel cooling ponds are due to the fuel stored therein and the activity of the water. The total activity of the fuel assemblies situated in the cooling ponds of Units No. 1 and 2 is on the order of 15 megacuries; the specific activity of the water in cooling ponds totals about $10^{-3}$ curies per liter, including

- $4 \times 10^{-6}$ curies per liter for $\mathrm{Cs}^{134}$

- $8-11 \times 10^{-4}$ curies per liter for $\mathrm{Cs}^{137}$

- $5 \times 10^{-7}$ curies per liter for $\mathrm{Co}^{60}$.

Information on the radiation environments in a number of areas of Units No. 1 and 2 is summarized in Table 2.7 .

The extent of the radiation dosimetry performed at the Beloyarsk NPP is governed by the requirements set forth in Radiation Safety Standards document number NRB-96 and other operative normative documents at this NPP.

\subsubsection{Handling of the Spent Nuclear Fuel of Units No. 1 and 2}

During the operation of Units No. 1 and 2 from 1964 through 1989, some 7,196 fuel assemblies passed through the reactor cores. Of these, 2,202 fuel assemblies are in storage at a nuclear fuel reprocessing plant. The remaining fuel assemblies $(4,994)$ are being stored in cooling ponds near the reactors. Approximately $15 \%$ of the fuel assemblies in the cooling ponds have clads with failed seals. Taking reactor protection and control system channels, absorbers, and protective plugs into account; the cooling ponds have 5,943 cells filled.

There are two cooling ponds for the phase 1 units (one for each reactor unit). Each of the cooling ponds consists of a rectangular vat with a water surface area of 144.6 square meters. The pond linings are made of carbon steel. The cooling pond bays have been in operation for 30 years. The last cooling pond lining repair was performed during 1981-1982.

Table 2.7. Radiation Conditions in Some Areas of the Beloyarsk Nuclear Power Plant FirstPhase Units

\begin{tabular}{|c|c|c|c|c|}
\hline $\begin{array}{l}\text { Area } \\
\text { Name }\end{array}$ & $\begin{array}{l}\gamma \text {-Radiation Dose Rate } \\
\text { Immediately Adjacent } \\
\text { (microroentgens/sec) }\end{array}$ & $\begin{array}{c}\gamma \text {-Radiation Dose } \\
\text { Rate at } 1 \text { meter } \\
\text { (microroentgens } / \mathrm{sec} \text { ) }\end{array}$ & $\begin{array}{l}\text { Alpha Contamination } \\
\text { (unrecorded) } \\
\left(\mathrm{p} / \mathrm{cm}^{2} / \mathrm{min}\right)\end{array}$ & $\begin{array}{l}\text { Beta Contamination } \\
\text { (unrecorded) } \\
\left(\mathrm{p} / \mathrm{cm}^{2} / \mathrm{min}\right)\end{array}$ \\
\hline TsZ-1 & $0.8-20$ & $0.8-5$ & up to 5 & up to 9,000 \\
\hline TsZ-2 & $0.8-20$ & $0.8-5$ & up to 5 & up to 8,000 \\
\hline$\overline{B V-1}$ & up to 200 & up to 20 & up to 20 & $1,200-6,000$ \\
\hline BV-2 & $3-170$ & $7-70$ & up to 5 & $400-5,000$ \\
\hline $\begin{array}{l}\text { Container } \\
\text { area }\end{array}$ & $5-80$ & $5-40$ & up to 50 & $800-8,000$ \\
\hline
\end{tabular}


The specific activity of the water in these cooling ponds comes to roughly $10^{-3}$ curies per liter, which is due to seal failure of the carbon-steel cans containing the spent nuclear fuel assemblies and to seal failure of the fuel assemblies themselves. The failures have come about as a result of the long-term corrosive influence exerted by the cooling pond water. Based on observation, the rate of increase in overall activity within the cooling ponds comes to approximately 100 curies per year.

The bottoms are 8-mm-thick carbon steel. According to estimates, the corrosive processes taking place might result in water leaks from the cooling ponds.

Water treatment systems and localizing systems for coping with the eventuality of cooling pond leaks were not envisioned in the cooling pond design. In the event of cooling pond leaks, the free volume of the liquid radioactive waste storage vessels available at the Beloyarsk NPP is inadequate to take on the water from the cooling ponds. All the radiation monitoring systems from the original design and subsequent redesign are still in operation. However, there is no automatic radiation monitoring.

The problem of continued long-term storage of the spent nuclear fuel is complicated by the impossibility of inspecting the cooling ponds without totally draining them and by the presence of 147 defective carbon steel fuel assemblies, which have a holding capacity of 17 items each.

The fuel of the AMB reactors is not undergoing reprocessing because it is impossible to use the existing technology and equipment, which were developed for fuel assemblies that do not contain graphite and have a length of no more than $3.5 \mathrm{~m}$. The development of a new production line, especially for AMB reactor fuel assemblies, has been deemed inadvisable for economic reasons. Neither can the withdrawal of the AMB reactor spent nuclear fuel for burial in geological structures be realized, because the status of research on the burial of spent nuclear fuel from NPPs is such that the resolution of the associated problems cannot be anticipated any earlier than the year 2010 . In addition, the transportation problem has yet to be resolved, since the existing means of transportation (TK-AMB container cars) cannot be used to haul fuel assemblies along the railroad tracks of Russia's Ministry of Transportation Routes.

The storage and transportation-engineering operations associated with the spent nuclear fuel of the Beloyarsk NPP first-phase units are being performed pursuant to the requirements set forth in the following documents:

- the instructions governing the accountability and monitoring of nuclear fuel at the Beloyarsk NPP

- the instructions governing the assurance of nuclear safety during the transportation and storage of the spent nuclear fuel of the AMB-100 and AMB-200 reactors

- the instructions governing the work associated with technological channels and their tracts.

In late December 1995, the scientific and technical council of the Rosenergoatom was convened to select an alternative for the safe handling of the spent nuclear fuel of Beloyarsk NPP Units 1 and 2. This scientific and technical council found that

1. The established operating procedure ensures the nuclear-safe storage of the subject spent nuclear fuel in cooling ponds BV-1 and BV-2.

2. Conditions do not favor the occurrence of a sustained nuclear chain reaction in association with a maximum beyond-design-basis event-the accidental draining of either of the cooling ponds. 
3. Engineering and organizational measures aimed at reducing the risk of a radiation accident are being implemented in the requisite volume.

4. It will be necessary to proceed with research and development work for the comparative analysis and substantiation of an optimum storage system for the spent nuclear fuel.

The scientific and technical council of the Rosenergoatom recommended that the concept of the safe, monitored storage of spent nuclear fuel assemblies within an NPP operations area and the subsequent assurance of the readiness of this spent nuclear fuel for removal for reprocessing or final burial be taken as the basis for handling the Beloyarsk NPP Units 1 and 2 spent nuclear fuel. It was further recommended that the proposal concerning the conversion of the spent nuclear fuel assemblies from the first-phase reactors to dry containerized storage within the NPPs operations area be reviewed. Here, the spent nuclear fuel assemblies would be taken from the cooling ponds, placed into special containers, and stored within the operations area without removing the fuel assemblies from their cans. To this end, a packaging and transfer system must be developed that would ensure the safe storage of the AMB reactor fuel assemblies within the NPP operations area for a period of not less than 50 years, as well as the subsequent transportation of the fuel assemblies to a reprocessing or burial site.

It was noted by the scientific and technical council that, in compliance with the order issued to the Rosenergoatom on August 2, 1995, the work associated with handling the Beloyarsk NPP firstphase units spent nuclear fuel had been classified as especially important. Priority funding of the work is envisioned. In addition, the oversight of the receipt and expenditure of funds for this work has been instituted.

According to the regulatory documents, Beloyarsk NPP Units 1 and 2 are regarded as being in a state of preparation for decommissioning until the spent nuclear fuel assemblies are removed from the cooling ponds, and they must comply with the performance requirements of the operating license. A decommissioning license for Units 1 and 2 may only be issued by state safety regulation agencies (the Russian State Committee on Nuclear and Radiation Safety) following the removal of the spent nuclear fuel assemblies from the cooling ponds. Thus, the length of the decommissioning preparation stage for the first-phase units will be determined by the time required to resolve the problem of the removal of the spent nuclear fuel assemblies from the cooling ponds and to acquire a license for the decommissioning. According to the Rosenergoatom, the preparation stage could be roughly 8-10 years (i.e., could last until the years 2002-2004).

\subsubsection{Radioactive Wastes Handling Problems Associated with Decommissioning Unit No. 1 and Unit No. 2}

\subsubsection{Handling (disposition) of Liquid Radioactive Wastes}

The following equipment is presently available at the Beloyarsk NPP for processing liquid radioactive wastes:

- an evaporator for the processing of low-salinity water that consists of three lines, each with a productive capacity of 6 tons per hour

- two evaporators for processing sewage, bath water, reprocessing water, and active laundry water, each with a productive capacity of 2 tons per hour

- a final evaporator for liquid radioactive wastes within the liquid radioactive waste storage facility that has a productive capacity of 0.5 tons per-hour. 
The technical condition and operating characteristics of the liquid radioactive waste processing equipment conform to the design values. The total capacity of the reactor water cleanup systems ensures a considerable reserve capability.

The condensate treated in the evaporators is returned to the technological process. The imbalanced water treated therein is discharged through the domestic sewer system with a permissible radionuclide concentration (one that is below the norm).

Following concentration, the liquid radioactive waste residue is forwarded for disposal in the liquid radioactive waste storage facility vessels. The parameters of this residue are $\mathrm{pH}=10.3-12.7$, a salt content of 230 - 290 grams per liter, and specific activity of $3 \times 10^{-5}-5 \times 10^{-4}$ curies per liter.

The total volume of the liquid radioactive waste residues storage vessels is $6,400 \mathrm{~m}^{3}, 5,230 \mathrm{~m}^{3}$ of which has already been filled. The total activity in the liquid radioactive waste storage facility vessels comes to approximately 700 curies for the radionuclides $\mathrm{Cs}^{137}, \mathrm{Cs}^{134}, \mathrm{Co}^{60}$, and $\mathrm{Sr}^{90}$.

The annual intake of liquid radioactive wastes, according to the design, is 80 tons of salts. The equipment for collecting radioactive water and liquid radioactive wastes is in serviceable condition at the Beloyarsk NPP.

The storage of liquid radioactive wastes can represent a potential radiation hazard due to the possibility of leakage. The design does not establish a service life for the liquid radioactive waste storage facility. The condition of the metal walls of the liquid radioactive waste storage facility vessels, which are made from corrosion-resistant steel, is being investigated.

For eliminating the potential radiation hazard of liquid radioactive waste leaks at the Beloyarsk NPP, a storage facility is being designed that is equipped with plants for the exhaustive evaporation and contact precipitation of the slurry (the $\mathrm{KhZhO}-3$ facility). The $\mathrm{KhZhO}-3$ facility is scheduled to start up in 1996.

It is estimated that the amount of liquid radioactive wastes formed during decommissioning Units No. 1 and 2 will reach $\sim 15 \%$ of the existing operational liquid radioactive wastes. The complement and the productive capacities of the operational liquid radioactive wastes processing plant at the Beloyarsk NPP will be capable of processing the wastes formed over the course of the decommissioning process.

\subsubsection{Handling of Solid Radioactive Wastes}

A special section collects and takes possession of solid radioactive wastes for processing - compacting, incinerating, decontaminating, or burying. Soft solid radioactive wastes are compacted on a "Briket" press at a force of 16 megaPascals in a ram that has dimensions of $400 \times 400 \times 200 \mathrm{~mm}$ in the state of compression. Metallic wastes are decontaminated in standard decontamination vats with volumes of $2.5 \mathrm{~m}^{3}$ and $0.25 \mathrm{~m}^{3}$ with redox technology (the two-vat method). Wastes subject to incineration are placed into temporary storage in a bay (of the solid waste storage facility) that has been allocated for this purpose, while all remaining wastes are placed unprocessed into the bins of the solid waste storage facility.

The Beloyarsk NPP first-phase solid radioactive waste storage facility (the KhTO-1 facility) has a volume of $16,000 \mathrm{~m}^{3}$. The KhTO-1 is a bin-type storage facility sunk to a depth of $3.0 \mathrm{~m}$; it has both metal and concrete waterproofing. The KhTO-1 facility was constructed according to a design from the late 1950 s and thus does not conform to current rules and regulations. 
During 1986-1990, various means for the processing solid radioactive wastes were gradually introduced at the Beloyarsk NPP. The new means made it possible to substantially reduce the average annual volume of wastes (Table 2.8 ).

Table 2.8. Dynamics of the Intake of Solid Radioactive Wastes at the Storage Facility of the Beloyarsk NPP

\begin{tabular}{|c|c|}
\hline Year & $\begin{array}{c}\text { Intake of solid } \\
\text { radioactive wastes }\left(\mathrm{m}^{3}\right)\end{array}$ \\
\hline 1985 & 483 \\
\hline 1986 & 237 \\
\hline 1989 & 194 \\
\hline 1991 & 51 \\
\hline 1992 -current & 47 (annual average) \\
\hline
\end{tabular}

For metallic radioactive wastes from decommissioning, an integrated exhaustive chemical decontamination pilot plant and a unit for remelting decontaminated metal were constructed during 19871988. The decontamination subassembly of the unit is outfitted with a 1 cubic meter vat, in which the induction heating of the metal and the decontamination solution is carried out. The unit for remelting decontaminated metallic wastes consists of an induction steel-melting furnace with a volume of 100 kilograms and the fettling of crucibles made from periclase. The melting time is 60 minutes. Upon completion of melting, the slag is removed and the metal is poured into cast-iron ingot molds without scavenging. After they have cooled, the metal ingots are removed from the molds and are forwarded for outgoing dosimetry.

The UST-25 unit at the Beloyarsk NPP is designed for incineration of slightly active solid wastes. The capacity of this unit is 26.2 kilograms per hour, the flue-gas cleaning coefficient is $10^{6}$, the temperature in the incineration chamber is $800 \quad 50^{\circ} \mathrm{C}$, and the temperature in the afterburner is $1,00050^{\circ} \mathrm{C}$. The incineration chamber operates on liquid kerosene; consumption is 11 liters per hour, and the electric power use is equal to 50 kilowatts.

A system is being designed for processing wastes associated with the decommissioning of the firstphase units of the Beloyarsk NPP. The system will be a unified production line, the makeup of which includes

- a unit for liquid decontamination of equipment (either assembled or following dismantling), with subassemblies for filtration of the decontamination solution and treatment of waste water

- an automated unit for thermal decontamination and processing of complex metallic wastes

- an induction unit for remelting, pyrometallurgical decontamination, and processing complex metallic wastes

- a unit for thermal sterilization and wet-dry cleaning of flue gases

- equipment for treatment, mechanical dressing, and air-plasma cutting

- equipment for monitoring the activity of and sorting metallic wastes

- a compacting unit consisting of two presses with forces of 1 megaNewton and 10 megaNewtons for the first stage and the second stage, respectively. 
The system developed must ensure waste processing under conditions that comply with the requirements set forth in state-of-the-art standards for radiation safety and protection of the environment. The engineering solutions incorporated into the system design have been checked under industrial test conditions at individual enterprises involved in Russia's nuclear power-engineering fuel cycle. The subject system has the following technical characteristics:

- a capacity to process 2,000 to 5,000 tons per year

- a production area of $2,500 \mathrm{~m}^{3}$

- an electrical equipment installed capacity of 3,000 kilowatts

- a metal content of 500 tons.

Plans are being made for placing this system in the machine room area of the first-phase power units.

In addition, the units of the system can be used for prerepair decontamination of detachable equipment and processing the radioactive wastes formed over the course of the production and operation processes.

\subsubsection{Study of the Feasibility and the Development of Technologies for Dismantling Equipment and Structural Elements}

\subsubsection{Analysis of the Feasibility of Dismantling the Reactor Circuit Piping with Explosive Energy}

The need for reducing the personnel radiation dose will require highly productive technologies for dismantling highly radioactive equipment. One such technology is the explosive curting of structural elements and equipment. Specialists from the Paton Welding Institute (in the Ukraine) were invited to study the feasibility of employing explosive cutting at the Beloyarsk NPP because these specialists have the requisite test facilities and a pilot plant for manufacturing shaped-charge pipe cutters.

These series-produced shaped-charge pipe cutters are designed for cutting pipes with diameters of 219 to $1,220 \mathrm{~mm}$ and a wall thickness of up to $40 \mathrm{~mm}$. The subject pipe cutters consist of two semirings of shaped copper tubing filled with an explosive (hexogen), and polyethylene parts - locking devices, a detonator, and a detonator holder.

An extended shaped charge serves as the actuator for the pipe cutter. The explosive energy of the cutter, when directed at an obstacle, cuts it apart. The concentration of the subject explosive energy is achieved by means of a shaped-charge recess. Some $0.9 \mathrm{~m}^{3}$ of gases $\left(\mathrm{NO}, \mathrm{CO}_{2}\right.$, and $\left.\mathrm{CO}\right)$ are formed, and some 0.6 grams of metal are evaporated from the cutting area per gram of explosive. The width of a cut is determined by the diameter of the pipe cutter.

The feasibility of dismantling the reactor circuit piping at the Beloyarsk NPP using shaped-charge pipe cutters has been studied. This piping has dimensions of $219 \times 14 \mathrm{~mm}$ and $133 \times 10 \mathrm{~mm}$, a total weight of approximately 9.2 tons, is made from stainless steel, and is situated in the primary coolant circulation pump vaults. Some 37 pipe cutters were used over the course of the tests. The total amount of time expended on dismantling came to nine hours; the work crew consisted of three persons. 


\subsubsection{Analysis of the Electrohydropulse Technique for Demolition of the Substructure}

Electrohydropulse demolition of concrete substructures and other structural elements is based on the water hammer energy produced by a high-voltage pulsed discharge. The "Bazalt" unit, which was installed for this purpose, is a mobile apparatus that weighs 3 tons.

The "Bazalt" unit was used in the demolition of structural elements. Boreholes with a diameter of $42-45 \mathrm{~mm}$ and a depth of $400-600 \mathrm{~mm}$ were drilled into a concrete substructure. An electrode, which is a subassembly of the "Bazalt" unit, was inserted into the borehole and the space around it was filled with water. A high-voltage pulse of $\sim 100 \mathrm{~kJ}$ was fed to the electrode. The resulting discharge current caused the pressure pulse within the borehole to reach tens of thousands of atmospheres, demolishing the substructure in the vicinity, any shearing sections weighing 20 to $100 \mathrm{~kg}$.

The electrohydropulse unit makes it possible to mechanize the demolition of concrete in hard-toreach areas. The volume of work is reduced by 10 to 12 times, as is the exposure to negative health factors such as dust, vibrations, and noise.

An electrohydropulse unit was used at the Beloyarsk NPP to demolish the substructures in a steam generator rebuild area that was being upgraded. Approximately $15 \mathrm{~m}^{3}$ of concrete was demolished. The productivity was $2 \mathrm{~m}^{3}$ per hour; the work crew consisted of three persons.

During testing, approximately $90 \%$ of the time was spent on substructure boring, while the remaining $10 \%$ was spent on the readjustment of the electrode, preparation, and manipulations at the unit's main console. Substructure demolition was accompanied by the shearing off of medium-sized segments ( 10 to $20 \mathrm{~kg}$ ) and by slab breakup (separation of the binding layer from the broken concrete).

\subsubsection{Dismantling the Reactor Metalwork and Graphite Stack of Unit No. I}

In 1984, while preparations were being made to repair the graphite stack on the reactor of Unit No. 1, a graphite stack dismantling technology was developed, which was tried out on the unit. The sequence consisted of dismantling the metalwork over the repair area and the subsequent exposure of the top plate to ensure access to the graphite stack. The following operations were performed:

- removal of the reactor's side protective cover

- removal of transverse service lines that impeded lifting the steam-water piping lengths (the neutron sensor cables and the electromagnets of the emergency protection system rods)

- dismantling of the steam-water piping passing over the dismantling area

- installation of the side protective cover

- removal of the fuel channel standpipes in the dismantling area

- cutting an opening of $310 \mathrm{~mm}$ in diameter in the upper layer of the top plate

- cutting an opening in the lower layer of the top plate using a long cutting torch

- installation of a special protective plug over the dismantling area.

The trial dismantling of the graphite stack was undertaken using a special long tool that had clamps and was equipped with an air cylinder. During the trial work on Unit No. 1, 38 graphite blocks were dismantled in nine cubicles. The labor and total radiation exposure of the personnel involved in the work came to 1,732 man-hours and 18.4 roentgen equivalents-man, respectively.

At the same time, the basic approaches to the technology for dismantling the reactor's graphite stack were studied and subjected to critical analysis by specialists from the Scientific Research and 
Design Institute of Power Engineering (Moscow) within the framework of the work involved in the handling of the irradiated graphite of the AMB-100 reactor at the Beloyarsk NPP.

According to the analysis, the dismantling of the AMB-100 stack must be carried out using a "manless" technology that calls for a remote-controlled complex equipped with robotic systems that have various functional applications. Such a remote-controlled system must ensure performance in disassembling the graphite stack, moving individual graphite blocks from their normal location into a transfer vessel, lifting a transfer vessel filled with graphite blocks onto a work platform in the central area of the reactor, treating the graphite with a preservative, and hermetically sealing the containers.

The circular guide and support structure of the remote-controlled system that serves as a mount for its lower gantry, which ensures the circular movement of the remote-controlled system, is installed at the floor level of the reactor's central area. The upper gantry of the remote-controlled system, which ensures circular movement independent of the lower gantry, is installed on the lower gantry.

Before dismantling the remote-controlled system, the reactor's central area must be cleared of equipment, rigging, and other objects that are not used during the dismantling work. The permissible level of radioactive emissions in the reactor's central area must conform to the requirements for spaces occupied by personnel.

In the central area of the reactor under the transfer aisle, an installation aperture with dimensions of $3.5 \times 5.0 \mathrm{~m}$ must be cut and equipped with a removable protective plate that allows the transfer of the dismantled reactor equipment and the containers holding the graphite onto a cargo trailer.

The work area for dismantling the reactor's graphite stack is a hermetically sealed space, isolated from the central area of the reactor and formed by the following metalwork: the upper layer of the bottom shroud plate (an elevation of $+1.98 \mathrm{~m}$ ), the inner shell of the biological shielding tank (with an interior diameter of $10.5 \mathrm{~m}$ and a wall thickness of $20 \mathrm{~mm}$ ), the cowling of the remote-controlled system's lower gantry (with an interior diameter of $12.0 \mathrm{~m}$ and a wall thickness of $20 \mathrm{~mm}$ ), and the metalwork of the remote-controlled system's lower and upper gantries. The work area at the interface between the remote-controlled system's lower gantry cowling and the biological shielding tank, as well as at the interface between remote-controlled system's upper and lower gantries, is made airtight through the use of a hydraulic seal.

For the purpose of suppressing the gas aerosols, the fine, thinly dispersed dust, and the other particles formed during the dismantling of the graphite stack, the work area is equipped with plenumexhaust ventilation that exhausts the air from the work area constantly and away from the reactor's central area through the graphite stack and on through the reactor's gas system piping to the filters, then into the power unit's exhaust system.

During dismantling operations, the temperature in the work area must be no higher than $60^{\circ} \mathrm{C}$, with a relative humidity of $90 \%$. The gamma radiation dose rate above the graphite stack of the reactor must be constantly monitored to fit the changing condition of the stack over the course of the layerby-layer dismantling of its graphite blocks.

The use of water in the graphite stack, for example, spraying the stack to suppress the formation and transmission of radioactive dust, or rinsing with water during the milling of the cubicles, is not permitted. 
The entire dismantling of the AMB-100 graphite stack, starting with lifting the graphite blocks and ending with the transportation of the graphite containers to the storage facility, is usually broken down into steps:

- Step one - Preparatory work is performed for the decontamination of the walls and floor of the reactor's central area, the technological channel piping and standpipes, the reactor protection and control system component channels, and the other equipment and piping installed on the upper shroud plate. Following the preparatory work, the equipment and piping of the bench for treating the irradiated graphite with a preservative, as well as the welding equipment for the hermetic sealing of the containers, is installed on a specially assigned work platform within the reactor's central area. Above the transfer aisle, an aperture is equipped for conveying the containers that house the radioactive wastes onto a cargo trailer. Thereafter, the remote-controlled system's equipment, the transfer containers, the reusable technological vessels, and any other items of technological equipment required for the dismantling are delivered to the reactor's central area.

- Step two - The dismantling of the equipment is carried out to facilitate access to the work area and the graphite stack. This dismantling work is performed by remote control using a special dismantling deck (an innovation of the Volgodonsk branch of the All-Russian Scientific Research, Planning, and Design Institute of Nuclear Power Machinery Construction) that is equipped with a protective booth for the attendant personnel, master-slave manipulators, clamping devices, hoisting gear, cutting equipment, and other apparatuses. The piping, the technological channel standpipes, the standpipes of the reactor protection and control system channels, the reactor protection and control system cables, the pulse tubes of the fuel element clad hermeticity monitoring system, and other equipment is dismantled. The upper layer of the shroud plate is decontaminated by milling and treatment with chemical solutions. Two sections of protective plating (according to the number of work areas) are mounted on the shroud plate to facilitate installation of plugs in the openings of the cut-away standpipes, marking out the plate for subsequent cutting into transportable fragments, welding on clamp hardware for the "retention" of the cutout fragments, etc.

The remote-controlled system gantry is installed, and the dismantling work area is hermetically sealed, which consists of the enclosed space between the lower gantry section and the floor of the reactor well, the gantry cowling, and the inner plate of the biological shielding tank. Following a check of dismantling space hermeticity, a telescopic hoist equipped with clamps, work platforms for the transfer containers (through the dismantling hatch in the upper gantry of the remote-controlled system), a stereo television unit equipped with lighting equipment and a video monitor, gamma-ray detector monitoring systems, control systems, and other equipment are installed.

The schematics of the design and installation of the remote-controlled system are presented in Figures 2.21-2.23. The remote-controlled system design developed by the specialists of the Scientific Research and Design Institute of Installation Technology (Moscow) for dismantling RBMK reactor equipment was selected as the prototype.

The remote-controlled system is to be used in conjunction with plasma-cutting torches to cut the shroud plate metalwork into individual transportable pieces with dimensions (proposed) of approximately $1.5 \times 3.5 \mathrm{~m}$ and a height of up to $1.5 \mathrm{~m}$. Each fragment will weigh roughly 2.5 tons. After cutting, the shroud plate metalwork fragments are removed from the dismantling space through the 2-m-wide aperture in the gantry and transported by the central area's traveling 
Figure 2.21.

$$
2.77
$$


Figure 2.22. 
Figure 2.23. 
crane to the installation aperture (approximately $3.5 \times 5.0 \mathrm{~m}$ at the floor level of the central area), then to the transfer aisle, where they are loaded into a protective container that has been placed onto a cargo trailer.

The cast-iron blocks of the layered shielding of the reactor's graphite stack are subsequently dismantled.

- Step three - The layer-by-layer disassembly of the reactor's graphite stack is performed using the remote-controlled system. During the disassembly process, the blocks are sorted by radioactive contamination group: those blocks with spent nuclear fuel impurities are identified by means of gamma-ray detectors and placed into separate transfer baskets-i.e., they must be separated from the other, "cleaner" blocks-for loading into a special container. This container is hermetically sealed by welding (or using a liner), then, following treatment with a radiationresistant preservative, is transported to long-term storage.

Slip hooks, tongs, electromagnetic clamps, and vacuum suction cups are used to disassemble the graphite stack. The cutting of the steel rods is accomplished with a cutting wheel using a special attachment.

- Step four - The baskets containing the "clean" graphite blocks from the dismantling space to the reactor's central area and the treatment of the extracted graphite with a preservative are removed. The baskets containing the graphite are placed into a container that is hermetically sealed by welding around the contour of its cover. Personnel are permitted to be present during these operations.

The technological source data, conditions, and characteristics of the environment in the area of influence of the dismantling of the graphite stack of the AMB-100 reactor are quite similar to those of RBMK units. The fundamental provisions described herein for the AMB-100 dismantling technology can be used, with specific refinements and adjustments, as a basis for dismantling the graphite stack of RBMK reactors.

Additionally, the experience acquired in organizing the work associated with creating an airtight work area isolated from the reactor's central area, developing remote-controlled equipment for the dismantling process, developing a bench for treating the irradiated graphite-packed containers with a radiation-resistant preservative, and the other work performed during Steps 1 and 2 above can be considered and adapted to decommissioning of RBMK units.

Moreover, instead of the layer-by-layer stack disassembly technology adopted for the graphite stacks of AMB reactors, a technology for dismantling stacks in fragments (sectional lengths) that take the form of columns (with a height on the order of $2.5 \mathrm{~m}$ each; for example, four blocks with a height of $600 \mathrm{~mm}$ each), immediately placing the entire section into a container, is feasible for dismantling of the graphite stacks of RBMK reactors.

A positive argument in favor of such a technology may be the possibility of using an RBMK reactor technological channel pipe as a carrier when transferring the column fragments from the work area to the container (during the work involved in Steps 3 and 4).

\subsubsection{Critical Analysis of Dismantling of Equipment and Structural Assemblies}

According to the decommissioning plan for Beloyarsk NPP Units No. 1 and 2, the complete dismantling of the machine room equipment and the two primary coolant circulation pump vaults would be carried out first, while leaving the construction section in place. It is suggested that this work be performed to position a radioactive waste processing system in the machine room area. 
Design innovations have been implemented for dismantling the first-phase Beloyarsk NPP units, such as a plan for placing the AMB-100 reactor into long-term safe storage, the technical substantiation of the dismantling work associated with Unit No. 1, and the design of technologies for dismantling the AMB-100 reactor, the equipment from the areas of Unit No. 1, and the first-phase machine room. The innovations have illustrated the complexity of the problems associated with dismantling, not only because of radiation conditions, but also because of the lack of consideration for decommissioning in the initial design and construction, even though dismantling work is inevitable during the final stage of the active life of a reactor.

The need for well-reasoned and proven dismantling technologies has become obvious, as has the substantiated implementation of the technologies from the standpoints of safety and technical and economical feasibility. At the Beloyarsk NPP, the most important condition for implementing a dismantling technology is the possibility of using remote-controlled work performance modes, which necessitates the development of a complex, multifunctional technique that is well adapted to such modes and the associated equipment. It should be noted that a sufficient number of critically analyzed analogs do not exist for many of the requisite innovations (for example, remote-controlled systems for dismantling the reactor well and for dismantling work in radiation-hazardous areas).

A wide range of survey, research, and testing work is required, with a great deal of attention given to the training of personnel. There is also a need to develop an appropriate set of regulatory and guidance documents that will regulate the basic principles of the organization and the safety of decommissioning NPP units.

Allowance should be made for the fact that each NPP unit has some unique features: the specific nature of the engineering solutions employed, design and operating features, reasons for the cessation of operation, etc. From this standpoint, the Beloyarsk NPP first-phase units, as previously described, have many specific differences. In addition, only two AMB units were constructed in the former Soviet Union, and no similar reactors have been operated abroad. Therefore, there ís no domestic experience in dismantling and decommissioning AMB-100s, and opportunities for tapping foreign experience are limited. Consequently, domestic repair experience must be used and missing experience must be acquired for the resolution of the many problems associated with decommissioning AMB-100s.

A survey was made of the basic approaches for dismantling equipment and structural elements at the Beloyarsk NPP first-phase units. The survey concentrated on resolving the problems associated with decommissioning AMB-100s, and basic principles were formulated as a result, foremost among which are the following:

1. When selecting dismantling technologies, answers must be obtained to the following questions:

- What state should the equipment and structural elements be in during the performance of this work (initial, intermediate, and final)?

- By what means can this state be achieved?

- What technology is needed to achieve this state?

- What is the sequence and content of the dismantling operations?

- How is safety ensured?

- What are the labor hours, labor input, and personnel dose costs for performing the work? 
- What is the number of personnel taking part in the dismantling work likely to be and what is the skill level of these personnel?

2. Technological solutions for dismantling must be tailored to the specific nature of the work and its radiation-hazardous conditions, foremost among which are the following:

- the minimization of the personnel exposure to harmful conditions in the work area and the harmful secondary products formed as a result of the work

- the maximum reasonable reduction of labor input and work duration

- the minimization of personnel residence in the work area

- the minimization of the number of harmful byproducts formed

- the maximum prevention of propagating radioactive contamination outside the work area

- means for ensuring the compatibility of the dismantling technology, the decontamination process, and dosimetry.

3. During the handling of equipment, structural elements, and products of their dismantling that have spent nuclear fuel spills, applicable measures and regulations must be observed.

4. The dismantling technologies and work conditions must satisfy the following general requirements

- Acceptable economic outlays for work are ensured.

- A sufficient level of work productivity is ensured and is matched to the productivity of the waste processing technology used.

- The reasonable and achievable standardization of the dismantling methods and techniques is carried out.

- Maximum use is made of commercially available technologies.

- An analysis is made of the conformance of resultant dismantling products to the requirements of the technology used for the subsequent handling of the products.

- The requisite technology stability and reliability are ensured for given working conditions and environmental parameters.

- The use of standard power systems and unit power sources is maximized.

- The technological equipment used ensures the effective functioning of the dismantling technology while observing safety requirements that conform to existing state-of-the-art requirements, which make maximum use of standard NPP hardware, permit cleaning and decontamination, and lend themselves to the performance of repairs and servicing.

5. The classification of areas as a function of radiation conditions is essential to the selection and development of dismantling work technologies (the basis for such classification may be, for example, the classification used in the decommissioning feasibility study for the Armenian NPP, as well as for Units No. 1 and 2 of the Novovoronezh NPP)

- area category 4 (a radiation background of up to 2.8 milliroentgens per hour) - no restriction on the length of the personnel workday

- area category 3 (a radiation background of 2.8 to 10 milliroentgens per hour) - the length of the personnel workday is limited to the time over the course of which the individual radiation dose is not exceeded 
- area category 2 (a radiation background of 10 to 50 milliroentgens per hour) - direct personnel participation in the work is inadvisable or is not permitted (the feasibility of improving the radiation conditions by means of long-term storage or decontamination to a radiation level that conforms to category 3 areas must be analyzed)

- area category 1 (a radiation background greater than 50 milliroentgens per hour) - the feasibility of significantly improving the radiation level is, by and large, difficult, or when resources for such improvement do not exist.

The demarcating lines between the area categories, with the exception of category 4 , which is regulated, are quite tentative. The demarcation line for the radiation backgrounds of area categories 2 and 3 is selected considering the personnel workday limit for dismantling work. Depending upon the classification selected, manual and mechanized items may be employed in area categories 4 and 3, while remote-controlled technologies (remote-controlled systems) are used in area categories 2 and 1.

6. The work must be structured with the precise organization of work areas, their localization, and the attendant radiation shielding.

7. The selection of dismantling technologies and methods may be dictated by equipment designs and materials, area configuration and location, the presence of the requisite energy sources and hoisting equipment, and other factors.

8. The performance of a preliminary analysis of the feasibility and use of a variety of different methods is necessary, for the purpose of seeking out solutions that satisfy the conditions and requirements of the dismantling work to the maximum extent possible.

For example, the use of plasma-arc cutting is advisable for the rough cutting of equipment and piping made from corrosion-resistant steels, while oxygen cutting is expedient for equipment and piping made from carbon steel, with plasma-arc cutting being recommended in certain situations.

The extensive use of mechanical means for pipe dismantling must be examined - cutting shears, abrasive cutting techniques, and pipe cutters, depending upon pipe diameters and materials.

Piping valves must be dismantled using mechanical methods (in addition to thermal and mechanical cutting), with assembled equipment also being dismantled given the possibility of the mechanized transfer of the resultant large-sized subassemblies and parts.

Mechanized tools and thermal cutting with an oxygen lance must be used for the disassembly of structural elements. Seeking out and making use of more efficient methods is also essential; for example, the thermal gas-jet cutting technique, which is based on the use of liquid-propellant jet microengines.

The use of an explosive technology based on extended shaped charges appears to be an effective dismantling method, primarily for piping, metalwork, and structural elements.

All methods other than the mechanical disassembly of large equipment must be adapted for working with remote-controlled manipulators.

Dismantling techniques used in situ are preferred. Ensuring radiation safety is easier, although technological solutions may be more complicated. The dismantling of large equipment in bulk through the installation apertures is preferable in the machine room, due to the tight packing of the equipment into the turbine vaults. This equipment is then dismantled for subsequent processing on a special system that is temporarily installed in the machine room. 
9. A general approach to dismantling work must envision the following sequence:

I. The dismantling of the technological systems required for preparing the reactor unit for decommissioning.

II. The dismantling of the technological systems and equipment not required during long-term storage.

III. The dismantling of equipment and systems in accordance with the decommissioning plan for the chosen end state.

At the Beloyarsk NPP, the equipment in the areas needed for the waste processing system must be dismantled first (these areas consist of the primary coolant circulation pump vaults and the machine room). The dismantled equipment from these areas can be temporarily stored in the free areas of the machine rooms until the date of processing (under radiation shielding that is set up as necessary).

The actual sequence for the performance of the work associated with the power unit areas must be envisioned by the design. Here, a transition from clean areas to radiation-contaminated ("dirty") areas is preferable (provided "dirty" areas are not needed for performing dismantling work in clean areas).

Due to the loaded configuration of the equipment in most NPPs, the organization of the frontal transaction of dismantling work - without the selective dismantling of individual objects-may be more expedient in the practical sense. Here, the more radiation-contaminated objects along the work transaction front should be dismantled first to reduce the dose levels.

10. The handling and transfer of dismantled equipment must satisfy the same conditions and requirements as during dismantling, primarily safety requirements.

It is advisable that the transfer of dismantled equipment, i.e., wastes, be coordinated with the waste processing. Therefore, transfer operations should be viewed as one of the components of the waste processing. In this vein, the containers used (baskets, boxes, pallets, casks, and so forth) must be adapted to the conditions and requirements of the attendant dismantling and waste processing technologies.

Existing standard hardware - telphers, hand pulleys, and traveling cranes-should receive first consideration for use as hoisting and transfer equipment. The use of a freight elevator is advisable for the vertical transfer of wastes. Work areas must be equipped with powered dollies, hand trucks, wenches, gate reloaders, and freight manipulators. In the event that standard transfer equipment is not available or cannot be used, electric forklifts must be used in the transfer aisles.

Radiation shielding devices and remote control equipment must be employed in all radiationhazardous situations.

11. In dismantling work, it is necessary to perform a certain volume of preparatory tasks, among which is the creation of installation apertures.

Other complicated and time-consuming types of preparatory work consists of the installation or reinstallation of transfer chambers in both installation and standard apertures, and the installation of technological equipment and hoisting equipment.

\subsubsection{Conceptual Approaches to Dismantling}

The experience and data acquired in developing engineering solutions and selecting technologies and specialized equipment for upgrading reactors, and optimizing the basic principles of equipment 
dismantling during decommissioning of the Beloyarsk NPP form the basis for planning and organizing the work associated with the dismantling of the equipment, systems, and structural elements of RBMK units.

It is proposed that dismantling operations be divided into several categories based on specific criteria, for example, radiation criteria, technical criteria, etc. The criteria must be determined on the basis of the corresponding work performance indexes or conditions. For example, a radiation criterion must primarily be determined by such indexes as the ionizing radiation dose rate in the work area, the magnitudes of the specific and total activity of the equipment and systems being dismantled, and the decontamination coefficient. A technical criterion must also be determined by several indexes, such as the mass and surface of the equipment being dismantled, the extent of the technological effectiveness of the reactor's structural elements relative to dismantling work (the stability of the metalwork with respect to mechanical cutting techniques, the tightness of the packing of the metalwork into the concrete reactor well, the thickness of the metalwork's walls, etc.), and the spatial configuration of the specialized technological equipment relative to the object to be dismantled (technological equipment incorporated into the object and fulfilling the function of localization and shielding, technological equipment that demolishes the object with the uncontrolled release of radioactivity into the work area, technological equipment that was used led to the accumulation of radioactivity either within or on the surface of the equipment, etc.).

Additional structuring or limitations may be introduced within each index. For example, dividing technological equipment into safety categories based on the (General Safety Regulations document No. OPB-88) probability of operational failures that constitute initiating events for potential emergency situations or accidents involving the release of radioactive agents into the production areas of the NPP or to the environment.

The radiation-related state of an object and its dismantling conditions make it possible to divide all equipment and systems into the following three safety categories that can be used to establish categories of technological operations:

- category $I$ - auxiliary units and systems, as well as machine room equipment, with negligible surface radioactivity (some few hundred becquerels per $\mathrm{cm}^{2}$ ) (in this case, general industrial dismantling can be employed with the appropriate protective measures, primarily personal protection devices)

- category 2 - coolant circulation circuit systems and equipment that come into contact with radioactive contaminating agents during operations (the specific surface radioactivity can reach $10^{4}$ to $10^{5}$ becquerels per $\mathrm{cm}^{2}$ ) (in this case, decontamination should be using a specialized technique that ensures protection of personnel against overexposure)

- category 3 - reactor structural elements (the top load-bearing structure, the bottom load-bearing structure, housing, and the main biological shield tank, the graphite stack, the technological channels) that are activated during operations (the specific activity of these structural elements can reach a figure on the order of $10^{8}$ to $10^{9}$ becquerels per $\mathrm{cm}^{2}$ ) (a remote-controlled technique is required for this category of equipment, together with stringent measures aimed at protecting personnel against overexposure).

Under the proposed classification scheme, the dismantling complexity increases with an increase in the category number. Each category is assigned an appropriate quantitative index, which can be determined by empirical means. 
The implementation of a category-based strategy makes it possible to plan and control dismantling (in space and/or time). Objects from the lower-number categories are dismantled first, followed by objects from the higher-numbered categories. Here, dismantling objects that have been relegated to a single category is consolidated in time. The proposed classification approach also makes it possible to certify the requirements imposed on the equipment falling into each category, as well as to define requirements for the specialized technological equipment needed for dismantling the corresponding category of equipment and systems. It is proposed that the classification approach be used to develop a basic plan for dismantling the equipment and structural elements of reactor plants equipped with $R B M K$ reactors.

\subsubsection{Preparation for Decommissioning}

The "Program for the Preparation and Decommissioning of Unit No. 1 and Unit No. 2 of the Beloyarsk Nuclear Power Plant" was developed in 1996 and was approved by the Rosenergoatom.

The development of this program was undertaken for the following purposes:

1. to determine the basic steps in decommissioning Units No. 1 and 2 of the Beloyarsk NPP according to the selected decommissioning alternative

2. to establish a list of interconnected tasks for the preparatory stage of decommissioning Units No. 1 and 2, as well as a list of the tasks to be performed during decommissioning step 1-the preparation of the power units for long-term storage

3. to describe basic safety assurance measures during the preparation of Units No. 1 and 2 for decommissioning.

The basic steps of this work, the execution of which is envisioned by the subject program, are outlined in the next subsection. However, the following two factors should be noted.

- First, the requirements imposed on developing a program for preparing the units of the NPP for decommissioning and for decommissioning have yet to be formulated or approved by the Rosenergoatom.

- Second, the "Program for Preparation and Decommissioning of Units No. 1 and 2 of the Beloyarsk Nuclear Power Plant" that has been developed has not yet undergone requisite coordination with Russian state safety regulation agencies.

Thus not all the tasks or their procedures as described in the subject program are in compliance with the regulations being developed for the acquisition of decommissioning permits (licenses).

\subsubsection{Temporary Storage and Preparation for Decommissioning}

The principal limitations on the preparation and decommissioning of Units No. 1 and 2 of the Beloyarsk NPP are related to the lack of processing or burial of AMB reactor spent nuclear fuel and the necessity for long-term storage of the spent nuclear fuel within the AMB NPP's operations area. Taking into account the complexity and the large amount of time involved in resolving the problems surrounding the removal of the spent nuclear fuel, the main objectives are the temporary storage and preparation of the reactor units for decommissioning and ensuring safe storage of the spent nuclear fuel in the fuel cooling ponds.

To enhance the safety and reduce the decommissioning work for the AMB units during temporary storage and preparation for decommissioning, it is advisable that equipment, systems, and structural 
elements be decommissioned, accumulated radioactive wastes be processed, and equipment and systems be placed into long-term storage, isolated, and partially dismantled.

The primary tasks for the temporary holding and preparation of AMB reactor units for decommissioning are as follows:

- the operation of the equipment, systems, buildings, and facilities of the first-phase power units in accordance with accepted procedure

- the servicing of the equipment, technological systems, and structural elements that remain in operation to ensure their reliable functioning

- the assurance of the safe storage of the spent nuclear fuel in the cooling ponds

- the development of a complex that ensures the processing and safe storage of radioactive wastes

- the partial dismantling of the machine room equipment and metalwork

- the placement in the freed-up areas and the operation of the waste handling and storage complex

- the development of the appropriate project documentation, the acquisition of the requisite special permits (licenses), and the dismantling or placement into long-term storage of the equipment and technological systems to be ultimately dismantled

- the placement into prolonged storage and/or the isolation of the highly radioactive equipment and systems in the reactor unit reactor section areas for the period of time specified by the special engineering permits or the plan for placing the equipment and systems into long-term storage

- the performance of tasks for preparation and removal of the spent nuclear fuel from the cooling ponds of Units No. 1 and 2

- the development and approval, in accordance with the established procedure, of a plan for step 1 of the decommissioning of the first-phase units-the step involving the preparation of reactor units for supervised custody and the acquisition of a permit (license) for decommissioning.

The length of time occupied by this step will depend on the time required to resolve the problem of removing the spent nuclear fuel from the reactor units. Bearing in mind the predicted time frame for the creation of a storage facility to hold the spent nuclear fuel of the AMB reactors within the operations area of the Beloyarsk NPP, this step is assumed to take roughly 8-10 years.

In the event that technologies are developed and implemented that ensure the safe storage of the spent nuclear fuel from the AMB reactors in the main building of the first-phase power units, the temporary holding and preparation time could be shortened.

\subsubsection{Preparation for Long-Term Storage}

The preparation for long-term storage begins on the date the decommissioning permit (license) is acquired from state safety regulation agencies. Preparing for long-term storage constitutes the first step of decommissioning Beloyarsk NPP Units No. 1 and 2. This step takes approximately five years, during which the following tasks must be performed:

- operation of the equipment, systems, buildings, and facilities of the reactor units pursuant to the requirements of the project documentation for the assurance of the radiation safety and engineering safety of the Beloyarsk NPP first-phase units 
- repair and modernization of the systems that remain in operation and installation of auxiliary systems in compliance with the project documentation

- development, coordination, and approval, in accordance with the established procedure, of the documentation required to obtain the appropriate permits authorizing the next step in the decommissioning-long-term storage

- dismantling and removal of the clean, slightly contaminated, and low-activity equipment and systems, with the subsequent salvaging of the clean equipment, as well as the processing, packaging, and managed storage of resulting radioactive wastes in facilities within the NPP's operations area

- redesign of the areas, buildings, and facilities of the first-phase reactor units that have been freed up.

During the preparation for long-term storage, the serviceability of the radiation monitoring systems, optimized to fit the altered status, the requisite parameters, and the corresponding volume of radiation monitoring must be ensured, as must the integrity and serviceability of those items of equipment that provide for the safe maintenance of the reactor units under long-term storage and subsequent decommissioning.

\subsubsection{Long-Term Storage}

The length of time occupied by this step must be based on the attendant design and may be dependent upon the following factors:

- the service life of the structural elements within which the isolated equipment is located

- the time frames for the construction and the placement into service of a regional storage facility (burial ground) for radioactive wastes

- development and adoption of an efficient technology for dismantling and processing the reactor equipment and structural elements, including the blocks of the reactor's graphite stack

- the reduction of structural element activity as a result of natural radionuclide decay to levels that make it possible to decommission the reactor units with a minimal total radiation exposure for the attendant personnel and with the minimal use of remote-controlled hardware

- the need for freeing up the operations area of the NPP as quickly as possible to facilitate construction of engineering facilities therein

- other factors.

According to estimates, the long-term storage may be roughly 30 to 50 years. The length of time for this step must be more accurately defined in the future in line with the formulation of a plan for decommissioning.

During long-term storage, the following tasks must be performed:

- operation of the equipment, systems, buildings, and facilities of the first-phase reactor units in long-term storage pursuant to the requirements of the documentation for the assurance of the radiation safety and engineering safety

- dismantling of the equipment and systems of the first-phase units that are outside the isolation areas and not involved in long-term storage 
- requisite redesign and the building of areas of the first-phase reactor units following the equipment and system dismantling

- processing of the dismantled equipment, the resultant wastes, and the operations wastes from the first-phase reactor units and the subsequent performance of dismantling work

- implementation of measures that ensure the formulation and approval of a plan for the final decommissioning of the first-phase reactor units, as well as the development of technological processes and design documentation for the manufacture of the custom-built equipment and technological equipment needed in order to perform the work specified by said plan.

During the final decommissioning planning, the advisability of demolishing the main construction structures of the first-phase units after dismantling the equipment, systems, and structural elements of the first-phase reactor units must be examined, including the bedplate, which might be used in the future for constructing nuclear power engineering facilities.

In addition, consideration should be given to the fact that a portion of the buildings and the waste processing complex might be used in decommissioning a third reactor unit, equipped with a BN-600 fast reactor, that is now in operation at the Beloyarsk NPP.

\subsubsection{Final Decommissioning}

During the last step of decommissioning the first-phase reactor units - the final decommissioning of the reactor units - the following tasks must be performed:

- dismantling the isolated equipment and systems

- demolition of the buildings that are not expected to be used in the future

- processing, packaging, and removal of radioactive wastes from the operations area of Units

No. 1 and 2 (or assurance of the long-term storage of the radioactive wastes within the operations area)

- requisite restoration of the freed-up premises of the operations area to meet nuclear power engineering needs.

The concluding step of decommissioning the first-phase reactor units must be determined during the formulation of the decommissioning plan. According to estimates, this step may take roughly 5 to 10 years.

Taking into account the uncertainty that exists with respect to the end state of the first-phase units of the Beloyarsk NPP, which is due to the remoteness of the time frame for implementing the concluding step, and based on the results of reactor unit inspections, it seems advisable that the final decommissioning plan examine alternatives for the first-phase reactor units, for example, burying the reactor in place in its well, with the subsequent demolition of remaining structural elements. Such an analysis must be done to define and substantiate the selection of the best alternative as well as to make allowance for the conditions actually in place at the time the plan is formulated.

\subsection{Development of New Technologies for Dismantling Nuclear Reactors}

The experience previously described relative to dismantling in Russia does not fully satisfy state-ofthe-art safety requirements. The total dose levels associated with the upgrading work performed to date-for example, the upgrading of plutonium-production reactors-have reached 1,000 roentgen equivalents-man per person (10 sieverts per person). Consequently, using "manless" technologies for tasks under radiation-hazardous conditions was subsequently noted as desirable. 
A number of research and design organizations in Russia have recently developed unconventional techniques and technologies for dismantling the equipment and structural elements of reactor plants. A brief description of some of these techniques and technologies is presented below.

\subsubsection{Development of Remote-Controlled Systems for Dismantling the Highly Radioactive Structural Elements of Nuclear Reactors}

As foreign and domestic experience demonstrates, the main thrust of technologies for dismantling channel-type and pressure vessel nuclear reactors consists of dismantling the reactor into parts directly in the reactor vessel. For dismantling reactors, there is a need for specialized technological equipment - remote-controlled dismantling systems that realize the principle of the "manless" work performance technology. In addition, such systems can also be used to perform other unique operations, such as removing the contents of the "Shelter" facility at the Chornobyl NPP.

Critical analyses of the designs of several versions of remote-controlled systems intended for dismantling the highly radioactive channel-type and pressure vessel nuclear reactors have recently been conducted in Russia. No insoluble problems exist in principle with respect to their development and manufacture. The practical realization of these systems requires only the requisite research and development to substantiate working specifications, developmental prototypes, optimization of the prototypes on full-scale benches, and the training of personnel. Unfortunately, the financial resources required for the performance of this work are not available in Russia.

\subsubsection{Remote-Controlled Systems for Dismantling Channel-Type Nuclear Reactors}

At the Volgodonsk branch of the All-Russian Scientific Research Institute for Nuclear Power Machine Building, a rough design has been developed of a remote-controlled system for dismantling the channel-type AMB-100 unit at the Beloyarsk NPP and that, in principle, could also be used for dismantling VVER vessels and internals. The basic requirements taken into account during the development of this remote-controlled system design were as follows:

- compliance with the NPP decommissioning concept and technology adopted in Russia

- efficient task sharing by the remote-controlled system and the equipment used in the subsequent handling of the dismantled subassemblies

- the need for the working and auxiliary parts of the subject remote-controlled system to function within the requisite parameters and confines of the attendant work space

- high reliability, serviceability, and maintainability indexes.

A diagram of the remote-controlled system for dismantling a channel-type nuclear reactor, which was developed with AMB-100 Unit No. 1 of the Beloyarsk NPP in mind, is depicted in Figure 2.24. The remote-controlled and automatic technology consists of a complicated production arrangement with a varying degree of interaction between the systems and subsystems that go into its makeup.

The support and transfer system is a load-bearing unit made of carbon steel. It is designed to position the mechanisms, subassemblies, and metalwork of the other systems and subsystems of the remote-controlled complex. In addition, this system functions in the isolation of the work area, the radiation shielding of the space adjacent to the work area, ensures the functioning of the technological tools, and the movement of the remote-controlled system above the work area. 
Figure 2.24 
The manipulation system is designed for remote dismantling work. This system includes two manipulators with different hoisting capacities (lightweight and heavy-duty manipulators), as well as a freight telpher, all of which have remote-control with programming components.

The hoisting and transfer system is designed to move the dismantling products from the work area to the initial waste handling area. This system consists of a freight platform that is conveyed vertically along a boom by an individual drive. The hoist penetration assemblies in the support and transport system structure have movable radiation shielding plates.

The initial radioactive waste handling system performs the preliminary preparation of radioactive wastes for subsequent transfer to the section where the wastes are processed. This system is equipped with remote-controlled and automatic mechanisms, and its operation is synchronized within the remote-controlled complex, by means of external links with other systems. The ventilation, dust suppression, and filtration system is designed for the filtering, suppression, and removal of the secondary gaseous and dust-like products formed over the course of dismantling work. The energy supply system provides the technological equipment, auxiliary equipment, and mechanisms of the remote-controlled complex with energy sources: electric power, compressed air, water, oxygen, and acetylene.

The remote-controlled complex's control system is designed to control the complex's systems and technological equipment in the remote and automatic modes. The proposed design for the remote-controlled system resolves radiation safety problems and the protection of the environment during reactor dismantling. It's metalwork consists of a closed-type structure that isolates the work space and divides it into three work areas that have different levels of radioactivity. The operations associated with dismantling nuclear reactor equipment are performed in the first work area. This work area has the highest level of radioactivity; therefore, it is separated from the second work area, which has a lower level of radioactivity, by means of a protective barrier of radiation shielding plates. When specifically prepared for this purpose, the second work area can be used as an intermittently attended space for maintenance of the mechanisms, subassemblies, and equipment of the remote-controlled system that have been moved into this space. The third work area is the refueling containment vault, which is separated from the second work area by the remote-controlled system's bearing metalwork and from the environment by radiation shielding plates. Most of the remote-controlled system's mechanisms are located behind the radiation barriers, but when the drives are situated in the work area (as is the case with the manipulator drives), their structural elements are made from radiation-resistant materials. The principal technical characteristics of the remote-controlled system are as follows:

Overall dimensions

Hoisting capacity:

- of the light-weight manipulator

- of the heavy-duty manipulator

Load-lifting capacity of the hoist

Installed capacity of the drives

Weight
$18,000 \times 15,800 \times 12,000 \mathrm{~mm}$
350 Newtons
2,000 Newtons
7,000 Newtons
$25 \mathrm{~kW}$
$420,000 \mathrm{~kg}$ 


\subsubsection{Remote-Controlled Systems for Dismantling Pressure Vessel Type Nuclear Reactors}

Designs for a remote-controlled system for dismantling VVER pressure vessel reactors have been analyzed at the Volgodonsk branch of the All-Russian Scientific Research Institute of Nuclear Power Machine Building with allowance for the requirements previously discussed. The design of the remote-controlled system has a structure similar to the one described above, with both remote and automatic modes for servicing the attendant working parts and for monitoring and control of the dismantling process.

One proposed process for enhancing the efficiency and safety of dismantling VVER reactor vessels involves the continuous milling of the reactor vessels from within, carried out from top to bottom along a circular trajectory, with the diversion of the resultant chips to the floor of the reactor vessel through a specially provided internal cavity in the carrier rod, which simultaneously anchors the reactor vessel (Figure 2.25).

To facilitate the installation of the remote-controlled system, an opening is cut for the tip of the carrier rod (here, the reactor internals are dismantled beforehand). Using a centering device, the carrier rod is coaxially anchored to the vessel.

The method of vessel cutting by milling does not release secondary radioactive wastes in the form of gas. Therefore, special ventilation systems are not required in the work area. The established "net" time for cutting a VVER reactor vessel using the milling method ranges from 5,100 to 6,200 hours.

The advisability of using the proposed technology for dismantling pressure vessel reactors is dictated by the following factors:

1. The structural materials from which this reactor are made possess an acceptable level of machinability (for comparison, the machinability coefficient of brand 45 structural carbon steel is equal to 1.0 , while that of the brand 15Kh2MFA heat-resistant steel used in the reactor vessel and the brand $0 \mathrm{Kh} 18 \mathrm{~N} 10 \mathrm{~T}$ corrosion-resistant steel used in the reactor internals is equal to 0.5 ).

2. The structural elements of the vessel (with the exception of its floor) and those of the reactor internals (with the exception of the shielding pipe module) have simple geometric shapes and ample rigidity, which is convenient from the standpoint of the machining of these structural elements, the simplicity of process kinematics, and process control.

3. The use of the concrete reactor vessel as an isolated dismantling work area precludes the necessity of setting up new, radiation-contaminated sites for dismantling work within the reactor unit building or outside its confines.

4. The mechanical machining process has extensive industrial use and the designs of the tools and equipment have been optimized (this process adapts well to remote and automatic control, while, at the same time, the milling process is one of the most productive, universal, and reliable machining methods available).

5. The chips produced as a result of vessel milling are short and have a regular shape; therefore, they are technologically efficient from the standpoint of their subsequent handling as radioactive wastes (the organization of chip sorting by level of radioactivity is possible over the course of the milling process).

6. When using carbide-tipped tools for milling, a cooling liquid is not obligatory, thereby making it possible to avoid the formation of secondary associated radioactive wastes. 
Figure 2.25. 
7. The chip formation process associated with the clean metal of the structural elements of a reactor does not lead to the release of any sort of dusts or gases, which exempts this work from the need for an active ventilation system and preserves the possibility of work area surveillance (it is true that the possibility of the presence of loosely adhering deposits on the surfaces of the reactor components that can form dust-like fractions, albeit in small amounts, is not ruled out; therefore, the installation of a local active ventilation system with a low capacity [from 0.6 to $0.8 \mathrm{~kW}$ ] in the area of influence of the milling process and the connection of this system to the common active ventilation system is advisable in this instance).

8. The design of the attendant metal-cutting complex, which has a series of main and auxiliary cutting motion mechanisms, which envisions the positioning of the reactor components during their machining, as well as the diversion and packaging of the resultant chips, and which features automatic tool replacement, is no more complicated than that of other dismantling complexes that achieve dismantling by other methods necessitating the use of complicated manipulators, hoisting gear, energy source delivery systems, etc.

9. The main circulation piping can be cut off of the reactor vessel directly during the milling process.

The proposed technology is also preferable from the standpoint of radiation and ecological safety requirements, contributions to which are made by following factors:

- the virtual absence of secondary radioactive wastes, the initiation of radionuclide release, and changes in the phase structure of the attendant radioactive materials

- the possibility of the isolation of a dismantling work area within the concrete reactor well, with the placement of metal plates of the requisite thickness on top of the well serving as a protective barrier

- the good adaptation of the milling process to the requirements surrounding the organization of a technology involving remote- and automated-control

- the ease of handling of the radioactive products of the dismantling process-short chips with a regular shape-during loading, unloading, transfer, and conditioning operations requiring radiation protection devices

- the possibility of installing the subject complex above the work area in a water-filled reactor vessel, thereby eliminating the need for special protective barriers

- the possibility of creating a pressure in the work area that is lower than that in the central area of the reactor.

One shortcoming of the proposed dismantling technology is the fact that it calls for slightly more labor hours and power consumption than the cutting process that results in fragments of $200 \mathrm{x}$ $200 \mathrm{~mm}$ or larger. However, this shortcoming is partially offset by operations involving the handling of the radioactive products generated by the dismantling process in the form of chips.

The principal characteristics of the design of the subject complex for the milling alternative as applied to the vessels of nuclear reactors of the VVER type are as follows: 
Overall dimensions

- height

- width

- length (as a function of direction)

$11,000 \mathrm{~mm}$

$14,000 \mathrm{~mm}$

$10,000 \mathrm{~mm}$

Weight (without the radiation shielding)

90 tons

Number of drives

24 items

Installed capacity of the drives

$60 \mathrm{~kW}$

Bridge movement along the rail track

$6,000 \mathrm{~mm}$

Rate of bridge movement

$0.5 \mathrm{~m} / \mathrm{s}$

Maximum vertical path of the tool heads

$12,700 \mathrm{~mm}$

Number of tool heads

2 items

Number of attendants per shift

Volume of chips generated

Number of containers (casks with a capacity of $0.2 \mathrm{~m}^{3}$ )

4 persons

$400 \mathrm{~m}^{3}$

required given the condition of chip compacting

Power consumption for the milling of a reactor vessel

Number of cutters used

- without regrinding

1,000 items

- with regrinding

$79,000 \mathrm{~kW}-\mathrm{h}$

2,040 items

170 items

\subsubsection{Tool Support for the Remote-Controlled Systems Developed in Russia}

The remote-controlled system structures previously described in this text also include domestically designed manipulators (lightweight and heavy-duty) that were developed and fabricated at the pilot plant of the All-Russian Scientific Research and Design Institute of Power Engineering (St. Petersburg).

To provide support for dismantling metalwork, the remote-controlled system includes a set of special accessories - tools and attachments, that ensure a direct impact on the object being dismantled; i.e., on nuclear reactor metalwork and concrete. The following items are used as tooling for the reactor metalwork dismantling process:

- the RZM-2 low-pressure oxygen cutting torch for machining and cutting thick metal (an innovation of the Institute of Machine Building Research, Design, and Technology)

- flux and plasma-cutting torches that are series-manufactured (mass production) by domestic industry.

The basic technical data of the technological components developed for cutting the vessels of nuclear reactors are presented below:

Oxygen cutting torch

Thickness of the metal to be cut

$100-600 \mathrm{~mm}$

Rate of cutting

$1.2-3.0 \mathrm{~mm} / \mathrm{s}$

Weight

$30 \mathrm{~kg}$

Maximum overall dimensions

$550 \mathrm{~mm}$ 


\begin{tabular}{ll} 
Plasma cutting torch & \\
Thickness of the metal to be cut & up to $180 \mathrm{~mm}$ \\
Rate of cutting & $1.6-1.8 \mathrm{~mm} / \mathrm{s}$ \\
Weight & $20 \mathrm{~kg}$ \\
Maximum overall dimensions & $150 \mathrm{~mm}$ \\
Flux cutting torch & \\
\hline Thickness of the metal to be cut & $100-600 \mathrm{~mm}$ \\
Rate of cutting & $1.5-3.3 \mathrm{~mm} / \mathrm{s}$ \\
Weight & $25 \mathrm{~kg}$ \\
Maximum overall dimensions & $500 \mathrm{~mm}$
\end{tabular}

In addition to technological components for use in flame cutting, a hydroabrasive cutting device was designed that uses high-pressure water-jet energy for cutting. Structurally, this device satisfies the operating criteria previously cited. Prototype cutting torches developed by the Ritm Research and Production Association served as its cutting heads. The device has the following characteristics:

$\begin{array}{ll}\text { Thickness of the metal to be cut } & \text { up to } 70 \mathrm{~mm} \\ \text { Water pressure } & 300 \mathrm{MPa} \\ \text { Rate of cutting } & \text { up to } 0.0013 \mathrm{~mm} / \mathrm{s} \\ \text { Weight } & \text { up to } 20 \mathrm{~kg}\end{array}$

The tool support kit for the manipulator of the remote-controlled system also includes mechanical tools: power brushes for collecting the cutting chips, dust, and wastes; a vibroimpact tool; a drilling head; power shears, and a device for collecting large fragments.

This remote-controlled system's manipulator is also outfitted with gripping mechanisms that are designed for holding, transporting, and placing reactor vessel fragments into a container. These clamps consist of a set of devices with a wide range of technical capabilities as far as their compatibility with the objects being manipulated. The design of these clamps is based on accepted engineering solutions, and their functional capabilities are essentially no different than those of the models currently used in industrial robotics. One distinctive feature of the clamps is the special coupling subassemblies for remote mounting (or removing) the clamps on the wrist of the manipulator. The basic technical data of the clamps are as follows:
Size of the fragment to be clamped
$160-730 \mathrm{~mm}$
Weight of the fragment to be clamped Weight of the clamp up to $200 \mathrm{~kg}$ up to $300 \mathrm{~kg}$

Structurally, all the clamp types, as well as the mechanical tools, are configured in such a manner that the actuator drive is situated on the end link of the manipulator and the transmission of movement is accomplished through a special coupling sleeve. This is done to ensure the possibility of the remote replacement of subassemblies of the technological equipment. 
The technological equipment tools and accessories previously examined make it possible to outfit both of the remote-controlled system's manipulators (the lightweight manipulator and the heavyduty manipulator), which operate simultaneously, and to ensure the performance of the operations involved in the subject reactor dismantling technology.

In conclusion, we note that the development of tools and technological equipment for this remotecontrolled system's manipulators, as well as the assortment, types, and structural design of the tools and technological equipment, will depend, to a considerable extent, on the object being dismantled and the attendant environmental conditions, especially the radiation conditions in the work areas. There is no doubt that final design solutions employing domestic tools can be adopted based on the results of the manufacture, bench testing, and normal use of equipment for the manipulators of remote-controlled systems designed for on-site dismantling of reactor equipment during the decommissioning of NPPs.

\subsubsection{Development of Techniques for Dismantling the Structural Elements of Nuclear Reactors}

As a result of the conversion of the defense sectors of domestic industry, new techniques have recently been developed and recommended for the dismantling of metalwork and concrete structural elements during the decommissioning of NPPs, among which are the thermite cutting technique, the thermal gas-jet cutting technique, the abrasive steam cutting technique, the heat shock decontamination and dismantling technique, and so forth. A brief description of the new techniques developed for dismantling the metalwork and concrete structural elements of nuclear reactors is presented below.

\subsubsection{The Thermite Cutting Technique}

The thermite cutting process consists of heating and melting the metal in the cutting area by the thermal energy released during combustion of a thermite mixture (under conditions of an exothermic reaction). The products generated by combustion of the thermite mixture issue from the combustion chamber under pressure in the form of a mixture of condensed gases, which affords the opportunity of cutting almost any metal in any attitude. The application of this cutting technique to nonmetallic materials also seems feasible, especially the dismantling of the reinforced concrete structural elements. However, no domestic experience has been acquired to date using thermite cutting in nuclear power engineering.

Research to substantiate the preliminary design and technological solutions of cutting metalwork with the thermite cutting technique have made it possible to identify the following conditions for cutting plate-type materials and piping:

- the products resulting from the combustion of a thermite compound must be generated in the form of a directed jet and must possess a large store of heat and kinetic energy

- the combustion products must ensure a high level of convective heat exchange during the demolition of metalwork

- during the combustion of a pyrotechnic compound, a maximum number of condensed liquid products with a high heat capacity must be formed

- the number of gaseous products formed must be minimal, but sufficient for transporting the condensed phase to the obstacle. 
Two conceptually diverse compounds were evaluated in the research studies: slightly gassy mixtures based on a ferroaluminum thermite with the addition of potassium perchlorate and strontium nitrate (compound " $\mathrm{A}$ " mixtures), and gassy mixtures based on an aluminum-magnesium alloy with an oxidizer using polytetrafluoroethylene as its base (compound " $\mathrm{B}$ " mixtures).

Charges with a diameter of $42 \mathrm{~mm}$ were pressed from the compounds developed. The B-20SN brand compound was used as the igniter composition. The characteristics of the compounds produced are presented below (the compound B-1 and compound B-2 mixtures cited differ with respect to the percentages of the components contained therein).

\begin{tabular}{ll} 
Compound A mixture & \\
\hline Thermal effect in argon & $1.437 \mathrm{kilocalories} \mathrm{per} \mathrm{gram}$ \\
Gas volume & $14.0 \mathrm{cc} / \mathrm{g}$ \\
Aggregate burning rate & $10 \mathrm{~g} / \mathrm{s}$ \\
Heat input & $14.4 \mathrm{kilocalories} \mathrm{per} \mathrm{second}$ \\
Gas input & $140 \mathrm{cc} / \mathrm{g}$ \\
Compound B-1 mixture & \\
\hline Thermal effect in argon & $0.936 \mathrm{kilocalories} \mathrm{per} \mathrm{gram}$ \\
Gas volume & $50.0 \mathrm{cc} / \mathrm{g}$ \\
Aggregate burning rate & $78 \mathrm{~g} / \mathrm{s}$ \\
Heat input & $73.6 \mathrm{kilocalories} \mathrm{per} \mathrm{second}$ \\
Gas input & $3,930 \mathrm{cc} / \mathrm{g}$ \\
Compound B-2 mixture & \\
\hline Thermal effect in argon & $1.048 \mathrm{kilocalories} \mathrm{per} \mathrm{gram}$ \\
Gas volume & $43.7 \mathrm{cc} / \mathrm{g}$ \\
Aggregate burning rate & $35 \mathrm{~g} / \mathrm{s}$ \\
Heat input & $37.0 \mathrm{kilocalories}$ per second \\
Gas input & $1,540 \mathrm{cc} / \mathrm{g}$
\end{tabular}

These characteristics show that the composition of the mixtures using polytetrafluoroethylene as a base has a heat input 2.5-5.0 times higher than that of the mixture based on thermite. These mixtures were tested on bench generators. The target consisted of plates made from Kh1 $8 \mathrm{NT}$ brand stainless steel with dimensions of $100 \times 100 \mathrm{~mm}$ and with a thickness of 2 to $6 \mathrm{~mm}$, which were set up $50 \mathrm{~mm}$ from the generator nozzle.

The feasibility of using pyrotechnics for cutting was assessed by bench testing a prototype cutting torch (i.e., by means of securing the cutting torch to an assembly jig). The piece of metalwork being cut was secured or was advanced with an electric drive at $3 \mathrm{~mm} / \mathrm{s}$ or faster.

The testing of the thermite cutting technology was carried out on single pipes made from Kh18N10T brand steel with diameters of $57 \times 4$ and $89 \times 6 \mathrm{~mm}$; on tube bundles consisting of three, five, and seven pipes made from Kh18NB10T brand steel with diameters of $25 \times 3$ and $16 \times 3 \mathrm{~mm}$, and with a distance between pipes of 5 to $8 \mathrm{~mm}$; on a pipe made from the D16AT brand aluminum alloy with a diameter of $60 \times 4 \mathrm{~mm}$; and on a pipe made from $35 \mathrm{GS}$ brand rebar steel that was manufactured in accordance with State Standard document number GOST 8479-80 and that had a diameter of $32 \mathrm{~mm}$. 
Over the course of the study and optimization of the thermite cutting technology, the following features were revealed:

1. Unilateral cutting (without changing the position of the cutting torch) can be carried out in the presence of combustion chamber pressures of up to $0.3 \mathrm{MPa}$ (stainless-steel pipes with a diameter of $89 \times 6 \mathrm{~mm}$, a duralumin pipe with a diameter of $60 \times 4 \mathrm{~mm}$, a tube bundle consisting of seven items made from Kh18N10T brand steel with a diameter of $25 \times 3 \mathrm{~mm}$, a plate made from Kh18N10T brand steel with a thickness of $6 \mathrm{~mm}$, and rebars with a diameter of up to $32 \mathrm{~mm}$ were cut under these conditions).

2. The unilateral slitting of a pipe with a diameter of $57 \times 4 \mathrm{~mm}$ is carried out while advancing the pipe at a rate of $12-15 \mathrm{~mm}$ per second, while through slitting is carried out at a rate of advance of $7-8 \mathrm{~mm}$ per second.

3. The metalwork thermite cutting operation can easily be automated and operated by remotecontrol.

4. Large-diameter pipes made from different materials can also be cut using the termite cutting technique. However, it is necessary to comply with one of the following conditions:

- to move the cutting torch along the circumference

- to raise the pressure of the combustion products in the cutting torch's chamber. However, this entails an increase in the consumption of the thermite compound and a decrease in the erosion resistance of the nozzle assembly.

5. Cutting through a concrete block with a thickness of up to $100 \mathrm{~mm}$ is performed within 12-15 seconds.

As a result of the experimental work performed, the following conclusions were reached:

- Almost any metal or nonmetallic material can be subjected to thermite cutting.

- The thermite cutting process can be performed in different attitudes (i.e., without manipulating the articles being cut).

- The thermite cutting technique makes it possible to cut tube bundles when access is only possible from one direction.

- The thermite cutting technique ensures autonomous work performance under conditions of high radioactivity away from electric power, fuel gas, and oxygen supply sources (in the presence of high ionizing radiation dose rate levels).

- The thermite cutting technique is characterized by maneuverability and the small dimensions of its devices, which allows use of the technique in hard-to-reach locations.

- The pyrotechnic cutting torch can be used with automatic and remote-control systems.

Additional research and development is needed to optimize the cutting techniques for NPP unit equipment dismantling. Specific areas to address are the compound formulas, the selection of materials, the refinement of the designs of the nozzle, thermite mixture ignition initiation subassembly, and the cutting torch housing heat-shield coating. In addition, the designs of the cutting torch's housing and holder, the configuration of the thermite charge, the conditions affecting an optimum pyrotechnic compound combustion process, the dynamics of the processes occurring during the cutting of different materials, and the cutting technology itself are in need of additional analysis, as are the implementation of the commercial production of the requisite pyrotechnic 
compound, the manufacture and assembly of the cutting torch, and the development of the regulatory and technical documentation governing the technology for the attendant work.

\subsubsection{The Thermal Gas-Jet Cutting Technique}

The recently developed thermal gas-jet cutting technique is a unique technology for cutting concrete, reinforced-concrete structural elements, and metalwork. This type of thermal cutting is based on domestic experience acquired in the development of rocket engines, a technique for the destruction of materials by means of their exposure to the heat and force of the high temperature supersonic jet formed during the combustion of a hydrocarbon fuel (a mixture of diesel fuel, kerosene, and gasoline) in an oxygen atmosphere, and a design for a reactive oxygen torch that serves as the generator of the high-temperature jet.

The design of the reactive oxygen torch is similar to that of a liquid propellant jet engine combustion chamber. Within the combustion chamber, the combustion process occurs at a pressure of 1.0 1.5 $\mathrm{MPa}$, making it possible to achieve a very high combustion product temperature at the reactive oxygen torch nozzle outlet (some 2,800 to $3,000^{\circ} \mathrm{C}$ ), which also pushes the gas flow far past the speed of sound.

The intense concentrated delivery of heat from the reactive oxygen torch to the surface of the material being destroyed causes this material to melt rapidly. Here, the molten slag formed and the particles stripped from the material are efficiently eliminated from the cutting cavity by virtue of the pressure of the gas jet produced; provided that the torch's holder is inclined at an angle of 35 to $75^{\circ}$ with respect to the surface being destroyed. The low weight and small dimensions of the reactive oxygen torch make it possible to use thermal gas-jet cutters equipped with similar torches in highly constricted areas where other destruction equipment would not work.

The design can be used independently or in conjunction with the other reinforced-concrete demolition technologies. The combined technologies could be used for slotting structural elements to the reinforcement bar depth and the subsequent cutting of the reinforcement bar to facilitate the demolition of the concrete by other methods. An oxygen lance system that is equipped with oxygen powder cutting torches constitutes an analog of the design, as do electroarc melting and plasma cutting units.

The principal technical characteristics of the thermal gas-jet cutting unit are as follows:

Capacity
Cutting process productivity
Torch weight including the
attendant locking devices
Working rod length
Nozzle diameter
Oxygen consumption
Fuel consumption
Cooling water consumption
$0.9-1.2 \mathrm{MW}$

$0.3-0.5 \mathrm{~m}$ cut cross-section per hour

$2.0-2.4 \mathrm{~kg}$

$1-2 \mathrm{~m}$

$25-40 \mathrm{~mm}$

$70-90 \mathrm{~m}^{3}$ per hour

$25-30 \mathrm{~L}$ per hour

$0.3-0.45 \mathrm{~m}^{3}$ per hour 


\subsubsection{The Abrasive Steam Cutting Technique}

An abrasive steam cutter has been developed at the Russian Academy of Sciences' Institute of High Temperatures (Moscow) for cutting concrete structures (the containment shells, reinforced-concrete substructures, and structural elements of NPP units).

The design of the abrasive steam cutter is based on a device that creates a high-velocity jet consisting of steam and an abrasive material (sand, corundum, etc.); orients the high-velocity jet at a specific angle with respect to the surface of the article being cut; and controls the movement of the high-velocity jet with respect to the article being cut. The abrasive steam cutter design allows cuts to be made in the horizontal and vertical planes. It is possible to make irregularly shaped cuts using a special version of this abrasive steam cutter.

The abrasive steam cutter design incorporates a steam source, a vessel for the abrasive material, a batcher, a mixer, and an accelerating nozzle. The abrasive steam cutter package may also include a commercial television unit for remote supervision of the cutting process.

Several modified versions of this cutter are presently being developed: the PAR-01 version, which is designed for permanent installation (this version is connected to an existing steam source), the PAR-02 version, which is a mobile model that makes it possible to undertake the cutting of articles without hooking up to a steam source (in this event, the ranks of the facilities at which the subject process can be used are expanded considerably, for example, such facilities might include construction sites, mine workings for the burial of reactors under a reactor section, etc.), and versions for abrasive steam cutting through the use of a batching agent (steam and air).

The principal technical characteristics of the PAR-01 version of the abrasive steam cutter are as follows:

Dimensions of the article being cut

Cut depth for a single cutter position

Cut length without the repositioning of the cutter

Time required to make a subsurface cut (with a depth and length of $1 \mathrm{~m}$ )

Steam parameters:

- pressure

- temperature

- steam consumption

Cutter weight no limitations

not more than $1,000 \mathrm{~mm}$

no limitations

approximately 20 minutes

$3.5-18.0 \mathrm{MPa}$

$450-550^{\circ} \mathrm{C}$

$5,000 \mathrm{~kg}$ per hour

$700 \mathrm{~kg}$

\subsubsection{The "Heat Shock" Technique for Decontamination and Dismantling Concrete Structural Elements}

The "heat shock" technique for decontamination and dismantling concrete structural elements, which was developed at the Russian Academy of Sciences' Institute of High Temperatures (Moscow), falls into the category of physico-mechanical techniques and makes it possible to undertake the layer-by-layer removal of concrete that has been contaminated by radionuclides. The essence of the "heat shock" technique is the abrupt heat exposure of the surface of the concrete structures or structural elements. The mechanical stresses from an exposure of this type result in the separation 
of the concrete layers. The development of breaking stresses in the concrete is due to the nonuniformity and the transient state of the attendant temperature field and to temperature-related changes in the properties of the concrete, as well as to phase transitions, differences in the ability of the concrete to resist compressive and tensile stresses, etc.

A heat exposure may consist not only of abrupt heating but intense cooling as well. Depending upon the design features and characteristics of the concrete, the "heating-cooling" cycle can be repeated several times.

Heat exposure is accomplished through the use of special sources that operate in accordance with a preset routine and that ensure a heat flow of several MW per square meter. Depending upon the magnitude of the heat flow, the properties of the concrete, and the features of the attendant concrete structural element, the thickness of the concrete layer removed over the course of one or several heat shock exposure cycles can range from 0.3 to $3.0 \mathrm{~mm}$. The time required for the separation of the concrete layer can range from a few tenths of a second to a minute.

A diagram of the proposed technique is presented in Figure 2.26. A utility panel housing the heat sources is installed on the surface being machined through the use of special mounting fixtures. The designs of the panel and heat sources are such that their dimensions can be varied within certain limits as a function of the technology. This same panel can also be employed for cooling the section being machined if necessary, for which normal service water is used. If cooling is not necessary, this service water is then used to clear away the products generated by the demolition process.

To prevent the waste byproducts from spreading throughout the area, special fixtures tightly clamp the panel to the surface being machined and a rarefaction is created in the space between the panel and surface with a fan. During the work, the water containing the disintegrated material proceeds to the settling chamber of the waste collection system, where the separation of the large particles takes place. Next, this water, which now contains a dust suspension, passes through a filter, where the solid particles are removed. The purified water, which possesses a low level of radioactivity, is then discharged into a special storage vessel.

The air that is present during the performance of "heat shock" decontamination and dismantling proceeds to a separator. There, the water and part of the dust contained in this air are removed and sent to a filter. For purification, the air is then passed through a series of coarse and fine filters. Thereafter, the purified air is channeled into the ventilation system with a fan that creates a rarefaction within the work area as a whole.

The proposed technique makes it possible, to a large extent, to speed up concrete removal and can be employed under conditions where other technologies-such as explosive, percussive, and chemical technologies, is inadmissible. The "heat-shock" technique can be used during the decontamination and dismantling of not only the structures and highly radioactive concrete structural elements reactors used in nuclear power engineering and in industry, but also other structures and concrete structural elements that require the layer-by-layer removal of concrete that has been contaminated or has deteriorated.

\subsubsection{Contact Arc Cutting of Structural Elements of Nuclear Reactors}

Another effective technology for dismantling highly radioactive reactor subassemblies and systems is the contact arc cutting technique, which was developed and subjected to extensive practical testing by the Scientific Research Institute of Physical Metallurgy and Heat Treatment (Moscow). The contact arc cutting technique is based on the thermal influence exerted by pulsed arc discharges on 
Figure 2.26. 
the material being machined. The duration of the contact and arc phase of these electric discharges over the course of the machining process is largely determined by the speed of the relative movement of the electrodes (the tool and the part), as well as by the electric power parameters of the power source and the electric circuit. Transformers with a flat voltage-current characteristic and with a capacity of $100 \mathrm{~kW}$ or more serve as the power source.

The contact arc cutting technique is characterized by the exposure of the part being cut to a negligible amount of force, by the possibility of completing the cutting process with a single advancing motion of the tool in the direction of feed, and by the quite acceptable stability of this process in air and in water. The technique is distinguished by a higher arc discharge capacity and a higher rate of cutting than those of the "kindred" processes of the electrospark and electroerosion cutting techniques. The contact arc cutting technique is used to cut almost all structural materials (carbon steel, austenitic steel, and aluminum), as well as combinations thereof within a single structural element.

One of the principal shortcomings of the contact arc cutting technique is that the particles formed during the cutting of activated materials can be propagated in the form of aerosols; thus, any surfaces on which these particles settle become contaminated. This deficiency is weakly manifested during underwater cutting, however, because the surrounding water is broken down by the arc discharges generating a small amount of hydrogen. For this reason, a gas treatment system and active ventilation are required in a number of cases. In addition, although water constitutes an optimum cutting environment, visibility diminishes over the course of the cutting process as a result of contamination by the cutting products formed. This effect must be taken into consideration when developing the cutting equipment.

Various graphites find application in the cutting tools used to perform contact arc cutting. Pyrolytic graphite constitutes the best material for the manufacture of these cutting tools, because it possesses the highest levels of mechanical strength and erosion resistance. However, it is also one of the most expensive of all graphite materials.

Two basic types of tools may be employed-rotary and fixed. Rotary tools have found use in stationary cutting machines such as units for cutting spent fuel assemblies at plants that reprocess spent nuclear fuel. However, the considerable gyrating masses in these cutting devices and the large power losses associated with tool rotation in water limit the use of rotary tools in such applications.

Rotary tools are of no use for cutting structural elements during upgrading and dismantling work. In such instances, graphite electrodes with different configurations are employed, depending upon the specific objectives. Flat graphite electrodes are used for through cutting, while cylindrical or tubular electrodes, as well as electrodes with other geometric shapes, are used for broaching openings.

Depending upon specific objectives, graphite electrodes are reinforced with different structural elements made from metallic materials that melt down in proportion to graphite electrode consumption. In certain cases, the subject metallic structural elements are incorporated into these tools to ensure the delivery of water and the removal of the cutting products generated when cutting is carried out in air. In such instances, the multifunctional structural elements of the tools used (the electrodes) quite often serve a dual purpose--the assurance of mechanical strength and the delivery of water. Here, moving an electrode in the requisite directions and along the requisite trajectories is ensured by the design of the cutting devices that are being developed for specific technologies. 
The contact arc cutting technique is most effective in the following instances:

1. Cutting nuclear reactor structural elements with a gamma activity of more than 100 roentgens per hour that have been placed into the spent fuel cooling ponds of NPP units and that are being stored under the water that is used as a biological shield (in such cases, the subject disposition of structural elements goes well with the advantages of contact cutting under water).

2. Cutting structural elements that have varying thicknesses along the length of the cut, as well as different structural cross-sections and T-section angles, which suggests the practical unsuitability of the use of other cutting techniques.

3. Cutting structural elements in which materials of different types, with different mechanical properties and chemical compositions, have been used.

4. Cutting multilayer and multiwall structural elements, as well as structural elements with an intrinsic hardness that is insufficient for the use of mechanical cutting techniques.

5. Broaching openings with different cross-sections in heavy-walled structural elements.

In addition to the instances noted above, the contact arc cutting technique can be effectively used as an item of technological equipment for remote-controlled systems.

\subsubsection{The Plasma Arc Technique for Dismantling the Structural Elements of Nuclear Reactors}

The basis of the plasma arc cutting technique is that a gas flow is introduced into the torch combustion region simultaneously with the development of an arc between the electrode and the object being cut. Consequently, a high-temperature plasma gas flow is formed in the torch combustion zone. The object being cut melts partially under the influence of the heat of the arc and the heat of the plasma. Here, the resultant molten metal is blown off by a gas jet. One advantage of the plasma arc technique is that the head (tip) of the cutting torch has small dimensions; thus, this technique is recommended for cutting in tight quarters.

A unit for the mechanized plasma cutting of metallic structural elements was developed and underwent successful testing at the Svarka (Welding) Engineering Center of the Orgenergostroy State Institute. The unit can be used to dismantle the metalwork and equipment of various nuclear power engineering and industrial facilities. Using this unit, straight-line cuts can be made in any attitude:

- on flat structural elements

- on cylindrical structural elements of any size along the cylinder axis

- on cylindrical structural elements with a cross-sectional diameter of more than $6,000 \mathrm{~mm}$.

An automatic head and a plasmotron move along a rack that has been installed in any position on the article with magnetic suction cups. The length of this rack is not limited, rather it is determined by the number of rack components assembled. The unit can be remote-controlled.

The makeup of the unit developed includes a plasmotron of the PRV-402 type, a tractor-type automatic head, a set of guide rack components, a plasma arc power source, and a control apparatus. The principal technical characteristics of the unit developed are as follows:

Rate of cutting

Thickness of the metal being cut

Nominal cutting process operating current No-load voltage
$2-50 \mathrm{~m} / \mathrm{hr}$ up to $200 \mathrm{~mm}$

up to 600 amperes

$300 \mathrm{~V}$ 


$\begin{array}{ll}\begin{array}{l}\text { Nominal cutting process operating voltage } \\ \text { Nominal power consumption }\end{array} & 300 \mathrm{~V} \\ \begin{array}{l}\text { Overall dimensions } \\ \text { - of the automatic head }\end{array} & 180 \mathrm{~kW} \\ \text { - of a guide component } & 440 \times 480 \times 222 \mathrm{~mm} \\ \text { - of the control apparatus } & 2,010 \times 320 \times 75 \mathrm{~mm} \\ \text { - of the power source } & 530 \times 245 \times 234 \mathrm{~mm} \\ \text { Design component weight } & 2,150 \times 1,550 \times 1,750 \mathrm{~mm} \\ \text { - of the automatic head } & \\ \text { - of a guide component } & 22 \mathrm{~kg} \\ \text { - of the control apparatus } & 23 \mathrm{~kg} \\ \text { - of the power source } & 21 \mathrm{~kg} \\ \text { Plasma - forming gas } & 2,600 \mathrm{~kg} \\ \text { Plasmotron cooling working environment } & \text { oxygen } \\ & \text { water }\end{array}$

\subsubsection{Technology for Nuclear Reactor Entombment}

At the Mining Institute of the Russian Academy of Sciences' Kola Research Center, a technology has been developed for the burial of NPP unit reactors by the gradual transfer of the reactors to a burial site at the requisite depth beneath the reactor section. This technology makes it possible to transfer a decommissioned nuclear reactor, together with its concrete reactor well, to a burial site without cutting the reactor well and the reactor internals into components, thereby almost totally eliminating personnel contact with the highly radioactive equipment.

In principle, the technique is suitable for burial of NPP reactors of the VVER, RBMK, and BN types, as well as others. The technique is based on the experience acquired in drilling deep wells. This technique was developed for the construction of underground NPPs.

The principles of creating a hydraulic engineering structure sluice serve as the basis of the burial technology. One distinctive feature is a free-flowing medium used as the working environment for sinking the reactor. This free-flowing medium is formed by loosening the soil beneath the reactor within the transfer channel. To create this transfer channel, a series of underground headings is fashioned in the soil beneath the reactor, forming a burial chamber with the required buttressing and waterproofing at the requisite depth. Following the completion of the preparatory work in which the reactor, together with its concrete well, is separated from the adjoining structural elements of the primary-circuit equipment and the associated piping is sealed with plugs, the structure is lowered and brought into contact with the loose rock medium underneath the substructure using a special technology.

Thereafter, the loose rock is released through specially prepared orifices located in the bottom of the burial chamber. The released rock is shifted upward and is backfilled over the nuclear reactor. Here, the reactor transfer channel is kept constantly filled. Following the sinking of the reactor into the burial ground, the reactor pressure vessel is coated with an insulating, heat-conducting compound. The burial ground is subsequently isolated and monitoring of its status is begun.

The proposed technology provides for the temporary diversion of water during the traversal of the attendant water-bearing strata, as well as the full reestablishment of the preexisting hydrosystem following the sinking and burial of the reactor. 
The specialized technology for bringing the underlying soil to a free-flowing state ensures the accurate centering of the reactor and its sinking without any deviations from the axis of the transfer channel. The effectiveness of this technology has been proven by numerous experiments conducted on a large-scale bench model for studying the release of free-flowing media.

The proposed technology can be used both in hard rocky soil and in soft sedimentary rock masses. A reactor sinking rate of $10 \mathrm{~m}$ per day can be achieved if necessary. Preparing the transfer channel and burial site for the sinking of a reactor takes no longer than one year.

The technology has been patented in Russia and ensures the sinking of the structures being buried without any deviations, thereby totally eliminating the possibility of these structures becoming wedged within the transfer channel. Here, the size and weight of the structures sunk using the technology described is of no fundamental importance. 


\subsection{U.S. Experience With Decommissioning Nuclear Power Reactors}

\subsection{Introduction}

Major commercial power production using nuclear reactors began in the United States when the Shippingport facility came on line in 1957. The nuclear power industry expanded significantly over the next 25 years; there are now 109 commercial nuclear power plants at 71 sites. In addition, test facilities such as the Experimental Boiling Water Reactor (EBWR) and the Experimental Breeder Reactor II (EBRII) have been used to produce small amounts of electrical power as a subsidiary operation.

Shippingport was shut down in 1982, as planned, then fully decommissioned to green field status. Economic, technical, and other considerations have forced the licensees of several of the other facilities to permanently cease operation of their nuclear plants, in most cases before their operating licenses were due to expire. Thus, these facilities and several others have entered the decommissioning process earlier than originally anticipated. Some basic information and the present status of 25 shutdown power reactors are summarized in Table 3.1.

\subsection{Regulation of Decommissioning of Nuclear Power Plants}

This report is not intended to provide a detailed evaluation of the regulations that apply when considering decommissioning a nuclear power plant. However, some description of the basic elements is beneficial so that the regulatory framework surrounding decommissioning can be appreciated.

All nuclear-related aspects of the design, construction, licensing, operation, and decommissioning of commercial nuclear power plants are regulated by the U.S. Nuclear Regulatory Commission (NRC). These regulations are to be found in Chapter 1 in Title 10 ("Energy") of the Code of Federal Regulations (10 CFR). Section 50.2 of Part 50 (10 CFR 50.2) defines decommissioning as "to remove (a facility) safely from service and reduce residual radioactivity to a level that permits release of the property for unrestricted use and termination of license."

In the U.S., decommissioning of nuclear power plants involves consideration of three alternatives, known by the acronyms DECON, SAFSTOR, or ENTOMB. These are defined as follows:

DECON The equipment, structures, and portions of the facility and site containing radioactive contaminants are removed or decontaminated to a level that permits the property to be released for unrestricted use shortly after cessation of operations.

SAFSTOR The nuclear facility is placed and maintained in a condition that allows it to be safely stored and subsequently decontaminated (deferred decontamination) to levels that permit release for unrestricted use. SAFSTOR usually involves three phases: Custodial (layup), Passive, and Hardened. SAFSTOR alone is not an acceptable decommissioning mode; it must be followed by decontamination to unrestricted use.

ENTOMB Radioactive contaminants are encased in a structurally long-lived material such as concrete, after which the entombed structure is appropriately maintained and continued surveillance is carried out until the radioactivity decays to a level permitting unrestricted release of the property.

Whichever method is selected, decommissioning must be completed within 60 years of plant shutdown. This, in effect, determines the length of time in which a plant may be in SAFSTOR until 
Table 3.1. Decommissioning Status of Shutdown Power Reactors

\begin{tabular}{|c|c|c|c|c|c|}
\hline Reactor & Type $^{(a)}$ & $\begin{array}{c}\text { Power, MW } \\
\text { (thermal/electric) }\end{array}$ & Location & $\begin{array}{l}\text { Operational } \\
\text { Life }\end{array}$ & Present Status \\
\hline Argonne EBWR & BWR & $20 / 5$ & Lemont, IL & $12 / 56-10 / 67$ & DECON \\
\hline Shippingport & PWR & $238 / 72$ & Shippingport, PA & $10 / 57-10 / 82$ & Decommissioned \\
\hline Vallecitos VBWR & BWR & $50 / 5$ & Pleasanton, CA & $10 / 57-12 / 63$ & SAFSTOR \\
\hline Santa Susana SRE & LMCGM & $20 / 6$ & Santa Susana, CA & $5 / 58-5 / 66$ & Decommissioned \\
\hline Dresden Unit 1 & BWR & $680 / 210$ & Morris, $\mathbb{I L}$ & $8 / 60-10 / 78$ & SAFSTOR \\
\hline Yankee Rowe & PWR & $600 / 185$ & Franklin, MA & $7 / 61-10 / 91$ & SAFSTOR/DECON \\
\hline Saxton & PWR & $24 / 3$ & Saxton, PA & $5 / 62-1 / 72$ & SAFSTOR/DECON \\
\hline Indian Point Unit 1 & PWR & $615 / 275$ & Buchanan, NY & $10 / 62-10 / 74$ & SAFSTOR \\
\hline Hallam & LMCGM & $256 / 80$ & Hallam, NE & $12 / 62-9 / 64$ & ENTOMB \\
\hline Humboldt Bay Unit 3 & BWR & $210 / 65$ & Eureka, CA & $8 / 63-7 / 76$ & SAFSTTOR \\
\hline Piqua & OCMR & $46 / 11$ & Piqua, $\mathrm{OH}$ & $1 / 64-2 / 66$ & ENTOMB \\
\hline $\begin{array}{l}\text { Carolinas-Virginia } \\
\text { Tube Reactor }\end{array}$ & PTHW & $65 / 17$ & Parr, SC & $2 / 64-2 / 67$ & SAFSTOR \\
\hline Elk River & BWR & $58 / 22$ & Elk River, MN & $7 / 64-1 / 68$ & Decommissioned \\
\hline Pathfinder & BWR & $190 / 66$ & Sioux Falls, SD & $7 / 66-9 / 67$ & Decommissioned \\
\hline Vallecitos EVSR & BWR & $17 /$ & Pleasanton, CA & $12 / 64-2 / 67$ & SAFSTOR \\
\hline $\begin{array}{l}\text { Boiling Nuclear } \\
\text { Superheater (BONUS) }\end{array}$ & BWR & $50 / 17$ & $\begin{array}{l}\text { Punta Higuera, } \\
\text { Puerto Rico }\end{array}$ & $8 / 65-7 / 67$ & ENTOMB \\
\hline Fermi Unit 1 & LMFBR & $200 / 61$ & Monroe, MI & $12 / 65-9 / 72$ & SAFSTOR \\
\hline Peach Bottom Unit 1 & HTGR & $115 / 42$ & York, PA & $5 / 67-10 / 74$ & SAFSTOR \\
\hline San Onofre Unit 1 & PWR & $1347 / 460$ & San Clemente, CA & $1 / 68-11 / 92$ & SAFSTOR \\
\hline La Crosse & BWR & $165 / 55$ & La Crosse, WI & $11 / 69-4 / 87$ & SAFSTOR \\
\hline Fort St. Vrain & HTGR & $842 / 330$ & Platteville, CO & $1 / 77-8 / 89$ & DECON \\
\hline Rancho Seco & PWR & $2772 / 883$ & Sacramento, CA & $1 / 75-6 / 89$ & SAFSTOR \\
\hline Trojan & PWR & $3423 / 1178$ & Portland, OR & $12 / 75-11 / 92$ & Possession Only Lic. \\
\hline $\begin{array}{l}\text { Three Mile Island } \\
\text { Unit } 2\end{array}$ & PWR & $2772 / 956$ & Middletown, PA & $12 / 78-3 / 79$ & Monitored storage \\
\hline Shoreham & BWR & $2436 / 849$ & Shoreham, NY & N.O. (b) & Decommissioned \\
\hline
\end{tabular}

(a)BWR - boiling water reactor; PWR - pressurized water reactor; LMCGM - liquid-metal-(sodium)-cooled graphitemoderated reactor; OCMR - organic cooled and moderated reactor; PTHW - pressure tube, heavy water moderated reactor; HTGR - high-temperature gas-cooled reactor; LMFBR - liquid metal (Na) fast breeder reactor.

(b)Never fully operational; operated briefly at low (under 5\%) power before shutdown in June 1989.

entering the deferred DECON phase. If a method is proposed that involves completion of decommissioning beyond 60 years, it will only be given consideration if it can be demonstrated that it is essential to protect public health and safety in accordance with NRC regulations.

The principal regulatory procedures for decommissioning a nuclear plant are delineated in several sections of $10 \mathrm{CFR}$. These include, but are not restricted to: 


\subsection{1 - 20.1408, "Radiological Criteria for Decommissioning" \\ 50.75, "Reporting and Recordkeeping for Decommissioning Planning" \\ 50.82, "Application for Termination of License" \\ 51.53, "Postconstruction Environmental Reports" \\ 51.95, "Postconstruction Environmental Impact Statements."}

Other relevant regulations can be found in 10 CFR 40, "Domestic Licensing of Source Material," 10 CFR 61, "Licensing Requirements for Land Disposal of Radioactive Waste," 10 CFR 71, "Packaging and Transportation of Radioactive Material," and 10 CFR 72, "Licensing Requirements for the Independent Storage of Spent Nuclear Fuel and High-Level Radioactive Waste." Because some of the legislation is relatively recent, rules that apply to the decommissioning of plants shut down before 1998 are slightly different from those that ceased operation in later years.

In addition to those regulations contained in Title 10, others of relevance can be found in Titles 29, "Labor"; 40, "Protection of Environment"; and 49, "Transportation." Individual states are likely to have their own regulations and demand, at the very minimum, consultation regarding decommissioning plans. For example, the State of Oregon performed its own independent analysis of the decommissioning plan for the Trojan nuclear power plant.

The NRC, in a 1996 Technical Issues paper, presents an overview of the regulations and regulatory activities associated with decommissioning nuclear power plants. The paper addresses, among other items, the need to provide a decommissioning plan in a timely manner. If a plant is currently operating, a preliminary plan should be submitted to the NRC five years before operations are planned to cease. Thereafter, authority to perform the decommissioning should be requested within one year of the expiration of the operating license. The application for this authority must be accompanied, or preceded, by the proposed decommissioning plan. The plan should include a description of the decommissioning alternative chosen and the activities involved, a financial plan, and an environmental report. If, after reviewing the plan, the NRC finds it to be satisfactory, it can issue a decommissioning order and authorize decommissioning. License termination follows after completion of the decommissioning activities and the termination radiation survey. The NRC has also issued guidance regarding activities, such as the removal of large components, that may be permitted before the decommissioning plan receives final approval.

\subsection{Individual Plant Decommissioning Experience}

Table 3.1 is a list of 25 civilian nuclear power reactors that have ceased operation and been decommissioned to various stages. The types of reactors used at these facilities are representative of the spectrum of designs employed or investigated for nuclear power production in the U.S. and encompass both experimental and commercial facilities. Thus decommissioning has involved pressurized water reactors (PWR), boiling water reactors (BWR), liquid-metal-cooled reactors, and gas-cooled reactors. Information on some of those reactors are given in the following subsections, including one on the activities at Three Mile Island Unit 2, although it is recognized that this represents an exceptional decommissioning project. Decommissioning experience at Hallam, Santa Susana SRE, Fort St. Vrain, and Peach Bottom Unit 1 is contained in a separate report on U.S. experience with graphite-moderated reactors. 


\subsubsection{Argonne Experimental Boiling Water Reactor}

The Argonne Experimental Boiling Water Reactor (EBWR) was a prototype facility that began operation in 1956 as a $20 \mathrm{MWt} / 5 \mathrm{MWe}$ unit. It later ran for short periods at up to $70 \mathrm{MWt}$ then was upgraded for operation at up to $100 \mathrm{MWt}$. The plant was shut down in early 1967, defueled, then placed in what was termed "dry layup" (SAFSTOR). Final decommissioning began in 1986 and was completed in 1996.

The first major activity in the final decommissioning stage was the removal of asbestos. Lack of consideration of this action in the original design of the plant led to the need for significant time being spent in preparation (erecting temporary floors, setting up equipment, etc.) due to the many different piping configurations present. It was estimated that preparation time consumed about $80 \%$ of the total time involved in removing the asbestos. In the end, a total of $\sim 74 \mathrm{~m}^{3}$ of asbestos was removed, of which only $1 \mathrm{~m}^{3}$ was radioactively contaminated.

The second phase comprised the removal of primary and secondary system components. The piping system had been subjected to some decontamination at the time of the shutdown in 1967, and piping scale samples consequently showed minimal loose or transferable contamination in 1986. Thus a major decontamination effort for these components was not thought to be justified on a cost basis and only a minor action using wet wipes was performed. However, larger equipment items (condensers, etc.) required a more comprehensive decontamination procedure.

Removal of the reactor internals began in late 1989 and was completed in 1993. Preparation for this phase required the construction of several new systems, including a waste filtration and transfer system and a HEPA filter system. In addition, a mockup of the reactor internals was fabricated and numerous work tables and platforms erected. The reactor internals were removed from the vessel and the majority of the segmenting and packaging work carried out in the refilled spent fuel pool. This included cutting with underwater plasma arcs, cutoff wheels, guillotine saw, and other tools. Size reduction was emphasized to ensure minimization of wastes.

With completion of the removal and packaging of the reactor internals, work began on removal and size reduction of the thermal shield, the bottom shield plug, the control thimbles, control rod bottom guidelines, and miscellaneous nozzles. The reactor pressure vessel (RPV) was lifted from the reactor cavity using an " $\mathrm{A}$ " frame and hoist and segmented with an abrasive water jet system. Prior to this project this type of system had been effective in cutting concrete, aluminum, and steel components but had never been used to segment an RPV. The system incorporated garnet, aluminum oxide, and iron filings as abrasives and operated at a pressure of $241 \mathrm{MPa}$ (35 ksi).

The final phase of dismantling involved removal of the carbon steel reactor cavity liner and the lead brick shielding, followed by decontamination of the remaining structures (cavity, fuel pool, shell), then removal of the activated concrete.

\subsubsection{Shippingport Atomic Power Station}

Shippingport, the first large-scale commercial nuclear power plant in the United States, began operation in December 1957 and was shut down in October 1982 after producing over 7.4 billion $\mathrm{kW}$ hours of electricity ( $841 \mathrm{MWe}$-years). The project was a cooperative venture between the U.S. government and the commercial industry. It was located about 25 miles northwest of Pittsburgh, Pennsylvania, on land leased from the Duquesne Lighting Company by the U.S. Atomic Energy Commission (AEC) (later the Department of Energy [DOE]) for 40 years. Importantly, the 1954 Memorandum of Understanding that documented the lease also required the U.S. government to 
return the land to the utility company in a condition free from radioactivity at the end of the lease period. Thus the only decommissioning option available when the reactor was shut down was prompt dismantlement.

The reactor was a four-loop PWR, with the nuclear steam supply system and the associated waste processing system owned by DOE and the turbine generator and balance of plant by Duquesne. The RPV and neutron shield tank (NST) were located in the reactor containment vault; the steam generators (SGs) and auxiliary equipment resided in three separate vaults. Two of the vaults, the boiler chambers, each contained two of the four coolant loops; a concrete wall separated the loops to reduce radiation levels when one of the loops was undergoing maintenance. Other units in the reactor complex included the fuel handling building and refueling canal, a radioactive waste processing facility, a heat dissipation system, and numerous storage tanks.

The decommissioning of Shippingport was a two-phase project. The first phase, performed by DOE with the assistance of three subcontractors (UNC Nuclear Industries, Burns and Roe Industrial Services Corporation, and Nuclear Engineering Services, Inc.), was completed in September 1983 with the issuance of the detailed engineering decommissioning plan. The second phase, involving decommissioning operations, was started in March 1984 with the General Electric Company as the DOE's Decommissioning Operations Contractor and Morrison Knudsen-Ferguson as the integrated subcontractor. Actual physical activities were initiated in September 1985, and the site was released for unrestricted use in September 1989, and formally returned to Duquesne three months later. The project was completed six months ahead of schedule and $\$ 7 \mathrm{M}$ under the budget of $\$ 98.3 \mathrm{M}$. Additionally, though it was initially estimated that the project would result in a radiation exposure of 1007 man-rem, the actual man-rem of exposure turned out to be 155, attributed mainly to the use of good ALARA practices.

Radiation surveys of the primary coolant system and reactor containment indicated relatively low levels, generally on the order of $100 \mathrm{mR} / \mathrm{h}$ or less but with some readings greater than $200 \mathrm{mR} / \mathrm{h}$. Consequently, it was concluded that gross reactor system decontamination was not required.

A unique aspect of the decommissioning was the decision to remove the RPV/NST in one piece. The RPV was $\sim 3.3 \mathrm{~m}(10 \mathrm{ft})$ in diameter and $\sim 10.3 \mathrm{~m}(31 \mathrm{ft})$ long with the head installed. It weighed $\sim 335$ tonnes $(370 \mathrm{t})$ and contained $\sim 16000 \mathrm{Ci}$ of radioactivity, mainly ${ }^{55} \mathrm{Fe}$ and ${ }^{60} \mathrm{Co}$. The NST, which supported the RPV and surrounded its lower two-thirds, was $\sim 5.4 \mathrm{~m}(17.7 \mathrm{ft})$ in diameter and weighed $\sim 64$ tonnes $(71 \mathrm{t})$. Compared with segmentation, one-piece removal was the safest, most cost-effective method of dismantling. It was also pointed out that the RPV/NST as a single unit was similar in size to the RPV of a much larger (1100 MWe) plant, and that the experience gained would be relevant to the decommissioning of the generally larger commercial plants.

Shipment of the RPV/NST unit to its final disposal site at Hanford, Washington, was by barge, its physical size precluding the use of rail transport. Before shipment, the non-fuel-bearing core components that had been removed during defueling were reinserted in the reactor cavity, thus taking advantage of the available void space. Non-shrink grout was then poured into the cavity to provide structural rigidity and fix the radioactive contamination on the inside surfaces. Grout fill was also introduced into the NST and into the annular air space between the NST and the RPV. Lifting and handling of the unit was facilitated by the installation of a lifting beam and skirt over the reactor head and the top of the RPV, thus forming part of the containment boundary. Space in the region between the beam/skirt and the vessel/head structures was filled with grout, again to provide structural rigidity and radiation shielding. The overall size of the final RPV shipping package was 
$\sim 5.5 \mathrm{~m}(18 \mathrm{ft})$ in diameter by $\sim 12.7 \mathrm{~m}(41.2 \mathrm{ft})$ in length. The gross weight was $\sim 907$ tonnes $(1000 \mathrm{t})$. The surface contact radiation exposure rate was $\sim 2 \mathrm{mrem} / \mathrm{h}$.

The decontamination methods used at the plant were designed to establish a safe working environment, meet the site release criteria (total dose to the maximum exposed individual not to exceed $1 \mathrm{mSv} / \mathrm{y}$ ) and low specific activity shipping limits, and prepare material for unconditional release. The principal methods used for external surface decontamination were scabbling (for the concrete structures) and abrasive vacuum blasting and manual methods (for painted steel structures). In some instances (e.g., the RPV head) loose contamination was fixed in place with paint using a remotely operated spray gun. Decontamination of the inside surfaces of certain equipment (tanks, pressurizer, embedded piping) was mostly performed using hydrolasing and manual techniques to remove spot contamination. Dismantlement of components made use of techniques of existing techniques (e.g., remote mechanical and plasma arc cutting) that had been used successfully in the maintenance and modification of the plant during its operating lifetime. Volume reduction of solids was accomplished using an hydraulic compactor with a reduction capacity of up to 10:1.

Decommissioning of the Shippingport facility generated a total radioactive waste volume of $\sim 8,200 \mathrm{~m}^{3}, 25 \%$ of which was liquid waste with an activity of $0.64 \mathrm{Ci}$. The total activity of the solid wastes was $16,608.75 \mathrm{Ci}, 16,467$ of which was contained in the RPV package. The volume of the RPV package was a relatively small $283 \mathrm{~m}^{3}$; the largest identifiable contributors to the solid radioactive waste stream were asbestos $\left(1072 \mathrm{~m}^{3}\right)$ and metallic waste $\left(1801 \mathrm{~m}^{3}\right)$. The rest of this waste stream comprised spent resins, solidified sludge, concrete, lead, soil, compacted trash, large onepiece components, and $2,123 \mathrm{~m}^{3}$ of "other solids."

The Shippingport decommissioning project also provided the industry with a series of management "lessons learned" that it was hoped. would contribute to the success of future projects:

- establish a clear understanding of the site release criteria

- allow adequate lead time for the development of a detailed decommissioning plan

- conduct a cost-effective radiological site characterization program

- schedule a realistic learning period for each major work activity

- enforce procedure compliance and maintain an aggressive industrial safety program.

\subsubsection{Dresden Unit 1}

The Dresden Nuclear Power Station is located about 50 miles southwest of Chicago, Illinois, and comprises three power units. Unit 1 was the first full-scale privately financed nuclear plant in the United States, and its BWR was rated initially at $180 \mathrm{MWe}$, later uprated to $210 \mathrm{MWe}$. It began commercial power operation in August 1960 and generated 1,800 MWe-years of electricity until shut down in October 1978. The shutdown was initially to refuel, to make system modifications to meet new federal regulations, and to perform chemical decontamination of major piping systems. Later, following the accident at Three Mile Island Unit 2, additional compliance requirements were imposed, requiring significant investment in new modifications. The utility concluded that, based on the size of the unit and its age, the investment was not justifiable on economic grounds, and announced in August 1984 that it was retiring Unit 1. The operating license was amended to a possession-only status in July 1986. The subsequent decommissioning plan, based on the SAFSTOR option, was approved in September 1993. The utility intends to keep Unit 1 in a SAFSTOR condition until Units 2 and 3 are ready for decommissioning, possibly beginning in 2017. 
Dresden Unit 1 was defueled in 1978 and all the fuel assemblies discharged to the pool. The intent is to leave these assemblies in the pool, together with assemblies discharged earlier, while alternative storage options are pursued.

The bulk of the internal contamination in the primary system has been removed by chemical decontamination, and the system itself has been drained. Water, of course, remains in the fuel pool and is monitored on a regular basis. In addition, a baseline radiological survey has been completed, and radiological surveys are conducted quarterly.

Dresden experienced a significant problem during SAFSTOR when, in January 1994, about 55,000 gallons of water were discovered in the containment building. The water was found to have come from a service water line that had frozen and ruptured within the unheated containment building. A subsequent NRC inspection team concluded that the cause lay in the utility management's failure to maintain the required systems and staffing of Unit 1 in accordance with their decommissioning plan. In addition to imposing a fine on the utility, the NRC followed up with a review of the likelihood of similar events occurring at other permanently shutdown facilities and issued a bulletin that, among.other items, requested that actions be taken to ensure that the cooling and shielding for fuel in the spent fuel pool were not compromised.

Although final decommissioning of Dresden Unit 1 has yet to be performed, projections exist of the amount and characteristics of the radioactive waste likely to be generated. When the reactor was shut down in 1978, it was estimated that the activity in the RPV and internals was $\sim 4 \mathrm{MCi}$. If dismantling of the reactor does not occur until 2017 , this activity should drop to $\sim 16 \mathrm{kCi}$. This will be contained in a volume of $259 \mathrm{~m}^{3}$ which will constitute a very minor part of the total volume of waste generated, greater then $7500 \mathrm{~m}^{3}$, most of which will be of very low activity.

\subsubsection{Yankee Rowe}

The Yankee Atomic Electric Company began operating its nuclear power station at Rowe, Massachusetts, in July 1961 . The 185-MWe PWR subsequently operated at an average capacity factor of $74 \%$ until concerns about reactor vessel integrity stopped power operations in February 1992 . The decommissioning plan was submitted to the NRC in December 1993 and approved in February 1995.

The decommissioning plan indicated that the facility would remain in SAFSTOR until the year 2000 , then it would enter the DECON stage with dismantlement continuing through 2002. In the interim a dry cask spent fuel storage facility would be constructed and loaded with spent fuel. Subsequent shipment of spent fuel would continue through 2018, after which the DECON would be completed and the site released for unrestricted use.

The first phase of the decommissioning plan was the component removal project. This was initiated in 1993 following the issue of the NRC Staff Requirements Memorandum on implementing decommissioning activities before the decommissioning plan was approved. Activities in this phase included component asbestos removal; shield tank cavity modifications; removal and shipment of the four SGs and pressurizer, reactor coolant pumps and, contaminated piping; and the segmentation, packaging, and shipment of the reactor internals.

The asbestos removal program, which was confined to those components to be taken out and shipped, was both time- and exposure-intensive and resulted in a total exposure of about 73 personrem. This significant reduction from the initial estimate (about 149 person-rem) was attributed in part to the learning curve as the program progressed through the four SGs. 
The design of the plant included shielding installed for maintenance activities. Additional shielding was installed after plant shutdown to lessen radiation exposure to workers during the dismantling project. Actual dismantling of the SGs involved cuts in the hot and cold leg piping using automatic mechanical cutters, after which the SGs and the pressurizer were removed from the containment. Prior to shipment offsite for disposal; the SGs were filled with grout to fix internal contamination and steel shielding attached so that the transportation dose rate criteria could be met. It was estimated that each SG had an activity of $\sim 325 \mathrm{Ci}$. Shipment of the SGs to the Barnwell, South Carolina, low-level radioactive waste disposal site took place at the end of 1994; the reactor coolant pumps and contaminated piping were shipped in June 1994.

The procedures for dismantling the SGs were tested beforehand using a SG mockup to familiarize the workers with field operations and, ultimately, reduce radiation exposures. Further dose reductions were achieved by keeping the secondary side filled with water as long as practical. Measurements of the dose rates at various points on an SG disclosed that, on average, the rates were $75 \%$ less when the secondary side was filled with water after it had been drained. The actual total dose for the SG removal operation was about 50 person-rem, significantly lower than the initial estimate of 72 person-rem.

The reactor vessel internals, estimated to contain over $1 \mathrm{MCi}$ of radioactivity, were segmented entirely under water using a plasma cutting torch. The lower-activity material was put into casks and shipped offsite for disposal. However, the core baffle; which contains most of the total activity, was cut up and stored on site as greater than Class $\mathrm{C}$ material.

The removal, packaging, and shipment of the reactor internals was completed in June 1994, after which activity began on removing the 150 tonnes ( $165 \mathrm{t}$ ) RPV. This was accomplished by lowering the RPV through the equipment hatch into a specially designed shipping container where it will remain until being shipped offsite for disposal.

Decommissioning of Yankee Rowe is incomplete at this time, but it is projected that the cumulative radioactive waste volume (excluding the spent fuel) will amount to more than $3850 \mathrm{~m}^{3}$ and activity of $\sim 1.16 \mathrm{MCi}$. The core baffle alone contains $\sim 1.02 \mathrm{MCi}$ but is an insignificant part $\left(2.1 \mathrm{~m}^{3}\right)$ of the total volume of waste. Half of the total volume of waste is made up of very low-activity general plant inventory.

\subsubsection{Saxton Nuclear Experimental Reactor}

The Saxton Nuclear Experimental Reactor, located in Saxton, Pennsylvania, was a 3-MWe PWR that began operating in May 1962. It ceased operation at the start of 1972 after generating $\sim 10.4$ MWe-years of electricity. The reactor was placed in SAFSTOR at that time and remained so until the DECON phase was initiated in 1986. Decontamination and demolition of all structures except the containment structure was completed in 1992. Decommissioning of the latter structure and restoration of the site for unrestricted use is scheduled for completion in 2000. To date, $\sim 450 \mathrm{~m}^{3}$ of radioactive waste has been generated from dismantling the reactor.

\subsubsection{Indian Point Unit 1}

Indian Point Unit 1, a 275-MWe PWR, began operation in October 1962. It generated 1440 Mweyears of electricity before being shut down permanently in October 1974 because the emergency core cooling system did not meet regulatory requirements. The reactor was defueled in 1976 and a proposed decommissioning plan submitted to the NRC in October 1980. Following extensive review by the NRC, a revised decommissioning plan was submitted. 
The reactor is currently in SAFSTOR until Unit 2 reaches the end of its projected operating life in 2013. Both units will be decommissioned at that time. It is estimated that dismantling Unit 1 will generate $\sim 11,800 \mathrm{~m}^{3}$ of radioactive waste. Total activity in the RPV and internals at that time will be $\sim 25 \mathrm{kCi}$.

\subsubsection{Humboldt Bay Power Plant Unit 3}

Unit 3 at the Humboldt Bay power plant was the only nuclear-powered unit at the site, the other two being natural gas-fired plants. Unit 3 was a 65-MWe BWR that began operation in August 1963. It generated a total of $545 \mathrm{MWe}$-years of electrical energy before being shut down in July 1976. Closure took place because the utility decided that it could not justify the economics of performing a retrofit to accommodate seismic concerns. The decommissioning plan, submitted to the NRC in July 1984 and approved in July 1988, proposed the SAFSTOR option for 30 years, then DECON in 2018.

The spent nuclear fuel has been removed from the reactor and placed in the spent fuel pool. The original intent was for the fuel to remain in the pool until a federal repository is opened. Concerns about potential seismic activity affecting the storage pool have led to consideration of transferring the fuel to dry cask storage. Early estimates of the total radioactive waste volume likely to be generated when Unit 3 is finally dismantled indicated $\sim 3000 \mathrm{~m}^{3}$, but later estimates revised this down to $\sim 1575 \mathrm{~m}^{3}$.

\subsubsection{Elk River Reactor}

The Elk River Reactor was similar to the Shippingport project in that it was a joint venture between the AEC and a commercial utility, in this case, United Power Association (UPA) of Elk River, Minnesota. The reactor was owned by the AEC and built on land leased to them by UPA, which operated the plant. It was a 22-MWe BWR that began power operations in July 1964 and produced 58 MWe-years of energy until it was shut down in January 1968. At that point, the contract that UPA had with the AEC to operate the plant expired, and the utility declined an option to purchase the plant. Under the terms of the contract and a later modification, the AEC was obligated to dismantle the reactor and make the site suitable for unrestricted use. Physical dismantling began in 1972 and was completed by August 1974.

The dismantling of the Elk River Reactor was divided into several major tasks. Estimates made of the radioactive inventory of the components within the biological shield indicated that the total activity would be on the order of $10 \mathrm{kCi}$, of which $7.7 \mathrm{kCi}$ were contained in the inner thermal shields, the shadow shields, and the core and shroud plate. The maximum contact radiation level was $8000 \mathrm{R} / \mathrm{h}$ in the core and shroud plate, and maximum levels of $3000 \mathrm{R} / \mathrm{h}$ and $2800 \mathrm{R} / \mathrm{h}$ were calculated for the shadow shields and the upper shroud, respectively. This information was incorporated into the design of the dismantling program and the amounts and location of shielding required to minimize worker exposure during those activities, including the packaging and transportation of the radioactive waste generated.

The removal of noncontamination or low-contamination systems was accomplished using conventional techniques. The removal of the more highly radioactive components such as the reactor internals required long-handled special purpose tools similar to those in use at many reactor installations. These included a remotely operated hydraulic bolt shearer, long-handled socket wrenches, and an air-operated impact wrench. 
A remotely operated plasma arc torch was used to segment the inner thermal shield (under water) and the RPV (in air). A hand-held plasma arc cutting torch was used to segment the steam baffle. Segmentation of the outer thermal shield, which basically consisted of a lead annulus sandwiched between two carbon steel plates, was performed with an oxyacetylene torch to avoid significant lead vaporization. This particular task was the most complex of the segmenting operations and involved approximately 300 cuts of six different types.

The reinforced concrete biological shield was removed with a controlled explosive blasting technique. The decision to use this technique was made after other methods of concrete removal (core boring and rock-jacking, flame cutting, thermic lancing) had been reviewed and an explosives testing program had been conducted. The latter indicated that airborne contamination could be contained and that no significant vibrations would be generated if the maximum charge per detonation was limited. (The vibration concern arose because of potential interference with the operation of the UPA fossil-fired steam plant located at the same facility.)

Personnel exposures were controlled and monitored throughout all aspects of the dismantling operation. It was estimated that the average whole-body exposure for the approximately 100 people involved was $\sim 0.8 \mathrm{rem}$. The maximum dose received by any one individual was $4.5 \mathrm{rem}$. Most of the total exposure was accumulated during the removal of the RPV and the outer thermal shield and amounted to $\sim 45$ rem.

Dismantling of the Elk River Reactor generated $\sim 3377 \mathrm{~m}^{3}$ of radioactive waste, $99.5 \%$ of which was low-activity (contaminated concrete and miscellaneous other contaminated materials). The total activity of the waste generated was more than $10.3 \mathrm{kCi}$. Of this, $8.77 \mathrm{kCi}$ were contributed by the reactor internals and $1.1 \mathrm{kCi}$ by the RPV.

\subsubsection{Pathfinder Atomic Power Plant}

The Pathfinder Atomic Power Plant was a 66-MWe demonstration BWR with a nuclear superheater, built and operated by the Northern States Power Company and located about six miles northeast of Sioux Falls, South Dakota. The reactor first went critical in 1964, entered into commercial operation in 1966, then was shut down on September 16,1967, due to mechanical failure of the steam separators. The total output, $\sim 140,000 \mathrm{MWe} h$, amounted to 88 days of equivalent full power operation. The shutdown became permanent in 1968 after it was established that the structural and design upgrades required were not economically justifiable. The plant itself was reconfigured to operate with gas-fired boilers.

Beginning in 1969, the reactor was defueled and the fuel itself shipped offsite. The RPV was drained with the internals left in place. The control rods and blades were placed within the vessel, which was then filled with gravel, after which the head was reinstalled. The reactor was thus partially decommissioned to SAFSTOR status by 1971 . The decision to complete the decommissioning was made in the late 1980s. Actual dismantlement of the nuclear portions of the plant began in 1990 , and the final decommissioning process was completed in 1993. The decommissioning operations were generally managed and conducted by the utility staff; outside contractors were employed only when expertise was not available on site.

The structures and facilities included in the decommissioning were

- the RPV

- the reactor building and contents 
- the fuel transfer vault

- the fuel handling building and contents.

The major item of consideration was the RPV. This had an overall length, with the head

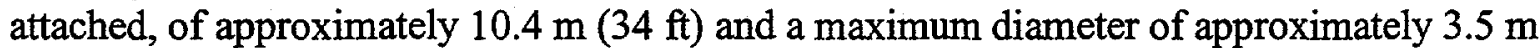
$(11.5 \mathrm{ft})$. Both the vessel and the head were made of ASME A212 Grade B carbon steel with a stainless steel overlay. The reactor internals were fabricated of stainless steel with the exception of the zircaloy- 2 boiler boxes. The control rods and blades were of boron stainless steel and contained boron pellets. The RPV and its contents were estimated to contain $560.92 \mathrm{Ci}$ of radioactivity, an amount that did not require segmentation and transport for disposal in separate shielded shipping containers. The shielding and activation analyses indicated that the vessel and internals qualified as low specific-activity material, and after packaging could be shipped in one piece as a Type A container.

Prior to shipping, grout was pumped into the vessel to stabilize the gravel, fill any void spaces, and fix loose contamination. The attached piping was then cut off, the openings sealed, and the vessel lifted from the reactor cavity and laid on its side in a temporary enclosure. Remaining attachments were cut off and the external asbestos insulation was removed. A 44-mm (1.75-in.) thick cylindrical steel plate was welded to the vessel shell outside diameter to provide shielding over the core region. An impact limiter of Hexcel (aluminum in a honeycomb configuration) and wood was installed around the entire vessel and the whole encased in 6-mm $(0,25$-in.) steel shield fabricated in a cylindrical shape. The overall diameter of the shipping package was $4.0 \mathrm{~m}$ (approximately $13 \mathrm{ft}$ ). Transportation to the final disposal site (Richland, Washington) was via rail on a heavy duty, 12-axle car.

The total volume of radioactive waste resulting from all activities (all solid) was $975 \mathrm{~m}^{3} ; 113 \mathrm{~m}^{3}$ of this was contributed by the RPV package, which, with its $560.92 \mathrm{Ci}$ of activity, comprised over $99.8 \%$ of the total waste activity, $561.82 \mathrm{Ci}$. Other radioactive waste items included asbestos, reinforced concrete, the bioshield, recirculation pumps and motor, and $567 \mathrm{~m}^{3}$ of dry active waste (piping, cable, shield blocks, filters, paper, etc.).

\subsubsection{San Onofre Unit 1}

The first of three units at the San Onofre Nuclear Generating Station was a 460-MWe PWR that began operation in 1968 . The plant was shut down in the early 1980 s for upgrading of the safety systems, which proved to be very expensive. Subsequent operation was unreliable and availability was low. Rather than incur even more costs for additional required modifications, the utility elected to close it permanently in 1992. Up to then, Unit 1 had generated a total of 6045 Mwe-years of electrical energy.

The reactor was defueled in March 1993, and a proposed decommissioning plan was submitted to the NRC in November 1994. The plan calls for Unit 1 going into SAFSTOR until Units 2 and 3 are ready for decommissioning.

At the present time, only estimates exist of the volumes of radioactive waste generated by dismantling the plant after the SAFSTOR period, projected to end in 2013. The grand total is thought to be $\sim 5650 \mathrm{~m}^{3}$, of which $\sim 2060 \mathrm{~m}^{3}$ will include the RPV, reactor vessel internals, primary system components and piping, and the spent fuel racks. 


\subsubsection{La Crosse}

The La Crosse BWR was a 55-MWe unit that began operation in November 1969. It generated $\sim 462$ MWe-years of electricity until ceasing operation in April 1986. It was placed in SAFSTOR in 1991 with DECON planned for 2012-2025. Discussions are in progress concerning the construction of an onsite independent spent fuel storage installation (ISFSI). Projections of the radioactive waste finally generated indicate a total volume of $\sim 3180 \mathrm{~m}^{3}$ and a total activity of $\sim 9400 \mathrm{Ci}$.

\subsubsection{Rancho Seco Nuclear Generating Station}

The Rancho Seco nuclear plant, a 883-MWe PWR operated by the Sacramento Municipal Utility District, is located in southeastern Sacramento County, California, about 25 miles from the city of Sacramento. It began commercial operation in October 1974 but was shut down in June 1989, when the voters in the utility's service area failed to authorize continued operation of the plant.

Following the shutdown, the utility instituted a "protective layup" program. This was designed to prevent or minimize degradation or deterioration of the plant systems while taking the measures necessary to protect the safety of the public and plant personnel. The reactor itself was defueled in December 1989 and the primary mechanical systems filled with demineralized water. Vessel piping and internals were pressurized with inert gas (nitrogen). Subsequently, the utility reviewed the decommissioning options, elected to put the reactor in SAFSTOR for 20 years prior to final DECON, and submitted the plan to the NRC. Approval of the decommissioning plan was initially delayed because of potential environmental issues. These were later resolved, and the NRC issued the order authorizing decommissioning of the plant on March 20, 1995.

The first phase of decommissioning involved putting the plant into Custodial SAFSTOR. During this phase, all systems useful for decommissioning activities are maintained. No decontamination is performed on internally contaminated plant systems, but the reactor building is closed and preserved. All 493 fuel assemblies used during the plant's service life continue to be stored in the spent fuel pool (in the fuel storage building), while an onsite ISFSI using dual purpose (storage/transport) casks is constructed.

The second phase, termed Hardened SAFSTOR and originally planned to be in place by 1998 , will be initiated with completion of the transfer of spent fuel from the pool to dry storage at the ISFSI. Maintenance of systems useful for decommissioning activities will continue, but some of the internally contaminated systems will be decontaminated. All the reactor systems will be drained, vented, and isolated, and the Reactor Building, Fuel Storage Building, and parts of the Auxiliary Building will be hardened. The Interim Onsite Storage Building, which provided storage space for solid radioactive waste materials during the plant's operational life, will be decontaminated and secured.

Plans for the third phase, Deferred DECON, are still to be developed. Implementation will take place after a SAFSTOR period of at least 15 years. At the present time, only estimates exist of the volumes of radioactive waste generated by the dismantlement of the plant after a SAFSTOR period of 20 years. The grand total is thought to be $\sim 5650 \mathrm{~m}^{3}$, of which $\sim 2060 \mathrm{~m}^{3}$ will be contributed by the RPV, reactor vessel internals, primary system components and piping, and the spent fuel racks.

\subsubsection{Trojan Nuclear Power Plant}

The Trojan nuclear plant, a 1130 MWe PWR located on the Columbia River west of Portland, Oregon, began commercial operation in December 1975 and produced over 10,000 MWe-years during its operational life. It was shut down permanently in January 1993, when replacement of the 
SGs was deemed financially unjustifiable. The reactor was defueled later that month, and the utility announced its decision to decommission the plant.

The decommissioning plan was formally submitted to the NRC and the Oregon Department of Energy (ODOE) in January 1995, identifying the utility's intention of implementing the DECON option. The plan was approved by the ODOE in March 1996.

In November 1994, the utility began the large component removal project, essentially the four SGs and pressurizer. This was completed in November 1995 with shipment of these components to the low-level radioactive waste burial site at Hanford, near Richland, Washington. Decontamination and dismantling of the remaining radioactively contaminated components are scheduled for completion by 2001. Fuel in the spent fuel pool will be transferred to an ISFSI. Projections of the total volume of radioactive waste to be generated by dismantlement of Trojan indicate that it will be on the order of $8,860 \mathrm{~m}^{3}$.

\subsubsection{Three Mile Island Unit 2}

Unit 2 at the Three Mile Island nuclear station was powered by a 956 MWe PWR. The reactor began power production in late 1978 and had generated $\sim 231$ MWe-years of electrical energy before a partial core meltdown accident in March 1979 caused it to be shut down permanently. The utility, GPU Nuclear, subsequently proposed a monitored storage plan for Unit 2, permitting the plant to remain in a safe, monitored state until the license of Unit 1 expires, at which point the two units would be decommissioned together. An associated Safety Analysis Report was issued in 1988 with a request that the license be amended to possession-only for Unit 2 . This request was granted in 1993. Unit 2 is now in a monitored storage status, a condition similar to, but not the same as, SAFSTOR.

Cleanup activities conducted thus far include defueling and removal of core debris from the damaged reactor, completed in 1990, and processing of accident-generated water, completed in August 1993. The spent nuclear fuel and core debris had a total activity of $\sim 6.9 \mathrm{MCi}$ packaged in a volume of $\sim 124 \mathrm{~m}^{3}$. Other highly active wastes included resin liners and filters from the submerged demineralizer system $\left(\sim 0.67 \mathrm{MCi}\right.$ in $\left.58 \mathrm{~m}^{3}\right)$ and the EPICOR II system $\left(\sim 83 \mathrm{kCi}\right.$ in $\left.1073 \mathrm{~m}^{3}\right)$. The largest volume of radioactive waste shipped for disposal is $\sim 7500 \mathrm{~m}^{3}$ of dry active waste with an activity of $745 \mathrm{Ci}$.

\subsubsection{Shoreham Nuclear Power Station}

The Shoreham Nuclear Power Station used a BWR and was designed to provide a gross output of 849 MWe. The plant, owned by the Long Island Lighting Company, was located approximately 50 miles east of New York City, on the north shore of Long Island. It achieved initial criticality in February 1985 and operated intermittently at up to $5 \%$ of full power until being shut down in January 1989 under an agreement between the utility and the State of New York. It had accrued an estimated two effective full power days of average fuel exposure by the time it ceased operation. Under the terms of the shutdown agreement, the ownership was transferred to the Long Island Power Authority for decommissioning, and the DECON option (prompt removal of radioactive material and release for unrestricted use) was selected. The radiological criteria for unrestricted release were a limit of $5 \mu \mathrm{R} / \mathrm{h}$ at $1 \mathrm{~m}$ surface contamination and $8 \mathrm{pCi} / \mathrm{g}$ for soils and bulk materials. The NRC issued an order approving the Shoreham decommissioning plan in June 1992.

The irradiated fuel was removed from the RPV in August 1989 and placed in the spent fuel pool until subsequent shipment offsite for use in Philadelphia Electric's Limerick power station. Transfer 
of the fuel to Limerick was completed in June 1994. Characterization of the facility identified a total of $\sim 600 \mathrm{Ci}$ of radioactivity, almost all of which was in the RPV and internals. The radioactive inventory of structures and systems other than these was estimated at $3 \mathrm{MCi}$. Practically all the contamination was associated with metallic structures and systems; contamination of concrete was found to be restricted to one small area in Radwaste Building. The decision was made to perform immediate dismantling. The scope of this included removal only of the RPV and internals, and other contaminated systems and structures. This involved segmentation of the vessel and internals, demolition of the biological shield, and decontamination and/or removal of the other structures.

Industry-accepted and proven techniques were used in the dismantling process. For the RPV and its associated components, these included diamond wire saw cutting and plasma arc (both in air and under water) cutting. Other systems and structures were dismantled using band saw cutting, split outside diameter milling, and simple mechanical removal. When decontamination was deemed desirable, the techniques employed were again consistent with those used routinely throughout the nuclear industry. They included in-situ chemical decontamination, abrasive grit blasting, and highpressure and ultra-high-pressure water lancing. The total dismantling process produced $\sim 2200 \mathrm{~m}^{3}$ of low-level radioactive waste, of which $-460 \mathrm{~m}^{3}$ were made up of the RPV and internals. The Long Island Power Authority announced completion of dismantlement of the facility in October 1994, and the license was terminated in April 1995. 


\subsection{Conclusions}

Uranium-graphite channel-type reactors similar to domestic RBMK reactors are not operated in the nuclear power industries of other nations, with the exception of the RBMK units constructed in the former Soviet Union at the Chornobyl NPP (in the Ukraine) and at the Ignalina NPP (in Lithuania). For this reason, the extent to which foreign experience may be tapped during planning and dismantling associated with the decommissioning of nuclear power plant RBMK units may be limited. Therefore, the resolution of the numerous problems associated with decommissioning RBMK units will primarily be based on the analysis and generalization of extant domestic experience.

Russia has experience in repairing and dismantling or upgrading equipment and systems within high-level ionizing radiation fields at operational reactor plants of different types. In particular, a large number of repairs and dismantling have recently been performed while upgrading uraniumgraphite plutonium-production reactors, experience has been acquired in design work, and partial dismantling has been performed on the reactors already shut down.

Russia's repairing and upgrading experience illustrates the complexity related to planning and performing full-scale dismantling. The complexity is due not only to radiation-hazardous conditions but also to the ill-considered nature of the engineering and design solutions employed in the construction of the reactors, when no consideration was given to the decommissioning phase needs.

Upgrading and major repairs of uranium-graphite channel-type plutonium-production reactors in Russia provided practical experience in different types of dismantling, installation, and repair work on these complex, radioactive structures. The tasks provided some idea of the nature and the organization of this work, the quality of the techniques and technological equipment used, the cost, the nuclear reactor idle time, the labor input, and the dose levels sustained by personnel.

It can be assumed that the practical experience acquired in upgrading plutonium-production reactors, the careful analysis of this experience, and the data accumulated will make it possible to more reasonably select a strategy and estimate the technical and economic outlays required for the dismantling work involved in decommissioning NPP RBMK units.

The repair and dismantling work performed on nuclear power plant RBMK units (primarily the wide-scale replacement of technological channels, installation of an emergency steam dumping system, mounting check valves on the batch-distributing manifolds, and other operations), together with the techniques and principles for the organization of the repair and dismantling work, are quite similar to the work that will be done when decommissioning RBMK units.

Experience in the development of the Program for the Preparation and Decommissioning of the First-Phase Uranium-Graphite AMB Units at the Beloyarsk NPP, as well as the results of the work already performed on these power units, must also be used when preparing for the decommissioning of RBMK units. From this standpoint, the first-phase units of the Beloyarsk NPP can be used as a proving ground for optimizing engineering and organizational solutions aimed at ensuring the safe and economically acceptable decommissioning of RBMK NPPs.

It is obvious that all this experience can be fully used when planning and dismantling radioactive equipment and structural elements during the RBMK unit decommissioning phase.

The domestic experience acquired while repairing and upgrading uranium-graphite plutoniumproduction reactors and modernizing RBMK reactors suggests the feasibility of equipment and 
system dismantling using existing technologies. Nevertheless, it must be said that the cumulative radiation dose sustained by the personnel may be unjustifiably high in this instance.

For this reason, despite the optimistic point of view that some Russian specialists hold about performing the entire decommissioning of RBMK units using existing technologies and equipment, it will be necessary to conduct a wide range of survey, design, and test studies; focus on educating and training personnel with the appropriate skills; and prepare the pertinent regulatory documents to ensure safety during decommissioning.

Experience indicates that the most complex work associated with dismantling will be cutting and removal of the most contaminated reactor metalwork (the top load-bearing structure, the bottom load-bearing structure, the housing, and the main biological shield tank), as well as the disassembly and removal of the reactor's graphite stack. During the next 30-70 years, the disassembly of these structural elements will require specialized technological equipment, including remotecontrolled systems that are installed and operated in the central area of the reactor. It is possible that the disassembly and removal of the blocks composing the graphite stacks of RBMK reactors will also make it necessary to employ remote-controlled systems or to find simpler, but possibly less efficient technologies. There is an abundance of such technologies in Russia.

Special repair departments are in operation at each NPP in Russia. They have their own tools and equipment to perform the work required during the final phase of the life cycle of the NPP units. Depending upon the time frame for decommissioning the units of an NPP that has the necessary financial resources, those technologies will be at its disposal for achieving their desired end state (the end point of a power unit and/or its operations area). Nevertheless, the final selection of the dismantling solutions and the corresponding equipment, with allowance for the assurance of safety requirements, will be made based on the preparation and approval of the documentation governing the decommissioning of that unit, including a state ecological study.

Robotic devices and other "manless" technological equipment have not been used in Russia to repair and dismantle uranium-graphite plutonium-production reactors or nuclear power plant units, except for a few technological operations. The analysis of extant innovations in the designs of remote-controlled systems by domestic design organizations makes it possible to reach two basic conclusions:

First, there are no problems that are insoluble in principle relative to the development and manufacture of such systems. Second, in addition to their main purpose (dismantling highly radioactive equipment), remote-controlled systems can also be adapted and successfully used to perform operations such as removing the contents of the "Ukrytiye" unit at the Chornobyl NPP in line with the attendant cleanup work. Thus, bringing extant domestic technologies to a level where they can be put to practical use within radiation and ecological safety requirements appears to be both advisable and pressing.

Russia is at the forefront of innovations in the design of remote-controlled equipment. The practical implementation of the remote-controlled system designs that have been drawn up will necessitate research and development work to train personnel, prepare work schedules, and manufacture and optimize industrial prototypes, bringing them up to a level of practical readiness. Specific material and financial resources, which are not available in Russia, will be needed to achieve all this. 
Not all the practical Russian experience that can be used for planning RBMK unit decommissioning has been presented in this document. Other available results must also be analyzed and taken into consideration while planning for and decommissioning RBMK units, including the problems with handling the irradiated graphite stack of a reactor and those associated with decontamination of the entire primary coolant circuit, individual system and equipment components, and the results of other research and development work.

The economic situation in Russia is slowing the search for the best engineering solutions for NPP decommissioning problems and the development of equipment needed for decommissioning, including remote-controlled systems. The slowdown, in turn, is leading to the breakup of existing scientific and creative teams of specialists, which may also lead to the loss of Russian scientific and technological potential.

It seems reasonable that the techniques, technologies, and design developments described in this document to be used for seeking out and organizing cooperation among nations that use nuclear technologies to assist in resolving the problems surrounding decommissioning different types of reactors and nuclear fuel cycle facilities.

The organization of such international projects and participation therein will make it possible for Russia not only to preserve and augment the practical experience acquired and scientific and technological potential accumulated, but also to prepare the scientific, technological, and regulatory base needed to ensure the feasibility of safe, ecologically acceptable, and cost-effective decommissioning of nuclear power plants, including those equipped with RBMK reactors. 


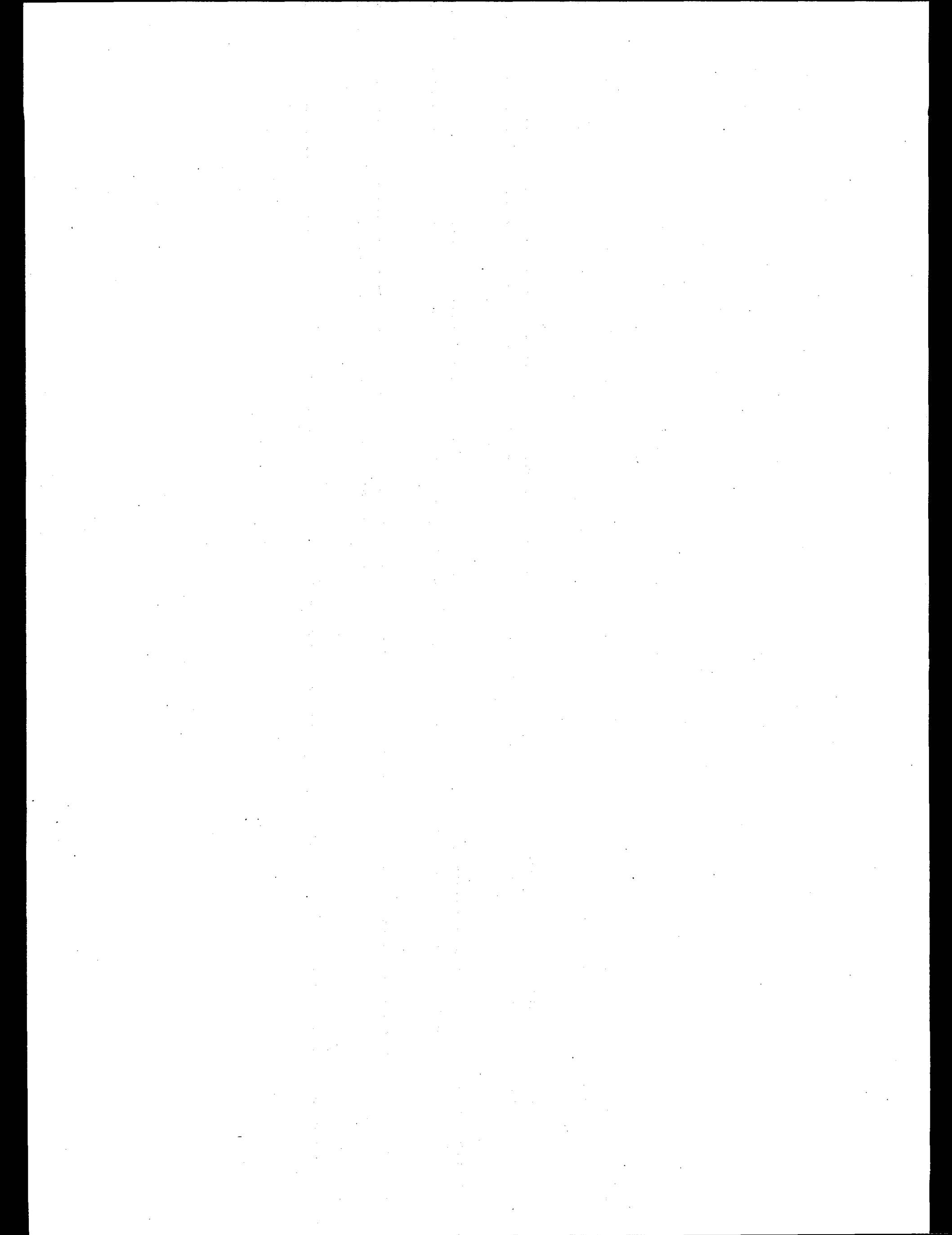




\subsection{Bibliography}

\subsection{Related Documents}

The 20th Year of Nuclear Power Engineering. 1974. Atomizdat Publishing House, Moscow.

The Safety of Nuclear Power Plants Equipped with Channel-Type Reactors: The Upgrading of the Core. 1996. Energoatomizdat Publishing House, Moscow.

Nuclear Power Plant Safety: A Handbook. 1994. Rosenergoatom Publishing House and EDFEPN-DSN, Paris.

The Development of Radiation-Safe Technologies and Equipment for the Dismantling of Nuclear Reactors in Russia: A Bulletin of the Nuclear Power Public Information Center. 1996. Central Scientific Research Institute of Management, Economic and Information, Russian Ministry of the Nuclear Industry, Moscow, No. 6.

A Concept for the Decommissioning of Nuclear Power Plant Units. 1991. Soviet Ministry of Nuclear Power Engineering and the Nuclear Industry, Moscow.

The Problems Surrounding the Decommissioning of the First-Phase Units of the Beloyarsk Nuclear Power Plant. 1994. In: Collected Scientific Works of the Ural Branch of the Russian Academy of Sciences, Yekaterinburg.

A Program for the Preparation and Decommissioning of Unit No. 1 and Unit No. 2 of the Beloyarsk Nuclear Power Plant. 1996. Publishing House of the Rosenergoatom Concern, Moscow.

The Selection of Alternatives for the Safe Handling of the Spent Nuclear Fuel of Unit No. 1 and Unit No. 2 of the Beloyarsk Nuclear Power Plant. 1995. Resolution of the Scientific and Technical Council of the Rosenergoatom Concern dated 12/14/95.

A Report on the Activities of the Russian Federal Oversight Committee on Nuclear and Radiation Safety During 1995 (Document Number RD-03-02-95). 1996. Publishing House of the Russian State Committee on Nuclear and Radiation Safety, Moscow.

Remote-Controlled Systems for the Dismantling of the Highly Radioactive Equipment of Nuclear Power Plants. 1995. Heat Engineering, No. 5, Moscow.

Technology for the Dismantling of the Reactors of Domestic Nuclear Power Plants: A Review. 1992. Central Scientific Research Institute of Information and Feasibility Studies in the Area of Heavy Machinery Construction, Series 8, No. 18 - 19, Moscow.

A Technological System for the Dismantling of Reactors of the VVER Type. 1996. Heavy Machinery Construction, No. 8, Moscow.

Experience in the Area of the Dismantling of Nuclear Reactors. 1990. Nuclear Power, Vol. 69, No. 3, Moscow.

Means for the Further Improvement of Nuclear Power Plant Repair Services. 1978. Power Engineer, No. 8, Moscow.

A Technology for the Burial of the Nuclear Reactors of Above-Ground Power Engineering Plants Involving the Positioning of a Graveyard Under the Reactor Block. 1994. In the Collected Works: New Technologies for the Comprehensive Use of the Natural Resources of the North. Publishing House of the Kola Research Center, Russian Academy of Sciences, Apatity. 
The Selection of Metal-Cutting Techniques During the Repair of Nuclear Reactors. 1973. Nuclear Power, Vol. 34, No. 6, Moscow.

On the Evaluation of the Effectiveness of Technologies for the Dismantling of Nuclear Power Plant Equipment. 1993. Heat Engineering, No. 8, Moscow.

The Problem of Substantiating the Technical Feasibility of the Dismantling of Nuclear Power Plant Units. 1992. Heavy Machinery Construction, No. 4, Moscow.

\subsection{References}

Anagnostopoulos, H. 1994. "Cold Weather Effects on Dresden Unit 1." Paper 9-7 in Third Intl. Workshop on Implementation of ALARA at Nuclear Power Plants, Hauppauge, NY, May 8-11, 1994.

Bowser, RW, DR Keuter, and KR Miller. 1991. "Spent Fuel Storage: A Decommissioning Perspective." JNMM (May 1991), pp. 13-16.

Closs, J. 1993. "Case Study: Pathfinder Decommissioning," in Decontamination and

Decommissioning of Nuclear Facilities and Properties, ASME, Denver, CO, August 2-5, 1993.

Crimi, FP. 1985. "Shippingport Atomic Power Station Decommissioning Program and Applied Technology." Pp. 393-408 in Waste Management '85, R.G. Post, editor.

Crimi, FP. 1992. "Shippingport Station Decommissioning Experience." Pp. 6 A-1-6 A-4 in Proceedings of the 8th Pacific Basin Nuclear Conference, Taipei, R.O.C., April 12-16, 1992, Supplement Number 2 to Volume 65 of Transactions of the American Nuclear Society.

Crimi, FP. 1994. "Shippingport Station Decommissioning Project ALARA Program." Paper 92 in Third Intl. Workshop on Implementation of ALARA at Nuclear Power Plants, Hauppauge, NY, May 8-11, 1994.

Granados, B, G Babineau, B Colby, and B Cox. 1994. "An Overview of ALARA Considerations During Yankee Atomic's Component Removal Project." Paper 9-6 in Third Intl. Workshop on Implementation of ALARA at Nuclear Power Plants, Hauppauge, NY, May 8-11, 1994.

LaGuardia, TS. 1993. "Decommissioning Power Reactors in the USA: Forcing the Pace," Nuclear Engineering International (August 1993), pp 32-34.

Long Island Power Authority. 1993. "Shoreham Nuclear Power Station Updated Decommissioning Plan," (NRC Docket No. 50-322), February 1993.

Murphie, WE. 1992. "Aspects of the U.S. Department of Energy Decommissioning Program with Selected Examples of Current Technology and Environmental Compliance." Pp. 6 G-1 - . 6 G-6 in Proceedings of the 8th Pacific Basin Nuclear Conference, Taipei, R.O.C., April 12-16, 1992, Supplement Number 2 to Volume 65 of Transactions of the American Nuclear Society.

Murphie, WE, LE Boing, and CE Fellhauer. 1993. "The Status of the Experimental Boiling Water Reactor (EBWR) Decontamination and Decommissioning Project." Pp. 193-202 in Decontamination and Decommissioning of Nuclear Facilities, IAEA-TECDOC-716, International Atomic Energy Agency, 1993. 
Nemec, JP. 1978. "Decommissioning of Nuclear Power Plants." Pp. 303-319 in Nuclear Power Waste Technology (AA Moghissi, ed.), ASME, New York, 1978.

Roberts, JTA; R Shaw, and K Stahlkopf. 1985. "Decommissioning of Commercial Nuclear Power Plants." Pp. 251-284 in Annual Reviews of Energy, Volume 10, 1985.

Sacramento Municipal Utility District. 1991. Initial Study and Proposed Negative Declaration: Rancho Seco Nuclear Generating Station Proposed Decommissioning Plan. SMUD Environmental Services, Sacramento, CA, June 19, 1991.

Schreiber, JJ, et al. 1988. "Shippingport Station Decommissioning Project." Pp. 72-81 in Volume 56 of Transactions of the American Nuclear Society, 1988.

Schreiber, JJ, et al. 1989. "Shippingport Decommissioning: Final Progress Report." Pp. 64-72 in Volume 59 of Transactions of the American Nuclear Society, 1989.

U.S. Dept. of Energy. 1995. Integrated Database Report-1994: U.S. Spent Fuel and Radioactive Waste Inventories, Projections, and Characteristics. Revision 11, DOE/RW-0006, Rev. 11, September 1995. Also, earlier revisions.

U.S. Nuclear Regulatory Commission. 1996. Decommissioning Nuclear Power Plants, Technical Issues Paper No. 24, 1996.

Wells, M. 1992. "Putting TMI 2 into Storage," Nuclear Engineering International (August 1992), pp. 18,20. 


\section{Joint U.S./Russian Study on the Development of a Decommissioning Strategy Plan for RBMK-1000 Unit \#1 at the Leningrad Nuclear Power Plant}

\section{Appendix B}

A Summary of the Regulatory Environment for the Shutdown and Decommissioning of Nuclear Power Plants in the United States and the Russian Federation

September 1998

Prepared for

The U.S. Department of Energy under Contract DE-AC06-76RLO 1830

Pacific Northwest National Laboratory Richland, Washington 99352 


\section{Table of Contents}

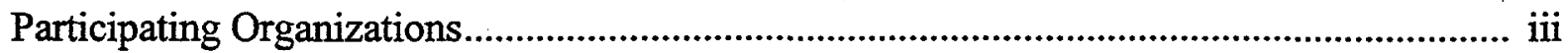

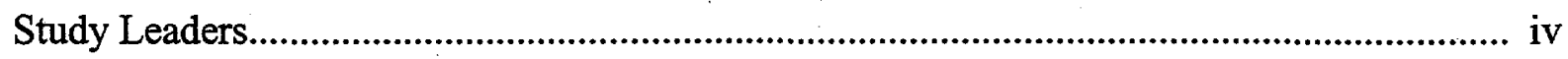

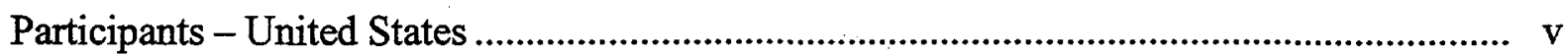

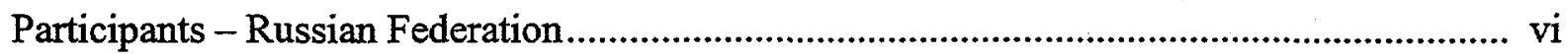

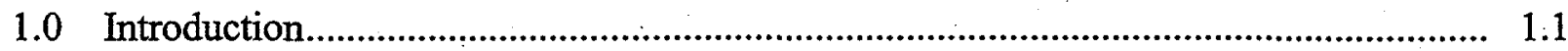

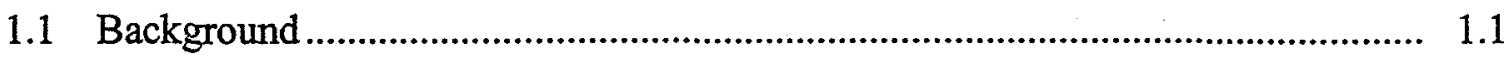

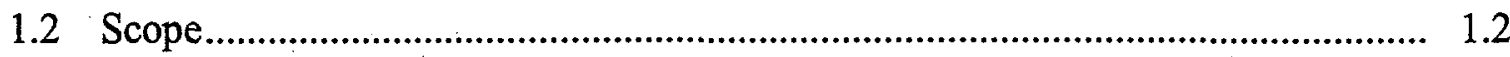

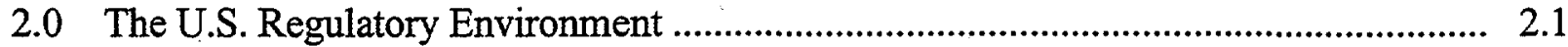

2.1 Historical Perspective ............................................................................. 2.1

2.1.1 The Atomic Energy Act ................................................................... 2.1

2.1.2 National Environmental Policy Act ..................................................... 2.1

2.1.3 Energy Reorganization Act............................................................... 2.2

2.1.4 The Current Decommissioning Environment and the NRC ..................... 2.2

2.1.5 NRC Rules Relevant to Decommissioning ............................................... 2.2

2.1.6. The States' Role in Regulation .............................................................. 2.4

2.1.7 The EPA Role in Regulation............................................................. 2.4

2.1.8 The Department of Transportation Rules on the Transportation of Hazardous Waste...................................................................................... 2.5

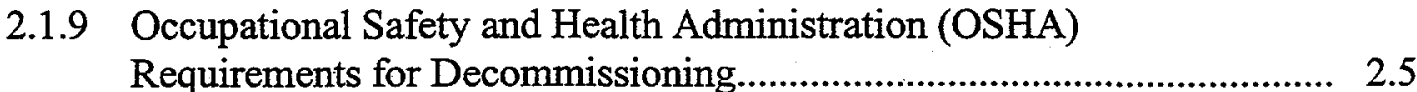

2.1.10 National Environmental Policy Act (NEPA) Requirements for Decommissioning Activities.................................................................... 2.5

2.2 The Decommissioning Regulatory Process ....................................................... 2.6

2.2.1 Decommissioning Alternatives.......................................................... 2.6

2.2.2 Steps Involved in Decommissioning .................................................... 2.7

2.2.3 Requirements for an Application to Decommission ................................ 2.10

2.2.4 Purpose and Content of the License to Decommission ........................... 2.11

2.3 Indemnification During Decommissioning...................................................... 2.12

2.4 The New NRC Decommissioning Rule ..................................................... 2.13

2.5 Unrestricted Site Release Criteria, Waste Management, and Safety ................... 2.14

2.5.1 Radioactive Waste ........................................................................... 2.14

2.5.2 Decommissioning Accident Analysis .................................................... 2.15

2.5.3 Release Criteria for Decommissioning .................................................... 2.15

2.5.4 Surveys to Support Decommissioning .................................................. 2.16 
2.5.5 Proposed Updates for Unrestricted Release Criteria.

2.6 Public Involvement

2.6.1 Public Involvement

2.6.2 Guidelines for Public Meetings

3.0 The Russian Legislative and Regulation Environment

3.1 Regulating Activities in the Nuclear Power Sector

3.1.1 Group One.

3.1.2 Group Two

3.1.3 Group Three

3.1.4 Group Four. 3.8

3.1.5 Guidelines of GAN

3.2 Laws of the Russian Federation Regulating the Legal Basis of Decommissioning Nuclear Power Plant Units

3.2.1 Law of the Russian Federation on the Use of Nuclear Energy.

3.2.2 The Law of the Russian Federation on Radiation Safety of the Population

3.2.3 Law of the Russian Federation on Environmental Protection

3.3 Russian Documents Regulating Procedures for Decommissioning Nuclear Power Plant Units

3.3.1 General Safety Regulations for Nuclear Power Plants

3.3.2 Nuclear Safety Rules for Reactor Operation at Nuclear Power Plants

3.3.3 Requirements to NPP Quality Assurance Program

3.3.4 Typical Content to NPP Technical Safety Substantiation

3.3.5 Typical Content to Nuclear Installation Technical Safety Substantiation.

3.3.6 Requirements of Report Content on Technical Safety Substantiation for NPP with VVER Units

3.3.7 Norms of Radiation Safety.

3.3.8 Basic Sanitary Rules for Handling Radioactive Substances and Other Sources of Ionizing Radiation.

3.3.9 Sanitary Rules for NPP Design and Operation

3.3.10 Radiation Safety Regulations on NPP Operation

3.3.11 Requirements to NPP Utilities.

3.3.12 Draft of the Guideline General Requirements to Safety Assurance for Decommissioning of Nuclear Power Plant Units. 
3.4 Rosenergoatom Documents Regulating Decommissioning Procedures of Nuclear Power Plant Units.

3.4.1 Guideline Document Basic Provisions on the Decommissioning of Nuclear Power Plant Units.

3.4.2 Draft Guideline Document Typical Content for the Plan for Preparation of the NPP Unit for Decommissioning.

3.4.3 Draft Plan of the Guideline Document "A Comprehensive Engineering and Radiation Inspection of the Nuclear Power Plant Unit"

3.4.4 Draft Plan of the Guideline "A Typical Content of Technical and Economic Studies Aimed at the Shutdown of Nuclear Power Plant Unit Operations".

3.4.5 Draft Plan of the Guideline "A Typical Content of Technical and Economic Substantiation of the Nuclear Power Plant Unit Decommissioning Option"'"

3.4.6 Draft Plan of the Guideline "A Nuclear Power Plant Unit Decontamination Program Typical Content and Development Procedures".

4.0 Licensing Procedures for Nuclear Power Plant Units Decommissioning in Russia......

4.1 General Regulations on Decommissioning of Nuclear Power Plant Units in Russia

4.2 Description of Russian Approach to Licensing Procedures for Nuclear Power Plant Units Decommissioning

4.3 A List of Documents Substantiating the Application for the Nuclear Power Plant Decommissioning License.

4.4 Certain Features of the Russian Approach to Licensing Procedures for the Decommissioning of Nuclear Power Plant Units

4.5 Requirements for the Condition of the Unit with RBMK Reactor Necessary for Obtaining a Decommissioning License

5.0 Specific Features of NPPs with RBMK Reactors Requiring Accounting when Decommissioned.

6.0 Problems, Requirements, and Supervision of Environmental Safety Assurance During Decommissioning of Nuclear Power Plant Units

6.1 Main Provisions and Terms of Environmental Protection.

6.2 Review of Current Russian Legislation and Regulatory Documents Governing Environmental Protection and Ecological Safety in Decommissioning Nuclear Power Plant Units

6.3 The Concept of Ecological Safety as Applied to the Decommissioning of Nuclear Power Plant Units.

6.4 Determination of Permissible Changes Biogeocenosis Vital Functions in the Area of the Decommissioned Nuclear Power Plant Unit.. 


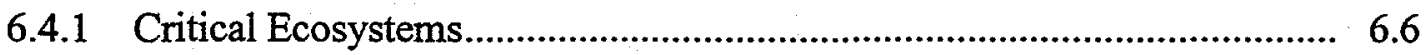

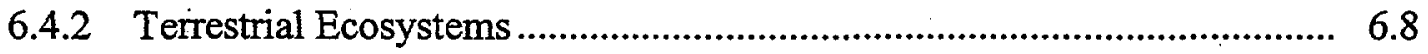

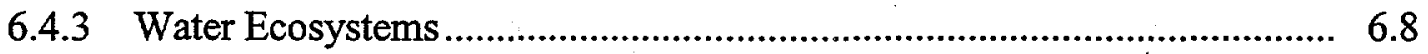

6.4.4 Critical Group of the Populace ........................................................... 6.10

6.5 Procedures for Determining Permissible Changes in Vital Functions of

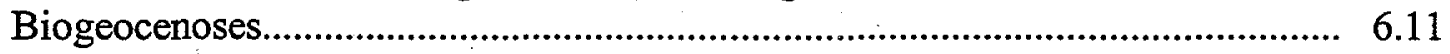

6.6 Supervision of Activities in Dismantling Nuclear Power Plant Units .................. 6.13

6.7 On Possible Radiation-Hazardous Accidents During Decommissioning of Nuclear Power Plant Units.

6.8 Requirements for Ecological Monitoring in the Area of the Nuclear Power Plant Units Being Decommissioned

6.9 Recommendations on Content and Preparation of Materials on Estimating the Effect on the Environment of NPP Unit Decommissioning Activities.

6.10 Conclusions on Procedures for Substantiation of Ecological Safety .................... 6.20

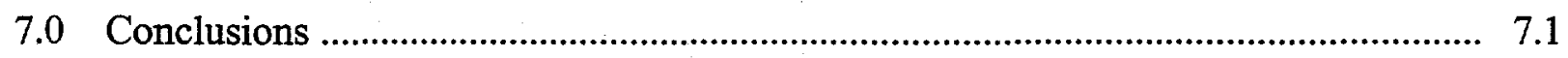

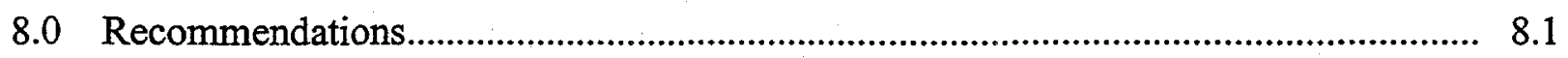

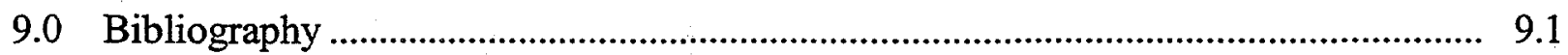

\section{Figures}

3.1 Structure of Russian Legislative and Regulatory Environment on Use of Nuclear Energy in the Russian Federation

3.2 Structure of the Russian Federation Regulations and Rules on Nuclear Power Utilization

3.3 Diagram of Administrative and Regional Structure of GAN

3.4 Structure of a List of Documents on Main Technical Standard and Rules of GAN......

6.1 Diagram of Preparation of Ecological Design Documents for Decommissioning of Nuclear Power Units.

6.2 Diagram of Ecological Monitoring in NPP Region.

6.3 Diagram of Preparation for Decommissioning of Nuclear Power Unit.

\section{Tables}

3.1 List of Nuclear Power Plant Units in the Russian Federation 


\subsection{Introduction}

As a follow-on to the Joint Electric Power Alternative Study for Russia (JEPAS) and the Joint Parallel Nuclear Alternative Study for Russia (JPNAS), the governments of the United States and the Russian Federation have undertaken a site-specific RBMK decommissioning study. This joint study aims to come to a preliminary understanding of the processes and requirements for decommissioning a Soviet-designed, first-generation RBMK reactor. As part of this analysis, a comprehensive analysis was performed of both the U.S. and Russian regulatory infrastructure for decommissioning.

This Regulatory Overview Report is part of the effort to perform the initial strategic requirements analyses to identify and characterize the regulatory and technical plans to safely, efficiently, and, with minimum socio-economic impact, shut down, decommission, and environmentally sitestabilize the candidate first generation RBMK. Subsequent to this activity it is anticipated that plans will be developed to shut down and decommission the candidate site. This U.S. regulatory approach to decommissioning has been evolving over the last 20 years. While initially very expensive, time consuming, and arduous, the U.S. regulatory structure has been greatly simplified over the last five years. Responsibility for the oversight and implementation of the decommissioning activities in the United States has gradually shifted from the U.S. Nuclear Regulatory Commission (NRC) to the utilities themselves.

The approach of the Russian Federation to decommissioning has not yet matured. The new Russian Nuclear Power Law (October 1995) has been the impetus for the first comprehensive analysis of the country's regulatory needs pertaining to decommissioning. The initial regulations show a decided bent toward centralized administration and monitoring with the oversight of the process split among Gosatomnadzor (GAN), the power utilities, and the nuclear power plant (NPP) itself.

The U.S. approach, while quite practical in the West, would be very difficult to implement in the Russian Federation due to financial constraints and lack of decommissioning experience by the utilities and the NPPs.

\subsection{Background}

Recent analyses of the Russian nuclear power sector (JPEAS and JPNAS) have identified several crucial assistance activities that require implementation to support the financially challenged Russian nuclear power infrastructure. One of these was the need for a site-specific RBMK decommissioning analysis and plan. Assuming no extensions, current Russian schedules require the shutdown and decommissioning of their four first-generation RBMK reactors over the next 10 years. These first generation units are at best only partially compliant with OPB-73 and OPB-82, and at worst, completely noncompliant.

To date very little analysis and planning has taken place in this area due to Russia's severe economic conditions. The first RBMK scheduled to reach the end of its service life, and the engineering model for this study, is Leningrad Unit \#1 in 2003, followed by Leningrad Unit \#2 in 2005, Kursk Unit \#1 in 2006, and Kursk Unit \#2 in 2008. The Russians estimate and U.S. experts concur that more than five years of planning are required before an RBMK can be decommissioned safely and efficiently. 


\subsection{Scope}

This report characterizes the regulatory and legislative environments in both the United States and the Russian Federation. It was envisioned early in the study that, for the Russian Federation to successfully undertake a decommissioning, the legal edifice must exist to facilitate success. Unlike the Russian Federation, the legal and engineering infrastructure pursuant to decommissioning has been alive and evolving in the United States for some time. The analogous structure in the Russian Federation is relatively new, resulting from a revamp of the Russian civilian nuclear power laws late in 1995. Sections 5 and 6 in this report provide details on each country's current state.

This report, to the extent possible, is intended to be site-specific, concentrating on Unit \#1 at the Leningrad NPP. The results of this study will, with some modification, be applicable to other RBMK sites because it characterizes the entire Russian regulatory infrastructure.

This document presents the results of analyses of the regulatory and legislative infrastructures for decommissioning civilian nuclear power plants for both the United States and the Russian Federation. Every attempt was made to comprehensively survey each country's currently functioning and evolving legal environment for decommissioning. No attempt has been made to characterize the effectiveness of one system versus another or to identify the failings of either system had they been implemented within the other country. 


\subsection{The U.S. Regulatory Environment}

\subsection{Historical Perspective}

This section provides a synopsis of the historical aspects of U.S. decommissioning regulation and details of the current regulatory environment. We discuss the Atomic Energy Act, the formation of the NRC, and the NRC's rules and regulations from a historical perspective.

\subsubsection{The Atomic Energy Act}

Initial U.S. regulations pertaining to the control of nuclear reactions and fissile material were based on the U.S. Atomic Energy Act of 1946, which created the five-member Atomic Energy Commission (AEC). The AEC, at that time, was given responsibility for all military applications of atomic energy. During the 1940s, the vast majority of efforts in the field of atomic energy were military-based, primarily emphasizing the development and production of fissile materials and the production of nuclear weapons. As a result, the Atomic Energy Act and the AEC had no provisions for the commercial use of atomic energy.

The Atomic Energy Act was rewritten in 1954. This Act redefined the role of the AEC to include most military development and use of atomic energy and also the civil use of this new resource. The AEC was, at that time, encouraged to promote civilian use of atomic energy for peaceful purposes such as generating power. The amended act instructed AEC to prepare regulations to protect public health and safety from radiation hazards. The AEC's role increased to include three areas of concern:

- Continued weapons development

- Private use of atomic energy for peaceful applications

- Protection of public health and safety.

In response to this new mandate, the AEC developed the first set of rules and regulations pertaining to the licensing of commercial nuclear power reactors. They developed a two-step process:

- A safety analysis must be submitted by the utility and accepted prior to issuance of a construction permit.

- After construction is completed and the AEC determines that a plant meets safety requirements, an applicant receives a license to load fuel and begin operations.

Initially, recommendations of AEC staff and the Advisory Committee on Reactor Safeguards went to the commissioners for approval. Later, the AEC delegated approval responsibilities to the Atomic Safety and Licensing Board.

The late 1950s and 1960s saw an explosion in the number of nuclear reactors being licensed and operated. With this came an increase in the number of regulations that the AEC developed and then had to enforce. This placed enormous burdens on AEC regulatory staff and the utilities.

\subsubsection{National Environmental Policy Act}

In 1970, the U.S. Congress passed the National Environmental Policy Act (NEPA). This law created federal requirements for considering potential environmental impacts, alternatives, and cost/benefit analysis of proposed federal projects. This law was initially challenged on the grounds that the AEC had no responsibility to look out for environmental considerations, but federal courts (during litigation relating to the licensing of Calvert Cliff nuclear power plant) 
decided that the AEC must consider potential environmental impacts in addition to radiological impacts during its licensing procedures. This further increased the burden on the AEC and the utilities.

During the early 1970s, the nuclear industry as well as the government became increasingly aware of the obvious conflict of interest present in the AEC charter. The AEC was responsible for both promoting nuclear power and the regulation thereof. The public's awareness of health implications resulting from radiation exacerbated the problem. The 1972 and 1973 time period saw public and government discussions on emergency core-cooling systems, high-level waste disposal, reactor design and safety, quality assurance, probability of major reactor accidents, and other issues. The utilities, Congress, and the public were all pushing for change.

\subsubsection{Energy Reorganization Act}

In 1974, Congress passed the Energy Reorganization Act (ERA). The ERA split the AEC into the Nuclear Regulatory Commission (NRC), with responsibility for regulating the civilian uses of nuclear power, and The Energy Research and Development Agency (ERDA), with responsibility for military uses of nuclear power, research and development activities, and promotional demonstration projects. Federal reorganization in 1977 and 1978 abolished ERDA and created the Department of Energy (DOE).

\subsubsection{The Current Decommissioning Environment and the NRC}

The Executive Director for Operations has primary responsibility for regulation of civilian nuclear power plants. Under the Executive Director, the Deputy Executive Director for Nuclear Materials Safety, Safeguards, and Operations Support and the Deputy Executive Director for Nuclear Reactor Regulation, Regional Operations and Research implement the Commission's regulations. The following $\mathrm{NRC}$ offices are directly involved in the decommissioning of a civilian nuclear power plant:

- Office Of Nuclear Reactor Regulation - Responsible for licensing the plant design, plant operation, and inspection and decommissioning

- Office Of Nuclear Materials Safety And Safeguards - Responsible for fuel cycle management, waste disposal, industrial and medical isotopes, and decommissioning

- Office of Nuclear Regulatory Research - Responsible for safety research, regulatory guides, and regulations.

\subsubsection{NRC Rules Relevant to Decommissioning}

NRC rules and regulations are called out in Chapter 10 of the Code of Federal Regulations (10 CFR) and are subdivided into the following parts:
10 CFR part 20
Standards for Protection Against Radiation (in Appendix 5)
10 CFR parts $30-33$
Licenses for Ownership and Use of Special Nuclear Material
10 CFR part 40
Licensing of Source Material
10 CFR part 50
Licensing of Production and Utilization Facilities
10 CFR part 51
Environmental Protection Regulations for Domestic Licensing
10 CFR part 52
Licensing of Nuclear Power Plants
10 CFR part 53
Licensing of Spent Nuclear Fuel Facilities
10 CFR part 55
Operating Licenses 
10 CFR part 60

10 CFR part 61

10 CFR part 62

10 CFR part 70

10 CFR part 71

10 CFR part 72

10 CFR part 73

10 CFR part 74

10 CFR part 75

10 CFR parts $2,50, \& 51$
Licensing of High-Level Nuclear Waste Disposal

Licensing of Land Disposal of Low-Level Nuclear Waste

Emergency Access to Low-Level Waste Disposal Facilities

Licensing of Special Nuclear Material

Packaging and Transportation of Nuclear Material

Licensing of Independent Spent Fuel Storage Facilities

Physical Protection of Plants and Materials

Materials Control and Accountability for special nuclear materials

Safeguards on Nuclear Material

Final Rule on Decommissioning of Nuclear Reactors

\section{NRC Regulatory Guidance Documents}

Under United States law, the NRC is required to implement the tenets of the CFR by developing regulations and guidance documents. Several types of documents are part of the NRC system, including Regulatory Guides, NUREG Reports, and Generic Letters of guidance.

\section{Regulatory Guides}

Regulatory guides are intended to present methods acceptable to the NRC staff for implementing specific parts of NRC regulations as called out in the CFR. They specify techniques used by NRC staff in evaluating specific problems or postulated accidents. They provide guidance to applicants and licensees. When possible, national standards are endorsed. Regulatory Guides are not substitutes for regulations but serve as implementation guidance, and compliance with them is not a difficult requirement. For example, methodologies different from those in regulatory guides are acceptable if they provide a basis for meeting CFR requirements; however, deviation from the methodology included in the Regulatory Guides generally elicits more extensive $\mathrm{NRC}$ review.

\section{NUREG Reports}

NUREG Reports are a series of formal reports on regulatory, technical, and administrative issues of interest to staff, industry, other government agencies, and the public. In general, the reports present results of licensing studies on facilities as a preliminary step before initiating licensing actions. In addition, several other topics are documented in NUREG reports, including

- Results of analyses of problems of a regulatory nature that are of interest to industry

- Task force reports on specific topics

- Proceedings of conferences or workshops

- Administrative reports of interest to the staff, industry, and the public.

\section{Generic Letters}

Generic Letters inform applicants and licensees of regulator requirements on licensing matters and schedules for compliance. Generic Letters are used to clarify NRC policy, request information, and transmit information. They are also used when information being requested or disseminated is pertinent to other applicants or licensees. 


\section{Regulatory Guides Relevant to Decommissioning}

The following NRC Regulatory Guides (RGs) are relevant to decommissioning activities at a civilian nuclear power plant.

RG 1.86 Termination of Operating Licenses for Nuclear Reactors," 1974. Gives acceptable procedures for termination of operating licenses.

RG 3.65 "Standard Content and Format of Decommissioning Plans for Licensees Under 10 CFR Parts 30, 40, and 70," 1989. Provides guidance on preparing decommissioning plans.

RG 8.8 "Information Relevant to Ensuring that Occupational Radiation Exposures at Nuclear Power Plants will be As Low As Is Reasonably Achievable (ALARA)," 1978. This document provides radiation protection information that may be used to ensure ALARA doses.

\section{NUREG Reports Relevant to Decommissioning}

NUREG-2082 "Monitoring for Compliance with Decommissioning Termination Survey Criteria," 1981. Addresses the decontamination of sites for unrestricted release.

NUREG-5512 "Residual Radioactive Contamination from Decommissioning: Technical Basis for Translating Contamination Levels to Annual TEDE." Gives an acceptable methodology for translating residual radioactivity levels to doses to man.

NUREG-5849 "Guidance Manual for Conducting Radiological Surveys," 1992. Gives guidance on conducting and documenting radiological surveys.

\subsubsection{The States' Role in Regulation}

In certain cases, individual states sign an agreement with the NRC that allows them to regulate the use of nuclear materials for non-reactor nuclear facilities within their state. These states are known as "agreement states." All states negotiate their role in NPP decommissioning with the NRC. Agreement states would play a role in decommissioning facilities such as those involved with radioisotope production and distribution, radiographic services, etc.

\subsubsection{The EPA Role in Regulation}

The EPA was established in 1970 and assumed responsibility for several key health and welfare areas, including air pollution, solid waste control, agriculture substance regulation (including fertilizers and pesticides), and water pollution control. In addition, the EPA is responsible for regulation of radiation doses to the environment and to the public.

The EPA has, as its legal charge the implementation of several federal acts:

- The Clean Air Act (CAA) - establishes national air quality standards that are enforced by states.

- The Clean Water Act (CWA) - establishes national water quality standards to protect water use (individual states develop plans to achieve these standards).

- The Safe Drinking Water Act (SDWA) - regulates the quality of drinking water and provisions to prevent groundwater contamination. 
- The Resource Conservation and Recovery Act (RCRA) - regulates waste management practices and the disposal of hazardous waste in landfills, establishes minimum requirements for solid waste disposal facilities, bans some types of waste from landfills, and regulates underground storage tanks.

- The Comprehensive Environmental Response Compensation and Liability Act (CERCLA) regulates the control of inactive hazardous waste sites and responds to spills of hazardous from inactive hazardous waste sites.

\subsubsection{The Department of Transportation Rules on the Transportation of Hazardous Waste}

Federal laws pertaining to the transportation of hazardous waste are contained in Title 49 of the Code of Federal Regulations, Parts 172 through 178. Part 172 gives requirements on hazardous waste transportation both to the public and to federal state and local authorities. Part 173 provides federal requirements for shipment and packaging of hazardous wastes. Part 174 gives requirements for transporting hazardous waste by rail; Part 175 gives requirements for transporting hazardous waste by aircraft; and Part 176 gives requirements for transporting hazardous waste by ship. Part 177 gives requirements for transporting hazardous waste on public highways, and Part 178 provides specifications for shipping containers.

\subsubsection{Occupational Safety and Health Administration (OSHA) Requirements for Decommissioning}

OSHA, actually part of the U.S. Department of Labor, was established by the Occupational Safety and Health Act of 1970. OSHA's mission is to protect the worker from occupational dangers such as chemical, fire, and electrical hazards. To do this, OSHA develops and issues occupational and health standards and regulations, conducts investigations and inspections to determine compliance, and issues citations and proposes penalties for noncompliance.

\subsubsection{National Environmental Policy Act (NEPA) Requirements for Decommissioning Activities}

The NEPA establishes top-level national policy and goals to protect the environment. Part of NEPA, the Council on Environmental Quality, specifies provisions in Title 10 of CFR Parts 1500-1506. With this CFR are defined systematic processes that can be used to deal with environmental concerns. The NEPA allows public participation in the oversight of government activities through open public hearings. Typically, a comprehensive cost benefit analysis is used to decide whether a particular environmentally sensitive project should be carried out. Federal agencies whose activities may have adverse environmental impacts are required to establish criteria to determine whether an environmental impact statement (EIS) or an environmental assessment (EA) must be prepared, or if neither is required. If neither is required, a categorical exclusion exists because the proposed regulation falls into one of the exclusion categories defined in 10 CFR 51.22(c).

\section{Environmental Impact Statement}

The development of an EIS has four main milestones. First, a notice of intent must be published. Second, a draft EIS must be prepared for review and comment. Third, a final EIS is prepared that considers review comments on the draft. And finally, a record of decision is prepared explaining the reasons for the proposed actions. Any of the first three phases of this process may, and usually do, include public hearings. If it is suspected an EIS is not required, and the actions planned are not categorical exclusions, then an Environmental Assessment (EA) must be 
prepared. In this case, the EA determines whether an EIS is actually needed. If an EIS is not needed, then the EPA issues a finding of "no significant impact" on the environment.

\subsection{The Decommissioning Regulatory Process}

\subsubsection{Decommissioning Alternatives}

In this section we discuss NRC definitions of the three most common decommissioning strategies; "DECON," "SAFSTOR," and "ENTOMB."

- DECON refers to the immediate decommissioning of the facility. Contaminated equipment, structures and portions of the facilities are either removed or decontaminated to levels that permit unrestricted use. In addition, the site itself is decontaminated to meet free release criteria.

- SAFSTOR, or delayed DECON, refers to the safe storage of the facility to allow radioactive decay over a period of up to 60 years. This process reduces worker exposure and waste activity when final dismantlement begins. The NPP facility and site are decommissioned as under DECON at the end of the safe storage.

- ENTOMB refers to a facility being entombed in a long-lived material such as concrete. The NPP facility is monitored until radiation decreases to free release levels. This alternative tends to be impractical because long-lived radionuclides will probably still be present after 300 years.

Due to the long half-life of several radionuclides usually present as a result of NPP operation, the usual decommissioning alternatives are SAFSTOR and DECON. SAFSTOR usually involves some aspects of DECON; for example, prior to safe storage spent fuel will be removed from a reactor, radioactive components may be shipped offsite, nuclear and hazardous wastes will be shipped to an external disposal facility, radioactive liquids will be drained and removed from the facility, and surfaces may be decontaminated to reduce worker exposures.

\section{NRC Impact on Selection}

Compliance with NRC rules has a direct effect on the decommissioning approach chosen for an NPP site. The most important NRC rule affecting alternative selection is 10 CFR Part 20. This rule establishes standards for protection from ionizing radiation resulting from activities licensed by the NRC. 10 CFR Part 20 is a comprehensive law that covers the NPP licensee radiation protection program, occupational dose limits for facility workers, surveys and monitoring for worker dose, respiratory protection/controls to limit worker exposure, storage and control of licensed materials, some waste disposal requirements, record keeping as it pertains to the radiological program, reporting requirements (e.g., loss of material or exposures in excess of limits), applications by licensee for exemptions to rule, and enforcement of requirements. Further, it defines the requirements for a radiation protection program. It requires that the licensees develop, document, and implement a radiation protection program and adopt ALARA principles (meaning that doses to workers and the public should be maintained at values that are as low as is reasonable achievable. It requires that the licensee review, at least annually, its radiation protection program and the program's implementation. This has a direct impact on the SAFSTOR decommissioning option. After a facility shuts down, it may, under the "SAFSTOR" option, be placed in a safe storage mode for up to 60 years. However, certain activities must be carried out during the storage period to minimize system degradation and the possibility of release of radioactive and hazardous material to the worker, public, and the environment. This includes an ongoing radiation 
protection program. The section of this document detailing the steps in the decommissioning process also outlines some of the activities that should be undertaken as part of a safety strategy for removing wastes and decontaminating components and systems. In doing so, the amounts of radioactive and hazardous material that could be released is greatly diminished.

Surveillance and Maintenance During SAFSTOR (10 CFR Part 20)

Most facilities in SAFSTOR will require continued periodic surveillance and maintenance to prevent the degradation of facility components and the release of contaminants. Records kept during facility operations are to be preserved so that components that are likely to deteriorate are identified and monitored. Equipment for monitoring the release of contaminants is to be installed and maintained, including monitors outside the facility to detect leaks to the atmosphere, the surrounding soil, or the groundwater. Any degradation or leakage problems are required to be rectified and steps taken to prevent their recurrence.

Occupational Dose Limits as per 10 CFR 20

A licensee is responsible for controlling occupational dose limits to individual adults, except for special exposures, to the following limits:

1. an annual limit, which is the more limiting of

a. a total effective dose equivalent of 5 rems (roentgen-equivalents man) or $0.05 \mathrm{~Sv}$ (Sieverts)

b. the sum of the deep-dose equivalent and the committed dose equivalent to any individual organ or tissue other than the lens of the eye being equal to 50 rems $(0.5 \mathrm{~Sv})$

2. the annual limits to the lens of the eye, to the skin, and the extremities, which are

a. an eye dose equivalent of $15 \mathrm{rems}(0.15 \mathrm{~Sv})$

b. a shallow dose equivalent of 50 rems $(0.50 \mathrm{~Sv})$ to the skin or any extremity.

To determine the individual's dose, 10 CFR 20 contains a table that gives derived air concentration values, which are the concentration of a specific radionuclides that if inhaled by an individual over a 2,000 hour working year will cause him/her to reach the annual limit on intake.

Public Dose Limits as per 10 CFR 20

10 CFR 20 defines public dose limits in the following way:

The licensee shall conduct operations so that

1. the total effective dose equivalent to an individual member of the public does not exceed 0.1 rem (1 millisievert), exclusive of background radiation, medical treatment, etc.

2. the dose in any unrestricted area from external sources does not exceed 0.002 rem $(0.02 \mathrm{mSv})$ in any one hour.

\subsubsection{Steps Involved in Decommissioning}

Typical steps taken at a nuclear power plant in the United States, from the initial decisionmaking process to permanent shutdown of the facility to the end state achieved through decommissioning, are described in this section. Typically, this includes characterization of the facility to identify radiation and other hazardous materials, the actual decommissioning and decontamination (D\&D) of the reactor and plant facilities, and release of the site for unrestricted access. 
The main objectives of a decommissioning and decontamination project should be to identify and manage risks posed by the facility, minimize the amount of wastes generated and wastes requiring special treatment, minimize decommissioning costs, and provide for the safety of the workers and the environment. With these end products in mind, a decommissioning has four primary phases:

- assessment

- development phase

- operations phase

- closeout and facility release.

The Assessment Phase

The assessment phase has two major parts, the preliminary characterization and the review and decision-making process. The preliminary NPP characterization is used to develop project baseline data and includes chemical, physical, and radiological characterization. Data can be acquired from many sources:

- construction drawings

- current facility status

- location, type, and quantity of hazardous, radioactive, and toxic wastes remaining on site

- unique site features (roadways, rail spurs, access to waterways)

- location of any physical obstructions (overhead utility lines, narrow doorways)

- status of pressurized systems

- systems, structures, and components necessary for the safe storage of the spent fuel.

The Development Phase

The development phase is initiated after the characterization data are analyzed and a decommissioning alternative has been chosen. Detailed engineering follows applicable regulations. The results of this work are documented in the Post-Shutdown Decommissioning Activities Report (PSDAR). Items considered include

- summary of the characterization data

- the decommissioning alternative chosen and the justification

- identification of all applicable regulations and provision for compliance

- estimates of cost, personnel exposure, and waste generated

- decommissioning schedule (for use by both plant staff and regulators)

- plan for worker and environmental protection including

- An ALARA Program

- A health physics program

- A waste management program

- facility management structure

- quality assurance program

- final survey and site release criteria 
- type and operating conditions for instruments to be used

- methods to obtain and analyze survey data

- auditing and data verification methods

- plans for building and grounds survey

- estimates of expected remaining radioactivity levels.

The Operations Phase

The operations phase consists of the actual decommissioning operations. Specific decontamination techniques and process are outside the scope of this document. However, key operational aspects typically include

- drainage of liquids from systems to minimize corrosion

- depressurization and sealing of systems to prevent leaks

- securing of systems to prevent inadvertent personnel contamination

- operations on contaminated materials and systems

- onsite storage of materials awaiting processing or disposal

- packaging and transport of materials offsite for disposal

- decontamination

- dismantlement

- demolition

- waste management.

Regarding packaging and transport of materials offsite for disposal, it is important to note that in addition to the decommissioning processes, material handling is required. Some areas for consideration related to packaging and handling include

- preparation of storage areas for material awaiting processing

- availability of transporters to move material

- adequate material lay down areas for handling and processing

- easily accessible areas for recyclable material

- protected and controlled areas for contaminated or hazardous materials

- areas for packaging, surveying, and shipping materials for offsite disposal.

Contaminated material can be managed by in situ decontamination, removal, treatment and disposal, or removal and decontamination. Specific waste treatment processes are outside the scope of this document.

\section{The Closeout and Facility Release Phase}

The closeout and facility release phase verifies that the final configuration of the site complies with the previously established release criteria. In addition, confirmatory radiation surveys are performed in accordance with prescribed sampling plans that ensure that contamination does not exceed acceptable levels. Following this, independent verification surveys are performed to ensure that the site complies with the release criteria. 


\subsubsection{Requirements for an Application to Decommission}

This section addresses the process taken by an NPP owner once the decision is made to cease operation. The PSDAR, the NRC review process, and the activities an NPP owner can perform before formal approval of a PSDAR is obtained are also described.

Once the decision has been made to permanently cease operations, written notification is made to the NRC. The requirements state that the NRC must be notified within 30 days of the decision to cease operations, rather than actual facility shutdown. If the facility has already been shut down, the date would correspond to the day the decision is made not to restart the facility. If the NRC orders the facility to cease operations, the date would correspond to the date the legal order was enacted. In either event, the notification must be signed and notarized.

The receipt of the certification of permanent cessation of operation is viewed as a commitment to cease operations. The NRC must be notified in writing if facility startup is desired; this may require a relicensing.

\section{Certification of Permanent Removal of Fuel}

The licensee must notify the NRC in writing of the date the fuel was permanently removed from the reactor vessel and stored in the spent fuel pool or placed in an Independent Spent Fuel Storage Installation (ISFSI). There is no time frame in which the removal must be completed; however, no relief from any operating regulatory requirements can be considered until the fuel removal process is complete.

\section{Post-Shutdown Decommissioning Activities Report}

Within two years of the decision to permanently cease operations at the NPP, a PSDAR must be submitted to the NRC. Copies are also sent to all affected states within two miles of the facility. Following receipt of the PSDAR, there is a 90-day waiting period to allow for its review. When the document is received, it is docketed; notice of receipt is placed in the federal register; and comments are solicited from interested parties.

The PSDAR includes a detailed description and schedule of the planned decommissioning activities. Also included is a detailed cost estimate and justification for concluding that environmental impacts of decommissioning are bounded by previously issued EISs. If an environmental review has not been performed, one must completed be prior to any major decommissioning activity. Revisions to the PSDAR that modify actions or schedules, or significantly increase costs, require NRC notification so that inspection and oversight can be updated.

Though the NRC reviews and provides comments on the PSDAR, approval is not required. If deficient, the NRC notifies the licensee and requires correction before major decommissioning activities take place. Some typical reasons for finding a PSDAR deficient might include an unrealistic scope that could not be completed as described; the decommissioning process could not be completed in 60 years; the scope could not be completed for the estimated cost; or the decommissioning would endanger public health and safety, violating the NRC's health and safety regulations or resulting in a major detrimental environmental impact.

Following receipt of the PSDAR, the NRC schedules a public meeting within 90 days. This meeting is held near the licensee's facility. The meeting notice is published in the Federal Register and in places readily available to individuals near the site. At the public meetings the NPP licensee presents the decommissioning plan, and the state discusses their role in the process. The 
NRC regulatory process is also discussed, and time is allowed for questions and answers. Following the meeting, a written transcript is made publicly available.

Decommissioning activities must be performed in accordance with the provisions of $10 \mathrm{CFR}$ 50.59. Basically, 10 CFR 50.59 says that no activities are to be performed that result in an unreviewed safety question (USQ), would forefend the release of the site for possible unrestricted use, would cause the occurrence of an unreviewed environmental impact, or would cause significant cost increases. The facility must also comply with the following requirements:

- 10 CFR Part 20 - Radiation Protection for Workers and the Public

- 10 CFR 50 Appendix B - Quality Assurance

- Site-Specific Technical Specifications

- safety limits

- limiting safety system settings

- limiting control system settings

- limiting conditions for operation

- surveillance requirements

- design features

- administrative controls

- effluent releases (including annual report on principal radionuclides released and estimated resultant dose to the public)

- maintenance rule (for systems, structures, and components important for the storage and control of spent fuel)

- environmental qualification of electrical equipment

- fire protection requirements

- actions by certified fuel handlers.

In addition, a Final Safety Analysis Report (FSAR) (update to be submitted to NRC every 24 months) must be completed and include a full facility description, a Radiation Protection Plan, a Conduct of Operations Plan, a detailed Site Characterization, a thorough Accident Analysis Plan, and details regarding Fire Protection requirements.

Relief from specific operating plant technical specifications may be granted in the areas of combustible gas control requirements, emergency core cooling systems acceptance criteria, containment leakage testing, fracture prevention measures, fracture toughness requirements for protection against pressurized thermal shock events, and anticipated transient without scram requirements. All of these reliefs are, of course, predicated on the fact that the core has been defueled.

\subsubsection{Purpose and Content of the License to Decommission}

This section provides information on the purpose and content of the NRC's review of the PSDAR, the public involvement in the review process, and the basis for the NRC review.

Prior to the new decommissioning rule, the NRC formally documented their review in a Safety Evaluation Report (SER) and an EA. However, under the new decommissioning rule, an NPP may undertake many decommissioning activities under $10 \mathrm{CFR} 50.59$, and the NRC will no 
longer document the results of their review by issuing a SER or an EA. Instead, the PSDAR will be reviewed, and the licensee will be notified of any problems within 90 days of submittal of that document. During the PSDAR review, the NRC will review the planned decommissioning activities, including the option chosen (long-term storage or immediate decommissioning). In addition, the NRC PSDAR review will focus on the following areas:

- Schedule - The proposed schedule for decommissioning as a sanity check and to ensure the process will be completed in 60 years. Once the NRC and NPP have agreed on the schedule it will be used to project and schedule NRC oversight.

- Cost - During the PSDAR review, the NRC evaluates the cost estimate. Primarily they want assurance that there is sufficient money in a decommissioning trust fund to complete decommissioning, or at least maintain the facility in a safe and stable condition, and that the cost estimate is realistic and based on the costing of prior successful decommissioning efforts.

- Environment - The NRC will review the environmental impacts to ensure that impacts associated with the decommissioning are bounded by the previously issued EIS and the FSAR.

The NRC retains cognizance of the decommissioning via site personnel and the decommissioning project manager. A more detailed review will be performed when the facility is ready to be released. The NRC may perform their own confirmatory surveys before releasing the site.

Public involvement is an important part of the decommissioning process. Within 90 days of the submittal of the PSDAR, a public meeting is held near the facility to inform the public of the plan and solicit public comments and concerns. Representatives of the facility, the state, and the NRC participate. In addition, when the licensee submits the detailed termination plan, public meetings and hearings will be held regarding the NPP's plan for ensuring availability of funds for final site release, radiation release criteria for final release, and adequacy of the final survey to verify that release criteria are met.

Though the results of the NRC review will be documented only in the event deficiencies are found, some of the attributes that will be reviewed include

- decommissioning alternatives

- plant activation and contamination levels

- radiological and nonradiological impacts of decommissioning

- spent fuel disposition

- postulated accidents

- occupational and public health and safety

- quality assurance.

\subsection{Indemnification During Decommissioning}

The U.S. Congress, under the Price-Anderson Act (as amended in 1988), established a "no fault" insurance system to provide financial coverage for the consequences of a major reactor accident. Both commercial insurance and self-insurance is required under this law. Large NPPs are required to have the maximum amount of commercial insurance available, which is currently $\$ 200$ million. In addition, each NPP contributes to a fund for self-insurance. In 1993, with 110 NPPs operating in the U.S., funds (commercial plus self-insurance) exceeded $\$ 8$ billion. 
Insurance payments cannot, by law, exceed the total funds available, and if available insurance is not adequate to cover claims, additional funding can come only from Congress via the federal allocation process. The aforementioned insurances are for settling claims for the offsite impact of an accident. In addition to offsite insurance, the NRC requires utilities to maintain \$1 billion in onsite property damage insurance for site cleanup after an accident. The Price-Anderson Act applies to the following situations:

- nuclear accidents

- precautionary evacuations of the general public

- offsite releases of contaminants

- land contamination

- power plant effluents

- storage/transportation of spent fuel

- radioactive wastes.

For non-operating reactors or spent-fuel storage facilities, the NRC may permit a lower level of indemnification because of the reduced risks to the public and environment compared with operating reactors. Violations of the Price-Anderson Act may be punished by civil or criminal penalties.

\subsection{The New NRC Decommissioning Rule}

This section discusses how the NRC's rules were modified to simplify decommissioning procedures. Before 1988 there were no specific requirements for decommissioning; each NPP was treated on case-by-case basis. The $1988 \mathrm{NRC}$ rulemaking provided general requirements for decommissioning reactors that had reached the end of their service life but did not adequately address prematurely shutdown plants. The 1996 NRC Decommissioning Rule provides further guidance for implementing decommissioning activities.

The intent of the new NRC Decommissioning Rule is to simplify and hasten decommissioning by making regulations more flexible for the plant owners. The new rule minimizes paperwork and unnecessary regulations in order to reduce the plants' and the NRC's work load. The new rule uses the licensee's FSAR as a basis for decommissioning safety evaluations. In addition, the new rule uses the site and generic EIS as a basis for environmental reviews associated with the decommissioning process.

As a result of the new ruling, current regulations under 10 CFR 50.59 allow the plant licensee to make a change to a facility (i.e., decommissioning activities) to a facility without prior NRC approval, provided the change was previously evaluated in the licensee's FSAR, is part of a change that has been incorporated into the NRC license, or does not pose a USQ. In this case, a USQ is defined as a proposed change, test, or experiment at a facility being decommissioned that

- increases the probability or consequences of a previously considered accident

- may result in a new type of accident that was not previously considered

- reduces the margin of safety at the facility.

For any of these cases, a new safety analysis is required for NRC review and approval. 
If there are no USQs, decommissioning of a facility may be planned using procedures similar to those used during facility operation. After shutdown, a licensee may request removal of some requirements that are needed for facility operation, including those for maintaining

- technical specifications

- combustible gas control

- emergency core cooling system

- environmental qualification

- fracture prevention.

\subsection{Unrestricted Site Release Criteria, Waste Management, and Safety}

This section reviews the criteria for unrestricted site release and radiological survey methods. Typical information provided by a facility to address managing radioactive waste and typical accident scenarios during decommissioning are also presented.

\subsubsection{Radioactive Waste}

In the PSDAR, the NPP defines detailed radiation protection features and methods for controlling radioactive wastes including

- off-gas treatment and ventilation

- vent collection system

- containment ventilation system

- fuel and auxiliary building ventilation system

- liquid waste treatment and retention

- clean radioactive waste system

- dirty radioactive waste system

- solid wastes

- spent resin transfer system

- filter handling

- process and effluent monitoring systems

- liquid monitoring systems

- liquid radioactive waste discharge monitoring system

- component cooling water monitoring system

- liquid sample collection system

- gas monitoring systems

- containment, auxiliary building, spent fuel pool building monitoring systems

- radiation protection

- shielding, radiation zoning, and access

- control

- area radiation monitors

- control of personnel radiation exposure

- AlARA 
- policy considerations

- design considerations

- operational considerations.

\subsubsection{Decommissioning Accident Analysis}

Following the decision to permanently shut down and defuel a facility, accidents associated with reactor operation are not applicable. Accidents associated with irradiated fuel storage and radioactive waste storage and handling remain applicable. Examples of potential decommissioning accidents for analysis include

- radioactive gas waste system leak or failure

- failure of a waste gas decay tank

- failure of a liquid waste tank

- fuel handling accident

- dropped fuel assembly

- spent fuel pool accidents resulting in

- loss of spent fuel pool decay heat removal

- spent fuel pool draindown.

Possible initiating events may include

- explosions

- toxic chemicals

- fire

- loss of intake structure

- cooling tower collapse

- seismic events.

\subsubsection{Release Criteria for Decommissioning}

NRC Regulatory Guide 1.86, "Termination of Operating Licenses for Nuclear Reactors," provides regulatory limits for unrestricted release and for the following types of residual radioactivity:

- surface contamination of structures, structures, and components

- induced contamination of structures, components, and equipment

- volumetric contamination of soil and debris

- contamination of groundwater.

Surface and induced contamination

Acceptable surface and induced contamination levels inside structures can be no more than $5 \mathrm{FR} / \mathrm{hr}$ at 1 meter.

\section{Volumetric contamination}

Volumetric contamination of soil and debris can produce an exposure rate of no more than $10 \mathrm{FR} / \mathrm{hr}$ at 1 meter. 


\section{Groundwater}

Contamination of groundwater is controlled by U.S. EPA drinking water standards. The allowed dose is $4 \mathrm{mrem} / \mathrm{yr}$.

\subsubsection{Surveys to Support Decommissioning}

Surveys are performed both indoors and outdoors to determine acceptability for site release: Indoor surveys are based upon readings on a 1- or 2-meter grid and scan, while open land outdoor surveys are based on a 10-meter grid soil sampling and scanning.

\subsubsection{Proposed Updates for Unrestricted Release Criteria}

Proposed revisions to the Decommissioning Rule include having NPPs decommission a facility so that any residual radioactivity levels are indistinguishable from background. Additionally, proposed updates to the Decommissioning Rule include a dose-based criterion for unrestricted release of $15 \mathrm{mrem} /$ year from all dose pathways combined. Restricted release would be acceptable if further contamination reduction is not technically achievable, is prohibitively expensive, or would result in public or environmental harm. However, sufficient financial insurance is required to support oversight.

\subsection{Public Involvement}

This section presents the policy for public involvement in planning and conducting decommissioning activities, including

- public involvement in the licensing process

- nature of public concerns

- how the NRC provides information to the public

- how public concerns can influence decommissioning plans

- guidance on effective ways to address public concerns.

\subsubsection{Public Involvement}

Although the public can make recommendations, and although there is a requirement for public hearings, the public cannot make binding decisions. Typically, the nature of public concerns centers on uncertainties about public safety from a new nuclear activity (decommissioning), the release of radioactivity, the offsite shipment of radioactive wastes, and the cessation of emergency planning activities with the nearby community after plant shutdown.

The NRC philosophy on public involvement is essentially to abandon the old AEC philosophy of secrecy and be open to the public, to seek their comments and respond seriously to their concerns. The NRC tries to act as arbiter between licensee/applicant and the public and provides accurate and non-sensational information to news media.

The U.S. experience in the last thirty years has identified a number of methods for involving the public during the planning and implementation of an NPP decommissioning:

- provide information to the newspapers

- provide information to the electronic media (TV and radio)

- supply information to public document rooms

- respond to written and telephoned questions 
- conduct public meetings.

Experience shows that public meetings are the most effective public involvement method but must be carefully managed.

\subsubsection{Guidelines for Public Meetings}

The NRC has suggested the following guidelines for organizing and running public meetings:

- It is important that the meeting be publicized, including the date, location, and intended purpose of the meeting.

- Meetings should be held in the evening near the facility to be decommissioned.

- Meetings should be moderated by local government officials to highlight their involvement.

- Inspect the meeting location early and provide for appropriate security.

- The meeting itself should not deviate from its publicized agenda.

- Subsequent to the meeting, a written transcript of the meeting should be prepared and distributed.

- Questions that cannot be answered orally at the meeting should be answered in writing as an addition to the transcript. 


\subsection{The Russian Legislative and Regulation Environment}

There are 29 electrical power units in operation in nine nuclear power plants with a total capacity of $21,242 \mathrm{MW}(\mathrm{e})$, which constitutes $10.6 \%$ of the total electrical energy capacity of Russia.

As shown in Table 3.1, NPP units with various kinds of nuclear energy reactors are in operation:

- $440 \mathrm{MW}(\mathrm{e})$ units with VVER-440 water-moderated water-cooled power reactors.

(modifications V-179, V-230 and V-213)

- 1,000 MW(e) units with VVER-1,000 water-moderated water-cooled power reactors. (modification V-187, V-338 and V-320)

- 1,000 MW(e) units with RBMK-1,000 reactors (channel-type with graphite moderator, lowenriched fuel, and uninterrupted refueling).

In addition, there are four units with low-power [12.5 MW (e)] EGP-6 water-graphite channel reactors in operation at the Bilibinsk NPP and a unit with the BNB600 fast neutron reactor with sodium coolant at the Beloyarsk NPP.

There are two independent operating organizations in Russia: Rosenergoatom, made up of the units of the Balakovsk, Beloyarsk, Bilibinsk, Kalininsk, Kolsk, Kursk, Novovoronezhsk and Smolensk NPPs; and the Leningrad NPP with four units with RBMK-1,000 reactors (Table 3.1).

Since 1981, two units of the Beloyarsk NPP, similar to the RBMK water-graphite channel AMB reactors, and two units of the Novoronezhsk NPP with VVER-210 and VVER-365 reactors have been shut down for decommissioning. Ten additional NPP units will have completed their service life by the year 2006, and it will become necessary to decide the issue of their decommissioning. By 2010 , service lives will be completed and decommissioning will be needed for 24 units with a total capacity of $12,565 \mathrm{MW}$.

Country-wide, the basic provisions of the operating concept for decommissioning nuclear units was developed by the Ministry of Atomic Energy and Industry of the former Soviet Union. In 1991, the Ministry of Atomic Energy and Industry prepared and adopted the Concept for the Decommissioning of NPP Units, in which attempts were made to identify strategies and general approaches to the planning and solving of decommissioning problems. The basic provisions of the concept adopted for the decommissioning of NPP units include the following:

1. Decommissioning of units or NPPs, as a rule, must proceed after the service life has been exhausted or in the event it becomes technically impossible to provide further safe operations.

2. When planning for the decommissioning of NPP units, it is necessary to proceed from the principle of renovation (full restoration) or replacement of exhausted power plants with new and safer units.

3. Site of decommissioned NPPs should be used to the greatest extent possible.

4. Buildings, structures, and equipment from decommissioned units or NPPs should be put to the greatest possible use in the interests of conducting scientific research on problems of safety of operating and future NPPs and to promote the approval of design concepts for new nuclear units.

5. It is necessary to evaluate the feasibility of conversion of decommissioned NPP units. 
Table 3.1. List of Nuclear Power Plant Units in the Russian Federation 
According to current legislation in Russia, the decommissioning of an NPP unit involves activities after removing nuclear fuel from the unit, preventing its use as an energy source and providing for the safety of personnel, the population, and the environment. In strict compliance with this definition, Russian organizations operating NPPs at this time are not prepared to fully implement decommissioning. Nor are they prepared to reprocess, transport, and bury the large quantities of radioactive wastes associated with decommissioning. Moreover, the experience in Russia is that shutting down an NPP unit does not mean that it is in a safe condition. This is corroborated by the 1992 incident in the stage-one units of the Beloyarsk NPP, where there was a spill of radioactive wastes while burying liquid wastes.

In 1993, there was a joint conference of GAN and leaders of ministries and organizations responsible for operational safety during decommissioning of shutdown stage one units of the Beloyarsk and Novoronezhsk NPPs. This conference examined and analyzed violations of nuclear and radiation safety principles at these units, and revealed the absence of agreed-upon plans for conducting decommissioning these units and the financial and technical support that would require resources. Based on inspections and the results of the conference, GAN has made it mandatory that normal operating regimes be ensured at these shutdown units.

Authorization was given only to conduct operational maintenance activities at the first stage units of the Beloyarsk NPP. Due to the possible effects on the safety of existing units, the dismantling of equipment of Novovoronsk NPP Units 1 and 2 has been prohibited. As a result, dismantling operations are not being conducted on shutdown NPP units. According to information from Rosenergoatom, which is the using organization of the NPPs mentioned above, only decommissioning preparatory work is being conducted on the shutdown units.

In connection with the above observations, Russia's primary technical concepts on the decommissioning of NPP units are aimed at the long-term safety oversight or conversion of shutdown nuclear units.

Considering the condition of NPP sites, the country's lack of regional burial sites for the storage/ internment of highly active radioactive wastes from NPPs, and foreign and domestic experience in the decommissioning of research and experimental nuclear installations, Rosenergoatom has recommended the following basic stages for the decommissioning of NPP units:

1. Shut down the unit.

2. Unload nuclear fuel from the reactor and from the unit

3. Temporarily hold (conservation) the shutdown unit

4. Dismantle nonradioactive systems and partially dismantle slightly radioactive systems and equipment of the unit

5. Maintain the unit in a safe condition for the long term

6. Completely dismantle and bury the reactor section of the decommissioned units

7. Completely eliminate decommissioned NPP units.

In October 1995, a working conference of representatives of GAN and the member-states of Euratom was held in Moscow. This conference was devoted to an analysis of problems in licensing the decommissioning of NPP units. GAN, in analyzing work begun on decommissioning shutdown NPP units in Russia, and in analyzing the current state of these units, noted the following causes for delays in the organization and full-scale decommissioning operations: 
- lack of a legislative groundwork to ensure safety of the population when radioactive materials and radioactive substances are being handled

- lack of legislative requirements for a number of specific features for providing safety when working at decommissioning NPP unit

- imprecision in organizing reprocessing or safe long-term storage of spent nuclear fuel of NPP units with RBMK reactors

- unpreparedness of process and technical resources for providing safety during dismantling activities

- lack of reliable burial sites for interring large quantities of radioactive wastes formed during decommissioning of the NPP units

- chronic non-fulfillment of plans for producing and financing preparatory work on decommissioning NPP units.

These situations and causes blocking the development of large-scale decommissioning of shutdown NPP units in Russia are also characterized in the 1995 reports on the activities of GAN.

This document presents a description of Russian legislation and statutes governing the decommissioning of NPP units. Attempts have been made to analyze adequacy of the legislation and statutes. The Russian approaches to procedures in licensing decommissioning of NPP units are also described.

\subsection{Regulating Activities in the Nuclear Power Sector}

All activity in the nuclear power environment, as in the nuclear energy sector as a whole, is regulated by a system of legislation and regulatory documents. This system regulates activities in the nuclear energy sector and has a multi-layer hierarchical structure. The following are the legislative and regulatory documents of this system:

- Laws of the Russian Federation

- Regulatory Statements of the President and of the Government of the Russian Federation

- Federal regulations and rules governing the uses of nuclear power

- Regulations and rules of government safety regulatory agencies in the nuclear energy sector

- Government standards, building rules and regulations, and regulations of government nuclear energy regulatory agencies.

The structure of this system is illustrated in Figure 3.1.

The first level of this system includes Laws of the Russian Federation, establishing legal relationships in the use of nuclear energy. Among the primary laws in effect in Russia governing the use of nuclear energy are the Law of the Russian Federation on the Use of Nuclear Energy, the Law of the Russian Federation on Radiation Safety of the Population, and the Law of the Russian Federation on Preserving the Environment. The Law of the Russian Federation on Handling Radioactive Wastes is in the preparatory stage.

The second level of this system is the Regulatory Statements of the President and of the Government of the Russian Federation. This level includes provisions of the federal executive agencies implementing government control over the use of nuclear energy (for example, Decrees of the President of the Russian Federation on the Ministry of Nuclear Energy of the Russian Federation 
Figure 3.1. Structure of the Russian Legislative and Regulatory Environment on Use of Nuclear Energy in the Russian Federation 
and on Operating Organization of Nuclear Power Plants or the Russian Federation) and government regulation of safety in the use of nuclear energy (for example, the Decree of the President of the Russian Federation on GAN) and also about 30 documents that are being developed in the implementation of the Law of the Russian Federation on the Use of Nuclear Energy.

The federal executive agency regulating the use of nuclear energy is the Ministry of Atomic Energy of the Russian Federation (MINATOM RF). Federal executive agencies regulating safety in the use of nuclear energy are GAN, Gossanepidhadzor Russia, Gosorgtekhnadzor Russia, and the Main Administration of the Government Fire Service attached to the Ministry of Internal Affairs Russia.

The third level of this system includes federal regulations and rules governing safety in the use of nuclear energy. Federal regulations and rules governing safety in the use of nuclear energy are approved by the government nuclear safety regulatory agencies mentioned above. Federal regulations and rules related to statutes establishing requirements for the safe use of nuclear energy, including requirements for nuclear, radiation, technical and fire safety, requirements for physical protection, and control and accounting of nuclear materials, radioactive substances and radioactive wastes. These federal regulations and rules are approved by federal executive agencies implementing government control over the use of nuclear energy.

In accordance with Article 6 of the Law of the Russian Federation on the Use of Nuclear Energy, these regulations are mandatory when performing any type of activity involving nuclear energy. Federal regulations and rules are effective throughout the Russian Federation. Considering the mandatory requirement for compliance with federal norms and regulations, these statutes contain the aims, general requirements, principles, and criteria on providing nuclear and radiation safety, and specific requirements for systems and elements of the nuclear energy user.

The specific requirements define the levels for providing nuclear and radiation safety and are formulated so that the initiative of the organizations and specialists engaged in the specific activities involved. Federal regulations and rules involving the safe use of nuclear energy are divided into three groups described in the next three subsections.

\subsubsection{Group One}

Group One includes documents containing federal regulations and rules that establish the aims, principles, and criteria for nuclear safety and the technical aspects of radiation safety, and the general requirements regulating the different aspects of safety related to various types of nuclear energy facilities.

\subsubsection{Group Two}

Group Two includes documents defining federal norms and regulations for the sanitation and hygiene aspects of radiation safety.

\subsubsection{Group Three}

Group Three includes documents defining federal norms and regulations for fire safety. The structure of federal regulations and rules in the use of nuclear energy is presented in Figure 3.2. Federal regulations and rules are developed and approved in accordance with the procedure established by the government of the Russian Federation. These regulatory documents, before 
Figure 3.2. Structure of the Russian Federation Regulations and Rules on Nuclear Power Utilization 
approval, must be officially coordinated with other safety regulatory agencies and, when necessary, sent for concurrence to MINATOM Russia, if they come under the jurisdiction of other safety regulatory agencies.

In accordance with the provisions on federal executive safety regulatory agencies governing the use of nuclear energy, GAN is responsible for activities concerned with the organization, development, approval, and introduction of federal norms and regulations involving nuclear and radiation safety.

The primary tasks of GAN are

- participation in the formulation and implementation of the system of legal, organizational, and technical measures for providing nuclear and radiation safety

- establishment of criteria, regulations, and norms for nuclear and radiation safety

- regulation and oversight of compliance by federal executive agencies, enterprises, organizations, and members of the citizenry with the legislation of Russia for nuclear and radiation safety during the production, handling, and use of nuclear energy

- licensing of activities associated with nuclear energy users during their entire life cycle, including their decommissioning, the conduct of safety reviews, and a number of other tasks enumerated in the provisions governing GAN.

A diagram of the administrative and regional structure of GAN is presented in Figure 3.3. As seen in Figure 3.3, the Technical Science Center for Nuclear and Radiation Safety falls under GAN. The primary tasks of the Technical Science Center are

- scientific and technical support of GAN

- analysis and justification of criteria and principles of nuclear and radiation safety, and also the organization and coordination of the review and development of regulations, norms, and other documents required by GAN for safety regulation

- participation in the licensing for nuclear-hazardous and radiation-hazardous facilities and the conducting of boards of review

- the certification and verification of computer programs and methods.

The distribution of federal norms and regulations governing the safe use of nuclear energy in facilities under construction, in operation, and decommissioned has been re-worked and approved by GAN. This distribution must be undertaken considering the economic feasibility of technical and organizational measures proposed for implementation.

The necessity, scope, and time table for bringing facilities under construction, or in operation and those being decommissioned into compliance with re-worked and re-introduced federal norms and regulations in the area of safe use of nuclear energy are determined by the operating organization or by other legal entity bearing full responsibility for safety in the use of nuclear energy and approved by GAN.

\subsubsection{Group Four}

Group Four includes statutes and regulatory documents of GAN. Prior to the adoption in the Russian Federation of the Law on the Use of Nuclear Energy, GAN undertook its activities on the basis of a list of normative and technical documentation (the List), which is the legal basis for 


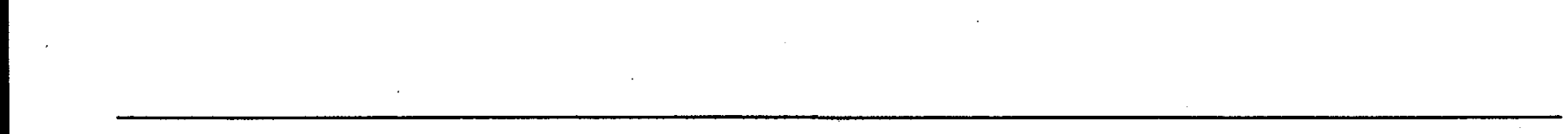

Figure 3.3. Diagram of Administrative and Regional Structure of GAN 
the cooperation between GAN and the ministries, agencies, and organizations in providing nuclear, radiation, technical, and fire safety at all stages of the life cycle of nuclear energy facilities, including decommissioning.

A three-tiered structure, including documents of conceptual, regulatory, and methodological levels, served as the basis for building the List in the area of safety for nuclear power facilities, considering the recommendations formulated in INSAG (IAEA) document Basic Principles of Safety for Nuclear Power Plants.

The first (conceptual) level included documents defining the basic concepts, aims, and principles of safety.

The second (regulatory) level included documents containing established norms and regulations, which covered and made specific the basic provisions of documents of the first level. In the aims of a fuller detailing of general technical and specific principles of safety formulated in INSAG (IAEA) documents, first-level documents of the List were divided into five sublevels.

The third (methods) level included documents for the determination of recommendations for implementing the requirements formulated in the level-two documents. With this aim, documents of the methods level had the same subsections as did the documents of the second, or regulatory, level.

The structure of the List described above and used previously by GAN, in the area of safety of facilities that use nuclear power, is presented in Figure 3.4.

After the introduction of the Russian Federation of the Law on the Use of Nuclear Energy, the List was amended to bring it into compliance, since a number of documents on the List, mainly regulatory documents of the conceptual and regulatory levels, had acquired the status of federal norms and regulations. Now, the List of Gosatomnadzor Russia includes instructions on nuclear and radiation safety (safety instructions) and guidelines. Safety Instructions contain regulations governing nuclear and radiation safety, recommendations, methods and instructions that must be considered by the applicant (licensee) in providing safety of facilities that use nuclear energy.

GAN defines the mandatory requirements for the fulfillment by the licensee (applicant) of requirements for providing safety for facilities that use nuclear energy. If the licensee uses other solutions, then he must present the necessary justification on the basis of which GAN will decide on the sufficiency of these alternative solutions for providing safety to the facility that uses nuclear energy.

\subsubsection{Guidelines of GAN}

Guidelines can be divided into six groups based on their function and level of obligation:

Group One Organizational and administrative guidelines of GAN that define the tasks and functions of the central apparatus of GAN, its regional agencies and organizations, and organizational aspects of GAN. Mandatory for specialists of GAN and its organizations. 
Figure 3.4. Structure of a List of Documents on Main Technical Standard and Rules of GAN 
Group Two Instructions, methodologies, and guidance on nuclear and radiation safety, work methods, and methods for calculations, appraisals, and safety evaluations. Group 2 also contains documents with recommendations on implementing the requirements of federal norms and regulations (as they relate to nuclear and radiation safety).

The obligation of fulfillment of the requirements of the guidelines of this group can be determined by the licensing conditions.

Group Three Guidelines regulating the implementation of licensing activities. These guidelines are mandatory, both for GAN and for the licensee.

Group Four Guidelines governing oversight of nuclear and radiation safety. These guidelines are mandatory for GAN specialists.

Group Five Guidelines containing methods and methodologies for fulfillment by the licensee of oversight functions implemented by GAN specialists. These guidelines apply to GAN inspectors.

Group Six Guidelines containing information on the activities of GAN. They include, for example, annual reports, policy statements, etc.

Level Five in the system of regulations and rules in Russia includes government standards, building norms, and regulations and regulatory documents of agencies that control the use of nuclear energy and other agencies and organizations.

In accordance with the government system of standardization (GOST) of the Russian Federation (GOST R 1.0B92), regulatory documents on standardization are divided into the following categories:

- Government standards of the Russian Federation (GOST R); that is, national standards approved by the Government Committee of the Russian Federation on Standardization, Metrology and Certification (Gosstandart Russia) or by the Ministry of Architecture, Building and Housing of the Russian Federation (Minstroy Russia)

- Industry standards - OST, approved by the ministries (agencies) of the Russian Federation

- Technical specifications, which are the regulatory documents for a specific product (service) approved by the factory manufacturer

- Standards of enterprises and organizations - STP (unions, associations, concerns, joint stock companies, inter-industry and regional affiliations, etc.)

- Standards of scientific and technical associations and engineering societies - STO (unions, associations, and other organizations).

This level includes regulatory documents developed by Rosenergoatom and is provided to supplement and recommendations on providing safety in the operations and decommissioning of NPP units in Rosenergoatom.

\subsection{Laws of the Russian Federation Regulating the Legal Basis of Decommis- sioning Nuclear Power Plant Units}

In Russia, the legal basis of activities in the use of nuclear energy for peaceful and defense purposes (except for activities associated with development, manufacture, testing, operation, and disposition of nuclear weapons and nuclear energy installations used for military purposes) is regulated by the following laws: 
- "On the Use of Nuclear Energy," adopted by the Government Duma of the Russian Federation on October 20, 1995

- "On Radiation Safety of the Population," adopted by the Government Duma of the Russian Federation on December 5, 1995

- “On Environmental Safeguards," entered into force on December 19, 1991

and a number of other federal laws affecting the establishment of legal relations in the area of the use of nuclear energy.

\subsubsection{Law of the Russian Federation on the Use of Nuclear Energy}

The Law of the Russian Federation on the Use of Nuclear Energy defines the legal basis and principles of regulating the relations arising with the use of nuclear energy.

The basic principles of Article 2:

- safety - safeguards of individuals and the environment against radiation danger

- accessibility of information

- participation in discussions of government policy, drafts of federal legislation, other acts of the Russian Federation, and in the practical activities in the use of nuclear energy

- compensation for losses caused by radiation effects to citizens and workers of facilities that use nuclear energy, and the social protection of the citizens living and/or working at sites where nuclear energy is used.

Article 3 of the Law defines facilities subject to this Law as nuclear installations, radiation sources, burial sites for nuclear materials and radioactive substances, vaults for radioactive wastes, and other nuclear-hazard and radiation-hazard facilities throughout their life cycle, including decommissioning.

Article 4 defines the types of activities to which this Law applies, including:

- location, design, construction, and operation of nuclear installations, radiation sources, and burial sites for nuclear materials and radioactive wastes

- handling nuclear materials and radwastes

- ensuring safety when using nuclear energy

- control over nuclear, radiation, technical and fire safety of nuclear installations, radiation sources, and burial sites of nuclear materials and radwastes

- physical protection of nuclear installations, radiation sources, and burial sites of nuclear materials and radioactive wastes

- accounting and control of nuclear materials and radioactive substances.

Article 5 states that non-defense nuclear installations and radioactive waste and radioactive material burial sites come under federal jurisdiction unless otherwise established by law. All nuclear materials, radioactive wastes containing nuclear materials, and defense nuclear installations are under federal jurisdiction.

Articles 7-12 define the authority of the President of the Russian Federation, the Government of the Russian Federation, and the higher agencies of the representative, legislative, and executive powers of the Russian Federation and of the Subjects of Federation, nuclear regulatory agencies, 
and safety regulatory agencies. These articles also present the legal status of organizations that use nuclear energy.

The President of the Russian Federation determines the basic directions of government policy and makes decisions on matters of safety, warning, and response to emergencies involving the use of nuclear energy.

The Government of the Russian Federation

- defines the functions, operating procedures, principles, and obligations of nuclear regulatory agencies and nuclear safety regulatory agencies in accordance with legislation of the Russian Federation.

- controls nuclear materials, nuclear installations, radiation sources, and burial sites of nuclear materials, radwastes, and radioactive substances.

- makes decisions on the design, construction, operation, and decommissioning of nuclear installations, radiation sources, and burial sites for nuclear materials and radwastes under federal jurisdiction or having federal or international significance, including those located on the territories of closed administrative territorial entities.

Appraisal of design and other documents on nuclear energy and safety and protection of the environment with the use of nuclear energy, including decommissioning of nuclear installations, is under the combined jurisdiction of the Russian Federation and the Subjects of the Russian Federation.

Articles 13-14 define rules of organizations and citizens in the use of nuclear energy. These articles establish that organizations, including social organizations, and citizens have the right to participate in the discussion of issues relating to the location, construction, operation, and decommissioning of nuclear installations, radiation installations, and burial sites for radioactive wastes. They also have the right to recommend their own representatives for participation in appraisals at all stages of the life cycle.

Articles 23-24 establish that government safety regulation is implemented through authorized federal executive agencies commissioned by the President or the government. Government safety regulatory agencies regulate nuclear, radiation, technical, and fire safety. These agencies are independent of other government agencies and of organizations whose activities involve the use of nuclear energy.

Articles 26-27 of the Law determine that any activity in the area of the use of nuclear energy must be conducted only upon the appropriate authorization (license) granting the right to work. Licenses providing the right to work in the use of nuclear energy are issued by government safety regulatory agencies. The licenses are issued by the using organizations and also by organizations providing services in the area of the use of nuclear energy.

The activities for whose implementation a license is required and the procedures for issuing and repealing licenses are established by the Government of the Russian Federation.

Article 28 of the Law establishes that the decision on the design, construction, operation, and decommissioning of nuclear installations, radiation sources, burial sites for nuclear materials and radioactive substances, and vaults for radioactive wastes under federal jurisdiction or having federal or international significance, including those located on the territories of closed administrative and territorial entities, are made by the Government of the Russian Federation. 
Article 33 establishes that procedures and methods for decommissioning nuclear installations, radiation sources, and sites for the burial of radioactive wastes must be provided in the design of the facility for the use of nuclear energy in accordance with norms and regulations governing the use of nuclear energy.

Procedures for financing the decommissioning of nuclear installations, radiation sources, and burial sites for radioactive wastes are established by the government and must be defined before they are put into operation.

Proposals on decommissioning nuclear installations, radiation sources and site for the burial of radioactive wastes before the expenditure of resources set aside in the design for the use of nuclear energy may be introduced by government agencies of the Russian Federation, government agencies of the Subjects of the Russian Federation, agencies of local government, and social organizations when there is proper justification.

Decisions on early decommissioning of facilities that use nuclear energy are taken by agencies of the federal or local governments who previously decided their construction or by their successors before the timely notification of the operating organization in consideration of the technological and ecological capabilities of the using organization.

If it is decided to decommission a nuclear installation, radiation source or burial site for radioactive wastes early, not because of technical or ecological factors, losses accompanying such a decision are subject to compensation at the expense of the appropriate agencies that have made the decision.

Articles 34-35 of the Law determine that the complete responsibility for safety of the nuclear installation, including decommissioning, burial of nuclear materials and radioactive wastes, and the necessary handling of nuclear materials and radioactive substances, is borne by the using organization. The using organization must have complete authorization and financial, material, and other resources adequate for accomplishing its functional taskings.

The using organization, together with the corresponding nuclear regulatory agencies, establish a special fund for financing expenses associated with the decommissioning of nuclear installations, radiation sources, and sites for the burial of radioactive wastes. This fund is part of the resources stipulated by the budgets of the corresponding levels. Sources for putting this fund together and procedures for using it are established by the government.

The organization performing the work and providing services to the using organization shall bear responsibility for the quality of the work performed and services provided throughout the service life of the nuclear installation, radiation source, and site for burial of radioactive wastes or equipment developed for these sites.

\subsubsection{The Law of the Russian Federation on Radiation Safety of the Population}

The Law of the Russian Federation on Radiation Safety of the Population defines the legal basis for providing radiation safety of the population in the interests of preserving its health.

Article 3 establishes the principles for providing radiation safety, basic hygiene norms of irradiation (permissible threshold doses), and required measures for providing radiation safety:

- Principle of regulation - Permissible limits of individual doses to citizens from all sources of ionizing radiation are not exceeded 
- Principle of justification - Prohibits all uses of ionizing radiation in which the benefits derived for man and society does not exceed the risk of possible damage caused by the irradiation and beyond the existing radiation background

- Principle of optimization - keeping individual doses of radiation and the numbers of irradiated persons when using any source of ionizing radiation at the lowest possible level in light of economic and social factors.

Article 4 of the Law establishes that radiation safety must be ensured through conducting legal, organizational, technical engineering, preventive medicine, and educational measures. Radiation safety must be ensured through the implementation of measures that observe the regulations, rules, and norms of radiation safety by government agencies of the Russian Federation, government agencies of the Subjects of Federation, and agencies of local government as well as other legal entities and members of the citizenry. Radiation safety is also ensured by keeping the populace informed of the radiation environment and of measures in force to ensure radiation safety.

Article 7 establishes that government control of radiation safety is exercised by the Government of the Russian Federation, by specially authorized federal executive agencies, and by executive agencies of the Subjects of Federation.

Government oversight and control of radiation safety is exercised by authorized federal executive agencies.

Article 9 establishes that government regulation of radiation safety is exercised through the establishment of sanitation regulations, norms, hygiene regulations, principles of radiation safety, government standards, building regulations, and labor rules, and instructions, controls, methods documents, and other documents governing radiation safety.

Sanitation regulations, norms, and hygiene regulations governing radiation safety are approved in procedures established by legislation of the Russian Federation and by federal executive sanitation and epidemiology oversight agencies.

As of January 1,2000, the following basic hygiene regulations (permissible threshold doses) or irradiation will be in force in the Russian Federation:

- For the populace - the average annual effective dose will be 0.001 sievert (Sv); the effective lifetime dose ( 70 years) will be $0.07 \mathrm{~Sv}$. In individual years, higher effective doses are permissible under the condition that the average annual effective dose calculated for the five succeeding years does not exceed $0.001 \mathrm{~Sv}$

- For workers - the average annual effective dose will be $0.02 \mathrm{~Sv}$; the effective dose for the working life ( 50 years) will be $1 \mathrm{~Sv}$. Irradiation in an annual effective dose to $0.05 \mathrm{~Sv}$ is permissible under the condition that the annual effective dose calculated for the five succeeding years does not exceed $0.02 \mathrm{~Sv}$.

The regulated basic threshold doses of irradiation do not include doses from natural radiation and technogenically altered radiation background or doses absorbed by members of the citizenry (patients) during medical $\mathrm{X}$-ray procedures and treatment.

In the event of a radiation accident, irradiation exceeding the established basic hygiene regulations (permissible threshold doses) over a certain time interval and in a range defined by sanitation norms and regulations is permitted. 
Article 10 of the Law determines that scientific research work and experimentation in handling sources of ionizing radiation, designing and constructing sources of ionizing radiation, and transportation, storage, use, servicing, disposition, and burial of sources of ionizing radiation are performed only by special licenses issued by the appropriate agencies.

Article 13 establishes that during planning and conducting of radiation safety measures and when making decisions involving radiation safety, the effectiveness of these measures be analyzed by agencies of the federal and local governments and by organizations engaged in the use of sources of ionizing radiation.

A radiation safety survey must be implemented for the following basic indicators:

- characteristics of radioactive contamination of the environment

- analysis of radiation safety measures and of the fulfillment of norms, regulations, and hygiene rules governing radiation safety

- probability of a radiation accident and its scale

- degree of readiness for effective emergency response

- analysis of doses of irradiation absorbed by individual groups of the citizenry from all sources of ionizing radiation

- numbers of persons subjected to irradiation above established threshold doses.

The results of the radiation safety survey are to be recorded annually in the radiation hygiene log of the organization and site. Procedures for the development of radiation hygiene logs for the organization and site are approved by the Government of the Russian Federation.

Article 14 of the Law establishes that, when handling sources of ionizing radiation, the organization must comply with the following radiation safety requirements:

- plan and implement radiation safety measures

- ensure the radiation safety of materials and substances, technological processes, and products that are sources of ionizing radiation in support of public health

- implement systematic production control and monitoring of the radiation environment at the work place, in facility spaces, on the sites of organizations, in sanitation safety and observation areas, and control and monitoring of releases and discharges of radioactive substances

- provide accounting and control of individual doses of irradiation of workers

- regularly inform workers (personnel) on the levels of ionizing radiation at their work places and on the amounts of individual doses of radiation absorbed by them.

Article 15 establishes a ban on the use of building materials and products that do not comply with requirements for radiation safety.

Article 19 of the Law establishes that an organization in which a radiation accident is possible must have

- a list of potential radiation accidents with forecasts of their consequences and of the radiation environment

- criteria for making decisions in the event of a radiation accident 
- a plan of measures to safeguard the workers (personnel) and the populace from a radiation accident and its effects, coordinated with agencies of local government and executive agencies exercising government oversight and control of radiation safety.

Article 21 of the Law establishes that the scheduled excess irradiation of members of the citizenry employed in emergency response, rescue operations, and decontamination work may be invoked only by the need to save lives and/or to prevent their increased irradiation. The irradiation of members of the citizenry involved in emergency response must not exceed 10 times the average annual values of basic hygiene regulations governing irradiation for workers (personnel) as defined by this Law.

A scheduled increase in irradiation of members of the citizenry involved in emergency response is permitted on a one-time lifetime basis under their voluntary consent and having been informed ahead of time as to the possible doses of radiation and the risk to their health.

Article 26 of the Law establishes that members of the citizenry have the right to compensation for damages to their life and health and/or compensation for their losses caused by irradiation from ionizing radiation or as a result of a radiation accident causing above basic threshold doses as established by this Law.

Article 28 establishes that persons at fault for not complying with, or for violation of, radiation safety requirements shall incur administrative, civil, legal, and criminal liabilities in accordance with the laws of the Russian Federation.

\subsubsection{Law of the Russian Federation on Environmental Protection}

This law, in conjunction with organizational, legal, economic, and educational measures, is intended to facilitate the formation and consolidation of ecological law and order and ensure environmental safety in the territory of the Russian Federation and of the republics making up the Russian Federation.

Article 4 of the Law establishes that the following are subject to safeguards against contamination, injury, damages, and destruction in the territory of the Russian Federation and the constituent republics:

- natural ecological systems and the atmosphere's ozone layer

- the earth, its mineral resources, surface and subterranean waters, the air, forests and other vegetation, animals, microorganisms, the gene pool, and natural landscapes.

Article 7 of the Law refers to the jurisdiction of specially authorized government agencies of the Russian Federation in the area of environmental protection: the organization of environmental monitoring; the establishment and support of activities of the government environmental oversight service; the approval of norms and regulations; participation in the development of standards regulating the use of natural resources and protection of the environment against contamination and other harmful effects; the implementation of a government panel on the ecology; the issuing of licenses for the burial (warehousing) of industrial, household, and other wastes; and releases and discharges of contaminants into the environment.

Article 8 of the Law establishes that the following activities fall within the purview of constituent republics of the Russian Federation and autonomous regions in the area of environmental protection issuing licenses to use the land, natural resources, waters, forests and other vegetation, and animal life for locating, reprocessing, and burial (warehousing) of industrial, household, and 
other wastes; the management of the ecology service and the convening of government ecology boards; government ecological control and monitoring and adoption of resolutions on limiting and halting activities that have a harmful effect on the environment.

The following activities fall under the jurisdiction of the districts, regions, and agencies of local government in the area of environmental protection (Articles 9 and 10): accounting and control of the amount of wastes formed in production and spent products at the enterprises, institutions and organizations located in the territory of the region, independent of their affiliation or form of ownership.

Articles 25-34 of the Law define the necessity for regulating environmental quality. They establish basic requirements for regulating environmental quality, for regulating the maximum permissible concentration of contaminants and the maximum permissible level of releases and discharges of contaminants and other harmful effects. Regulations governing the maximum permissible level of radioactive contaminants in the environment and of combustion byproducts and the maximum permissible exposure of the populace are established at levels not posing a danger to health or to the human gene pool. These regulations are approved by specially authorized government agencies of the Russian Federation in the area of environmental protection and sanitation and epidemiology oversight.

Articles 41-44 establish general ecological requirements governing the location and technical and economic justification of projects and design when constructing, renovating, and activating enterprises, facilities and other sites. When performing these types of activities, requirements for environmental protection and short- and long-term ecological, economic, demographic, and moral effects must be considered.

The technical and economic justification of projects and designs for the construction of enterprises, facilities and other sites must pass through a government panel and, when necessary, through a panel of experts from the citizenry at large. Projects that fail to satisfy ecological requirements are not approved, and work on implementing these projects is not to be financed.

Article 45 establishes general ecological requirements in the operations of enterprises, facilities, and other sites. Enterprises, institutions, organizations, and the citizenry are required to take effective measures to observe the technological regime and to satisfy the requirements for protection of the surroundings. The release and discharge of contaminants and burial of wastes are allowed on the basis of a license issued by authorized government agencies. The license establishes regulations for the maximum permissible release and discharge of contaminants and other conditions ensuring environmental protection and human health.

Article 48 establishes basic ecological requirements for energy facilities. When locating, designing, building, and activating nuclear power stations, measures must be taken to ensure complete radiation safety of the environment and of the populace in accordance with international regulations. It is prohibited to locate, design, or build a nuclear power station in heavily populated areas in earthquake-hazard areas, or close to major water reservoirs that serve the public.

Article 50 of the Law obligates enterprises, institutions, organizations, and the citizenry to observe regulations governing producing, storing, transporting, using, disposing, removing, and burying radioactive contaminants (sources of ionizing radiation, nuclear materials). This article requires that the maximum permissible norms of radiation not be exceeded, and in those cases where they are exceeded, to immediately notify radiation safety agencies about excess levels of 
radiation hazardous to human health and to the environment and to take emergency response measures to eliminate the contamination.

Importing radioactive wastes and materials from other countries for storage, burial, or submersion, and sending radioactive wastes and materials into space for burial are prohibited.

Article 54 requires enterprises, institutions, organizations, and citizens to take effective measures for the decontamination, reprocessing, warehousing, or burial of industrial and household wastes and to observe existing ecological, sanitation, hygiene, and disease control rules and regulations. It is prohibited to place toxic wastes, including wastes from the nuclear industry, at sites close to cities and other population centers and in other places where a hazard might be created for human health and the environment. The authorization to bury toxic wastes or otherwise dispose of radioactive wastes is issued by specially empowered government agencies of the Russian Federation in the area of environmental protection upon agreement with agencies of sanitation and disease control oversight of the Russian Federation.

Articles 68-72 define the tasks of government, industrial, and public services in the area of ecological control and monitoring: monitoring of the environment and any changes in its status brought about by industrial or other types of activities, verification of plans for environmental protection and emergency response, and compliance with requirements of environmental protection legislation and environmental quality regulations.

Articles 81-84 establish liabilities for ecological crimes: disciplinary liability for ecological misdemeanors, material liability for officials and other workers guilty of causing harm to the environment, administrative liabilities for ecological crimes, and fines for those who violate laws on ecology.

Articles 86-90 define the obligation for complete remuneration for losses caused by ecological crimes and establish procedures and limits of compensation for damages caused by ecological crimes.

Article 92 of the Law defines principles of international cooperation in the area of environmental protection, according to which the policies of the Russian Federation follow from the necessity for ensuring comprehensive ecological safety and the development cooperative efforts in international environmental protection in the interests of this and future generations.

\subsection{Russian Documents Regulating Procedures for Decommissioning Nuclear Power Plant Units}

The primary Russian regulatory documents and guidelines used when regulating procedures for the decommissioning of NPP units are

- "General Safety Regulations for Nuclear Power Plants" (OPBB88)

- "Principles of Nuclear Safety for Reactor Operation at Nuclear Power Plants" (PBYA RU ASB89)

- "Requirements for Quality Assurance of Nuclear Power Plants" (TS TOB ASB85)

- "Typical Content to Technical Safety Substantiation of Nuclear Power Plants" (TS TOB ASB85)

- "Typical Content to Nuclear Installation Safety Substantiation" (TS TOB RUB87) 
- "Requirements of Report Content on Technical Safety Substantiation for Nuclear Power Plants with V.VER Reactors" (OOB AS)

- "Norms of Radiation Safety" (NRBB96)

- "Basic Sanitary Rules for Handling Radioactive Substances and Other Sources of Ionizing Radiation" (OSPB72.87)

- "Sanitation Principles for NPP Design and Operation" (SP ASB88/93)

- "Radiation Safety Regulations on NPP Operation" (PRB ASB89)

- "Requirements to NPP Utilities" (RDB04B03B93)

- Draft "Guideline General Requirements to Safety Assurance for Decommissioning of Nuclear Power Plant Units."

\subsubsection{General Safety Regulations for Nuclear Power Plants (OPBB88)}

"General Safety Regulations for Nuclear Power Plants" (OPBB88) is the regulatory document at the federal level, regulating questions of safety flowing out of the specifics of the nuclear power plant (NPP) as a possible source of radiation effects on personnel, the populace, and the environment. This procedure establishes the aims, directions, and basic criteria of safety and basic principles and character of technical and organizational measures aimed at achieving safety, including safety during decommissioning.

This document regulates that the scope, fullness, and depth of implementation of principles and safety measures that are established in special norms and regulations.

Section 2.6, Decommissioning, defines the following requirements that must be observed during the decommissioning of NPPs:

- The decommissioning of the NPP (NPP unit) must be taken into consideration when designing and during operations, technical maintenance, and repair.

- The using organization, no later than five years before the NPP unit completes its design service life, must develop a project for decommissioning the unit and must coordinate this project with the government safety regulatory agencies.

- The decommissioning must be preceded by a comprehensive inspection of the unit by a commission designated by the using organization.

- On the basis of the results of this comprehensive inspection, a decision is made and a plan developed for decommissioning the NPP unit.

- Based upon requirements of the government safety regulatory agencies, the unit may be decommissioned before its service life expires if the condition of the systems important for safety or the unit itself does not completely provide safety of the NPP.

Also, in the existing plan of the new edition (OPBB88/96) of this regulatory document, the requirement for the development of a plan for decommissioning of the NPP unit, no later than five years prior to the expiration of its design service life, has been replaced with the requirement the development of a program for decommissioning of the NPP no later than five years prior to the expiration of its design service life. 


\subsubsection{Nuclear Safety Rules for Reactor Operation at Nuclear Power Plants (PBYA RU ASB89)}

"Nuclear Safety Rules for Reactor Operation at Nuclear Power Plants" (PBYA RU ASB89) is the regulatory document that establishes general requirements for the construction, characteristics, and conditions of operation of systems and elements of the reactor units and the organizational requirements aimed at ensuring nuclear safety when designing, constructing, and operating the reactor units. This document establishes requirements for technical designs of reactor units, which includes the measures for decommissioning while observing the requirements for safety.

\subsubsection{Requirements to NPP Quality Assurance Program}

Requirements to NPP quality assurance program is the regulatory document at the federal level that establishes the aims, basic principles, requirements for construction, and content for procedures in development, coordination, and approval of the "Quality Assurance Programs for Nuclear Power Plants" (POKAS) and for oversight and responsibility for their development.

The "General Quality Assurance Program for Nuclear Power Plants" (POKAS O) includes the special Quality Assurance Program for Decommissioning (POKAS VE).

This Decommissioning Program POKAS VE must be developed considering requirements of the General Quality Assurance Program for Nuclear Plants (POKAS O) before the start of the development of the technical and economic justification for the decommissioning of the NPP.

The Quality Assurance Program for Decommissioning (POKAS VE) must be coordinated with the general designer of the NPP, the general designer of the reactor unit, the Chief Scientist, the General Subcontractor and GAN, and also, when necessary, with the equipment shipping agent. The "Quality Assurance Program for Decommissioning (POKAS VE)" is approved by the using organization, which is also responsible for its development and implementation.

\subsubsection{Typical Content to NPP Technical Safety Substantiation (TS TOB ASB85)}

The regulatory document, "Typical Content to NPP Technical Safety Substantiation" (TS TOB ASB85) contains requirements for information templates concerning safety of the NPP on the whole and its individual systems that are important for NPP safety.

The regulatory document, "Typical Content to NPP Technical Safety Substantiation" (TS TOB AS), contains template requirements and guidelines for the content of NPP design materials on technical substantiation of safety (TOB AS), which is the subject of the review board at the design and project stage of the NPP.

Chapter 6, Decommissioning of the NPP, of the regulatory document TS TOB AS establishes that in the project and design of the NPP, questions must be illuminated that deal with decommissioning the NPP, which must be done in accordance with requirements of the regulatory technical documentation currently in effect. This document applies to NPPs already operational.

\subsubsection{Typical Content to Nuclear Installation Technical Safety Substantiation (TS TOB RUB87)}

The regulatory document, "Typical Content to Nuclear Installation Technical Safety Substantiation" (TS TOB RUB87), in essence and in content, is analogous to TS TOB ASB85 but contains requirements for typical information (structure) on safety of the reactor unit and its individual systems important for safety. This regulatory document contains typical requirements and 
guidelines for content of materials of the reactor unit design for technical safety substantiation (TOB RU) and is the subject of the review board at the reactor unit design and planning stage.

Chapter 6, Decommissioning the Reactor Unit, establishes that the planning and design of the reactor unit must illuminate questions concerning decommissioning of the reactor unit, which must be done in accordance with the requirements of regulatory and technical documentation effective at the time of approval of the technical design of the reactor unit. This regulatory document applies to operational reactor units.

\subsubsection{Requirements of Report Content on Technical Safety Substantiation for NPP with VVER Units (OOB AS)}

Requirements of "Report Content on Technical Safety Substantiation for Nuclear Power Plants with VVER Reactors" (OOB AS) is the regulatory document at the federal level. This regulatory document was approved and entered into force on August 1, 1995, and supersedes regulatory documents TS TOB ASB85 and TS TOB RUB87, described above. This document presents requirements of GAN for the content and form of reports on safety for NPPs with VVER reactors. The report must be submitted in a packet of documents substantiating the application for a license for the construction and operation of new NPPs.

On the basis of information contained in "Requirements of Report Content on Technical Safety Substantiation for Nuclear Power Plants with VVER Reactors," GAN conducts an examination and evaluates the adequacy of the substantiation of safety for the NPPs placement, its construction, activation, operation, and decommissioning to ensure that it does not exceed established doses of radiation exposure for personnel and the populace and that it does not exceed standards for releases and content of radioactive substances in the environment under normal operations of the NPP and during design accidents, response to these design accidents, and decommissioning. These requirements can also be applied to NPPs with different types of reactors, considering their specifications and design features.

Chapter 18, Decommissioning, of the document presents safety requirements during decommissioning of the NPP. These requirements must be taken consideration when designing the NPP. The characteristics of possible sources of radiation exposure, formed both through the acceleration of neutrons and contamination with radionuclides, must be taken into consideration. Methods for reducing the acceleration of NPP components and estimates of acceleration of these components, depending on holdup time of the reactor after the NPP is shut down, are presented.

Based on an analysis of sources of ionizing radiation and of the characteristics of aerosols, requirements can be defined for the scope and structure of radiation control and monitoring. A special analysis must be performed of the radiation control and monitoring of re-use radioactive materials (organic and inorganic) in consideration of criteria and principles for lowering dose loads for personnel, the populace, and the environment.

The NPP design must take into consideration the requirements for simplifying the dismantling of structural safety features, systems, and equipment of the NPP that have been contaminated by radionuclides, and estimates must be presented for the adequacy of organic ventilation systems for support of dismantling operations.

Chapter 18, Decommissioning, of this document also presents a list of basic required documents and materials that must be prepared during the life cycle of the NPP unit. These documents include the concept of decommissioning of the NPP; an analysis of sources of radiation exposure 
in shutdown NPP units; an evaluation of reuse (inorganic) materials; a description of measures, systems, and equipment when decommissioning the NPP; a description of radiation control and monitoring systems in the shutdown NPP unit; and other documents.

\subsubsection{Norms of Radiation Safety (NRBB96)}

"Norms of Radiation Safety" (NRBB96) is the regulatory document at the federal level and is applied for providing human safety in all conditions of the effects of ionizing radiation exposure, whether of artificial or natural origin.

"Norms of Radiation Safety"' (NRBB96) entered into force on April 19, 1996, superseding the older edition (NRBB76/87). It is the baseline document regulating the requirements of the Law of the Russian Federation on Radiation Safety of the Populace in the form of a system of dose limits, permissible levels of ionizing radiation exposure, and other requirements for limiting human radiation exposure. All partial regulatory and methods documents must conform to NRBB96.

Norms of Radiation Safety (NRBB96) applies to the following types of effects of ionizing radiation exposure:

- radiation exposure of personnel and of the populace under conditions of normal operation of technogenic sources of ionizing radiation

- radiation exposure of personnel and of the populace under conditions of a radiation accident

- radiation exposure of workers of industrial enterprises and of the populace through natural sources of ionizing radiation

- medical treatment of members of the population.

Requirements for safety are formulated for each type of radiation. The aggregate dose from all types of radiation is used only for estimating the radiation environment and medical effects.

Based on "Norms of Radiation Safety" (NRBB96), the following basic principles of radiation safety must be used as working guidelines:

- established basic dose limits must not be exceeded

- all unwarranted radiation exposure must be prevented

- doses of radiation must be kept to a minimum.

The requirements and norms established by the regulatory document NRBB96 are mandatory for all legal entities, independent of their affiliation or form of ownership, as a result of whose activities radiation exposure of persons is possible. They are also mandatory for administrations of the subjects of the federation, local government agencies, and members of the citizenry.

Requirements and norms of the document NRBB96 must be applied for rebuilt, designed, and renovated enterprises (installations) using nuclear energy. When decommissioning the NPP, until radioactive substances are contained, and as long as the possibility exists of the release of these substances into the environment, the observance of the norms of NRBB96 are mandatory for all enterprises and organizations engaged in the decommissioning of the NPP. 


\subsubsection{Basic Sanitary Rules for Handling Radioactive Substances and Other Sources of Ionizing Radiation (OSPB72/87)}

"Basic Sanitary Rules for Handling Radioactive Substances and Other Sources of Ionizing Radiation" (OSPB 72.87) is a federal regulatory document that contains basic requirements for radiation safety of personnel and categories of irradiated persons, including the populace, and requirements for protecting the environment against contamination by radioactive substances.

"Basic Sanitary Rules for Handling Radioactive Substances and Other Sources of Ionizing Radiation" (OSPB72/87) determines principles for accounting, control, handling, and organization of work with sources of ionizing radiation and requirements for systems of ventilation, dust-filtering, heating, water, and sewage when working with open radionuclide sources. The document also contains requirements for content and decontamination of work places intended for handling radioactive substances and makes recommendations for individual protection and personal hygiene and for the implementation of radiation dosimetry control and monitoring.

"Basic Sanitary Rules for Handling Radioactive Substances and Other Sources of Ionizing Radiation" (OSPB72/87) establishes requirements and principles for gathering, removing, and disposing of radioactive wastes, which are divided into liquid and solid radwastes. In accordance with document OSPB72/87, liquid radwastes are divided into the following three categories for specific activity:

- low-active liquid wastes - less than $1.0 \times 10^{-5} \mathrm{Ci} /$ liter;

- medium-active liquid wastes - from $1.0 \times 10^{-5}$ to $1.0 \mathrm{Ci} / \mathrm{liter}$;

- highly active liquid wastes $-1.0 \mathrm{Ci} /$ liter and above.

Solid wastes are considered to be radioactive if their specific activity is greater than

- $2.0 \times 10^{-7} \mathrm{Ci} /$ liter - for sources of alpha-radiation (for transuranic elements, $1 \times 10^{-8} \mathrm{Ci} / \mathrm{kg}$ );

- $2.0 \times 10^{-6} \mathrm{Ci} / \mathrm{kg}$ - for sources of beta-radiation;

- $1: 0 \times 10^{-7}$ gram-equivalent rads $/ \mathrm{kg}$ - for sources of gamma-radiation.

The gathering of wastes must be performed directly at the sites of their formation and must be kept separate from ordinary refuse and divided according to their nature (organic, inorganic, biologic), aggregate state (solid, liquid), radionuclide waste half-life (less than 15 days and more than 15 days), explosive-hazardous and fire-hazardous (explosive- or fire-hazardous; explosivehazardous or non-fire hazardous), whether they are taken to burial sites or to specialized radwaste treatment facilities.

The system for removing and disposing of solid and liquid radwastes subject to burial must be centralized and must include waste collection, time of storage, removal, and disposal. When decommissioning the NPP, until radioactive substances are contained at the facility, and so long as the possibility exists of a release of substances into the environment, the observance of document OSPB72/87 is mandatory for all enterprises and organizations engaged in the decommissioning of the NPP.

\subsubsection{Sanitary Rules for NPP Design and Operation (SP ASB88/93)}

Sanitary Rules for NPP Design and Operation (SP ASB88/93) is a federal regulatory document that establishes requirements and radiation safety measures for personnel, the populace, and the environment. SP ASB88/93 was developed before the Law of the Russian Federation on the Use 
of Nuclear Energy was enforced, in accordance with requirements of OPBB88, NRBB76/87, and OSPB72/87. Document SP ASB88/93 regulates the implementation of sanitation and hygiene radiation safety requirements in the design, construction, operation, and decommissioning of NPP units.

Chapter 17, Requirements for Decommissioning NPP Units, of the document establishes the following provisions and requirements that must be observed when designing and decommissioning NPP units. The basic decommissioning strategy must consider the requirements of current regulatory documents, from the moment of expiration of its service life to completion of the decommissioning.

In accordance with the basic decommissioning strategy of the NPP unit, the above-mentioned chapter must present a preliminary analysis of the decommissioning of the NPP unit. This analysis must be based on an assessment of the possible degree of activity and of surface radioactive contamination of building and structural materials of the NPP unit at the moment its operation stops; an estimate of the radiation environment in process rooms of the NPP unit and the nature of changes in this environment following expiration of the service life of the NPP unit; an estimate of volumes of radioactive and nonradioactive wastes formed during the decommissioning.

This chapter must also contain

- a prediction of the radiation environment in the NPP unit at the moment its service life expires

- preliminary analyses of dosages for personnel when the selected decommissioning strategy is implemented

- estimates of the volumes of radwastes formed during the decommissioning of the NPP unit and a description of measures aimed at alleviating the radiation danger when handling radwastes at various stages in the decommissioning

- a list of organizational and technical and sanitation and hygiene measures aimed at improving the radiation environment in the process spaces of the NPP unit to lower possible dosages when performing work stipulated in the plan

- estimates of levels of radioactive releases and discharges into the environment during the performance of this work, in accordance with the selected technology and methods for continuous release and discharge into the environment above established limits

- specs and identification of radiation control and monitoring equipment used in the various stages of the work

- substantiation of the scope and frequency of radiation control and monitoring and lists of radiation parameters to be measured at the NPP site and in the environment at the different stages of the decommissioning

- a list of measures for preventing radiation accidents at different stages of the decommissioning of the NPP unit.

The decommissioning of the NP unit is the final stage in its life cycle, characterized by the change in the nuclear energy unit and by the gradual lowering of the level of required monitoring and control of the energy unit and its site during its decommissioning. The decommissioning is a process that undertakes a set of measures after the removal of nuclear fuel, preventing its use as an energy source and ensuring safety of personnel and the environment. The decommissioning 
plan must be developed in light of economic, ecological, and social conditions of the area where the NPP is located.

Radiation safety of personnel, the populace, and the environment during the decommissioning of the NPP unit must be ensured within limits established and regulated by current regulatory documents. All operations involving the handling of radwastes and stipulated during the decommissioning must satisfy requirements of regulatory documents in force at the time of the decommissioning that regulate the handling and long-term storage of radwastes.

Wastes formed during the dismantling of equipment, systems, and structural elements of the NPP unit must pass radiation control and monitoring and then are divided into radioactive and nonradioactive and registers as such. Nonradioactive solid wastes are subject to warehousing in specially provided sites with their subsequent additional radiation monitoring and control, registration, and shipment for reuse or burial in accordance with effective norms and regulations. Equipment and materials selected for inorganic use in the public sector must be brought into compliance with existing norms and forwarded with the appropriate registration.

When conducting decommissioning activities, control and monitoring of the radiation situation in the NPP unit and in the environment may be performed with radiation control and monitoring systems available at the NPP. These systems must be optimized in light of the specifics of the work being performed. The established scope of radiation monitoring and control must ensure the timely detection of changes in the radiation environment and provide a correct estimate of the possible level of radiation exposure of personnel and must contain any radioactive contamination.

The removal of protective barriers of the NPP limiting the release of radioactive substances into the environment must be performed only if possible releases and discharges into the environment do not exceed established permissible limits. Radiation control and monitoring of the environment stops after full shutdown of releases, or of contact transfer, of radioactive substances from the site of the NPP unit, to include any such potentially possible releases and/or transfers, so long as other units located at the NPP site are brought to an analogous condition.

Responsibility for observance of norms, regulations, requirements, and instructions on nuclear, technical, and radiation safety when performing decommissioning of the NPP units is borne by the using organization until this responsibility, by permission of government agencies, can be transferred to another organization in the established procedure.

For each stage of decommissioning of the NPP unit, GAN must approve in the established procedure the sanitation ecology log of the NPP unit subject to decommissioning, containing basic radiation specifications of the unit being decommissioned and making it possible to determine the level of radiation safety of the state of the unit for personnel, the populace and the environment.

When decommissioning NPP units following a large-scale radiation accident, the use of specifically established temporary criteria, norms, regulations, and instructions may be used for regulating individual questions of radiation safety for personnel, the populace, and the environment. In all stages of the life cycle of the NPP unit, data bank information necessary for developing and implementing the decommissioning plan must be formulated, accumulated, and stored. 


\subsubsection{Radiation Safety Regulations on NPP Operation (PRB ASB89)}

"Radiation Safety Regulations on NPP Operation" (PRB ASB89) is a federal regulatory document establishing requirements for radiation safety when operating and decommissioning NPP units. Chapter 11, "Requirements of Radiation Safety During Decommissioning of NPP Units" defines the following general provisions and requirements for radiation safety, which must be observed when developing the plan and when decommissioning the NPP unit.

For the shutdown power unit of the nuclear power plant, the following characteristics have been presented:

- aggregate activity of spent nuclear fuel for individual radionuclides

- activity of basic types of equipment, pipelines and structural elements

- volumes and activity of solid and liquid radwastes, methods for reprocessing these radwastes and sites for their burial

- estimate of the state of the radiation environment at the start of the decommissioning of the unit and forecasts of this environment for each stage in the decommissioning process and estimates of the expected collective dose for personnel and for the populace

- control releases and discharges of radioactive substances into the environment

- analysis of accident scenarios for the period of operation of the unit and their radiation effect

- list of equipment that can be used in other units operational in the NPP.

In the decommissioning plan for NPP units, design solutions for radiation safety must be set forth, considering the sequence of fulfilling basic technological stages: emptying the core and temporary storage and forwarding of spent nuclear fuel; releasing the nuclear storage well, hot chambers, and tanks of solid and liquid high-active wastes; removal of protective barriers with the dismantling of basic and auxiliary process equipment; dismantling or conversion of structural elements.

Design concepts for radiation safety must include the technology and safety measures for dismantling equipment; automated mechanisms, remote-control attachments, and robotics; technology for decontamination and control of its effectiveness; conditions of the use of organic systems of radiation control and monitoring at the different stages of the dismantling process; a list of possible accident scenarios during decommissioning; a plan of safety measures for possible emergency response scenarios.

The status of the radiation environment at the end of each stage must be recorded in the Sanitation Log of the NPP Unit. Each stage of the decommissioning must conclude with the preparation of organizational and technical radiation safety measures for the next stage. When moving from production to a new stage, organizational and technical measures must be adjusted, considering updated estimates of activity of the equipment and structural elements, radiation effects, volume and activity of solid and liquid radwastes, the effects of the work being performed on the environment, and possible accident scenarios. By the start of work on the next stage, sites must be prepared for the temporary storage of the entire amount of radwastes.

When preparing for dismantling large-size and highly-active equipment, the following must be prepared: sets of standardized protective screens and containers, ventilation units with filters for local exhausts, local signaling devices for radiation monitoring and control, temporary sanitation air locks, block and tackle, fittings, and specialized tools. 
Sections of process systems with radioactive media must be disconnected, drained, and washed out with clean condensate or a decontamination solution before dismantling. The dismantling area may be designated by safety signs, guarded by barriers, and equipped with filters and sanitation airlocks. The dismantled radioactive materials (equipment, sections of pipelines, structural elements) must be registered. All rooms with radioactive materials must also be recorded.

Oversized solid radwastes must be sized down to dimensions convenient for transport and burial. The partitioning of oversized components of metal and concrete must be performed using remote-control devices or robotics. The transporting of radwastes must be over pre-arranged routes with the use of safety containers and the application of all necessary measures to warn of contamination of spaces and sites of the NPP. Transport routes for dismantled equipment must be selected with a view to radiation safety in other NPP units in operation.

Radiation control and monitoring at all stages must be performed according to an approved schedule. Changes in the schedule of radiation control and monitoring must consider the results of the change on the radiation environment upon the completion of each stage.

Radiation control and monitoring of the state of safety barriers until their removal must be performed through measurements of activity of reference radionuclides or their groups in process media and in the air of the production spaces. The removal of permanent safety barriers of the NPP, preventing the removal of radioactive substances into the environment, must be performed under the condition that the sum releases and discharges do not exceed the maximum permissible level.

\subsubsection{Requirements to NPP Utilities (RDB04B03B93)}

The regulatory document "Requirements to NPP Utilities" (RDB04B03B93) establishes the responsibility of the using organization for decommissioning of the NPP units. The using organization is obligated to develop and implement a program for decommissioning the NPP units. For operational NPP units, the using organization must, no later than the standard time before shutdown of the NPP units, present to GAN a set of documents substantiating the application to decommission the NPP units. The using organization must also submit a report substantiating safety during decommissioning and must receive authorization (license) for decommissioning the NPP units. The report on the substantiation of safety of decommissioning the NPP units must include a job plan, a radiation safety program when performing the decommissioning, and measures for radiation monitoring of radioactive equipment subject to long-term storage at the NPP site.

When decommissioning the NPP units, the organization must ensure:

- safety for personnel, populace, and environment in performing all necessary work, including decontamination of equipment, structures, and structural elements, and, when necessary, the recultivation of the released sites

- radiation safety when processing radwastes formed during decommissioning of the NPP units and safe final disposition of radwastes

- dosimetry control and monitoring when returning materials and equipment to production for their future use. 


\subsubsection{Draft of the Guideline General Requirements to Safety Assurance for Decommissioning of Nuclear Power Plant Units}

At this time, the draft of the guideline "General Requirements to Safety Assurance for Decommissioning Nuclear Power Plant Units of Gosatomnadzor Russia" has been prepared and is in the approval process. This document, compiling and supplementing provisions and requirements of SP ASB88/93; PRB ASB89; and Chapter 18, Decommissioning of OOB AS regulatory requirements, contains concrete recommendations for the organization and safety when preparing for decommissioning and when decommissioning NPP units. It also contains recommendations on the development and content of programs of comprehensive (radiation and engineering) studies and decommissioning of NPP units and accounts on substantiation of safety for decommissioning. The draft of this document puts forth basic recommendations that must serve as guides when organizing and providing safety in preparations for decommissioning and when decommissioning NPP units.

The using organization, no less than five years before the expiration of the service life of the NPP unit, must develop a program for its decommissioning. The program for decommissioning the NPP unit must contain the substantiation of the selection of a version for decommissioning of the NPP unit and must be coordinated with GAN.

When preparing the NPP unit for decommissioning, information must be gathered and systematized on the history of operation of the unit; a program for decommissioning the unit must be developed; the reactor must be shut down; nuclear fuel must be removed from the unit; process media must be drained from the first and other circuits of the reactor unit; operational radwastes must be reprocessed and conditioned; equipment, systems, areas, and structural elements must be decontaminated; the unit must be inspected.

The license to operate the units, issued by GAN, is in effect from the moment the unit is shut down until the nuclear fuel is removed from the unit. Measures associated with the decommissioning of individual systems and elements, with reduced volume of technical maintenance and numbers of unit operating personnel, must be performed after the removal of the nuclear fuel from the unit in accordance with changes in terms of effect of the license, and they must be performed in the established procedures.

The decommissioning of the NPP unit must be preceded by a comprehensive inspection. This inspection is performed in several stages, the composition and scope of which depend on the manner in which the unit is decommissioned. The systematization and storage of results of this inspection of the unit can be performed according to the following levels of inspection:

- Level I - NPP site

- Level II - NPP unit, buildings and structures and the site of the NPP unit

- Level III - individual rooms of the NPP unit, buildings and structures

- Level IV - equipment and systems of the NPP unit.

The results of this inspection must be set forth in the appropriate report and are considered when developing the plan and reports on substantiation of safety of decommissioning of the unit. Decommissioning work must be performed after a license from Gosatomnadzor Russia is received. The using organization must implement optimal planning of the sequence and control of work associated with decommissioning. Radwastes formed during the decommissioning of the unit must be placed under radiation control, divided into categories according to level of 
activity (low-active, medium-active, and highly-active), reprocessed and conditioned. For storing conditioned radwastes at the NPP unit site, the appropriate storage facilities and equipment must be provided.

According to the results of the radiation control and monitoring of radwastes, radioactive materials suitable for further use are singled out. Radioactive materials suitable for further use must be divided into categories of organic and inorganic use. The storage of radioactive materials suitable for further use must be kept separate in specially provided and equipped sites. Before shipping to the consumer, radioactive materials suitable for further use must undergo additional radiation control and be appropriately recorded, accounted, and forwarded.

Requirements for the scope of radiation control must be defined in the decommissioning plan for the NPP unit. Radiation control must ensure the timely detection of changes in the radiation environment, the correct estimate of radiation exposure of personnel, and containment of radioactive contamination. Control of the radiation environment at the NPP unit may be exercised by the radiation control system at the NPP, supplemented and optimized in accordance with the decommissioning plan and considering the specifics of the work being performed.

The Appendixes to this document provide recommendations on the content of reports on the comprehensive inspection of the NPP unit, the contents of the NPP unit decommissioning plan, contents of the reports on substantiation of safety when decommissioning the NPP unit.

\subsection{Rosenergoatom Documents Regulating Decommissioning Procedures of Nuclear Power Plant Units}

According to the currently existing structure in Russia (see Section 2.1), Rosenergoatom regulatory documents and guidelines are part of the fifth level of the system of legal and regulatory documents governing the nuclear energy sector. Rosenergoatom, in accordance with scientific and technical program N 15, Decommissioning of NPP Units With Expired Service Life, adopted on March 7, 1991, the list of regulatory and technical documents and materials defining and regulating decommissioning work for NPP units that must be developed, put into force, and applied when working on the decommissioning of NPP units under the jurisdiction of Rosenergoatom. This List of regulatory and technical documents and materials, defining and regulating decommissioning of NPP units of Rosenergoatom stipulates the development of five groups of regulatory documents and guidelines.

Group One includes organizational and methodological documents of Rosenergoatom that define the basic regulatory provisions and guidelines on the organization and safety of decommissioning of NPP units. The following documents belong to this group: the guideline "Basic Provisions for Decommissioning of NPP Units," the regulatory document, "Decommissioning NPP Units," "Radiation Safety," "Typical Content of Logistical Support in Decommissioning NPP Units," and "Typical Content of Safety Systems and Oversight in Decommissioning NPP Units."

Group Two includes regulatory documents and guidelines regulating the solution of issues in decommissioning NPP Units in the design stage. This group includes a set of regulatory documents in addition to principles and norms in designing NPP units, their basic technical systems, equipment, architectural structural complex, conditions for decommissioning of NPP units; regulatory documents, "Typical Content of Quality Assurance Program for Decommissioning of NPP Units," "Typical Content of the Chapter on Decommissioning of NPP Units of Plans for Rebuilt 
NPP Units," and "Typical Content for Chapter 6, Decommissioning of Technical Safety Equipment of the NPP."

Group Three regulatory documents and guidelines include documents regulating the solution of problems in decommissioning of NPP Units in operation. This group of documents includes the following: "Requirements for Content of the Chapter, Decommissioning NPP Units," "Principles of the Technical Use of Electrical Networks and Stations," and procedures on gathering and storing of data on the operational characteristics of NOO units archived for the development of documentation on decommissioning and requirements for content of preliminary plan of decommissioning of NPP units.

Group Four regulatory documents and guidelines include documents defining the requirements for preparation of the NPP units for decommissioning. This group of documents includes the following: "Typical Content of a Program of Preparation of the NPP Unit for Decommissioning," "Comprehensive Engineering and Radiation Survey of the NPP Unit," Composition and Procedures," "Typical Content of Technical and Economic Studies Aimed at Decommissioning the NPP Unit," "Typical Content of Technical Economic Substantiation's for a Decommissioning Strategy," "Typical Content and Development of Procedures," and "NPP Unit Decommissioning Plan; Typical Content and Development Procedures."

Group Five regulatory documents and guidelines include documents regulating the decommissioning process of the NPP unit. This group of documents includes: "Principles in Handling Radioactive Wastes (PORO AS)," "Sanitation and Hygiene Requirements of Organizations for the Long-Term Storage of Radioactive Wastes on the NPP Site," "Determination of Permissible Levels of Radioactivity of Materials for Their Unrestricted and Restricted Use," "Typical Content of Sanitation Log for the NPP Unit," "Sanitation and Hygiene Requirements for Renovation at the NPP Site During Decommissioning," and "Procedures for Transferring the NPP Site and Sanitation Safety Area for Industrial Use and Unrestricted Use in the Public Sector."

Some documents from the list of regulatory documents and guidelines of Rosenergoatom cited above, primarily documents belonging to Group One, have already been developed and approved. Others are in the development or approval stage, while a number of them are yet to be developed. The current regulatory documents and guidelines and draft documents of Rosenergoatom were developed some time ago. Therefore, both regulatory documents and guidelines of GAN must be updated and brought into compliance with the basic provisions established in the "Laws of the Russian Federation on the Use of Nuclear Energy" and on "Radiation Safety of the Population," and also in accordance with the structure developed in Russia of the system of legal and regulatory documents when regulating activities involving nuclear energy.

\subsubsection{Guideline Document Basic Provisions on the Decommissioning of Nuclear Power Plant Units}

The guideline of the using organization, "Basic Provisions on the Decommissioning of NPP Units" (RD EO 0013B94), entered into force on October 1, 1994. This document is based on the concept accepted in Russia of the decommissioning of NPP units and defines the basic organizational and methodological approaches to decommissioning of NPP units.

This document regulates

- the site for shutting down the NPP unit (extension of service life and decommissioning of the NPP unit) within its life cycle 
- questions of planned preparation of the NPP unit for decommissioning in the design stage

- procedures for planned preparation of the NPP unit for decommissioning at the operational stage

- procedures for working on the NPP unit after expiration of the design service life

- procedures for selecting a decommissioning plan for the NPP unit and the implementation of the plan

- procedures for making solutions on the completion of decommissioning of the NPP unit

- questions of government oversight and control of decommissioning.

\subsubsection{Draft Guideline Document Typical Content for the Plan for Preparation of the NPP Unit for Decommissioning}

The draft guideline document of the using organization on typical content for the plan for preparing the NPP unit for decommissioning regulates the aims and tasks of the program of preparations for decommissioning of the NPP unit. This program of preparations of the NPP unit for decommissioning must contain a list, procedures and time table for performing specific organizational and technical measures which must be performed on the NPP unit after shutdown. It also contains requirements for development of various kinds of documentation in support of the decommissioning.

The program for the preparation of the NPP unit for decommissioning must include a description of the following:

- organizational and technical measures aimed at ensuring the operational efficiency of internal systems of the NPP unit, which will continue in operation during decommissioning

- procedures and terms for formulating a system of logistical support during decommissioning activities considering the various stages of decommissioning

- procedures and terms for formulating a decommissioning safety and oversight system.

The following main tasks must be accomplished within the framework of the preparations for NPP unit decommissioning:

- the change-over of the NPP unit to the nuclear-safe state (shutdown and cooling of the nuclear reactor, unloading of the nuclear fuel, cooling and sending the spent nuclear fuel for reprocessing or storage)

- draining and cleaning of coolant

- draining and cleaning of coolant from spent nuclear fuel the cooling pond, decontamination and cleaning of the cooling pond

- internal decontamination of the primary loop and associated systems

- treatment of accumulated operating liquid radwastes

- treatment and removal of solid operating radwastes.

Comprehensive engineering and radiation inspection (KIRO) of the NPP unit must be conducted during the stage of preparation of the NPP unit for decommissioning and a report on the results of this inspection must be prepared. Based on the results of this comprehensive inspection, technical and economic studies must be conducted to determine whether to extend the service life of the NPP unit or decommission the unit. 
When it is determined that it is impossible and/or economically not feasible to extend the service life of the NPP unit, additional studies must be aimed at specifying methods for solving the issue of decommissioning. In order to specify directions and stages of decommissioning, the method chosen for decommissioning must be technically and economically substantiated. The decommissioning method is selected on the basis of technical and economic studies and must provide the basis for the development of a decommissioning program.

This decommissioning program must contain

- specific organizational and technical measures implemented in the individual stages of decommissioning

- decommissioning logistics procedures

- basic organizational-technical and sanitation-hygiene measures aimed at ensuring safety during decommissioning.

On the basis of the NPP unit decommissioning program selected, a decommissioning draft is developed.

\subsubsection{Draft Plan of the Guideline Document "A Comprehensive Engineering and Radiation Inspection of the Nuclear Power Plant Unit"}

The guideline of the using organization, "A Comprehensive Engineering and Radioactivity Inspection of the Nuclear Power Plant Unit, Composition and Procedures," regulates the aims, tasks, and procedures for conducting the comprehensive engineering and radiation inspection (KIRO) of the NPP unit. The aim of this inspection is to acquire detailed information on the actual state of equipment, systems and structural elements of the NPP unit at the moment the inspection is being conducted.

Based on the results of this inspection of the NPP unit, a detailed analysis must be performed of the following items:

- design technical concepts implemented

- engineering-technical and technological characteristics of the NPP unit

- radiation environment in facilities of the NPP unit

- condition of systems providing safety and reliability of the NPP unit when conducting work after the expiration of the service life of the unit.

Results of this inspection must then be used when developing

- technical and economic inspections aimed at shutting down NPP unit operations

- technical and economic substantiation of the selection of NPP unit decommissioning method

- NPP unit decommissioning program

- NPP unit decommissioning draft plan.

In the technical inspection of the NPP unit, the main tasks are

- the gathering and analysis of data on the condition of equipment, systems, and structural elements of the NPP unit, including an analysis of capabilities for their fulfillment of primary functions and their residual service life at the moment of the inspection (considering their possible reuse) 
- analysis of requirements for repair/replacement of equipment of the NPP unit used in decommissioning.

The section of the radiation inspection of the NPP unit has the following main tasks:

- determination of the amount characteristics of long-life radionuclides formed as a result of the activation of elements of the internal devices, reactor vessel and surrounding safety structural elements, and radioactive contamination of equipment, systems, and structural elements

- creation of databases for the preliminary estimates of dose loads for personnel when performing dismantling work and for estimates of aerosol releases into the atmosphere during the use of different methods in dismantling equipment, systems, and structural elements

- identification of the radiation environment at the site and in the sanitation safety area of the nuclear power plant during decommissioning.

Based on the results of the radiation inspection of the NPP unit, the following must be performed:

- estimate of volumes of radwastes (solid, liquid and aerosol) formed during decommissioning of the NPP unit and the determination of their classification

- estimate of the amount (volume) of radioactive materials suitable for unrestricted use.

\subsubsection{Draft Plan of the Guideline "A Typical Content of Technical and Economic Studies} Aimed at the Shutdown of Nuclear Power Plant Unit Operations"

The guideline of the using organization, "A Typical Content of Technical and Economic Studies Aimed at the Shutdown of Nuclear Power Plant Unit Operations," regulates

1. Baseline data for the conduct of technical and economic studies, including information compiled on the history of the use of the NPP unit and results of the comprehensive engineering and radiation inspection of the unit, performed within the framework of the preparations for decommissioning.

2. A list of possible alternative methods for shutting down the operation of the NPP unit: extension of service life or decommissioning

3. Possible restrictions on the methods chosen to shut down the NPP unit

4. Procedures in the analysis of alternatives for each method of shutting down the NPP unit, its components, and the selection of the more preferable alternatives for shutdown method

5. Procedures in selecting a specific method for shutting down the NPP unit.

Technical and economic studies should be conducted in two stages:

Stage One is an analysis of possible options for extension of the service life of the NPP unit. The main criteria in the selection of options for extension of the service life of the NPP unit are technical feasibility and economic effectiveness. Technical feasibility of options for extension of service life can be estimated from the proposed list of equipment, systems, and structural elements that are used for extension of the service life; an analysis of their actual condition at the moment of extension of service life; and the possibilities of their use for extension of the service life, considering necessary repair and renovation work in the NPP unit.

Economic effectiveness of the options for extension of service life may be estimated on the basis of an analysis of their economic and cost-effectiveness, considering the acuteness of the 
problems to be solved as a result of the implementation of specific options for extension of the service life of the NPP unit. If the results of the technical and economic study arrive at a conclusion for the technical feasibility and economic effectiveness for more than one option of extension of service life, there must be technical and economic substantiation to identify the preferable option for extension of the service life of the NPP unit. If the results of the technical and economic study conclude that extension of the service life of the NPP unit is not feasible, then a follow-up (second) stage of technical and economic studies must be undertaken.

Stage Two is an analysis of possible options for decommissioning of the NPP unit.

In light of the aim of the decommissioning, as defined in the strategy, possible options for decommissioning the NPP unit are examined. An analysis of the decommissioning options for the NPP unit must proceed from

- an analysis of possible restrictions on the decommissioning process

- an analysis of the composition and characteristics of the logistics system supporting decommissioning and ensuring safety

- an analysis of the requirements for control and oversight of the decommissioning of the NPP unit.

Based on this second round of technical and economic studies, technically feasible options for decommissioning must be selected. These options are then subject to further comparison within the framework of technical and economic substantiation of the selection of a decommissioning option.

Thus, the two final aims of the technical and economic studies aimed at shutting down NPP unit operations are

- an analysis and estimate of the technical feasibility and economic cost-effectiveness of possible options for extension of the service life of the NPP unit with the substantiation of preferred options for extension of the service life

- an analysis and estimate of technical feasibility and economic cost-effectiveness of possible options for decommissioning the NPP unit with substantiation of the preferred decommissioning options.

\subsubsection{Draft Plan of the Guideline "A Typical Content of Technical and Economic Substantiation of the Nuclear Power Plant Unit Decommissioning Option"}

The guideline of the using organization "A Typical Content of Technical and Economic Substantiation of Nuclear Power Plant Unit Decommissioning Option" regulates activities aimed at the substantiation of the selection of a specific option for decommissioning of the NPP unit. With the selection based on the results of technical and economic studies aimed at shutting down operations according to the decommissioning of the NPP unit option, different options for decommissioning are subject to comparison and analysis within the framework of the technical and economic substantiation, as a result of which the preferred decommissioning option is selected.

The comparison and analysis of possible decommissioning options may be undertaken in light of the specific features of their implementation, including technical, technological, time, and financing factors as well as the level of safety of personnel, the populace, and the environment. 
The results of the technical and economic substantiation should include

- a description of the baseline information

- a description of the characteristics of the NPP unit

- a list of documentation used or considered

- requirements and taskings for conducting the technical and economic substantiation

- a description of alternative decommissioning options

- characteristics of alternative decommissioning options

- an estimate of restrictions inherent in the alternative decommissioning options selected

- criteria for selecting the preferred decommissioning option

- results of the comparison of alternative decommissioning options and the substantiation of the selection of the preferred decommissioning option.

\subsubsection{Draft Plan of the Guideline "A Nuclear Power Plant Unit Decontamination Program Typical Content and Development Procedures"}

The guideline of the using organization, "A Nuclear Power Plant Unit Decontamination Program Typical Content and Development Procedures," regulates the list, procedures, and terms for implementation of organizational and technical measures undertaken during decommissioning of the NPP unit. The decommissioning program must include the entire body of organizational and technical measures aimed at implementing the decommissioning option selected as a result of the technical and economic studies, beginning from the moment work begins on decommissioning up to the moment the final aim of the decommissioning is achieved.

The program must define procedures and time sequence for work, considering the individual stages of the decommissioning activities, procedures and identification of work at each stage, including:

- the logistics support system

- the operational safety and oversight system

- the decommissioning quality assurance system.

The decommissioning program may be divided into a number of sub-programs in accordance with types of activities characteristic for the decommissioning process. 


\subsection{Licensing Procedures for Nuclear Power Plant Units Decommissioning in Russia}

\subsection{General Regulations on Decommissioning of Nuclear Power Plant Units in Russia}

As follows from the provisions of the Law of the Russian Federation on the Use of Nuclear Energy set forth in Section 2.2, and adopted in October 1995, the decision on the decommissioning of nuclear power plants under federal jurisdiction is exercised by the Government of the Russian Federation. This provision of the Law of the Russian Federation on the Use of Nuclear Energy applies also to NPP units because all NPPs in Russia are under federal jurisdiction.

The Law of the Russian Federation on the Use of Nuclear Energy places responsibility for NPP decommissioning on the using organization. This Law also establishes that the using organization must have the authority, financing, material, and other resources sufficient to exercise its functions. In these interests, the using organization, together with the appropriate nuclear energy regulatory agencies, are obligated to create, within their resources as stipulated by the budgets for the corresponding levels, a special fund for financing costs associated with NPP decommissioning. Procedures and sources of the formation and procedures for the use of the special fund for financing decommissioning work are established by the Government of the Russian Federation. To perform such activities as NPP decommissioning, the using organization must receive a license issued by the appropriate government safety regulatory agencies.

Safety criteria in NPP decommissioning is the observance of radiological limits (permissible threshold doses) established by the Law of the Russian Federation on Radiation Safety of the Populace adopted in December 1995, and also by radiation safety norms NRBB96 and sanitation regulations OSPB72/87. If the levels of safety in decommissioning of the NPP do not comply with established regulatory limits, decommissioning work is not permitted, and the license is not issued.

Since the requirements cited above, defined by the Laws of the Russian Federation on the Use of Nuclear Energy and on Radiation Safety of the Populace were entered into effect in late 1995, all current regulatory and technical documents and guidelines issued prior to this date were revised and brought into compliance with the provisions of these two laws.

\subsection{Description of Russian Approach to Licensing Procedures for Nuclear Power Plant Units Decommissioning}

There is no approved and adopted document in Russia today defining licensing procedures for decommissioning NPP units. At this time, a more general document is being drafted under the title, "Provisions on Licensing Procedures in the Production and Use of Nuclear Materials, Nuclear Energy, and Radioactive Substances." This draft is going through the necessary rounds of coordination and approval. The basic provisions of this document apply also to such activities in the use of nuclear energy and NPP decommissioning. A brief description of the basic provisions of this draft document follows.

The draft of this document establishes general requirements for presenting applications, their review process, and the execution and issue of licenses for different kinds of activities in the area of the use of nuclear energy, which, according to Article 26 of the Law of the Russian Federation on the Use of Nuclear Energy, are defined by the Government of the Russian Federation. This 
draft document establishes general requirements for procedures in submitting applications, examining the applications, executing them, and issuing licenses for various kinds of activities involving the use of nuclear energy.

The list of activities, including decommissioning of nuclear power plants, which organizations and enterprises, independent of form of ownership, may execute on the basis of license, includes the following:

1. Construction, activation, operation, and decommissioning of nuclear installations (including MPP units), radiation sources and storage depots of nuclear materials and radwastes

2. Handling of nuclear materials and radioactive substances

3. Handling of radwastes (including reuse radioactive materials) for storage, reprocessing, transport and burial

4. Performance of scientific research and experimental work using nuclear energy and/or nuclear materials and radioactive substances

5. Management of hazardous operations, conduct of the technological process, and the exercise of production control of safety

6. Design and construction of nuclear installations (including NPPs), radiation sources, and nuclear material and radwaste storage depots

7. Construction and manufacture of equipment for nuclear installations (including NPPs) and other materials for determining the level of safety of nuclear installations, radiation sources, and nuclear material and radwaste storage depots.

The license granting the right to perform a specific activity is an official document that authorizes the performance of the activity listed in the license for a period defined in the license. The license also defines conditions under which this activity can be performed.

This draft document stipulates that procedures for issuing licenses to decommission NPP units shall include

- the conduct of preliminary control of the application of the using organization to decommission NPP units

- the examination in GAN of the set of basic documents to the application presented in support of the license request

- the decision by GAN to issue or refuse to issue the license

- the issue of the license giving the using organization the right to decommission NPP units with the identification of conditions under which this work is authorized

- the issue of the license to legal entities performing work of providing services to the using organization.

When reviewing the application and deciding the matter of the issue of the license to decommission the NPP unit, GAN coordinates its activities with the federal executive agencies and with agencies of the Subjects of the Federation.

To obtain a license to decommission NPP units, the using organization (applicant) presents the application to GAN. This application includes

- the decision of the Government of the Russian Federation on decommissioning the NPP unit 
- the application indicating the organizational and legal form of the entity, legal address, type of activity, the facility in question, and the period of effect of the requested license

- a document confirming consent for this type of activity from the executive agency of the Subject of Federation and from the corresponding agency of local government on whose territory the type of activity applied for is to be carried out

- the conclusion of the government ecology study

- the set of documents substantiating the application.

The list of documents substantiating the application for license to decommission NPP units is presented in Section 3.3. The application received by GAN is submitted for review or is declined according to the results of the preliminary check, in the process of which the documents submitted and the observance of established regulations in executing these documents are checked.

When examining the set of documents substantiating the application, the following factors must be analyzed:

- The proposed technology for decommissioning corresponds to current regulations and safety norms.

- Technical and organizational measures are adequate to ensure radiation safety during decommissioning.

- There is a system of quality assurance for decommissioning of the NPP unit.

- A process exists for accounting and control of radioactive substances, including radwastes and reuse (restricted and unrestricted) materials.

- Measures exist for the safe storage and treatment of radwastes.

- An organization is in place for physical security of radioactive substances.

- Personnel pass the required qualifications of the using organization (applicant).

- The necessary engineering technical and information support exists.

- Fire-prevention measures and emergency response and restoration are in readiness when decommissioning the NPP unit.

- Financial and logistical resources are adequate to undertake the decommissioning of the NPP unit, including resources for compensating possible damages in the event of a radiation accident.

In reviewing the application, GAN conducts an inspection of the NPP units subject to decommissioning, examines materials substantiating safety, and coordinates with the applicant on shortcomings uncovered and corrective actions to be taken. Decisions on issuing the license are made by the management of GAN based on the results of the materials of the export conclusion and the inspections conducted. The expert conclusion, based on materials substantiating safety when decommissioning the NPP units, must include a description of the type and location of the activity; an analysis of the fullness and adequacy of documentation submitted for review; a description of the tasks of the review, requirements, and criteria used when analyzing safety of the decommissioning.

The expert conclusion must contain an analysis of the concept and selected options for decommissioning of the NPP unit; an analysis of sources of ionizing radiation and reliability of estimates of their effect on personnel, the populace, and the environment; an analysis of resources for handling and control of radwastes, including reuse of materials; an analysis of the adequacy 
of the necessary radiation control and monitoring measures; and an analysis of measures, systems, and equipment necessary for decommissioning the NPP unit.

On the basis of the decision adopted, GAN issues the using organization (applicant) authorization (a license) with the conditions defining requirements for radiation safety during decommissioning of the NPP unit. Until the provisions on licensing procedures in the production and use of nuclear materials, nuclear energy, and radioactive substances, is approved, GAN issues a temporary license to work with nuclear energy, including decommissioning of the NPP unit. However, in the case of operational NPP units, there are no real requirements in Russia for safety materials, which are necessary for the issuing of the corresponding temporary license.

\subsection{A List of Documents Substantiating the Application for the Nuclear Power Plant Decommissioning License}

To receive a license to decommission NPP units, the using organization, in accordance with provisions on licensing procedures in the production and use of nuclear materials, nuclear energy, and radioactive substances, must submit the application to GAN with the following set of documents substantiating this application:

1. Decommissioning Program Plan

2. Report on the results of the comprehensive (radiation and engineering) inspection of the NPP unit (Radiation and Engineering Characterization Report)

3. Report on the substantiation of safety when decommissioning the NPP unit (Safety Analysis Report)

4. Program and work schedule for dismantling of equipment, systems and safety structural elements (Decontamination and Dismantling Plan)

5. Quality assurance program for NPP decommissioning (QA Plan)

6. Instructions on NPP emergency response and restoration (Emergency Operating Instructions) (for decommissioning)

7. A plan to safeguard personnel in the event of an accident at the NPP unit during its decommissioning (Emergency Response Plan)

8. A list of requirements for the condition of systems, equipment, and control measurement devices of the NPP unit, necessary for its decommissioning (equipment that remains online during decommissioning)

9. An estimate of the amount of radwastes and reusable materials resulting from the dismantling of equipment and structural elements (Waste, Recycle, and Reuse Estimates) (usually part of the U.S. Plant Characterization Plan)

10. An estimate of annual effective collective dose for workers and for the populace living in the area when decommissioning the NPP unit (population estimates at outer boundary of NPP sanitary zone) (local town is usually outside the outer boundary of the sanitary zone) (in the U.S., it's part of the EIS and FEIS)

11. Instructions on equipment and systems operations, considering stages of dismantling of equipment and systems in accordance with the dismantling program (operations and maintenance instructions for the equipment described in \#8) 
12. Project materials for decommissioning the NPP unit according to the list agreed to with GAN (Technical aspects of Decommissioning Program Plan) (GAN requires a subset of this information, usually those items related to safety)

13. A schedule for the removal of radwastes from the NPP site for burial (Waste Management Plan)

14. A plan for restoring and decontaminating the NPP site (what will happen to the site) (end point definition).

At this time in Russia, mandatory requirements for document content in substantiation of the NPP decommissioning license application have not yet been defined. However, it is expected that these requirements will be developed and entered into force in the prescribed manner in the future.

\subsection{Certain Features of the Russian Approach to Licensing Procedures for the Decommissioning of Nuclear Power Plant Units}

In Russia, all first-generation NPP units, including NPPs with RBMK reactors, operate in a special regulating regime in which the NPPs must receive annual licenses for the extension of the service life of the units for the following year. According to current norms and regulations, when the decision is made to decommission an NPP unit due to the expiration of his design service life, no special license from GAN is required for final shutdown of the unit.

However, in the event of a decision on the final shutdown of the unit and its decommissioning, the using organization will have to appeal to GAN for changes in the conditions of the annual operating license and must also coordinate its subsequent activities on decommissioning the NPP unit with GAN. Otherwise, the NPP unit will be considered to be in operation and subject to regulatory requirements governing operations, including requirements for operating documentation and personnel.

The legal base and regulatory base existing in Russia and governing the regulation of NPP decommissioning does not define for using organizations any restrictions either relative to the selection of a decommissioning option or to the selection of individual stages in the decommissioning. Nonetheless, the using organization when selecting an NPP unit decommissioning option must consider the following requirements of the current regulatory documents:

- problems in NPP decommissioning must be borne in mind when operating, servicing and repairing power units

- the using organization, no less than five years before the expiration of the design service life of the NPP unit, must ensure the development of the decommissioning program for the power unit, including the substantiation of the selection of NPP decommissioning option

- the decommissioning of the NPP unit must be preceded by its comprehensive (radiation and engineering) study

- based on the results of this comprehensive study, the using organization must provide the development of an NPP decommissioning plan, prepare a report on the substantiation of work safety when decommissioning the power unit, and obtain a license from GAN for the decommissioning of the NPP unit

- until the removal of spent nuclear fuel, the NPP unit shut down for decommissioning is operational 
- until receipt of a license to decommission the power unit, maintenance, decommissioning of individual systems and elements, and cutbacks in the number of operators can take place only upon agreement with GAN in accordance with changes in conditions of the operating license that have been introduced in the proscribed manner.

\subsection{Requirements for the Condition of the Unit with RBMK Reactor Necessary for Obtaining a Decommissioning License}

The using organization must submit to GAN an application, with a set of documents substantiating the safety of decommissioning, to obtain a license to decommission the NPP unit, regardless of the type of nuclear reactor. When there is a positive decision based on the results of the study of the set of documents, GAN issues a license to perform activities for decommissioning the power unit. The license to perform practical work at decommissioning the NPP unit enters into force the moment that spent nuclear fuel is removed from the unit. Other requirements on the condition of the NPP unit, including units with RBMK reactors, for obtaining a decommissioning license are not contained in Russian regulatory documents. 


\subsection{Specific Features of NPPs with RBMK Reactors Requiring Accounting when Decommissioned}

Current basic provisions and requirements of Russian documentation for regulating decommissioning of NPP units apply to all NPP units, including those with RBMK reactors; that is, they are independent of the type of nuclear reactor used in the unit. Nonetheless, for NPPs with RBMK reactors, there are several specific features that need to be specified in draft materials or requirements of regulatory documentation governing the decommissioning of units with this type of nuclear reactor.

First, NPPs units with RBMK reactors are characterized by the regime of uninterrupted refueling of nuclear fuel in the reactor core, during which the fuel assembly bank with spent nuclear fuel is immediately removed from the core and placed in the pre-reactor pond for short-term cooling of the spent fuel in order to lower residual heat release. Because of the prevailing economic nonfeasibility of reprocessing spent nuclear fuel of NPP units with RBMK reactors and the lack of centralized sites for storage or burial of spent fuel assemblies from units with RBMK reactors, the decision was adopted to store fuel assemblies with spent nuclear fuel on the nuclear power plant sites.

For this purpose, specialized vaults for spent nuclear fuel were constructed on the sites of NPPs with RBMK reactors. Fuel assemblies with spent nuclear fuel from all units operating on the NPP site are placed in these vaults after a certain amount of cooling in the reactor ponds. The storage of spent nuclear fuel on sites of NPPs with RBMK reactors has taken a heavy toll. Reactor cooling ponds for spent nuclear fuel are substantially overcrowded, and designs do not call for the capability of emergency dumping of the core. Therefore, filled spent nuclear fuel ponds can become a cause of the unscheduled shutdown of operations of NPP units with reactors of this type. Also, design capacities for spent nuclear fuel vaults in NPPs with RBMK reactors are more than $66 \%$ full.

Efforts are being made at NPP sites with RBMK reactors to increase the capacity of the reactor cooling ponds and the capacity of the spent nuclear fuel vaults by packing spent nuclear fuel assemblies in these vaults. However, technical concepts implemented do not take into consideration the need to dump and dispose of spent nuclear fuel from units in the event of their decommissioning, nor do they consider the need to continue long-term functioning of the spent nuclear fuel vault after the NPP units are decommissioned.

This is made worse by the fact that spent nuclear fuel vaults on NPPs with RBMK reactors have been constructed virtually simultaneously with the NPP, and the design service life of the spent nuclear fuel vault is 30 years, the same as for the NPP. Thus the problem of long-term storage of spent nuclear fuel on NPP sites with RBMK reactors requires additional consideration and regulation design materials or in regulatory documents.

Second, the presence of a large quantity of radioactive graphite, amounts of which from one unit are about 1,800 tonnes and which contain significant amount of ecologically harmful radionuclides with long half-lives, such as tritium, carbon-14, and others. Thus when decommissioning NPPs with RBMK reactors, required regulatory decisions must be made concerning possible alternative options for final handling of reactor stacking irradiated with graphite:

- long-term storage of graphite in the reactor core (after dumping of spent nuclear fuel from the reactor core) 
- dismantling of graphite stacking of the reactor core, processing and disposition of dismantled graphite units in special vaults for long-term storage

- dismantling of graphite stacking of reactor core, reprocessing, disposition, or burial of irradiated graphite.

Each of these solutions requires the corresponding measures of radiation safety in handling irradiated graphite.

Third, units with RBMK reactors have a single-loop configuration for heat removal from the nuclear core using rather branched and large loop for circulating steam coolant. This single-loop configuration can cause radiation contamination of steam lines of the circulating loop, which can occur both through corrosive activity and as a result of transfer and formations in the loop of fission byproducts in the case of non-hermeticity of heat-releasing elements in the core of the nuclear reactor. Compared with units with VVER reactors, in which the equipment of the first (reactor) loop is primarily subjected to radiation contamination, units with RBMK reactors all the equipment of the circulating loop, including the equipment of the machine room, that can be subjected to contamination.

This requires both an increase in the scope of decontamination and dismantling of equipment and lines of the steam loop of a unit with an RBMK reactor, additional regulations for how this work will be performed, and development of corresponding regulatory requirements for safety. Also, it may be necessary to establish additional requirements for exhaust radiation monitoring and control systems. 


\subsection{Problems, Requirements, and Supervision of Environmental Safety Assurance During Decommissioning of Nuclear Power Plant Units}

\subsection{Main Provisions and Terms of Environmental Protection}

The environmental situation in the world, in the opinion of most scientists and specialists, is difficult if not catastrophic. The present state of the environment indicates that problems in the ecology are caused for the most part by two major factors: the wasteful use of natural resources, which negatively affects regeneration of the biosphere; and pollution, which threatens every living thing, including man's health and well being. The atmosphere in Russia is no exception. A number of areas in Russia have been declared ecological disaster areas:

The reasons for the situation surrounding the state of the environment for the most part lie in the fact that over a long period of time, mankind tried to protect natural objects surrounding the atmosphere while continuing to work and observe sanitation and hygiene regulations defining the quality of life. It was supposed that man is less resistant to the anthropogenic effects of natural objects, and therefore of the conditions created for the protection and normal viability of mankind. At the same time, mankind recognized that these regulations are addressed to man and that protecting nature in and of itself can not protect of guard the air, water, soil, and vegetation or animal life. The best defense of nature is the defense of biogenesis.

With this recognition comes the need to comes to terms with the fact that sanitation and hygiene regulations have not always, everywhere, and completely been implemented and that the implementation of these regulations is not a guarantee of environmental conservation. At this time it has become clear that the strategy adopted for protecting the environment is not warranted, and moreover led to the condition.in the environment in which mankind now lives.

Since any kind of human activity leads to unavoidable interference in the viability of the natural surroundings and can have a negative effect on the viability of natural ecosystems (biogenesis), the need to change previous environmental protection strategies becomes clear. Mankind has also come to understand that the same activity, organized along different lines, may have a different effect on biogenesis and that the effect of any human activity on biogenesis must be rational and acceptable so that any damage will be within acceptable limits.

It has become clear that it is necessary to formulate a strategy for protecting nature, the gene pool, diversity, and living conditions. Thus, the strategy of protecting nature entails that any type of activity be ecologically safe. Today only ecologically safe activities are acceptable; that is, activities that preclude serious violations of the surroundings and that do not create unacceptable living conditions for man himself. Thus, the concept of ecological safety is a concept reflecting the state of the natural surroundings and of the human condition.

Activity may be considered to be ecologically safe if all possible measures have been taken to preserve the natural surroundings in the state they were in, or close to that state, during the activity. The indicators of the state of the ecological surroundings either remain unchanged or undergo change within limits acceptable for the given area and type of activity. The characteristics of the human condition conform to the requirements for sanitation and hygiene regulations, while the activity leads to no loss for the environment of the area or to the living standards more than that acceptable for the given area and type of activity. 
Decommissioning the NPP units is an activity that must be safe. As noted in Section 2.3, requirements of regulatory documents in effect today in the Russian Federation, in particular, "Sanitation Regulations in Designing and Operating Nuclear Power Plants" (SP ASB88/93), define the need for the development of a special plan for decommissioning NPP units. Thus, this plan must be such that its implementation is ecologically safe.

At this time, the strategy for implementing only ecologically safe plans for human activity have not yet become the official government strategy for environmental protection. However, guided by environmental legislation now in effect in the Russian Federation, it is possible to enact a strategy of ecological safety in designing, building, and operating NPPs and when decommissioning them. Of course, this does not relieve us of the necessity for adopting, at the government level, a strategy for ecological safety as official policy.

\subsection{Review of Current Russian Legislation and Regulatory Documents Governing Environmental Protection and Ecological Safety in Decommis- sioning Nuclear Power Plant Units}

The following are the main Laws of the Russian Federation defining legal foundations and principles governing the use of nuclear energy, and also foundations of legal regulations governing the relationship between man and the environment:

- Law of the Russian Federation on the Use of Nuclear Energy (adopted October 20, 1995)

- Law of the Russian Federation on Environmental Protection (adopted October 19, 1991)

- Law of the Russian Federation on Ecology Reviews (adopted July 19, 1995)

- Law of the Russian Federation on Radiation Safety of the Populace (adopted December 5, 1995).

and also the Laws of the Russian Federation on Sanitation and Epidemiological Well-Being of the Populace, on Protecting the Atmosphere, on Natural Resources, on the Earth's Plate, on Animal Protection, and several other laws.

In early 19.96, the President of the Russian Federation signed the Decree on the Transition of the Russian Federation to Stable Growth, which treats problems of ecological safety in Russia. The main provisions of this decree are based on principles of the successive transition to stable growth, providing a balanced resolution of Russia's socio-economic tasks, problems of preserving the environment and natural resources potential in order to meet the demands of this and future generations. It is clear that it makes no sense to talk about Russia's transition to stable growth unless problems of ecological safety are going to be addressed and ecological safety becomes a component part of the safety of the citizens of Russia, its national security, and, of course, the world peace.

The Law of the Russian Federation on the Use of Nuclear Energy defines the legal foundations and principles regulating relations arising when using nuclear energy. This law is aimed at safeguarding the health and well-being of citizens and the environment. This law establishes that one of the main principles of legal regulations in the area of the use of nuclear energy is radiation safety of individuals, of the populace as a whole, and of the environment. This law requires the enactment of norms and regulations providing radiation safety and establishes what activities are in violation of these laws, and defines legal relations both in the punishment of violators and in compensation for losses suffered by members of the population and by the environment. 
Another special Law of the Russian Federation on Protecting the Environment facilitates the formulation and consolidation of ecological law and order and ensures ecological safety in the territory of the Russian Federation (unfortunately, the text of this law fails to define the very concept of ecological safety). This law establishes that the task of environmental legislation of the Russian Federation is regulating relations in the area where society and nature come together to preserve the natural riches and quality of life and to prevent ecologically harmful effects of human activity. At the same time, this law of the Russian Federation does not turn away from its old concepts that ecological systems need to be protected against contamination, damage, harm, depletion, and destruction. The law establishes that each citizen has the right to protect his health against deleterious effects of the surroundings resulting from human activity.

It would seem that this Law of the Russian Federation corresponds to the basic provisions of the strategy presented above for protecting the environment. However, this law does not address this strategy, and the text of the section on regulating environmental quality, as in the past, is oriented especially to the use of sanitation and hygiene standards for purposes of environmental protection. At the same time, the Law of the Russian Federation on Protecting the Environment legislatively consolidates the need for ecological (government and social) reviews of all proposed human activities representing potential danger to the surroundings. This means that the project associated with the decommissioning of NPP units, as with other projects of human activity, must also undergo an ecology review process. Without a positive conclusion of the ecology review process, the project may not be implemented or financed.

Thus, following the provisions of this Law, it could be considered that with the correct organization of the ecology review process and its normal requirements, there is every possibility for preventing environmentally hazardous projects from being implemented. In developing these capabilities, a methodology for preparation of ecology draft materials has been developed and ecology review boards have been convened, a description of the basic provisions and recommendations of which is presented in Section 6.9.

In accordance with the recommendations of this methodology, for each area and type of activity there must be local ecology regulations for permissible effects of human activities on the biogenesis of the natural surroundings, according to which the projected activity will be developed and implemented. The ecology review of the project must establish that the project satisfies ecology regulations. Of course, this methodology was developed outside the framework of the Law of the Russian Federation on Protecting the Environment, but its provisions and recommendations may be applied also to projected decommissioning of NPP units.

Another Law of the Russian Federation on the ecology review process defines the tasks of the ecology review, establishes the legal position of the review board and the powers of agencies in authority, and also establishes liability for violations of provisions of this law. In particular, this Law establishes that the ecology review is a check on the conformity of the projected activity to ecology requirements. The ecology review also defines the terms and conditions of the permissible implementation of the project. However, neither this law nor others associated in any way with problems of environmental protection establish any kind of ecology requirements, specific criteria of permissible or impermissible implementation of the projected activity. Apparently, this is how it should be, since requirements and criteria for all types of human activity and for the entire territory of the Russian Federation cannot be established ad hoc. 
Laws of the Russian Federation on Radiation Safety of the Populace and on Sanitation and Epidemiological Well Being of the Populace relate directly to environmental protection and human health in the Russian Federation. These Laws govern sanitation and hygiene. They define permissible direct effects on the state of health, but they do not limit indirect effects; that is, through the breakdown of natural objects.

In addition to the laws mentioned above, the Laws on Protecting the Atmosphere, on Natural Resources, on the Earth's Plate, on Animal Protection and other legislation are in effect in the Russian Federation. These statutes have been in effect for a relatively long time, since the time of the former USSR, and now many of them need to be clarified and re-examined. Of course, not all the Laws mentioned above can be applied directly to problems associated with designing or decommissioning NPP units. However, some of their provisions must be considered and implemented, both when selecting a site for the NPP on the territory of the Russian Federation, designing the NPP, and when decommissioning NPP units.

It should be noted that some of these provisions of the Laws of the Russian Federation have been adapted to fit activities in the area of nuclear power, including the designing and decommissioning of NPP units, and they are reflected in specific requirements and recommendations of regulatory documents existing in Russia in the area of nuclear power. First and foremost, such regulatory documents as those described in Section 2.3 fall into this category: General Safety Provisions for Nuclear Power Plants (OPBB88), Sanitation Regulations in Designing and Operating Nuclear Power Plants (SP ASB88/93), Radiation Safety Regulations in Nuclear Power Plant Operations (PRB ASB89), and the corresponding Building Rules and Regulations (SNIP).

Regulatory documents, Sanitation Regulations in Designing and Operating Nuclear Power Plants (SP ASB88/93) and Radiation Safety Regulations in Nuclear Power Plant Operations (PRB ASB89), contain special sections defining requirements for decommissioning NPP units. Basic provisions of these sections establish a number of additional requirements for refurbished NPPs reflecting the need for taking the problems of decommissioning of these NPPs into account back in the designing stage. The provisions of these sections establish that NPP units must be decommissioned according to a specially developed plan. This plan must be developed in light of the results of the comprehensive (engineering and radiation) survey of the NPP unit.

When designing the process for decommissioning NPP units, radiation safety of the populace and the environment must be ensured and principles governing handling radwastes must be observed. The project must stipulate radiation control and monitoring for the implementation and methods of radiation control and monitoring the state of the environment.

It would appear from the position of today's strategy of protecting the environment, aimed primarily at the observance of sanitation and hygiene norms and defining the process of decommissioning as a specific type of activity implemented according to a specially developed project that must undergo social and governmental ecology reviews but whose tasks do not contain estimates of ecological safety, that one could consider that there is a legal basis for protecting the environment when decommissioning NPP units.

However, established laws and regulatory requirements within the framework of activities and tasks of the ecology review board have been defined in such a way that they do not consolidate priorities in estimating environmental safety when implementing any projected activity in the area of nuclear energy; in particular, projects calling for the decommissioning of NPP units. As a result, there is no guarantee that environmental safety will be provided, and this includes 
activities undertaken in decommissioning. Consequently, on the legislative and regulatory level, there are no guarantees of environmental safety although, of course, any project is developed in such a way that the consequences of its implementation, including consequences of decommissioning, will be minimal for the surroundings and will ensure radiation safety of the populace.

If there is agreement with the assertion that the current strategy in relation to protection of the environment must be changed (and it would be difficult not to agree with this), and changed in such a way that only ecologically safe projects would be permissible (which a priori must be established by the ecology review), then the regulatory and legal basis for the design of any kind of activity, including decommissioning of NPP units, must undergo serious revisions. It is clear that these revisions must be global and must apply to all projects and processes, not only in the area of nuclear energy but in any kind of activity.

At this time, it is proposed in Russia to create a body of Environmental Law to develop a number of blocks of draft legislation, defining the foundation of environmental protection: on Protecting the Atmosphere, on Drinking Water, on Soils, on Protecting Water Ecosystems, on Hazardous Materials, on the Safe Handling of Pesticides and Toxic Chemicals, on Protecting Health and Safety and the Environment from the Effects of Toxic Chemicals, on Industrial and Domestic Waste, on Handling Radwastes, on Ecological Monitoring, on Ecological Testing and Certification, on Ecological Regulations, on Ecological Insurance, and other documents in one way or another associated with the protection of the environment and ensuring environmental safety.

The contents of these regulatory provisions are not yet known. Therefore, it is hard to determine to what degree they will satisfy this ideology of environmental safety. However, it is clear that their content to a greater or lesser degree will concern issues of protection of the environment (natural ecosystems and human habitation) and human health. Consequently, additional and new requirements will appear, the compliance with which will be mandatory, including requirements in the designing and implementation of the NPP decommissioning process.

\subsection{The Concept of Ecological Safety as Applied to the Decommissioning of Nuclear Power Plant Units}

The concept of ecological safety of any type of human activity described above was developed initially in reference to activities in the area of nuclear power. The concept supposes that the NPP is ecologically safe when, in its building and operation in a biogeocenotic surrounding, changes occur that are deemed permissible for the region (as a result of effects from the NPP), while during an accident at the NPP and in other disruptions of its normal operations, losses to the surroundings do not exceed levels permissible for the region. The living conditions conform to sanitation and hygiene requirements.

The concept of ecological safety as applied to the decommissioning of the NPP units may be somewhat clarified and formulated in the following way. Decommissioning of the NPP unit may be deemed ecologically safe if all factors of the effect on the biogeocenotic surroundings of the unit being decommissioned, and if the living conditions of the populace in the area of the NPP unit do not result in changes in the status of biogeocenosis greater than is deemed permissible for the region, while living conditions are not worsened in comparison with conditions defined by sanitation and hygiene requirements.

It is supposed that the concept of a process of decommissioning of the NPP unit includes all operations and technological processes performed in accordance with the project, both directly at 
the unit and indirectly (transporting, warehousing, burial of radwastes and radioactive materials, drainage of process media, water, etc., used in the decommissioning process).

It is possible that the concept of ecological safety needs to be clarified to an even greater degree, since up to the decommissioning of the NPP unit, the entire NPP was operating, which affected biogeocenosis of its natural surroundings. This also affected living conditions.

It is natural to suppose that this NP was developed ecologically safely and limits were established on changes in the viability of the ecosystems located close by. Corresponding to these restrictions, levels of permissible effects of the NPP on biogeocenosis were established, while in accordance with sanitation and hygiene requirements, permissible absorptions of radionuclides and chemical substances into the atmosphere and waters of the facility were established, preventing violations of sanitation and hygiene regulations both for permissible concentrations in air and for concentrations in the water and food. It is possible that during the operation of the NPP, changes may have occurred in the ecosystems (their structure, composition, tropism, etc.); that is, technogenic succession began.

The decommissioning process of the NPP unit must not exacerbate or accelerate technogenic succession (that is, sharp changes in composition, structure, and other vital characteristics) in one biogeocenosis or another. In other words, changes in the state of the surroundings permissible during decommissioning of the NPP unit must not exceed changes permissible during its normal operating regime. Of course, this decommissioning process must not worsen living conditions; that is, the sanitation and hygiene standards must always be observed.

\subsection{Determination of Permissible Changes Biogeocenosis Vital Functions in the Area of the Decommissioned Nuclear Power Plant Unit}

According to the concept of ecological safety, for which control of ecological safety in the decommissioning process of the nuclear power station at the stage of technical and economic substantiation of the choice of decommissioning option, an estimate must be made of the effects of the decommissioning process on the natural surroundings. In accordance with the requirements of the ecological safety methodology and recommendations for its implementation (Section 6.9) and based on the results of this estimate, a concept for protection of the environment during decommissioning of the NPP unit must be developed. This concept must set restrictions on changes in the condition of the biogeocenosis of the area of the NPP in the implementation of this process and on changes in living conditions.

The determination of restrictions on changes in the condition of the biogeocenosis of the region is a rather complex task, whose solution must be arrived at on the basis of studies of the condition of the region and its distinctive features. Of course, it is not realistic to task the determination of permissible changes in the vital functions of all ecosystems in the area of the NPP, since its possible effects can be many. In this connection, critical ecosystems are selected in the area of the NPP, and restrictions are established for these critical ecosystems on changes in composition, structure, and other vital characteristics. The well-being of these critical ecosystems guarantees the well-being of all other ecosystems.

\subsubsection{Critical Ecosystems}

Critical ecosystems are those which, in light of their position relative to the NPP and in light of their composition, structure, and capabilities to store contaminants, can suffer to a greater degree 
from the effects of the NPP than other ecosystems, or which are better transfer agents of contaminants to humans than other ecosystems. Sanctuaries for rare and disappearing plants and endangered animal species listed in the Red books also belong to the group of critical ecosystems.

From the above definition of critical ecosystems, it is clear that stricter limits will be established on permissible effects. For example, stricter limits on absorption of contaminants if the ecosystem is composed of species with low resistance to contaminants, or types that store or are good transfer agents of contaminants to humans. Therefore, it can be said that by not exceeding permissible changes in the vital functions of critical biogeocenoses we guarantee their well-being and that of other, non-critical biogeocenoses.

Of course, the question arises: what can be considered a permissible change in the state (vital function) of biogeocenosis and what should be considered impermissible? It is known that in general, the state of biogeocenoses is characterized by many parameters, forming a multi-dimensional vector in " $p$ " space. Then a change of a vector can be deemed permissible within the limits of a certain multi-dimensional realm, the linear dimensions of which in the direction of each change (in the direction of the axis of the "i"-parameter, characterizing the state of the ecosystem) do not exceed the average annual fluctuation in value of this parameter. The average annual fluctuations of the values of the "i" $i$ "-parameter are caused or defined as yearly conditions; that is, air temperature and its distribution throughout the year, the amount and time pattern of precipitation, and other indicators, including internal biogeocenotic parameters.

Around this multi-dimensional realm, one can delineate a kind of corona, within the limits of which a change of vector can also be deemed permissible if the linear dimensions of the corona are such that they do not lead to changes in individual parameters of the state of the ecosystem capable of bringing about succession. Thus, the realm of permissible values of the vector of the state of biogeocenosis is that which is characteristic of or close to homeostasis of biogeocenosis, while the realm with the corona is the state when biogeocenosis evolves from homeostasis. Succession in biogeocenosis is not clearly expressed (in the opinion of a number of experts. This is a realm of creeping anthropogenesis; in other words, caused by human action, succession). The evolution of the vector of the state of biogeocenosis outside of the limits of the designated realm of multi-dimensional space is impermissible.

The description above characterizes a general case. In each specific case, we need to speak about a list of parameters characterizing the state of biogeocenosis, which must be restricted by changes that do not cause succession. It is clear that these parameters must be more sensitive to the anthropogenic effects that are easily observed and measured. Since practically any anthropogenic effect acts uniformly on the state of biogeocenosis, this effect thus causes a uniform change of any of the parameters, characterizing the state of biogeocenosis. Thus, to estimate the state of biogeocenosis, all parameters suitable and convenient for use are deemed to be bioindications of the anthropogenic effects on biogeocenosis.

If we proceed from the principle that the preservation of phytocenosis (the plant component), or its change within permissible limits of the ecosystem ensures the preservation of the sate of biogeocenosis in its entirety, or ensures a change in this state within permissible limits, then it follows that parameters of phytoindication (bioindication for plants) of the state of the ecosystem should be used. 


\subsubsection{Terrestrial Ecosystems}

In terrestrial ecosystems, the following can be parameters:

- yearly gain of biomass for one or another type

- productivity of one or another type

- surface area of the ground cover for individual types (especially in ecosystems with moss and deprived of ground cover, including epiphyte (which grows on the trunks and branches of trees)

- the gain in thickness (an increase in diameter) of the trunk of trees in the forest ecosystem

- the level of adaptation (the percentage of plant growth not indigenous for a given ecosystem) and synanthropy (the percentage of plant growth appearing in the ecosystem as a result of human activity)

- soil characteristics (density, moisture, mechanical composition, humus content, and biogeocenotic elements) and other parameters.

It is well known that the composition and structure of a property are deemed to be the primary indicators of the ecological health or sickness of an ecosystem. At the same time, it is deemed that there is not, nor can there ever be, a single set of objective criteria by which one can distinguish ecological health of the state of the ecosystem from ecological sickness (that is, that the ecosystem has become unfit for man). This is so if one does not distinguish between anthropogenic and natural succession and if one does not consider that to man it makes no difference in what natural surroundings he lives. Therefore, the modern phenomenon of ecological sickness in one or another ecosystem and measures taken to restore the ecosystem to the state of ecological health is the task for us to solve, which must have symptoms (if not objective indicators) for its solution.

Of course, all the indicators enumerated here, characterizing the vital functions of the ecosystem, can change as a result of natural causes. First, as a result of natural successions of aging; second, as a result of changes in meteorological conditions; and third, as a result of changes in local conditions not immediately noticed.

Natural successions in ecosystems are slow processes that cover huge territories and can be identified by certain signs. Anthropogenic successions in the area of a specific site, for example, an NPP, is a relatively fast process, covering the territory nearby (first of all, the territory of critical ecosystems). The effects of contaminants are generally more intensive in these areas.

\subsubsection{Water Ecosystems}

For water ecosystems, parameters characterizing its state are the characteristics of water organisms and the characteristics of the properties of the water organisms. The hydrochemical characteristics of the water ecosystem are temperature, transparency, acidity $(\mathrm{pH})$, reduction-oxidation potential (Eh), concentrations of biogeocenotic substances $\left(\mathrm{NO}_{2}^{-}, \mathrm{NO}_{3}^{-}, \mathrm{NH}_{4}^{+}\right.$, phosphates, common phosphorous, nitrogen in organic compounds), concentration of organic substances and of oxygen, the major ions and others, and their stratification.

In addition to the parameters of water, there are also characteristics of bottom deposits: thickness, distribution, speed of accumulation, type of deposits, content of interstitial moisture and organic substances. Parameters characterizing hydrocenosis of the water system are numerous: type composition of each property (photoplankton, zooplankton, microorganisms in bottom 
deposits, macrophytes, fish), number and biomass by types, characteristics of bacterioplankton and other parameters, and also information on concentration of chlorophyll "a" and the speed of production and destruction of organic substances. In the water ecosystem, characteristics of the living condition and of hydrocenosis are limited for the same reason as terrestrial ecosystems-to prevent impermissible changes in the state of the ecosystem of a given watershed.

If the NPP operates with a coolant reservoir, then the critical water section is the cooling reservoir section. In this case, it should be remembered and taken into consideration that the NPP cooling reservoir is a natural technogenic system with strong direct and reverse ties. Therefore, the state of the ecosystem of the cooling reservoirs is defined by the working of the NPP, and primarily by the release of heat in the reservoir; that is, by the thermal contamination of the reservoir.

Heat release leads to thermal eutrophication of the ecosystem of the reservoir (although chemical eutrophication is not precluded as a consequence of the absorption in the reservoir of chemical contamination). This determines that the ecosystem of any reservoir, when transformed into coolant reservoir, undergoes changes. Therefore, the fact that an ecosystem is formed during NPP operation must be taken into consideration when selecting indicators of vital function of the ecosystem of the coolant reservoir.

Since the life of the ecosystem of the coolant reservoir depends on how the NPP acts on the reservoir, while the characteristics of hydrocenosis are determined by the characteristics of living conditions of the hydrobionts, the primary indicator to be observed is the hydrochemical regime. Therefore, early in the working of the NPP, it is necessary to determine all indicators characterizing the state of the ecosystem (in numerous proposals, at least 20-30 indicators of the classification of water quality are recommended), and to discuss them. In observations of the degree of equilibrium of processes of production and destruction of an organic substance in the ecosystem of the reservoir, the ratio of speeds of these processes is determined. The value of this ratio, close to or equal to one, illustrates the equilibrium of the state of the ecosystem of the reservoir.

In observations, general indicators are determined that are the results of processing of hydrochemical and hydrobiological observations. Information on the type state of water organisms is the result of hydrobiological observations. This information is processed and represented in the same way as that for terrestrial ecosystems. The results of this information processing makes it possible to arrive at the same conclusions, and even broader ones at times, when there is a change of dominant species or an increase of types previously not characteristic for the reservoir; for example, blue-green algae.

Observations of ichthyfauna of the reservoir yield very useful information: its composition, numbers, and other characteristics, changes of which are probably restricted to the concept of preservation of the surroundings of the given NPP. Observations are made of the growth and spread over the waters of the cooling reservoir of surface vegetation, and the results of these observations are charted and annual maps compiled (there are well-known and developed methodologies for this). The overgrowth of the cooling reservoir is, generally speaking, a symptom of sickness in the ecosystem (in the critical ecosection) of the cooling reservoir.

One of the most important and sensitive indicators, especially for the hot ecosystem, which is what the ecosystem of the cooling reservoir is the indicator of, is stability of seasonal succession; that is, stability of the successive change of seasonal types (primarily, changes of microorganisms). When converting a reservoir into a cooling reservoir, not only does the type of 
hydrobionts in the reservoir change, but also the onset of maximum blossoming and wilting. Stability in this process is a characteristic of the stability of the ecosystem, while deviations in the time distribution of indicators of biological processes for one or another type is a symptom of sickness. This is a very precise and sensitive indicator of the vital function of the ecosystem, but it demands systematic observations.

Another series of indicators characterize the vital function, resistance to anthropogenic stresses of both terrestrial and water ecosystems, can be used to determine permissible changes in vital function of the natural surroundings of the NPP. However, some of them are less sensitive than those mentioned above, while others are not very user-friendly. Therefore, the indicators listed above are fully appropriate for establishing permissible changes and observations of values in ecological monitoring, organized for the NPP (both in terms of sensitivity and in terms of the capability to be used in measurements).

Generally speaking, when selecting indicators, one should proceed from the conceptual model of physical-chemical, biochemical, and biological processes anticipated for the critical ecosection during running of the NPP, and in accordance with this model, select the indicators. The diversity of parameters characterizing the state of terrestrial and especially water ecosystems complicates the selection of the values that must be limited to maintain the permissible state of biogeocenosis.

In principle, all parameters must be limited, but how the state of biogeocenosis is determined in any one system, whose existence is determined by many factors, must be determined by the parameters deemed primary. The primary parameters must be delineated. Unfortunately, there is still not enough information to make it possible to name the primary parameters (if they exist) for all biogeocenoses. But there is reason to hope that in a reasonable time (several years), the system of observations of the state of critical biogeocenoses may be able to identify the primary parameters of the state of specific critical biogeocenoses and to limit their changes.

Thus, in the area of each NPP, both when designing and operating the NPP or while conducting ecological monitoring, critical ecosystems must be identified and permissible changes of parameters characterizing their vital function must be established. Also, permissible effects of the NPP on these ecosystems must be established that do not cause changes in the vital function of the ecosystem greater than those permitted. Cumulative effect should also be considered; synergism of effect is precluded. If for some reason this is not done before, then it must be done when developing the NPP unit decommissioning plan.

Permissible changes in the vital function of critical ecosystems and the corresponding permissible effects on these ecosystems from the NPP (including effects from decommissioning the NPP unit) are deemed for the given region to be ecological standards of the anthropogenic effects from the NPP. By not exceeding these permissible effects, according to the concept of ecologically safe activity, ecological safety is guaranteed when decommissioning the NPP unit. According to the concept of ecological safety of activities, when decommissioning NPP units, the safety of the populace living near the NPP must also be ensured. Among the populace, one can single out a critical group.

\subsubsection{Critical Group of the Populace}

The critical group of the populace is one which, because of where they reside (distance from the NPP, direction from the NPP, the terrain, etc.), food supply, water use, and other reasons, might 
suffer from the effects of the NPP more than other groups. If safety is provided for the critical groups of the population, then safety is ensured for the entire populace living near the NPP. For the critical group of the population, the mediated effect of the process of decommissioning of the NPP unit will be safe if ecological safety of the natural surroundings is provided, and the direct effect of the decommissioning process will be limited by sanitation and hygiene regulations, which must be observed. It should be noted that in this case, these are not only requirements for sanitation hygiene but also requirements for ensuring ecological safety.

The maximum permissible concentration of chemical and radioactive substances in the near-earth layer of the atmosphere, in water, and in food, should also be included in these regulatory documents. In order not to exceed these maximum permissible concentrations of hazardous substances, the decommissioning project of the NPP unit must establish the maximum permissible release of hazardous substances into the atmosphere and the permissible discharge of hazardous substances into the hydrographic grid of the region, in light of local conditions.

When necessary for the technological process implemented when decommissioning the NPP, partial maximum permissible release (that is, threshold one-time, temporarily permissible, and others) and, similarly, partial permissible discharge of hazardous substances may be established.

\subsection{Procedures for Determining Permissible Changes in Vital Functions of Biogeocenoses}

This section considers the question of who, when, and how limits can be established on changes in parameters characterizing vital functions of critical biogeocenoses. As was noted above, the development of a plan for any kind of activity, in particular, the decommissioning of NPP units, must include draft materials based on their ecological safety of the planned activity: an estimate of the effects on the natural surroundings and substantiation of ecological safety of the proposed activity. These draft materials, according to the Laws of the Russian Federation, must undergo public and government ecology reviews. The materials are developed based on the results of a survey of the natural surroundings of the site where the activity is to be implemented and also on estimates and predictions of expected changes in the vital function of the natural surroundings should the planned activity be implemented (Figure 6.1).

When surveying the natural surroundings of the NPP, the characteristics in which changes are to be limited are observed over at least three years so that their fluctuations from one year to the next can be observed and time trends of these changes established. In this case, the range of values of a certain parameter, $\mathrm{Aj}$, characterizing vital function of critical biogeocenosis, is the range of permissible changes of this parameter both during operation of the NPP and during its decommissioning. This range of permissible changes must guarantee the preservation of the state of homeostasis or the state close to it (the Aj-parameter for $\mathrm{Aj}$-biogeocenosis).

This range may be somewhat expanded (especially for individual parameters), if there is agreement on certain deviations in the state of critical biogeocenoses in the future from their state at the present. These deviations are unavoidable (for example, a change in productivity or area as a result of the increased population in the region in connection with hiring additional groups of specialists in implementing the decommissioning plan.)

Values of permissible changes obtained in this way $\left(\mathrm{Aj}\right.$ " $\mathrm{A}_{1}$ ) for each $\mathrm{Aj}$ - critical biogeocenosis are recorded in the draft ecology materials, "An Estimate of the Effect of NPP, on Surroundings" 
Figure 6.1. Diagram of Preparation of Ecological Design Documents for Decommissioning of Nuclear Power Units 
(EENS NPP) or, with reference to decommissioning of the NPP, "An Estimate of the Effect of Decommissioning of the NPP on the Surroundings" (EENS Decommissioning).

These materials must undergo public and government review. Here it is not possible to preclude that, when reviewing EENS decommissioning materials, the public ecology review might demand a lowering of the values of individual permissible changes (that is, to have a margin of safety). Since experience shows that such situations take place, in this case there should be a consensus with the public ecology review. Then, the values $\mathrm{Aj}$ will be ecology regulations considering not only objective data of scientific observations of $\mathrm{Aj}$ (that is, parameters of the state of the ecosystem), but also considering the change in society in the area around the NPP.

Being in agreement with one or another review, approved by the Ecology Committee of the State Committee of the Russian Federation for Protection of the Environment, these materials attach to values $\mathrm{Aj}$ the status of ecology regulations for the region of the NPP being decommissioned. If the permissible changes in the parameters characterizing the state of critical biogeocenoses were developed, coordinated with the ecology review boards and approved by the Ecology Committee of the Russian Federation in the ecological materials in the designing or operating of the NPP, then when developing the decommissioning plan, these local ecology norms will act as sanitation hygiene norms; that is, they will be mandatory for all designers.

\subsection{Supervision of Activities in Dismantling Nuclear Power Plant Units}

Since the process of decommissioning the NPP unit should be looked at as one possible type of activity in the area of nuclear power, then all procedures and requirements currently in effect in Russia, including monetary fines and other sanctions associated with violations of regulations in amounts established by law, must apply to the implementation of this type of activity. In this and other areas associated with the administration of supervision of the implementation of production activity, Russia has amassed a significant amount of experience, and this experience must be put to use.

In the nuclear power sector in Russia, as in other developing nuclear power countries of the world, problems of supervision of compliance with established regulations in the area of all potentially dangerous production and ensuring their safety have always been subjects of great attention. Supervision of potentially dangerous work, supervision of the detection of deviations or violations of the technological process defined by the plan, and supervision of the application of fines when cases are established of deviations or violations may be preserved and applied to the decommissioning activities of NPP units. An important addition will be the necessity for administrative supervision of compliance with requirements of the concept of preserving the environment during decommissioning of the NPP unit. In this case, administrative supervision will not differ fundamentally from supervision over other parameters of the environment. Data from ecological monitoring will serve as a source of information for supervisory agencies and will also determine the procedures for compensation for damages caused by those who violate laws on the ecology.

However, as experience shows, the system of fines, economic sanctions, and other kinds of sanctions in place in Russia for damages to the natural surroundings is not (and cannot be) effective. Therefore, this system cannot be expected to help reduce the number of offenders. The proposal on changing the strategies of environmental protection-approval given only to the implementation of work that is environmentally friendly-is a positive factor. 


\subsection{On Possible Radiation-Hazardous Accidents During Decommissioning of Nuclear Power Plant Units}

In Russia, as in other countries of the world developing nuclear power, problems of nuclear and radiation safety in the accomplishment of all potentially hazardous types of work are receiving much attention. In Russia, the organization of this work and supervision over it does not differ (and cannot differ) from that practiced the world over. As a minimum, this practice may be preserved and applied to work at decommissioning of the NPP units. This means that the process of decommissioning of NPP units must be defined even in the design stage, and all possible nuclear-hazardous and radiation-hazardous accident scenarios must be analyzed in depth and their probability estimated. In addition, the project materials on decommissioning the NPP units must present organizational and technical concepts that will prevent the development of such accidents.

As a result, according to the concept of ecological safety of activity, when implementing work at decommissioning NPP units, guarantees of personnel safety, safety of the populace living in the vicinity of the NPP, and preservation of the natural surroundings must be provided. Dangerous consequences of accidents must not cause damage to the natural surroundings greater than those established for this process. Possible accident scenarios when decommissioning the NPP units, then, cannot have consequences more severe than accidents that are possible in principle for the operating NPP. Thus, and this must be based in the decommissioning plan, damage from accidents that are possible when decommissioning the units must not exceed losses deemed acceptable in for an accident involving an operating NPP. As accepted in the area of nuclear power, a plan of measures for protecting personnel, the populace, and the surroundings in the case of an accident must be developed.

\subsection{Requirements for Ecological Monitoring in the Area of the Nuclear Power Plant Units Being Decommissioned}

By definition, ecological safety must be supervised. It is necessary that supervision of ecological safety be, at a minimum, doubly redundant.

Control One - this is the control of the project materials on decommissioning the NPP units, the tasks of which are

- to ensure, by means of public and government review boards, that the process of decommissioning of the NPP units will be ecologically safe

- to either adopt or strengthen ecological standards of permissible changes of parameters characterizing the state of the natural surroundings in the vicinity of the NPP units being decommissioned.

As noted before, EENS (decommissioning) materials are subject to procedures of the public and government ecology review boards at the stage of technical and economic substantiation of the decommissioning of the NPP units, while in the decommissioning draft project, materials of the substantiation of ecological safety of the decommissioning process go through these review boards. The main task of the ecology review board in relation to the first of the materials mentioned above is to consolidate, or together with the developers, to strengthen regional ecology norms; that is, they concur and adopt the concept of preservation of the surroundings when decommissioning a specific NPP unit. 
In relation to the second set of materials mentioned above, the main task is to ensure and then verify that the project developed for decommissioning satisfies these regional ecology norms and also satisfies sanitation and hygiene norms, and to adopt the concept of preservation of the natural surroundings in the area of the NPP. The positive conclusion for the project developed to decommission the NPP unit defines the possibility for implementing the project. In any case, these are the proposed approaches when implementing strategies for ecological safety of activities, in particular, in nuclear power.

Control Two - this is direct control over the implementation of the project; that is, over the practical implementation of the decommissioning process. This supervision must be active and must be exercised by means of ecological monitoring.

If, by the time the decommissioning of the NPP unit starts, ecological monitoring has been introduced to the area where the NPP is located, then decommissioning may proceed as stipulated, but it must be supplemented by monitoring of substances absorbed into the surroundings that are dangerous for the surroundings and for humans. These substances may accompany the decommissioning process and may be monitored by observations of other indicators of the state of biogeocenosis (depending on the possible contaminants). Requirements for this monitoring must be established in the decommissioning draft project.

In this case, the question is one of ecological monitoring as a system of observations of the state of biogeocenosis in the area where the NPP is located and at which the decommissioning is to take place. This system of observations, which proceeds from the concept that the ecology is a biological science that does not permit the free interpretation of its concepts and definitions (of the type today - poor ecology; that is, conditions for the scattering of NPP releases are unfavorable).

Unlike systems of supervision answering Yes or No, or Can or Cannot, ecological monitoring presents dynamic information in quantitative expressions: in parameters characterizing the state of biogeocenosis and thus permitting estimates of a response of biogeocenoses to anthropogenic effects accompanying the decommissioning process.

As has been observed, this ecological monitoring must be exercised actively (Figure 6.2); that is, the results of the ecological monitoring must make it possible when necessary, in the case of violations of ecological safety in the decommissioning process, to send out an control alarm and to adjust and correct the decommissioning process.

Following the diagram in Figure 6.2, the following are tasks in the introduction of ecological monitoring:

- supervision of the state of critical biogeocenoses; that is, over parameters characterizing their state

- estimates on the basis of these parameters of recorded state (is it permissible?)

- prediction and estimate of anticipated state (does it satisfy requirements of the adopted concept of preservation of the natural surroundings?)

- development of a control signal when necessary to correct the introduction of the decommissioning process including those cases when the current state of biogeocenoses is estimated as permissible, but the anticipated (predicted) state is assessed as not permissible). 
Figure 6.2. Diagram of Ecological Monitoring in NPP Region 
It would appear that procedures for monitoring ecological safety in decommissioning NPP units are similar to the recommendations presented in the current regulatory documents of the Ministry of the Environment of the Russian Federation Procedures in implementing government ecological control of the natural surroundings and observing requirements of ecological safety in the production, use, storage, and burial of radioactive materials and sources of ionizing radiation. However, in terms of content, it is essentially a different system of control of ecological safety, which makes it possible to achieve active control and to attain the goals of ecological monitoring.

At the present time, ecological monitoring is not introduced at NPPs while they are being used, and studies of risk are designed in such a way that it is not possible to use their results or those of ecological monitoring.

Therefore, in opening decommissioning activities at NPP units, ecological monitoring in the areas of the placement of these NPPs must be organized in such a way that by the time decommissioning activities begin, the introductory stage of ecological monitoring would be concluded and the initial state of biogeocenoses of the NPP areas assessed (corresponding to the time, preceeding the decommissioning).

It needs to be understood that ecological monitoring as a system of control of the state of the NPP-environment complex and of other nature-technogenic systems is the only correct path for ensuring ecological safety of society. Thus, ecological monitoring must be an immutable part in the decommissioning process for NPP units.

\subsection{Recommendations on Content and Preparation of Materials on Estimating the Effect on the Environment of NPP Unit Decommissioning Activities}

There are several regulatory documents and guidelines presenting different approaches and recommendations on the development of materials for estimating the effects of projects on the environment. In principle, if one does not bear in mind the necessity for using the concept of ecological safety for the project, then any of these documents may be used as part of an NPP unit decommissioning plan. However, such an approach is unacceptable since the NPP unit decommissioning process must be ecologically safe.

At this time, the "Guideline for the Development and Composition of Substantiation of Ecological Safety of NPPs" (ROEB ASB91) has been developed and may be used for practical activities. This guideline presents the ideology and basic provisions for ecological safety of the NPP as well as other kinds of activities associated with building and operating nuclear power plants. This document, with several corrections and considering the distinctive features of NPP unit decommissioning, may be used as a guideline when developing ecological materials "EENS Decommissioning" and "OEB Decommissioning." Based on these two guidelines, the sequence in the performance of both EENS and OEB for decommissioning may be the following:

1. A general description is put together for the territory in a radius of $20-30 \mathrm{~km}$ surrounding the NPP and the area surrounding the nuclear power plant, including a general physicalgeographical and natural-climatic description of the region and a description of industry and population disposition in the region. Basic characteristics of terrestrial and water ecosystems are included as independent sections in this description. 
The description may be called a general eco-geographic sketch of the region. The description identifies the basic characteristics of the region in each natural-climatic zone, whether or not there are any sanctuaries or specially protected territories close by and what kind, for what purposes the individual territories of the region are used, and its hydrographic grid and transportation arteries. Usually this description is compiled from archival and bibliographical materials. In compiling this section, it is mandatory to use materials "EENS Decommissioning" (or "OEB NPP" if these materials were developed for the NPP's operations). If no such ecological materials were developed for NPP operations, then the EENS and OEB Decommissioning materials must be developed on the basis of special surveys using archival and bibliographical materials. All information for calculating the transfer of contaminants in the atmosphere as a result of their absorption with ventilated air must be presented.

2. A detailed description of the territory is provided for a radius of $5-7 \mathrm{~km}$ around the NPP. Ecological zoning, a description of the landscape with landscape and soil maps, maps of vegetation, geochemical cartographic information, etc., are presented. Critical ground ecosystems are identified according to these materials. The detailed description is a very important part of the ecological-geographic description of the region because it includes the information on surface ecosystems, from which it is possible to select and substantiate the choice of critical ecosystems as indicators of the region's health. The 5-7-km radius was selected based on the experience of observations in the regions of operating NPPs. This is the territory (with a certain amount of safety margin), within whose boundaries the effects of NPP operation may be observed (for example, the presence of plant radionuclides).

Among terrestrial ecosystems there may be several critical ecosystems. In order to select them correctly, the ecological zoning and landscape zoning, or a map of geochemical barriers (landscape cartographs) is used. Independent of what the ecological and landscape zoning (the map of geochemical barriers) yields, critical ecosystems must include sanctuaries, in the form of preserves, for rare and vanishing breeds of animals and plants.

Thus, the selection of critical ecosystems is not only the selection of indicators of the state of the region. This selection is the choice of parameters characterizing the ecological state of the area, and for different critical ecosystems, these parameters will most likely be different.

3. A detailed description is compiled of the hydrographic grid of this territory. The description is compiled so that critical water ecosystems can be selected and substantiated. If the NPP works with cooling reservoirs, the critical water ecosystem is usually the ecosystem of the cooling reservoir.

4. The next section is the description of the critical ecosystems. This section contains the information necessary for estimating today's state of these ecosystems as well as for predicting their possible states from the effects of the NPP. This section defines the initial state of parameters adopted for describing the state of the critical ecosystems. It also presents conclusions on the limits of permissible changes.

The information in this section must contain quantitative characteristics of critical (ground and water) ecosystems. Together with information in subsequent sections, this will make it possible to develop a concept of environmental preservation. That is, as was noted earlier, the ecological standard of preservation for the natural surroundings and the population of the region surrounding the NPP. 
All the information of this section must be presented in dynamic form to establish trends in the parameters selected as indicators of the states of the critical ecosystems. This means that this section must be developed on the basis of not less than three continuous years of observations of changes in the parameters. If there is no such information, it becomes necessary to initiate studies as soon as possible to obtain this information.

5. Materials from Section 5 are supplemented by the results of studies of the contamination levels in the critical ecosystems (for the most part, of those contaminants which might be absorbed during decommissioning). This section is also supplemented by the identification of parameters describing or regulating the transfer of contaminants in the ecosystems.

Since other NPP units may be operating during decommissioning of one unit, it is important to have data which would make it possible to establish whether a change (permissible or not permissible) in the state of a critical ecosystem results from decommissioning, NPP operating or from some other non-NPP source.

Therefore, information should be obtained on the reaction of the critical ecosystems to all possible effects during NPP unit decommissioning planning. This requires at least three years.

6. Estimates and predictions are presented of the expected state of the critical ecosystems under the effects caused by NPP unit decommissioning under planned and unplanned (e.g., accident) conditions. If the conclusion is drawn that one can expect impermissible responses from the critical ecosystems, then the project must be amended or safety measures incorporated that prevent such effects.

7. On the basis of data cited in sections, 4,5 and 6 in EENS decommissioning materials, ecological standards are formulated and acceptable damages to the natural surroundings of the area are established, that is, the concept of preservation of the environment (the concept of ecological safety) is defined for NPP unit decommissioning activities.

8. It is substantiated that the proposed decommissioning project will not lead to a disruption of the sanitation and hygiene standards for the state of the natural surroundings. This task may be solved by common methods; that is, by comparison of permissible sanitation and hygiene standards with permissible releases outside the NPP and concentrations formed by such releases. This task may also be solved by an estimate of dosages to the population from radioactive absorption during NPP unit decommissioning.

9. On the basis of information in Section 7 in the EENS materials and Section 6 in the OEB materials, a conclusion is made on the ecological safety of the execution of the proposed NPP unit decommissioning draft project. The tasks of estimating the effects of the NPP unit decommissioning process and substantiating its ecological safety are significantly simplified if one or the other is developed during the designing or operating of the NPP. In this case, Sections 1-5 and 7 can be clarified during development of the draft NPP unit decommissioning project, while Sections 6,8 , and 9 show that, along with the decommissioning of the NPP unit, the NPP itself continues to operate and continues its acceptable effects on the natural surroundings and living conditions of the population. 


\subsection{Conclusions on Procedures for Substantiation of Ecological Safety}

In summarizing the information presented above, the following conclusions can be drawn:

1. From an ecological safety standpoint, NPP unit decommissioning must not be any different from other human activities.

2. Prior to NPP unit decommissioning, concepts of the preservation of the natural surroundings, an NPP unit decommissioning project, and the accompanying draft ecological materials must be developed.

3. The draft and project materials for substantiation of ecological safety of the NPP unit decommissioning process must pass a public and a government review process.

4. The NPP unit decommissioning project must be accompanied by ecological monitoring.

5. Ecological monitoring must be organized along the following lines: observation of the state of the natural surroundings and human habitation ---> estimate of the state being observed ---> prediction of the expected state ---> estimate of the expected state ---> state control signal and corrective actions to the NPP unit decommissioning process (when necessary).

6. The regulatory documentation and guidelines current in Russia contain, in principle, provisions that may be used when developing ecologically safe activities in the area of nuclear power and also when estimating the effects of this activity on the natural surroundings and on the substantiation of their ecological safety.

7. However, the recommendations presented in current regulatory documents and guidelines must be clarified and systematized for NPP unit decommissioning process and the substantiation of its ecological safety.

On the whole, the procedures for preparation of the NPP unit decommissioning process must conform to the diagram cited in Figure 6.3. 
Figure 6.3. Diagram of Preparation for Decommissioning of Nuclear Power Unit 


\subsection{Conclusions}

One can note several features of regulatory documents in effect in Russia relating to NPP unit decommissioning:

1. At this time, Russia is creating a five-tier system of legislation and regulations governing activities in the area of nuclear power, including the decommissioning of NPP units.

2. Norms and regulations in effect in Russia regulating activities in the area of nuclear power still follow, in many ways, the system in effect in the former USSR, in which the law "On the Use of Nuclear Energy" had not been adopted.

3. The former USSR formed a system of norms and regulations governing activities in nuclear power with specific features:

- First, the norms and regulations used were characterized by great detail as a result of the wishes of the command administration mechanism of supervision of the nuclear power complex in the former USSR to increase the degree of regulation of all aspects of activities of nuclear power.

- Second, the system of norms and regulations was distinguished by a certain dynamism, as a result of which these norms and regulations considered and accumulated all new scientific test data and the sound experience of technical engineering concepts.

- Third, the system of norms and regulations acquired a sharply expressed imperial character, - under which any activity in the area of nuclear power required special authorization, since strict rules were observed, and if it was not approved, it was prohibited.

4. The Law on the Use of Nuclear Energy adopted in the Russian Federation eliminated the bureaucratic framework governing activity in the area of nuclear power and razed the foundations of the previously used command administration principle of decision making in the area of nuclear power.

5. The system of legal and regulatory documentation adopted in Russia and governing activities in the area of nuclear energy, following the positive features of norms and regulations existing in the nuclear power complex of the former USSR, is consolidation of the priorities of the Laws of the Russian Federation. In accordance with the Laws of the Russian Federation, activities in the area of nuclear power in Russia are open for specialists and the public and must be performed considering the requirements for causing the least possible damage to human health and to the environment.

6. Regulatory documents at lower levels of authority must not contradict general requirements, regulations, norms, principles, and criteria established in the regulations at higher levels. Federal norms and regulations have priority over norms and regulations contained in documents of lower levels, which may be developed and used by different organizations and agencies when implementing their own activities in the area of nuclear power. Lower-level regulatory documents may be used under the conditions that their provisions do not contradict norms and regulations at the federal level.

7. A number of federal norms and regulations need to be edited and updated to be brought into full compliance with the Law of the Russian Federation on the Use of Nuclear Energy and with the structure of the system of legal and regulatory documents created in Russia for regulating activities in the area of nuclear power. Also, certain new regulatory documents need to be developed at the federal level. Work in this direction has already begun. 
8. At this time, GAN is studying the possibility of establishing an institution to license NPP projects analogous to that used in the West for licensing new NPPs or for NPPs under construction. As a result, realistic procedures will be developed for substantiating and reviewing license applications for all types of activities in the area of nuclear power, including NPP unit decommissioning. Since a mechanism for licensing has not yet been fully established, procedures have been established for obtaining temporary licenses to perform activities in the area of nuclear energy, including NPP unit decommissioning.

9. GAN has established a review process for all project materials, including those for NPP unit decommissioning. The responsibility for organizing and conducting the reviews has been entrusted to the Science and Technical Center for Nuclear and Radiation Safety (NTC YARB).

10. Regulatory documentation in effect in Russia regulating NPP unit decommissioning in many ways reflect the features noted above of the system of legal and regulatory documents governing activities in the area of nuclear power. However, they have their own distinctive features.

11. At this time, Russia does not have actual experience in the comprehensive resolution of questions of supervision, planning, regulating, and licensing work on NPP unit decommissioning. The development of regulatory documents relating to NPP unit decommissioning are based, for the most part, on maintenance and dismantling experience at operating NPP units, industrial, research, and transportation nuclear reactors, and also on the results of scientific research work conducted in shutdown NPP units. Comprehensive (radiation and engineering) surveys were performed on shutdown units of the Arminsk and Novovoronezhsk NPPs with VVER reactors, and on shutdown first-generation units of the Beloyarsk NPP with water-graphite AMB reactors. Test studies were conducted on construction materials and a comparative analysis was performed of residual corrosive activity in the primary circuits of units with VVER reactors at the Armyansk NPP and the Lovinz NPP.

12. Relating to decommissioning, regulations have been identified only for projects of redeveloped and operational NPP units, in which the necessity for accounting problems in decommissioning apply to all stages of the life cycle of the unit, which was not done in operating NPPs.

13. The issuing of a decommissioning license or the changing of current operating licenses is possible only after nuclear fuel has been removed from the unit. Prior to the removal of nuclear fuel NPP units must comply with regulatory requirements for NPP operations, including the requirements governing operator personnel.

14. Regulatory documents require reports on the substantiation of safety in decommissioning activities. This report is to included in the project materials. Also stipulated is the necessity for estimating the effects on the environment. However, existing regulatory documents do not define the contents for the documentation.

15. Regulatory documents examine only two options for NPP unit decommissioning - the longterm storage followed by dismantling or conversion of the unit, or burying the unit based on the concept of NPP Unit Decommissioning adopted in 1991. However, the requirements for substantiating the selection of a decommissioning alternative is not stated, in particular for long-term storage. In addition, the regulatory documents do not examine the possibility of immediate dismantling. 
16. The current regulatory documents have defined requirements and terms for the development, substantiation, presentation for review, and adoption by GAN of a decommissioning plan for NPP units when their design service life has expired.

17. Regulatory documents have no provisions for unscheduled decommissioning of an NPP. That is, before the expiration of its design service life, there are no regulations related to the necessary materials for presentation to GAN. Nor are there criteria for making decisions in the absence of such regulations.

18. Regulatory documents contain requirements for performing a comprehensive (radiation and engineering) survey of NPP units and for a decommissioning program for NPP units. However, requirements for the contents of these surveys have not been fully defined and do not take into account the structural features of NPP units with different types of reactors.

19. Regulatory documents do not account for factors inherent in Russian NPPs, such as their multi-component nature and their construction in two-unit stages, as a result of which some systems, facilities, and structures are common for power units of one stage.

20. The Russian regulations governing safety of the population when handling radioactive materials and radioactive substances is weakly defined. There are no concepts, criteria, or requirements for handling and reuse of radioactive materials for domestic needs (restricted or unrestricted use). There will be significant quantities of radioactive materials produced when decommissioning NPP units.

21. The lack of proper facilities for storage or burial of large amounts of radwastes makes it necessary to plan for their long-term storage at the NPP sites. Regulatory requirements for constructing long-term storage and burial sites for radwastes on NPP sites have not been defined.

22. Concepts, criteria, and requirements for final handling of irradiated graphite when decommissioning NPP units with uranium-graphite reactors have not been formulated.

23. Ambiguity in the long-term safe storage or reprocessing of RBMK spent nuclear fuel during decommissioning requires the development of regulations governing safety and physical protection for long-term storage on NPP sites.

24. Because of lack of regulatory guidance, the practice has taken shape whereby proposed technical concepts must be substantiated and applied only after their coordination and approval by GAN.

25. At this time, GAN is working on the development of an integrated regulatory base for regulating safety in decommissioning of NPP units and at bringing corresponding regulatory documents into compliance with the Laws of the Russian Federation. When formulating this regulatory base, not only domestic but foreign experience is being put to use.

26. Today, only ecologically safe activities that prevent serious changes in the natural surroundings and that do not create unacceptable human living conditions can be permitted.

27. The Law of the Russian Federation on the Preservation of the Natural Surroundings establishes the need for conducting ecology reviews for all projects, including those in the area of nuclear power and decommissioning of NPP units. Substantiation of ecological safety of the decommissioning process must pass a government and public ecology review. However, no Law of the Russian Federation is in any way associated with the problems of preservation of the natural surroundings. That is, they do not establish any ecological requirements, such as specific criteria of permissibility or impermissibility, for an activity including NPP unit 
decommissioning. The Laws of the Russian Federation do not define the need for ecological monitoring in the area of nuclear power. To achieve environmental protection aims, the Laws of the Russian Federation are oriented primarily toward sanitation and hygiene standards.

28. The regulations and guidelines contain recommendations to be used when developing projects in the area of nuclear power, considering ecological safety, and also when estimating the effects of these projects on the surroundings and when substantiating their ecological safety. However, the recommendations presented in regulations and guidelines must be clarified and systematized as they apply to NPP unit decommissioning planning and in substantiating its ecological safety. 


\subsection{Recommendations}

GAN is developing an integrated regulatory base for decommissioning NPP units and is bringing regulations into complete compliance with the Laws of the Russian Federation. Both domestic and foreign experience is being used in their development. GAN needs to continue developing regulations for decommissioning and handling spent nuclear fuel. The following are some. specific regulatory recommendations related to decommissioning an NPP unit:

- Edit and update federal norms and regulations so they will be in full compliance with the Law of the Russian Federation, "On the Use of Nuclear Energy," and with the structure of the system of legal and regulatory documents created in Russia for regulating activities in the area of nuclear energy.

- Complete the establishment of procedures for licensing NPP projects similar to that used in the west.

- Revisit and modify regulations requiring operating licenses after shutdown so that some decommissioning activities, such as general cleanup and dismantling of non-safety-related equipment, can occur prior to decommissioning licensing while ensuring safety.

- Expand regulatory documents to define the requirements of the project substantiation documentation, including substantiation of its ecological safety.

- Expand regulations to allow for immediate dismantling as a decommissioning alternative.

- Develop regulations to address the requirements for decommissioning after an unplanned shutdown of an NPP unit.

- Expand regulations related to the comprehensive survey to better define the requirements of the survey and to address the structural features of different reactor types.

- Redefine regulations governing safety of the populace. Develop concepts, criteria and requirements for handling and reuse of radioactive materials for domestic use.

- Construct central storage and burial facilities for spent nuclear fuel and radwastes. However, requirements for constructing long-term storage facilities need to be defined for NPP sites until such centralized facilities are available.

- Adopt requirements, concepts and criteria for final handling of irradiated graphite.

- Define ecological standards, such as specific criteria of permissibility, for activities like decommissioning and for ecological monitoring.

- Clarify and systematize guidelines relating to substantiation of ecological safety as they apply to NPP unit decommissioning. 


\subsection{Bibliography}

1. Security of Nuclear Power Plants: Manual. Rosenergoatom and EDF-EPN-DSN, Paris, 1994.

2. NPP Decommissioning Concept. Moscow. Ministry of Atomic Energy and Industry of the USSR, 1991.

3. Conclusions from Operations of Nuclear Power Plants in the Russian Federation: Overview In: Proceedings of the Workshop on Licensing Activities Related to the Decommissioning of Nuclear Installations in the Frame of Transfer of Western European Regulatory Methodology and Practices to the Nuclear Safety Authorities of Russia (October 23-27, 1995, Moscow, Russia). - M.: Gosatomnadzor Russia, 1995.

4. Report on the Activities of the Federal Nuclear and Radiation Safety Oversight Committee of Russia in 1995. Moscow. Gosatomnadzor Russia, (RD-03-02-95), 1996.

5. Gosatomnadzor Russia. Information Bulletin, N2. Moscow. 1993.

6. Nuclear Energy: Legal Issues. Moscow: Nauka, 1985.

7. Gosatomnadzor Russia. List of Federal Norms and Regulations in the Area of the Use of Nuclear Energy (Draft). Moscow. 1996.

8. Law of the Russian Federation on the Use of Nuclear Energy.

9. Law of the Russian Federation on Radiation Safety of the Populace.

10. Law of the Russian Federation on Protecting the Natural Surroundings.

11. Gosatomnadzor Russia. General Provisions in Safety of Nuclear Power Plants (OPB-88)

12. Gosatomnadzor Russia. Principles of Nuclear Safety of Nuclear Power Plant Reactor Units (PBYA RU AS-89).

13. Gosatomnadzor Russia. Requirements for Quality Assurance for Nuclear Power Plants.

14. Gosatomnadzor Russia. Template Content of Technical Substantiation of Safety of Nuclear Power Plants (TS TOB AS-85).

15. Gosatomnadzor Russia. Template Content of Technical Substantiation of Safety of Reactor Units (TS TOB RU-87).

16. Gosatomnadzor Russia. Requirements for Content of Reports on Substantiation of Safety of Nuclear Power Plants with VVER Reactors (OOB AS).

17. Gosatomnadzor Russia. Radiation Safety Norms (NRB-96).

18. Gosatomnadzor Russia. Basic Sanitation Regulations in Working with Radioactive Substances and Other Sources of Ionizing Radiation (OSP-72.87).

19. Gossanepidemnadzor Russia. Sanitation Regulations in the Design and Operations of Nuclear Power Plants (SP AS-89/93).

20. Gossanepidemnadzor Russia. Principles of Radiation Safety in Nuclear Power Plant Operations (PRB AS-89).

21. Gosatomnadzor Russia. Requirements for Using Organizations of Nuclear Power Plants 
(RD-04-03-93).

22. Gosatomnadzor Russia. Draft Guideline Basic Safety Requirements in Nuclear Power Plant Unit Decommissioning.

23. Rosenergoatom. Guideline Basic Provisions in Decommissioning Nuclear Power Plant Units.

24. Rosenergoatom. Draft Guideline Template Content of a Program of Preparation for Decommissioning of Nuclear Power Plant Units.

25. Rosenerogatom. Draft Guideline Comprehensive Engineering and Radiation Survey of the Nuclear Power Plant Unit. Composition and Procedures.

26. Rosenergoatom. Draft Guideline Template Content of Technical and Economic Surveys Aimed at Ceasing Operations of Nuclear Power Plant Units.

27. Rosenerogatom. Draft Guideline Template Content of Technical and Economic Substantiation of an Option in Decommissioning of Nuclear Power Plant Units.

28. Rosenergoatom. Draft Guideline Nuclear Power Plant Unit Decommissioning Program. Template Content and Development Procedures.

29. Law of the Russian Federation AOn the Ecology Review Board.

30. Law of the Russian Federation AOn Sanitation and Epidemiological Well-Being of the Populace.

31. Law of the Russian Federation AOn Protecting the Atmosphere.

32. Law of the Russian Federation AOn Natural Resources.

33. Law of the Russian Federation AOn the Earth's Plate.

34. Law of the Russian Federation AOn Animal Protection.

35. Ecology of the Areas of Nuclear Power Plants: Manual. Moscow USSR. 1994.

36. Ecology of the Areas of Nuclear Power Plants: Manual. Moscow USSR. 1994.

37. Ecology of the Areas of Nuclear Power Plants: Manual. Moscow USSR. 1995.

38. Ecology of the Areas of Nuclear Power Plants: Manual. Moscow USSR. 1995.

39. Ecology of the Areas of Nuclear Power Plants: Manual. Moscow USSR. 1996.

40. Ecology of the Areas of Nuclear Power Plants: Manual. Moscow USSR. 1997.

41. Ministry of the Environment of the Russian Federation. Procedures in Government Supervision of Environmental Protection and Observance of Requirements of Ecological Safety in the Production, Use, Storing, and Burial of Radioactive Materials and Sources of Ionizing Radiation. 1993.

42. NIO ERAS Institute Atomenergoproekt: Draft Guideline on the Development and Composition of Substantiation of Ecological Safety of Nuclear Power Plants (ROEB AS-91), 1991. 


\section{Joint U.S./Russian Study on the Development of a Decommissioning Strategy Plan for RBMK-1000 Unit \#1 at the Leningrad Nuclear Power Plant}

\section{Appendix C Recommended Outlines for Decommissioning Documentation}

September 1998

Prepared for

The U.S. Department of Energy

under Contract DE-AC06-76RLO 1830

Pacific Northwest National Laboratory

Richland, Washington 99352 
Recommended Decommissioning Program Plan for Leningrad NPP Unit \#1 


\section{Recommended Decommissioning Program Plan for Leningrad NPP Unit \#1}

1.0 Executive Summary of the Decommissioning Plan

1.1 Description of the Decommissioning Plan and the

Decommissioning Technology Alternative

1.1.1 Introduction

1.1.2 Background on the Leningrad NPP Block \#1 site

1.1.3 Contents of the Decommissioning Plan

1.2 Major Tasks, Schedules and Activities

1.2.1 Description of Major Activities

1.2.2 Decommissioning Criteria

1.2.3 Decommissioning Schedules

1.3 Decommissioning Cost Estimate and Availability of Funds

1.3.1 Decommissioning Cost Estimate Details

1.3.2 Funding Plan

1.4 Regulatory Basis for the Development and Implementation of this Decommissioning Plan

1.5 Administrative Control during the Transition Period Prior to Approval of this Decommissioning Plan

2.0 Choice of Decommissioning Alternative and Description of Decommissioning Activities

2.1 Alternative Selection Process and Technical/Economic Justification

2.1.1 Decommissioning Alternative

2.1.2 Decommissioning Alternative Justifications

2.1.2.1 Technical

2.1.2.2 Economic

2.1.2.3 Social

2.2 Leningrad NPP Block \#1 Facility Description

2.2.1 Reactor Design Description Overview

2.2.3 Metal Structures

2.2.4 Graphite Stack

2.2.5 Fuel Assembly

2.2.6 Fuel Channel

2.2.7 Reactor Control and Protection Channels

2.2.8 Biological Shield

2.2.9 Primary Forced Circulation Loop 
2.2.10 Individual Channel Coolant Flow Control System

2.2.11 On-line Refueling System

2.2.12 Control and Protection System Cooling Loop

2.2.13 Reactor Gas Loop and Channel Monitoring System

2.2.14 Blowdown - Cooldown System

2.2.15 Process Monitoring Systems

2.2.16 Safety Systems

2.2.17 Turbine Plant

2.2.18 Electrical Systems

2.2.19 Water Chemistry Systems

2.2.20 HVAC Systems

2.2.21 Pressure Control and Relief System

2.2.22 Fire Protection and Detection System

2.2.23 Reactor Exterior Systems and Equipment

2.2.24 Fuel Storage Facilities

2.2.25 Site Characteristics

2.3 Decommissioning Activities and Planning

2.3.1 Introduction

2.3.2 Activities Prior to Decommissioning Plan Approval by GAN

2.3.3 Decontamination and Dismantlement Plan

2.3.4 Schedule of Decommissioning Activities

2.3.5 Decommissioning Exposure Projections

2.3.6 Decommissioning Radioactive Waste Projections

2.4 Decommissioning Organization and Responsibilities

2.4.1 The Leningrad NPP

2.4.1.1 Organization

2.4.1.2 Responsibilities

2.4.2 LeninErgo

2.4.2.1 Organization

2.4.2.2 Responsibilities

2.4.3 Gosatomnadzor

2.4.3.1 Organization

2.4.3.2 Responsibilities

2.4.4 Minatom

2.4.4.1 Organization

2.4.4.2 Responsibilities

2.5 Contracted Activities

2.5.1 Use of Contractors

2.5.2 Contractor Scope of Work

2.5.3 Contractor Qualifications and Experience

2.5.4 Contractor Administrative Controls 
2.6 Training Program

2.6.1 General Employee Training

2.6.2 Radiation Worker Training

2.6.3 Fuel Handler Training

2.6.4 Job Specific Training

2.6.5 Training Staff Qualifications

2.6.6 Training Records

3.0 Protection of Occupational and Public Health \& Safety

3.1 Block \#1 Radiological Status

3.1.1 Operating History

3.1.2 Radiological Scoping Survey

3.1.3 Scoping Survey Results: Systems, Structure, Components

3.1.4 Scoping Survey Results: Soil and Groundwater

3.1.5 Radiological Environment Monitoring Program

3.1.6 Radiologically Affected Area Identification

3.2 Radiation Protection Program

3.2.1 Introduction

3.2.2 Management and Mission

3.2.3 Organization and Functions

3.2.4 Training and Qualifications

3.2.5 ALARA Program

3.2.6 Administrative Dose Control

3.2.7 Radiation Worker Permits

3.2.8 Area Definitions and Posting

3.2.9 External Dosimetry

3.2.10 Internal Dosimetry Control and Monitoring

3.2.11 Respiratory Protection Program

3.2.12 Radioactive Materials Control

3.2.13 Surveillance

3.2.14 Instrumentation

3.2.15 Review and Audit

3.2.16 Radiation Protection Program Performance Analysis

3.3 Radioactive Waste Management

3.3.1 Spent Fuel Management Plan

3.3.2 Solid Radioactive Waste Processing

3.3.3 Liquid Radioactive Waste Processing

3.3.4 Airborne Radioactive Waste Processing

3.3.5 Mixed Waste

3.3.6 Radioactive Waste Minimization 
3.4 Accident Analysis

3.4.1 Introduction

3.4.2 Event Identification Process

3.4.3 Events Affecting Occupational Health and Safety

3.4.4 Events Affecting Public Health and Safety

3.4.5 Decommissioning Activity Events

3.4.6 Loss of Support System Events

3.4.7 Fire Events

3.4.8 Explosion Events

3.4.9 External Events

3.4.10 Spent Fuel Storage Events

3.5 Occupational Safety Program

3.5.1 Introduction

3.5.2 Management Policy Statement

3.5.3 Health and Safety Organization Functions

3.5.4 Safety Training and Meetings

3.6 Non-Radioactive Waste Management

3.6.1 Introduction

3.6.2 Management Policy Statement

3.6.3 Hazardous Material Management

3.6.4 Hazardous Waste Management

3.6.5 Sampling and Remedial Actions

3.6.6 Industrial Waste Management

3.6.7 Training

4.0 Final Radiation Survey Plan

4.1 Final Release Criteria

4.1.1 Block Release Criteria

4.1.2 Material Release Criteria

4.2 Final Survey Methodology

4.2.1 Introduction

4.2.2 Instrumentation

4.2.3 Documentation

4.2.4 Quality Assurance

4.2.5 Independent Verification

5.0 Decommissioning Cost Estimate and Funding Plan

5.1 Decommissioning Cost Estimate

5.2 Decommissioning Funding Plan 
6.0 Decommissioning Technical Specifications

7.0 Decommissioning Quality Assurance Plan

7.1 Management Policy Statement

7.2 Introduction

7.3 Organization

7.4 Decommissioning Quality Assurance Plan

7.4.1 Design Control

7.4.2 Procurement Control

7.4.3 Instructions, Procedures and Drawings

7.4.4 Document Control

7.4.5 Control of Purchased Material, Equipment and Services

7.4.6 Identification and Control of Materials, Parts, and Components

7.4.7 Control of Special Processes

7.4.8 Inspection

7.4.9 Test Control

7.4.10 Control of Measuring and Test Equipment

7.4.11 Handling Storage and Shipping

7.4.12 Inspection, Test and Operating Status

7.4.13 Nonconforming Materials, Parts, or Components

7.4.14 Corrective Action

7.4.15 Quality Assurance Records and Documents

7.4.16 Audits

8.0 Decommissioning Access Control

9.0 Fire Protection

9.1 Fire Protection Program Description

9.2 Fire Protection Program Implementation

9.2.1 Initial Decommissioning Stages

9.2.2 Dismantlement Period 
Recommended Decommissioning Radiation and Engineering Characterization Report Outline for Leningrad NPP Unit \#1 


\section{Recommended Decommissioning Radiation and Engineering Characterization Report Outline for Leningrad NPP Unit \#1}

1.0 Executive Summary of the Radiation \& Engineering Characterization report

$2.0 \quad$ Introduction

3.0 Organization

4.0 Facility Operating History

4.1 Operating Performance

4.2 Occurrences and Contaminations

5.0 Radiological Scoping Survey

5.1 Scoping Survey Basis

5.2 Scoping Survey Procedures

5.2.1 Administrative Program

5.2.2 Soil and Asphalt Samples

5.2.2.1 Soil Boring and test Pits

5.2.2.2 Asphalt Tests

5.2.2.3 Soil for Construction Excavations

5.2.3 In-Block Radiological Survey

5.2.4 External Radiological Survey

5.2.5 Groundwater Survey

5.2.5.1 Groundwater Sampling

5.2.6 Radiological Survey of Systems, Structures and Components

5.2.6.1 Graphite Stack

5.2.6.2 Blocks

5.2.6.3 Rods

5.2.6.4 Core Columns

5.2.6.5 Reflector Columns

5.2.6.6 Support Structure

5.2.6.7 Flanges

5.2.6.8 Heat Shields

5.2.6.9 Ducts

5.2.6.10 Pressure Tubes

5.2.6.11 Fuel Assemblies

5.2.6.12 Control and Protection System

5.2.6.13 Reactor Support Metal Structures

5.2.6.14 Ventilation Systems

5.2.6.15 Forced Circulation Systems

5.2.6.16 Blowdown and Cooldown System 


\subsubsection{Spent Fuel Storage Facility}

\subsection{Area Survey Maps}

5.3.1 Radionuclide Distribution

5.3.2 Activation Analysis

5.3.3 Activity Inventory

5.4 Site Characterization Results and Conclusions 
Recommended Decommissioning Safety Analysis Report for Leningrad NPP Unit \#1 


\section{Recommended Decommissioning Safety Analysis Report for the Leningrad NPP Unit \# 1}

1.0 Executive Summary of the Safety Analysis Report

2.0 Environmental, Safety and Health Policy Statement

3.0 Introduction

4.0 Organization

5.0 Decommissioning Alternatives and a Description of Activities and Tasks

5.1 Decommissioning Alternatives

5.2 Decommissioning Activities and Tasks

5.3 Schedule

5.4 Decommissioning Organization and Responsibilities

5.5 Training Program

5.6 Contractor Assistance

6.0 Occupational and Public Health and Safety

6.1 Facility Radiological Status

6.1.1 Facility Operating History

6.1.2 Radioactive Inventory

6.1.3 Block Radiation and Contamination Levels

6.1.3.1 Contaminated Structures

6.1.3.1.1 Block \#1 Building 401

6.1.3.1.2 Spent Fuel Storage Building 428

6.1.3.2 Contaminated Systems

6.1.3.2.1 Reactor Core

6.1.3.2.2 Piping Systems

6.1.3.2.3 Biological Shields

6.1.3.2.3.1 Lower

6.1.3.2.3.2 Side

6.1.3.2.3.3 Upper

6.1.3.2.4 Drum Separators

6.1.3.2.5 Distribution Headers

6.1.3.2.6 Two-Phase $\mathrm{H}_{2} \mathrm{O}$ Piping

6.1.3.2.7 Refueling System 
6.1.3.2.8 Fuel Channel Ducts

6.1.3.2.9 Downcomers

6.1.3.2.10 Pressure Header

6.1.3.2.11 Suction Header

6.1.3.2.12 Circulation Pumps

6.1.3.2.13 Other

\subsection{Radiological Protection}

7.0 Radioactive Waste Management

7.1 Liquid Radioactive Waste

7.2 Gaseous Radioactive Waste

7.2.1 Ventilation Systems

7.2.1.1 Vapor Container

7.2.1.2 Block \#1 Buildings and Structures

\subsection{Solid Radioactive Waste}

7.4 Waste Handling, Packaging Transportation and Disposal

7.5 Process and Effluent Radiological Monitoring Systems

7.6 Spent Fuel Disposition

7.6.1 Spent Fuel Cooling

7.6.2 Instrumentation Used to Monitor Spent Fuel

7.6.3 Drainage of the Spent Fuel Pool

8.0 Final Radiation Survey Plan

9.0 Technical and Environmental Specifications in Place During Decommissioning

10.0 Quality Assurance

11.0 Credible Accident Analyses

12.0 Cost Estimate for Safety Program

13.0 Conclusions 
Recommended Decontamination and Dismantling Plan for Leningrad NPP Unit \#1 


\section{Recommended Decontamination and Dismantling Plan for the Leningrad NPP Unit \# 1}

1.0 Executive Summary of the Decontamination and Dismantling Plan

2.0 Environmental Safety Policy Statement

3.0 Introduction

4.0 Órganization

5.0 Applicable Documents

6.0 Detailed Planning and Engineering Activities

6.1 Engineering Specifications

6.2 Decommissioning Procedures

7.0 General Decontamination and Dismantlement Considerations

7.1 Collateral Interference with Required Systems

7.2 Seismic Interactions

7.2 Hazardous and Radiological Waste Considerations

7.4 Isolation and environmental Release Mitigation of Highly Radioactive Components

7.5 Decontamination Sludge Removal and Disposal

7.6 Filtering of Radioactive Particulate Emissions

7.7 General Procedures of Removing Contaminated Systems

7.8 Piping and Tubing

7.8.1 Large Bore Pipe Cutting and Removal

7.8.2 Small Bore Pipe Cutting and Removal

7.8.3 Use of Remote Cutting Equipment

7.8.4 Covering Open-End Piping

7.8.5 Piping Penetrations

7.8.6 Dismantling Precedence 
8.0 Decontamination and Dismantlement Process

8.1 Radiological Surveys

8.2 Decommissioning Workpackages

8.3 Lockout/Tagout Procedures

8.4 Radiation Protection Procedures

8.5 Identification of Components

8.6 Contaminated Concrete and Steel

8.7 Buried Contaminated Components

9.0 Decontamination Methods

9.1 Chemical Decontamination

9.2 Cobalt 60

10.0 Dismantlement Methods

10.1 Mechanical Methods

10.2 Thermal Methods

11.0 Materials Cutting Station

12.0 Decontamination and Dismantlement of Systems Structures and Components

12.1 Reactor Vessel and Graphite Core .

12.1.1 Reactor Vessel Removal Alternatives

12.1.1.1 Intact Vessel Alternative

12.1.1.2 Segmented Vessel Alternative

12.1.1.3 Graphite Stack Alternatives

12.2 Fuel Assemblies

12.3 Fuel Channels

12.4 Control and Protection System

12.5 Control and Protection System Cooling Circuit 
12.6 Blowdown/Cooldown Systems

12.7 Forced Circulation System

12.8 Biological Shielding

12.9 Drum Separators

12.10 Steam/Water Systems

12.11 Refueling System

12.12 Fuel Channels and Ducts

12.13 Pressure and Suction Headers

12.14 Circulation Pumps

12.15 Waste Disposal Systems

12.15 Metal Structures

13.0 Conclusions 
Recommended Decommissioning Waste Management Plan Outline for Leningrad NPP Unit \#1 


\section{Recommended Decommissioning Waste Management Plan Outline for Leningrad NPP Unit \#1}

1.0 Executive Summary of the Waste Management Plan

2.0 Waste Management Policy Statement

3.0 Introduction

4.0 Organization

5.0 Non-Radioactive Waste

6.0 Radioactive Waste

6.1 Radioactive Waste Inventory

6.1.1 Solid Radioactive Waste

6.1.1.1 Graphite Stack

6.1.1.1.1 Blocks

6.1.1.1.2 Rods

6.1.1.1.3 Core Columns

6.1.1.1.4 Reflector Columns

6.1.1.1.5 Peripheral Reflector Columns

6.1.1.1.6 Supporting Slabs

6.1.1.1.7 Supporting Cups

6.1.1.1.8 Shielding Plates

6.1.1.1.9 Flanges

6.1.1.1.10 Guide Branches

6.1.1.1.11 Heat Shields

6.1.1.1.12 Ducts

6.1.1.2 Pressure Tubes

6.1.1.3 Fuel Assemblies

6.1.1.3.1 Hangers

6.1.1.3.2 Guides and Tailpieces

6.1.1.3.3 Carrying Rods

6.1.1.3.4 Upper Fuel Bundles

6.1.1.3.5 Lower Fuel Bundles

6.1.1.3.6 Caps

6.1.1.4 Control and Protection System

6.1.1.4.1 Absorber Rods

6.1.1.4.2 Bellows Compensator

6.1.1.4.3 Upper Plug

6.1.1.4.4 Servo drives

6.1.1.4.5 Lower Biological Shielding 
6.1.1.4.6 Upper Biological Shielding

6.1.1.4.7 Orifice

6.1.1.4.8 Water Piping

6.1.1.5 Reactor Cavity

6.1.1.6 Reactor Concrete Vault

6.1.1.7 Forces Circulation Systems

6.1.1.8 Reactor Support Metal Structures

6.1.1.8.1 "S" Scheme

6.1.1.8.2 "OR" Scheme

6.1.1.8.3 "E" Scheme

6.1.1.8.4 "KZh" Scheme

6.1.1.8.5 "L" Scheme

6.1.1.8.6 "D" Scheme

6.1.1.8.7 "A" Scheme

6.1.1.8.8 "G" Scheme

6.1.2 Gaseous Radioactive Waste

6.1.2.1 Ventilation Systems

6.1.2.1.1 Vapor Containers

6.1.2.1.2 Reactor Building HVAC Systems

6.1.2.1.3 Turbine Building HVAC Systems

6.1.2.1.4 Spent Fuel Storage Facility HVAC Systems

6.1.2.2 Gaseous Waste Processing

6.1.2.2.1 Hydrogen

6.1.2.2.2 Fission Product Gases

6.1.3 Liquid Radioactive Waste

6.1.3.1 Forced Circulation Systems

6.1.3.2 Blowdown and Cooldown System

6.2 Waste Handling, Packaging, Transportation and Disposal

6.2.1 Identification of Waste Handling Sites

6.2.2 Packaging

6.2.2.1 Low-Grade Waste

6.2.2.2 Mid-Grade Waste

6.2.2.3 High-Grade Waste

6.2.3 On Site Storage

6.2.3.1 Low-Grade Waste

6.2.3.2 Mid-Grade Waste

6.2.3.3 High-Grade Waste

6.2.4 Transportation

6.2.4.1 Low-Grade Waste

6.2.4.2 Mid-Grade Waste

6.2.4.3 High-Grade Waste

6.3 Process and Effluent Radiological Monitoring Systems 


\subsection{Spent Fuel Management}
6.4.1 Spent Fuel Management Strategy
6.4.2 Spent Fuel Storage Facility
6.4.3 Spent Fuel Cooling and Non-Criticality
6.4.4 Instrumentation Used to Monitor Spent Fuel
6.4.5 Drainage of the Spent Fuel Storage Pool

7.0 Conclusions 
Recommended Decommissioning Quality Assurance Plan for Leningrad NPP Unit \#1 


\section{Recommended Decommissioning Quality Assurance Plan for Leningrad NPP Unit \#1}

1.0 Executive Summary of the Quality Assurance Plan

2.0 Quality Assurance Policy Statement

3.0 Introduction

4.0 Organization

5.0 Quality Assurance Tasks, Structure and Implementation

\subsection{Design Control}

5.2 Procurement Document Control

5.3 Instructions Procedure and Drawings

5.3.1 Calibration Procedures

5.3.2 Radiation Protection Procedures

5.3.3 Special Process Procedures

5.3.4 Work Control Documents

5.3.5 Radioactive Material Processing

5.3.6 Audit Procedures

5.3.7 Administrative Control Procedures

5.3.8 Emergency Response Procedures

5.3.9 Inspection Procedures

5.3.10 Training/Qualification/Certification Procedures

5.3.11 Procurement Procedures

5.3.12 Design and Design Document Control Procedures

5.3.13 Nonconformance and Corrective Action Procedures

5.3.14 Quality Records

5.3.15 Access Control Procedures

5.3.16 Equipment Control Procedures

5.3.17 Site Characterizations Procedures

5.3.18 Fire Protection Procedures

\subsection{Document Control}

5.5 Control of Purchased Material, Equipment, and Services

5.6 Identification and Control of Material, Parts and Components 


\subsection{Control of Special Processes}

5.8 Inspection

$5.9 \quad$ Test Control

5.10 Control of M\&TE

5.11 Handling, Storage, and Shipping

5.12 Inspection, Test, and Operating Status

5.13 Nonconforming Materials, Parts and Components

5.14 Quality Assurance Records and Record-Keeping

5.14.1 Plans

5.14.2 Procedures

5.14.3 Reports

5.14.4 Personnel Qualification Records

5.14.5 Radiological and Environmental Site Characterizations

5.14.6 Dismantlement Records

5.14.7 Inspection, Audit, and Assessment Records

\subsection{Audits}

